\title{
Entering the New Millennium: Dilemmas In Arms Control
}

\author{
James Brown \\ editor
}


The views expressed by the writers in these papers are not intended and should not be considered to represent the views, attitudes, or policies of Sandia National Laboratories.

Sandia is a multiprogram laboratory operated by Sandia Corporation, a Lockheed Martin Company, for the United States Department of Energy under Contract DE-AC04-94AL85000.

SAND 99-2586 


\section{DISCLAIMER}

This report was prepared as an account of work sponsored by an agency of the United States Government. Neither the United States Government nor any agency thereof, nor any of their employees, make any warranty, express or implied, or assumes any legal liability or responsibility for the accuracy, completeness, or usefuiness of any information, apparatus, product, or process disclosed, or represents that its use would not infringe privately owned rights. Reference herein to any specific commercial product, process, or service by trade name, trademark, manufacturer, or otherwise does not necessarily constitute or imply its endorsement, recommendation, or favoring by the United States Government or any agency thereof. The views and opinions of authors expressed herein do not necessarily state or reflect those of the United States Government or any agency thereof. 


\section{DISCLAIMER}

Portions of this document may be illegible in electronic image products. Images are produced from the best available original document. 
A 


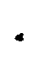




\section{Table of Contents}

Illustrations $\quad x i$

List of Acronyms xiii

About the Editor and Contributors xix

Acknowledgments $\quad$ xxix

Introduction $\quad x x x i$

Part I

Arms Control and Leadership: Entering the New Millennium

1 Arms Control in 2000-2010:

Forks in the Road Ahead

Brad Roberts

2 Arms Control at the New Millennium:

The Dilemmas

John D. Holum

Thérèse Delpech

4 Rethinking Security and Disarmament Agenda for the New Millennium Sola Ogunbanwo 
Part II

Formalizing Restraint: The Case of South Asia

5 Formalizing Restraint in South Asia Amit Gupta

6 A Restraint Regime for South Asia Ahmad Kamal

7 Formalizing Restraint: The Case of South Asia Dilip Lahiri

8 The Obstacles to A Nuclear-Weapon-Free Zone in the Middle East

Gerald M. Steinberg

Part III

Beyond START II

9 Deterrence and Arms Control:

A View from Europe

Bruno Tertrais

10 UK Nuclear Policies Within and After the START Process

George William Hopkinson

11 The Ballistic Missile Defense Challenge:

Consequences of the National Missile Defense for Strategic Arms Control Regime

Sergey M. Rogov

12 Jump-START: Retaking the Initiative to Reduce Post-Cold War Nuclear Dangers Jesse James 
Part IV

Regimes Under Assault: The Chemical and Biological Weapons Conventions

13 Arms Control Regimes Under Assault: Explaining the US Position in the Negotiations To Strengthen the Biological Weapons Convention Marie Isabelle Chevrier

14 Russian Approach to Strengthening the Regimes of the $\mathrm{CW}$ and $\mathrm{BW}$ Conventions Gennadi A. Lutai

15 OPCW: A Role Model for Peace in the New Millennium?

Sergei N. Kisselev

Part V

Nonproliferation Review $-\mathbf{2 0 0 0}$

16 Security Assurances and the NPT Michael O. Wheeler

17 Preparing for the 2000 Review Conference of the Parties to the Treaty on the Nonproliferation of Nuclear Weapons Hannelore Hoppe

18 The Nuclear Nonproliferation Treaty Review - 2000 Tariq Rauf

19 Using 1999 to Rescue the NPT Review Process Rebecca Johnson 
20 Safeguards into the Next Millennium

21 Comprehensive Nuclear Test Ban Treaty Towards a Safer and More Secure World Masabumi Sato 


\section{Illustrations}

\section{Tables}

XIII.1 Comparisons of Proposed Visits Under the BWC Protocol

\section{Figures}

XV.1

OPCW Structure

276

XV.2

OPCW Secretariat

280

XV.3

Order of Destruction of Category I

Chemical Weapons 


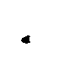


- 1

I

I

।

: 


\section{List of Acronyms}

ABACC

$\mathrm{ABM}$

ACDA

ACRS

AHG

ARF

BJB

BMD

BW

BWC

$\mathrm{C}^{3} \mathrm{I}$

CBM

CD

CFE

CIA

CSBM

CTBT

CTBTO

CW

CWC

DOC

DOE

DPRK

ECM

EIF
Argentina-Brazil Agency for Accounting and Control of Nuclear Materials

Anti-Ballistic Missile Treaty

Arms Control and Disarmament Agency

Arms Control and Regional Security

(Middle East)

Ad Hoc Group

ASEAN Regional Forum

Bharatiya Janata Party

Ballistic Missile Defense

Biological Weapons

Biological Weapons Convention

Command, Control, Communications, and Intelligence

Confidence-Building Measures

Conference on Disarmament (Geneva)

Conventional Forces in Europe Treaty

Central Intelligence Agency

Confidence- and Security-Building

Measures

Comprehensive Test Ban Treaty

Comprehensive Test Ban Treaty

Organization

Chemical Warfare

Chemical Weapons Convention

Department of Commerce

Department of Energy

Democratic Peoples' Republic of Korea

Electronic Counter Measures

Entry into Force 
ENDC

EURATOM

FMCT

FSS

FSU

FTE

GCI

GDP

G-8

HEU

IAEA

ICBM

ICJ

IDC

IMS

INF

IRS

LAC

LOW

LTBT

MC

MENWFZ

MOU

MTCR

NAC

NAM

NBC

NFU

NGO
Eighteenth National Disarmament

Conference

European Atomic Energy Agency

Fissile Material Cut-off Treaty

Federal Security Service

Former Soviet Union

Full-time Equivalent Employee

Global Communications Infrastructure

Gross Domestic Product

Group of Eight (Canada, France, Germany,

Italy, Japan, Russia, United Kingdom,

United States)

Highly Enriched Uranium

International Atomic Energy Agency

Intercontinental Ballistic Missiles

International Court of Justice

International Data Center

International Monetary System

Intermediate-Range Nuclear Forces Treaty

Internal Revenue Service

Line of Actual Control

Launch on Warning

Limited Test Ban Treaty

Main Committees (NPT)

Middle East Nuclear-Weapon-Free Zone

Memorandum of Understanding

Missile Technology Control Regime

New Agenda Coalition

Non-Aligned Members

Nuclear, Biological, and Chemical

No-First-Use

Non-Governmental Organization 


$\begin{array}{ll}\text { NMD } & \text { National Missile Defense } \\ \text { NNA } & \text { Neutral and Non-Aligned States } \\ \text { NPT } & \text { Nuclear Nonproliferation Treaty } \\ \text { NPTREC } & \text { Nonproliferation Treaty Review and } \\ & \text { Extension } \\ \text { NWFZ } & \text { Nuclear-Weapons-Free Zone } \\ \text { NWS } & \text { Nuclear Weapons States } \\ \text { NNWS } & \text { Non-Nuclear Weapons States } \\ \text { NSG } & \text { Nuclear Suppliers Group } \\ & \\ \text { OBW } & \text { Organization for Biological Weapons } \\ \text { OPCW } & \text { Organization for the Prohibition of } \\ & \text { Chemical Weapons } \\ \text { OSCE } & \text { Organization for Security and Cooperation, } \\ & \text { Europe } \\ \text { OSIA } & \text { On-Site Inspection Agency } \\ & \\ \text { P-5 } & \text { Permanent Five (China, France, Russia, } \\ & \text { United Kingdom, United States) } \\ \text { PAL } & \text { Permissive Action Links } \\ \text { PrepCom } & \text { Preparatory Commission } \\ \text { PDD } & \text { Presidential Decision Directive } \\ \text { P\&O } & \text { Principles and Objectives } \\ \text { PTBT } & \text { Partial Test Ban Treaty } \\ & \text { Research and Development } \\ \text { R\&D } & \text { Review Conference } \\ \text { RevConf } & \text { Science Based Stockpile Stewardship } \\ \text { SBSS } & \text { Strategic Defense Initiative } \\ \text { SDI } & \text { Strategic Defense Review (UK) } \\ \text { SDR } & \text { Submarine Launched Ballistic Missiles } \\ \text { SLBM } & \text { Short-Range Ballistic Missile } \\ \text { SRBM } & \text { Surface-to-Surface Missile } \\ \text { SSM } & \text { Strategic Arms Reduction Treaty } \\ \text { START } & \text { United Nations } \\ \text { UN } & \text { United Nations General Assembly } \\ \text { UNGA } & \\ & \end{array}$


UNSC

United Nations Security Council

UNSCOM

United Nations Special Commission (Iraq)

WEOG

Western and Other Group States

WMD

Weapons of Mass Destruction 


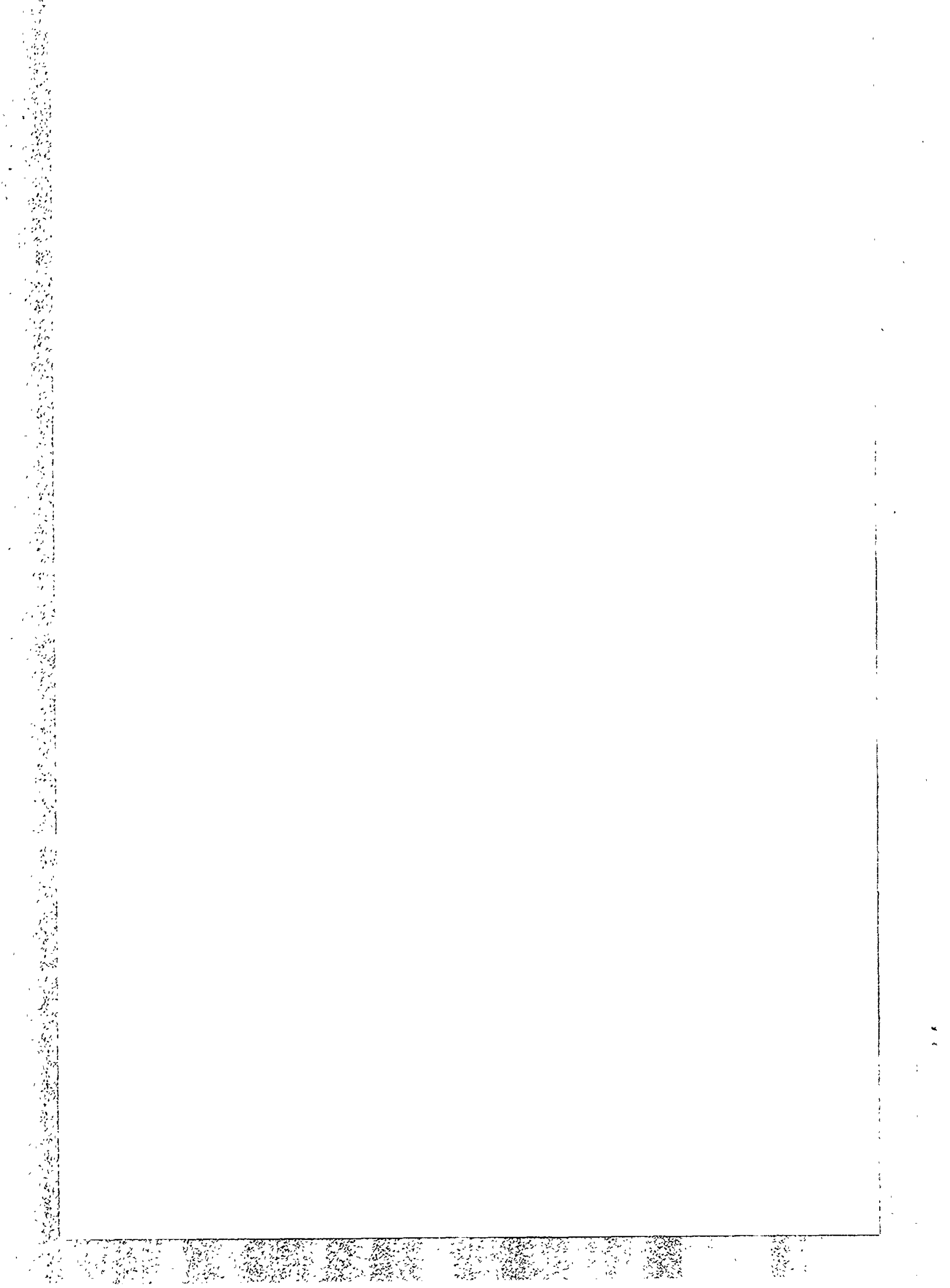


.

- 


\section{About the Editor and Contributors}

James Brown has Chaired the International Arms Control Conference, since 1990, and is a Principal Member of the Technical Staff of Sandia National Laboratories. His Ph.D. is from the State University of New York at Buffalo. Dr. Brown has served as a foreign affairs specialist at both the Department of Defense and the Arms Control and Disarmament Agency. Additionally, he was a Senior Fulbright Professor at the University of Ankara in Turkey. His publications are extensive, consisting of eleven authored and edited volumes and over thirty-five articles in the areas of civil-military relations and arms control and disarmament issues. Dr. Brown is a member of the International Institute for Strategic Studies.

Marie Isabelle Chevrier is an Associate Professor of Political Economy at the University of Texas at Dallas. She is a former associate director of the Harvard Sussex Program for Science and International Affairs at Harvard University. Dr. Chevrier's research is on the Biological and Toxin Weapons Convention, and she has authored numerous articles and contributed book chapters in this field of study. Her Ph.D. in public policy is from Harvard University. 
Kaluba Chitumbo is currently the Director of the Division of Information Technology in the Safeguards Department of the International Atomic Energy Agency. He was also a member of the team that confirmed the dismantlement of South Africa's nuclear weapons, and he served as the Secretary of Committee $V$ at the 1995 NPT Review Conference in New York. Dr. Chitumbo's Ph.D. is in nuclear physics from the University of Upsala (Sweden).

Thérèse Delpech is presently an advisor to France's Prime Minister in the area of politico-military affairs. She was previously Deputy Director of International Affairs at the Atomic Energy Commission and an advisor to the High Commissioner for Atomic Energy. Formerly, Ms. Delpech also served as a consultant to the Policy Planning Staff of the Ministry of Foreign Affairs on nuclear issues.

Sujit Dutta is a Senior Fellow at the Institute for Defense Studies and Analyses (India). His area of interest is Chinese foreign and defense policy and Asia-Pacific security, and his publications in his area of specialization are extensive. Dr. Dutta's Ph.D. is in Diplomatic Studies from the Jawaharlal Nehru University. Additionally, he was a Senior Fellow at the United States Institute of Peace in Washington, D.C. 
Amit Gupta, an Assistant Professor of Political Science at Stonehill College, specializes in international security issues. His publications have appeared in Orbis, Asian Survey, and Mediterranean Quarterly. He is currently co-editing a volume on India's Nuclear Program. Dr. Gupta was educated at the University of Dehli, Austrialian National University, and at the University of Illinois (Urbana-Champaign).

John D. Holum is currently Senior Advisor for Arms Control and International Security at the Department of State. He served for six years as Director of the Arms Control and Disarmament Agency (1993-1999); and for fourteen years (1965-1979), Mr. Holum was a member of Senator George McGovern's staff where he served as the legislative director. Subsequently, he was a member of the Policy Planning Staff of the Department of State. Mr. Holum's Doctor of Jurisprudence with Honors is from George Washington University School of Law.

George William Hopkinson read History at Cambridge University. A distinguished civil servant with the Ministry of Defense from 1986-1993, he served in many capacities, culminating as the Under Secretary of State (Policy). With a very broad portfolio, his responsibilities included arms control and nonproliferation. On leaving Her Majesty's Service in 1997, he became Head of the International Security Program of Chatham House. 
Hannalore Hoppe joined the United Nations Secretariat in 1984. She has been involved in numerous UN activities in the field of arms control and disarmament. Presently, she is the Chief of the Weapons of Mass Destruction Branch of the Department for Disarmament Affairs. Ms. Hoppe was also the Secretary of the PrepCom for the 2000 NPT Review Conference.

Jesse James is the Executive Director of the Committee on Nuclear Policy and a Senior Associate at the Henry L. Stimson Center. Prior to this position, he served as the Director of Office of Intergovernmental Affairs at the Department of State. Previously, Mr. James was a columnist and editorial writer for the Dallas Morming News. He holds a Masters degree from the Graduate School of Public and International Affairs of the University of Pittsburgh.

Rebecca Johnson is the Executive Director of the Acronym Institute (London) and managing editor of Disarmament Diplomacy. Since the early 1980s, Ms. Johnson's work has revolved around the issues of security and nuclear policy. Her publications authored and edited in this arena are very extensive. She writes regular updates for Disarmament Diplomacy on issues concerning disarmament, the CTBT, and the Nonproliferation Treaty review process. 
Ahmad Kamal has had a very distinguished career as a diplomat for Pakistan, holding the positions of Ambassador and Permanent Representative of Pakistan to the United Nations in New York and Geneva, and was also accredited to the Conference on Disarmament. Having recently retired, Ambassador Kamal continues a very active life of university teaching, being Chair of the Board of Trustees of the UN Institute and a member of the UN's Advisory Committee on Budgetary and Administrative Questions.

Sergei N. Kisselev serves as Assistant to the Director of Verification of the Technical Secretariat of the Organization for the Prohibition of Chemical Weapons. Before assuming this position, Mr. Kisselev had a distinguished career in both the Soviet Union/Russian Ministries of Foreign Affairs, holding increasing more important pasts, culminating as the resident representative of the Russian Federation to the OPCW.

Dilip Lahiri is currently the Additional Secretary (United Nations) of the Ministry of External Affairs of India. His distinguished career spans many years and several postings from being on the High Commission of India in Nairobi, Kenya; to Ambassador of India to Peru and Bolivia; to Joint Secretary of the Americas in the foreign ministry; and, to Dean of the Foreign Service Institute. 
Gennadi A. Lutai is presently the Head of the Department of Multilateral Disarmament of the Ministry of Foreign Affairs of the Russian Federation. He graduated from Moscow State Institute of International Relations and entered the Foreign Service of the then Soviet Union. He gained his expertise in arms control by being assigned to increasingly important positions in the Directorate for Security and Disarmament, the Deputy Foreign Minister's Office, and the Russian Federation's Permanent Mission to the Conference on Disarmament.

Malcolm Nicholas is an information analyst for the International Atomic Energy Agency. His primary responsibilities are the collection and evaluation of "open-source" information in support of the Strengthened Safeguards System. Prior to his current appointment, he was an analyst in the Australian government advising on issues related to nuclear proliferation and other WMD.

Sola Ogunbanwo is currently the Distinguished Diplomat-inResidence at Monterey Institute of International Studies' Center of Nonproliferation Studies, and is also the Chief Expert Adviser on the African Nuclear-Weapon-Free Zone. Before leaving the United Nations in 1998, Ambassador Ogunbanwo held several senior positions including Director of the UN's Disarmament Training Program and Secretary General of the Fourth Review Conference of the Biological Weapons Convention. $\mathrm{He}$ is a 
graduate of Leyden University (The Netherlands) with a Doctor of Laws degree.

Tariq Rauf is Director of the International Organizations and Nonproliferation Project at the Center of Nonproliferation Studies, Monterey Institute of International Studies. Previously, he worked for many years as director for nonproliferation and arms control policy research at the Canadian Center for Global Security. His Ph.D. is from the University of Toronto. Mr. Rauf has also taught international relations at the University of Toronto, Carleton College, and at Quaid-i-Azam University in Islamabad (Pakistan).

Brad Roberts is a member of the research staff of the Institute for Defense Analyses where he specializes on issues of counterproliferation, nonproliferation, counterterrorism, and weapons of mass destruction. Because of his expertise, he contributes studies for the Office of the Secretary of Defense and the joint military staff. He received his Ph.D. from Erasmus University (The Netherlands) and serves as an adjunct professor at the Elliott School of International Studies at George Washington University. 
Sergey M. Rogov is currently the Director of the Institute of USA and Canada in the Russian Federation. Dr. Rogov is a distinguished scholar who has authored thirteen books and over two hundred articles on Soviet Union/Russian foreign policy. Additionally, he is a member of the Advisory Board of the Security Council of the Russian Federation and a member of the Russian Academy of the Natural Sciences.

Masabumi Sato is Director of the Legal and External Relations Division of the Preparatory Commission for the CTBTO. His diplomatic career began in 1970 when he joined the Ministry of Foreign Affairs (Japan), and that career has spanned thirty years, culminating with the position of Minister of the Embassy of Japan in Vienna. He holds a BA degree from the University of Tokyo (Japan).

Gerald Steinberg directs the Program on Conflict Resolution and Diplomacy and is Professor of Political Studies, at Bar-Ilan University (Israel). He specializes and publishes in the fields of Middle East arms control and military strategy and US-Israeli defense policy. He has been a Research Fellow at the Massachusetts Institute of Technology, the US Peace Institute, and the Stockholm International Peace Research Institute. 
Bruno Tertrais is a special assistant to the Director of Strategic Affairs of the Ministry of Defense (France). He also was a visiting Fellow at the RAND Corporation. His publications are extensive and wide-ranging covering the areas of European security, transatlantic relations, and nuclear weapons issues. He holds a Ph.D. in Political Science from the Institute de'études politiques des Paris.

Michael $O$. Wheeler is on the senior research staff in National Security Studies and Strategic Group of Science Applications International Corporation (SAIC). Prior to joining SAIC, Dr. Wheeler was on the staff of the System Planning Corporation. That preceded a twenty-four year career in the US Air Force with a variety of assignments including positions on the National Security Council, State Department, and the Nuclear Regulatory Commission. He is a graduate of the Air Force Academy and holds graduate degrees in political science and in philosophy from Georgetown University and the University of Arizona. 


\section{Acknowledgments}

The chapters included in this volume are based on papers commissioned for and presented at the Ninth Annual International Arms Control Conference held in Albuquerque, New Mexico, under the sponsorship of the Cooperative Monitoring Center of Sandia National Laboratories.

The conference sponsors are indebted to the presenters for their thoughtful and insightful presentations that comprise this volume. The decision to publish these articles was indeed a very easy one, given the comprehensiveness and quality of these essays.

Financial support for this symposium came from the Defense Threat Reduction Agency of the Department of Defense, the Arms Control and Disarmament Agency, and the International Security Center of Sandia National Laboratories. Additional funding support came from our three corporate sponsors: Aquila, A Canberra Company of Albuquerque, New Mexico; the Chemical and Biological Arms Control Institute of Alexandria, Virginia; and Pacific-Sierra Research Corporation of Arlington, Virginia. I am most grateful to each of them for their sustaining interest and continued trust of these annual arms control symposia.

Special recognition and thanks go to a number of my colleagues at Sandia National Laboratories for their sustentation of this conference and their confidence in me. In particular, special thanks to Paul Robinson, President of Sandia National 
Laboratories; Roger Hagengruber, Senior Vice President of National Security and Arms Control; Tom Sellers, Director of The Center for International Security; Arian Pregenzer, Manager of the Cooperative Monitoring Center; and John M. Taylor, former Manager of the Nonproliferation Initiative Programs. The editor's indebtedness to each of them is gratefully acknowledged.

Special thanks to Mrs. Martha Lucero for her assistance in organizing the last three conferences.

I am also very grateful to Mrs. Evangeline Clemena for her diligent attention to detail in preparing this manuscript. Her unfailing support of this conference and this volume has made this project come to fruition.

The merits of this work belong to the authors. The views expressed in these articles are not intended and should not be considered to represent the official ideas, views, attitudes, or policies of any agency of the United States Government or any other Government.

The editor is responsible for errors of fact and interpretation.

\section{James Brown}

Editor and

Conference Chair 


\section{Introduction}

The end of the Cold War finds the international community no longer divided into two opposing blocks. The concerns that the community now faces are becoming more fluid, less focused, and, in many ways, much less predictable. Issues of religion, ethnicity, and nationalism; the possible proliferation of Weapons of Mass Destruction; and the diffusion of technology and information processing throughout the world community have greatly changed the international security landscape in the last decade.

Although our challenges appear formidable, the United Nations, State Parties, nongovernmental organizations, and the arms control community are moving to address and lessen these concerns through both formal and informal efforts. Many of the multilateral agreements (e.g., NPT, BWC, CWC, CTBT, MTCR), as well as the bilateral efforts that are taking place between Washington and Moscow employ confidence-building and transparency measures. These measures along with on-site inspection and other verification procedures lessen suspicion and distrust and reduce uncertainty, thus enhancing stability, confidence, and cooperation.

As we enter the new millennium, arms control will continue to be relevant in the evolving strategic landscape and may grow in importance. The challenges that are before us, old and new, will remain as profound, as complicated, and as messy as 
those we have faced in the Twentieth Century. In facing the new challenges, we will need to think creatively of a future based on common security needs and to reassess the traditional concepts, doctrines, and values pertaining to peace and security.

These broad observations provide a framework for the issues and subjects that are addressed by the twenty-one articles comprising this volume, and they hint at the themes that will dominate the arms control communities' discussions and activities as we enter the new millennium.

Part I of this edited volume consists of four papers that examine from various perspectives the arms control community's agenda for the new millennium. The first is written by Brad Roberts who emphasizes that the years ahead are not likely to see business as usual and that critical choices ("forks in the road") will have to be made. He argues that the arms control community has not thought through the nature of the necessary choices ahead or the types of security environments that might be encountered. The first issue that Roberts analyzes is the path of strategic reductions. The questions poised by the author include the effects of such reductions and whether they will be bilateral, involving the US and Russia, or whether China will be included, albeit the latter currently plays a very minor role. If these strategic reductions do follow a trilateral format, what will be the relationships among the three nuclear powers, and who will be willing to accept parity among them? Furthermore, whether the United States deploys a 
missile defense system may greatly affect the force structure preferences of both Russia and China. Another factor that must be considered in the new millennium is the nonproliferation regime. Roberts notes that the NPT decision was won through a lot of arm twisting, and it faces challenges. There are a significant number of States Parties that are dissatisfied with the implementation of Article VI by the Nuclear Weapon States, and these States may undertake extraordinary measures such as to opt-out or to "pause" their membership in the NPT in the Year 2005. Additionally, the nuclear status of India and Pakistan has increased the concern among NPT members regarding the viability of this regime. Although the Treaty will not collapse, it is likely that its mandate will be changed. Finally, Roberts analyzes the path of treaty implementation. A major crisis of confidence will arise if treaty compliance cannot be enforced on rogue states like Iraq and North Korea, and early successes in compliance are necessary for the NPT to remain effective. The relevance of arms control within the evolving strategic landscape cannot be minimized, and the leadership role of the United States will be not only necessary but also salient.

In Chapter Two, John Holum's companion piece notes that "transition" is the watchword in every aspect of our arms control endeavors as we look into the new millennium. The author nostalgically reviews the accomplishments of the Arms Control and Disarmament Agency and notes that for thirty-eight years 
ACDA tenaciously led sometimes recalcitrant US government agencies to champion major arms control achievements that we now take for granted. Holum laments the fact that today many efforts in arms control and nonproliferation are ensnared in unrelated political and diplomatic differences. To resolve these dilemmas, the author suggests that we need to return to first principles and explain how critical these activities are to US national security. He identifies a popular misconception: that arms control is soft, altruistic, and trusting - that the US negotiates agreements and simply hopes the rogues of the world will sign-up and comply. Holum emphasizes this is not the case and that US arms control and nonproliferation policy consists of a series of calculated, interconnected strategies that enable the US to confront and dispense with threats to our security without conflict. Moreover, the challenges in the new millennium will be grave, but Holum is quite optimistic that the "preventive medicine of arms control" is quintessential to advancing the US arms control agenda. In Chapter Three, Thérèse Delpech argues that there exists a lack of leadership in the arms control community throughout the world. The author attributes this to several elements: a weakened psychological foundation with the demise of the Cold War; fatigue of leaders; globalization; deterioration of relations among the major powers, namely the United States, China, and Russia; and, finally, the absence of a forceful "driver" from among the P-5. It appears to Delpech that a troubled era is more than likely for arms 
control in the new millennium, unless the P-5 begin to act decisively against violators of international law and the standards as established by the international community. Additionally, several factors, such as more transparency and less rhetoric from China, more emphasis for multilateralism by the US, more concern for internal security by Russia, and more responsibility from the Europeans, could temper the cacophonous "concert of nations."

The final presentation of this section is by Ambassador Sola Ogunbanwo who addresses the issue of the role of leadership in disarmament efforts. Outlining the attributes of leadership, the writer argues that the United Nations needs and seeks leadership partners not only from the United Nations and governments, but also from civil society. Elements of the latter were instrumental in delivering the landmark Ottawa Landmines Convention. Further Ogunbanwo forcefully argues that although many problems can be tackled in international fora, regional initiatives can also be quite effective. Several regional mechanisms were cited as being useful in resolving conflict in Africa, achieving an African equivalent of the "Helsinki Process." Many African leaders realize that without security and stability on their continent their capacity to achieve the necessary level of intra-African and inter-African cooperation will be impaired. This realization, Ogunbanwo notes, led to the Kampala Document, effectively outlining a framework for governance and development for Africa for the $21^{\text {st }}$ Century. This Document provides the framework for African States to craft an 
African agenda in which regional cooperation and institutions contribute to meeting the security challenges ahead. It also allows African States to serve as a model for other regions to take the first step in meeting the security challenges of the new millennium.

The initial chapter of Part Two is by Professor Amit Gupta who contends that for political, economic, and military-strategic reasons, it is necessary for both India and Pakistan to formally restrain their nuclear rivalry. Additionally, to address the South Asian conundrum, the international community must consider reshaping existing international regimes or facilitating creation of new ones that will permit de facto Nuclear Weapons States like India, Israel, and Pakistan to become participating members. Both India and Pakistan have committed themselves to a policy of deterrence, although with significant differences. In the case of India, its concept of deterrence includes no-first-use of nuclear weapons. While Pakistan has declared deterrence as its stated policy, it has not ruled out the use of a first strike to defend the country from India's conventional superiority. Unfortunately, both countries are reluctant to quantify their respective nuclear forces. Gupta points out that though other regions of the world have turned to confidence-building, arms control, and disarmament, South Asia is different because of the serious regional rivalry between India and Pakistan. Therefore, dealing with the South Asian case will require more than regional options. More importantly, nonproliferation policy at the international level must be reoriented 
in order to achieve success in the ever-changing international environment in which different states will undertake different roles at different levels of economic and military prowess.

In Chapter Six, Ambassador Ahmad Kamal states the case for Pakistan as a nuclear power. Kamal notes that the nuclear tests merely confirmed an existing reality; however, he points out a new and dangerous threshold was crossed, presenting new challenges for threat reduction, arms control, and crises management. His paper views the South Asian situation with historical perspective in order to better identify the contours and shapes of a credible restraint regime for South Asia. In the view of Pakistan, it was motivated to proceed with nuclear tests because the fundamental role of its nuclear forces is political, and their purpose is to preserve peace and prevent coercion and war. Kamal argues that it was the failure of US nonproliferation policy that prompted the Indian nuclear tests. In the future, any successful policy must be balanced and even-handed, and must confront the fact that India and Pakistan are, in an operational sense, Nuclear Weapons States. According to the author, the success of a nuclear restraint regime in South Asia depends not only on the two nuclear-armed states but requires the sustained engagement of the international community.

Dilip Lahiri's Chapter Seven considers aspects of restraint within the South Asian context. The author argues that an element of nuclear danger is unavoidable as long as nuclear weapons exist regardless of the restraints that are in place. The only true solution, 
according to Lahiri, is the complete abolition of nuclear arms, a position that India has long argued. Disarmament is unlikely to be realized, according to the author, as long as the Nuclear Nonproliferation Treaty continues to reaffirm the indispensability of nuclear weapons for nuclear security purposes. From a more global perspective, it is the writer's contention that there were elements in the United States during the Cold War that argued for nuclear superiority; therefore, arms control agreements with the Soviet Union only affirmed for the Soviets' nuclear "parity." The picture for South Asia is far brighter. In the case of both India and Pakistan, their leaders have repeatedly emphasized their intent to search out mutually acceptable solutions so as to create a climate of stability in South Asia (the Lahore Declaration). From the international perspective, the author argues that it is unrealistic for the Nuclear Weapons States to suggest that India and Pakistan are not NWS, albeit they are outside of the NPT. This is an illusionary argument that India does not accept. The importance of nondiscriminatory global instruments that further disarmament and reduce the danger of conflict, especially nuclear conflict, cannot be over-emphasized.

A companion piece by Gerald Steinberg provides insight into obstacles to creating a Nuclear-Weapon-Free Zone in the Middle East. Steinberg notes that the nuclear tests that were conducted by India and Pakistan, along with other developments in the international arena, demonstrate the challenges that the 
nonproliferation regime now faces. The author notes that one of the most important lessons of the past twenty years of nonproliferation initiatives is that each geographical area faces its own security concerns, and that global regimes need to be supplemented by some kind of regional framework. The NuclearWeapon-Free Zones (NWFZ) that have been negotiated and implemented in Latin America, the South Pacific, Africa, and Asia Pacific are examples where this has worked; and other areas where multifaceted approaches will be required include South Asia and the Middle East. Steinberg points out creation of a functioning NWFZ in these areas will require the settlement of intense, ongoing rivalries. Furthermore, if a nuclear potential or capability is seen as a necessary deterrent to non-nuclear threats, then a NWFZ must be linked to wider regional agreements. Although Steinberg specifically addressed the issues involved in creating a NWFZ for the Middle East, the approach and "lessons learned" would apply as well to the case of South Asia. An essential factor, in Steinberg's estimation, in creating a NWFZ in the Middle East, and by inference in South Asia, is progress towards comprehensive regional peace and security. Failure of the peace process will ultimately mean an end to any possibility of a regional zone.

Part Three includes four presentations on the general theme of examining strategic issues beyond START III. Chapter Nine by Bruno Tertrais focuses on France's and the United Kingdom's nuclear strategies. The author points out that roles of both 
countries' strategic forces have not significantly changed over time. The major military changes have come about on the conventional side. In fact, Tertrais notes that both countries' nuclear policies and doctrines are fundamentally the same. Each nation claims that its nuclear forces are a "minimum" deterrent force (France prefers the term "sufficiency") designed to protect their "vital interest." Additionally, the author notes that there is no realistic prospect for the two European powers to abandon their nuclear deterrent forces anytime soon. Furthermore, the question of whether France and the United Kingdom will participate in multilateral arms control negotiations will remain open, albeit this issue is now tackled differently than it was during the Cold War era. Tertrais makes a compelling argument that it makes no sense for either France or the United Kingdom to participate in "strategic" arms reduction talks. However, the author notes that there are two challenges for France and the UK, which potentially affect their nuclear arsenals. The first stems from the proliferation of Weapons of Mass Destruction, and the second arises from the evolution of European integration. Both European nuclear powers, according to the author, are not looking for new rationales for their nuclear deterrent posture, and neither nation presents its nuclear arsenal as an instrument of prestige or "swagger." These arsenals are simply instruments of international stability and political autonomy. 
A companion piece by George William Hopkinson proffers the view that perhaps the START process may have reached the end of the road; however, this in itself does not affect the United Kingdom's nuclear posture, nor its preferred way forward on nuclear issues. Furthermore, the author suggests that of the two European nuclear powers the UK, both officially and unofficially, is probably less attached to its nuclear arsenal. It has no burning security problems for which nuclear weapons are the only answer and no obligations that can be discharged only through possessing them. In fact, in its 1998 Strategic Defense Review, London made quite clear its full commitment to the NPT regime, including Article VI, but also expressed the view that for the current time it must retain a nuclear arsenal. The ultimate question that the author poses is how to move from where we are today to a situation in which all nuclear weapons are prudently set aside and in which there are proper international arrangements for dealing with attempts at cheating, break out, or blackmail. In the meantime, the United Kingdom will, according to the author, intensify its dialogue with France in developing the non-nuclear dimensions to the European Defense Identity. Perhaps fifteen years from now the UK will reassess its national security needs and may, at that time, choose to leave the nuclear club.

Sergey Rogov in Chapter Eleven makes a very compelling case that the National Missile Defense that the United States is considering deploying will affect overall strategic arms control 
negotiations between Moscow and Washington. The author strongly argues that the Russian Federation is not in a position to compete economically with the United States in developing such a strategic weapons system. Rogov attributes much of the push for a BMD system to US domestic politics involving Republican members of Congress and the Clinton Administration, and whether that push is successful will depend on who wins the national election in the year 2000. Moscow's reaction, according to the author, is not only to seek diplomatic solutions to the BMD issues, but more importantly, the Russian Federation needs to identify possible geopolitical strategies by calculating scenarios of an asymmetric response utilizing military-technical means. In addition, Rogov notes that any future deployment of a US strategic missile defense is a concern not only to Russia, but to China, India, and France. As a result, the author concludes that it is impossible to prevent the $\mathrm{BMD}$ in the future from turning into one of the key issues in arms control negotiations.

The final paper of this section is by Jesse James who presents alternatives for reducing the nuclear danger in the postCold War period. Much of this danger, according to the author, emanates from within the Russian Federation - danger arising from degradation of early warning satellites, questionable stability of ballistic missile systems, vulnerability of bomb-making materials to theft, and finally from opportunity for nuclear scientists to sell their knowledge to rogue states or terrorist organizations. These 
points are reinforced in this article by several poignant examples. James, representing the Committee on Nuclear Policy, urges the Clinton Administration to reduce the US's nuclear arsenal far lower than envisioned under the proposed START III Treaty and to take the US, along with Russian forces, off hair-trigger alert. The author argues that it is imperative for the Clinton Administration to break the current six-year logjam on START II ratification. Furthermore, as James' notes, the entire US-Russian nuclear relationship must be reformed, and Washington must take the lead in reducing both its reliance on nuclear weapons and the political value it attaches to them.

The three papers in Part Four of this volume focus primarily on the Biological Weapons Convention (BWC). The first article is by Marie Chevrier who details at some length the United States' position in negotiating an enhanced BWC regime and considers whether the US has succeeded in its leadership aspirations regarding this treaty. The author notes that the BWC has been under assault for sometime now because there is a lack of trust among the State Parties to this treaty. Two reasons are most pronounced: the inherent difficulty of detecting biological agents and toxins; and the mistrust that arose from the admission by the Russian Federation that the then Soviet Union had continued an extensive BW program in defiance of the BWC. The audacity of the Soviet Union in flagrantly disregarding its commitments has led some State Parties to question whether others have also 
successfully hidden BW programs. Chevrier points out that the US has made few 'contributions to the BWC Protocol discussions. However, in January 1998, President Clinton did announce a stronger effort in support of a strengthened and effective BWC, seeking a Protocol that the US Senate could ratify with confidence and one that could be implemented domestically. It is quite obvious in reading this article that the author is disappointed that the most heralded Washington initiative of 1998 has faltered. In Chevrier's view the US should renew its efforts to again be an active participant in the BWC negotiations.

In Chapter Fourteen, Gennadi Lutai explores the Russian Federation's approach to strengthening both the $\mathrm{CW}$ and $\mathrm{BW}$ Conventions. The author reviews historically the use of chemical weapons in conflict and then proceeds to discuss the legal imperatives involved in the Russian Federation's implementation of the CWC. Lutai notes that although Moscow wants to meet its obligations within the $\mathrm{CWC}$, it cannot do so because of the prohibitive financial costs involved. He emphasizes that Russia expects financial assistance from the international community to meet its CWC obligations.

Regarding the BWC negotiations, the author reviews the number of provisions that have been developed by Russia that were included in the "Rolling Text" of the draft Protocol. An important element that is stressed in this chapter is the importance that the Russian Federation places on on-site inspections for possible 
violations of the BWC. However, unlike the position held in Washington, Moscow is opposed to field investigations of the outbreak of infectious diseases. Lutai ends his presentation on a pessimistic tone noting that many outstanding issues for a BWC Protocol will be difficult to overcome. He further notes that the procedures for a balanced verification regime must not be too cumbersome or too costly to implement and must not cause damage to the national security interests or the industrial development of State Parties.

Chapter Fifteen by Sergei Kisselev is a highly descriptive piece on the organizational and administrative implementation of the Organization for the Prohibition of Chemical Weapons (OPCW). Kisselev notes that though the Chemical Weapons Convention is a very intricate and complex agreement, its complexity has not prevented State Parties from formally adhering to it even at such an early stage in its life. It should be noted that the CWC offers two challenges in the arena of arms control and in the requirements imposed on the chemical industry in declarations and verification requirements. Kisselev points out that given the technical complexity and political sensitivity of the CWC regime, it is the political willingness of the State Parties that has created a smoothness in the implementation of the CWC verification procedures. Success of the CWC will effect elimination of an entire category of Weapons of Mass Destruction. 
Part Five of this volume focuses primarily on the Nonproliferation Treaty Review process through five contributed papers, four concerned with the NPT and the IAEA and the other examining the Comprehensive Test Ban Treaty's structure and efforts toward its implementation.

Michael Wheeler's Chapter Sixteen sketches from a historical perspective both the positive and negative security assurances of the NPT and explains the current issues and circumstances surrounding the security assurance debate. The author explores why there is little prospect that the stalemates will be broken at the NPT Review Conference in 2000, and he recommends a new framework for future discussions on "comprehensive" security assurances which might break through the current deadlocks. His proposal is to move beyond negative and positive security assurances to those which might address, in an inclusive manner, the security concerns of both the Nuclear and Non-Nuclear Weapon States that are parties to the Nonproliferation Treaty. His encompassing proposal recognizes the fact that achieving a reasonable security formula is an inherent political activity and that sound international politics should be directly linked to international law. Wheeler notes that no quick or easy solution exists in what nuclear weapons represent. However, in the final analysis resolving these dilemmas is a matter of dealing with the problem of war itself. 
The piece by Michael Wheeler is followed by a detailed discussion of the various administrative and procedural issues surrounding the 2000 Review NPT Conference to be held in New York, April 2000. Hannelore Hoppe, author of Chapter Seventeen, will serve as the Review Conference's Secretary. The author's informative treatment of the review process leading to the Year 2000 Conference and her penetrating discussions of the work of the PrepComs illuminate the many issues and challenges that have confronted the State Parties to the NPT. It appears that the three Main Committees resulting from the PrepCom in 1999 will serve as the primary vehicles to prepare the groundwork for the Year 2000 meeting. Main Committee I will review the implementation of the provisions of the NPT and deal with issues of negative and positive security assurances. Main Committee II's responsibilities are to address the implementation of the provisions dealing with nonproliferation, safeguards and Nuclear-Weapon-Free Zones. Main Committee III will conduct a review of the Treaty's provisions that relate to the State Parties' rights to conduct research, to produce and use nuclear energy for peaceful purposes, and to conform to the articles of the NPT that pertain to the nonproliferation of nuclear weapons.

Chapter Eighteen by Tariq Rauf is a very detailed commentary aimed at enhancing the thought process on how best to conduct the Year 2000 Review Conference under the "strengthened review process." Rauf argues that it will be crucial 
to ensure a full and balanced review of compliance with all the provisions of the Treaty as well as a review of the implementation of the decisions made at the 1995 Conference. Rauf notes that the Nuclear Weapon States (NWS) were clearly opposed to the PrepCom as an on-going substantive review mechanism and prefer that the Prep Com engage in procedural preparations and drafting a list of recommendations for the review conference. Based on a package of interrelated decisions at the 1995 Conference, the NPT parties agreed without a vote to indefinitely extend the Treaty. The author finds the political milieu disturbing for the 2000 Review Conference because the Nuclear Weapon States are attempting to deflect criticism from the Non-Nuclear Weapon States who argue that NWS have made little progress on nuclear disarmament and have not reconsidered their nuclear policy in the post-Cold War era. In the end, the NWS risk undermining the NPT that provides for their own security, as well as for global security.

In Chapter Nineteen, Rebecca Johnson reviews and analyzes the third PrepCom held in 1999 and considers the prospects for the NPT Review Conference in 2000. Johnson discusses the implications for arms control and nonproliferation of the Indian and Pakistani nuclear tests and NATO's war on Yugoslavia and concludes that their affect on the 2000 conference is unclear. Conferring a nuclear status on India and Pakistan would be an anathema and could conceivably threaten the collapse of the nonproliferation norm. It is imperative, Johnson notes, that Israel, 
India, and Pakistan be pressured to accede to the Treaty. Additionally, because of the deterioration of US relations with Russia and China, the effect of NATO's action in the Balkans and US plans for developing a missile defense could be to effect closer relations between Russia and China. Johnson ponders whether these changing alliances are short-term responses to conditions in 1999, or if they might signal deeper transformations in international relations, creating an atmosphere in which nonproliferation and arms control progress becomes more difficult.

Chapter Twenty by Kaluba Chitumbo and Malcolm Nicholas argues that it is crucial to the NPT to be able to verify compliance and that the heart of this Treaty is verification and the safeguards system of the International Atomic Energy Agency (IAEA). Yet, according to the authors, securing the NPT's permanence does not isolate safeguards from the forces of change. In the crafting of safeguards one vital task is to ensure they are resilient enough to handle with global developments. This is especially crucial in a world where uncertainties of a political and security nature abound. In addition, it is also important to anticipate future safeguards issues. Thus, foresight and flexibility are essential to the operation of a robust safeguards regime. Having set forth the bases of their arguments, Chitumbo and Nicholas review in more detail the reasons for the evolution of strengthened, albeit flexible, safeguards and emphasize the importance of being prepared for the finalization of the Fissile 
Material Cut-off Treaty. The authors further note that the discovery of Iraq's clandestine nuclear program has spurred the evolution of the IAEA into more sophisticated and broadened management and analysis techniques in an attempt to ensure that the IAEA provides the best capability in verifying the peaceful use of nuclear materials.

The final paper of this volume, Chapter Twenty-one by Masabumi Sato, is a descriptive piece on the purpose, significance, and organization of the Comprehensive Test Ban Treaty and its accompanying structures, which are designed to form a coherent and functioning whole. Overall, Sato notes that it is the intent of the Comprehensive Test Ban Treaty Organization Preparatory Commission to move aggressively ahead so as to secure an early entry into force of the Treaty itself. As of this writing, the number of signatures (numbering 152) that the Treaty has garnered underscores the success of this Treaty; and of these signatories, 36 State Parties have ratified the instruments for deposit. These results attest to the enhanced universality of this regime as an effective instrument of arms control.

In conclusion, it is the editor's desire that the twenty-one presentations that make up this volume will stimulate debate and discussion within the arms control community. Discussion, clarification and analyses of the strengths, weaknesses, and failings of policies, processes, and procedures can only enhance our understanding of these very crucial and important topics. This will 
ultimately lead to charting a new and more innovative arms control and disarmament agenda for the new millennium. 


\section{Part I}

Arms Control and Leadership:

Entering the New Millennium 


\title{
Chapter 1
}

\section{Arms Control in 2000-2010: Forks in the Road Ahead}

\author{
Brad Roberts
}

How is arms control likely to evolve over the coming decade? Will arms control grow more important to the national security of the United States, or less so? Will growing numbers of states seek arms control as a stabilizing factor in international security, or to reject it as unreliable? These are perennial questions. Yet, they are gaining new currency as the first post-cold war decade comes to a close and as major elections loom in the United States, Russia, and elsewhere.

In the search for answers to these questions, it is useful to begin with a view of the past. Over the last decade, the trajectory of arms control has been shaped by many factors. The end of the Cold War brought with it a host of new possibilities for arms control in the bilateral US-Russian relationship. Some of the most important possibilities for deep nuclear reductions, however, have proven difficult to capture. The end of the Cold War also brought with it a new, nearly global consensus that proliferation challenges required substantial improvements to the nuclear, biological, and chemical weapons control regimes. These, too, have proven difficult to turn into reality. Bilateral approaches have receded in importance as multilateral approaches have multiplied and gained international prominence. Generally speaking, the political 
emphasis in Washington has shifted from negotiation to implementation. A large mẹasure of available political energy has been invested in issues of organization, as both the Departments of State and Defense have been reorganized to deal with the arms control agenda. Arms controllers have been asked to do more with less; some would prefer that they do less with less. Political gridlock in Washington has deepened, with the US Senate holding a growing number of treaties hostage. In some basic respects, this has been a period of drift for arms control in US policy and uncertainty within the international community about where arms control might be headed after the Cold War. The momentum generated by the end of the Cold War, a momentum that appears to be dissipating, has determined arms control's future in the first post-cold war decade.

In speculating about the role of arms control over the next decade or two, most experts in the arms control community anticipate the continued playing out of that momentum. By and large, they tend to predict an expanding writ for arms control through the broader and more effective implementation of existing regimes and the accretion of new instruments. The future they envision is a fairly linear projection of the past, though with some bumps along the way, to be sure. However, the future may prove rather different from this caricature of it. Momentum alone may not propel the process much further forward. The bumps may turn out to be rather severe. The writ of arms control may well decline. 
The central thesis of this chapter is that down the arms control road ahead are some big forks. The years ahead are not likely to see business as usual. Those forks are probably closer ahead than many believe. There is little to suggest that the analytical community has thought through the nature of the necessary choices ahead, or the types of security environments that might be encountered down one path or another. Without some clearer sense of the alternatives ahead, the United States is likely to find it difficult to know which direction to choose when a fork appears.

To overwork this analogy, the road ahead consists of three paths. One is the path to continued strategic reductions. The second is the path to strengthening the global treaty regime. The third is the path to restored compliance by non-compliant states. This chapter considers each of these paths in turn. In each case, the path ahead as it is usually conceived is identified. Then the forks are identified. The chapter closes with a discussion of the synergies among these various paths on the long-term viability of arms control.

\section{The future of strategic reductions}

The first fork lies on the path of strategic reductions. In the US arms control community it is still widely assumed that down the path ahead lies a continued progression of nuclear reduction and de-emphasis, and a widening scope for strategic arms control. 
How often do we frame the question "what is the future of arms control?" by asking "what will START III look like?" To be sure, arms controllers appreciate the many bumps on the START path, but for most it is simply a given that the bilateral reductions process between Washington and Moscow will continue to serve as the backbone of arms control for decades to come. As of Spring 1999, many experts seem to believe that the process will get back on track as soon as presidential elections in the two countries in 2000 restore a measure of predictability and initiative to the bilateral political dialogue.

However, waiting for START II ratification may yet prove to be rather like waiting for Godot. START II may well be dead; indeed, START may be dead. There are many hints of this already in Russia. The Russian military and political leaderships have reemphasized the role of tactical nuclear weapons in Russian military strategy. Russian force structure planning is dictated increasingly by budgetary factors and technological obsolescence rather than by arms control considerations. President Boris Yeltsin has made explicit threats to target the West with strategic rocket forces and even to make first-use of nuclear weapons to punish NATO for its actions in Kosovo. Russian experts have also made it clear that the national missile deployments by the United States may cripple bilateral agreements on offensive forces, except possibly in a narrow set of circumstances.

So how might Russia depart from START? Russian experts have already offered a variety of scenarios. Sergei 
Kortunov has described one possibility, in the form of a decision by Moscow to no longer pursue a parity-based nuclear relationship with the United States, and to turn its nuclear planning "eyes" to potential nuclear adversaries nearer to its periphery. Sergey Rogov has described another possibility, in the form of a decision to seek common cause with Beijing in an anti-hegemonic alliance based in part on Sino-Russian nuclear cooperation.

But even if the bilateral US-Russian strategic reductions process enjoys renewed political commitment in Washington and Moscow, the future of deep reductions is going to be determined in part by a factor that barely plays today: China. China has had a unique nuclear posture until now, depending on very low numbers of not particularly survivable strategic weapons backed by a relatively small nuclear infrastructure. However, China also has rising concerns about the viability of its nuclear deterrent and especially about (1) the survivability of assured second strike capabilities in the light of the advances in conventional weapons in the West, and (2) the emergence of a host of nuclear problems around its periphery.

What kind of a strategic relationship is possible among the three major nuclear powers? Is a trilateral $\mathrm{MAD}$ possible or desirable? Who is willing to accept parity with whom? How might US deployment of missile defenses, both theater and national, affect the force structure preferences of Russia and China? Indeed, what does the Sino-Russian leg of the triangle look like? How deeply unsettled would the world be by a sharp decline 
in Russian offensive forces, a robust increase in Chinese offensive forces, and some movement by the United States to limited national missile defenses?

As the US arms control community begins to puzzle through these questions, it typically turns to the strategic vocabulary of old. To think strategic is to think nuclear is to think deterrence. Never mind that deterrence is a language of enemies, and the big three may be adversarial but show no signs of actively planning to launch all-out war against each other. Never mind that the strategic nuclear dimension is increasingly likely to be defined by complex and ambiguous relations of offense and defense. For China to come fully into the conceptual picture of the US arms control community is likely to require a good deal of intellectual homework in the period ahead.

So, what are the forks in the strategic reductions path ahead? The arms control process seems certain to pause for at least a year or two. It may well have stopped entirely, if Russia opts to move in a novel and independent direction, and/or if China cannot be brought in. Alternatively, strategic arms control may lurch in an entirely new direction, with an agreement encompassing China, and perhaps France and Britain as well. Reductions by the United States and others seem likely to continue, at least for a while, though perhaps not as part of a formal process. Perhaps the least likely path ahead is the incremental and linear movement through a series of bilateral START measures leading later rather than sooner to virtual 
de-nuclearization by the so-called P-5 (the five permanent members of the United Nations Security Council).

\section{The future of the global NBC Treaty Regime}

The second fork lies on the path of the nonproliferation regime. Many in the US arms control community see the path ahead as continued progress toward strengthening the larger regime by making incremental improvements to each of its components and by bringing a larger number of states within the regime. Indeed, the decade of the 1990s began with a major push in this direction. The end of the Cold War made new things possible, and the Persian Gulf war made new things necessary. Since then, negotiation of the Chemical Weapons Convention (CWC) concluded and the treaty entered into force. The Nuclear Nonproliferation Treaty (NPT) was extended indefinitely at the review and extension conference in 1995, and the International Atomic Energy Agency (IAEA) has gained new rights, with the promise of more to come. Moreover, negotiators have been at work on a monitoring and compliance protocol for the Biological and Toxin Weapons Convention (BWC). These myriad activities all suggest that the international community is well focused on the work of strengthening the regime and that the result has been good progress.

However, appearances may well prove deceptive. The NPT decision was won with a lot of arm twisting and there is much evidence to suggest that a significant portion of the member states 
are sufficiently dissatisfied with the Article VI performance of the Nuclear Weapon States (NWS) to consider extraordinary measures. One plausible scenario would see a dozen or so especially aggrieved states opt to "pause" their membership in the NPT at the review conference in 2005. In addition, the emergence of India and Pakistan as de facto Nuclear Weapon States has heightened concern among a number of NPT parties about the long-term viability of the regime.

Similarly, CWC implementation has not gone smoothly. Initial entry into force was delayed by the failure of the principal chemical weapons possessors - the United States and Russia to act in timely fashion on ratification. Initial implementation has been hampered by the collapse of their bilateral agreement to jointly undertake to resolve their $\mathrm{CW}$ problems outside of the framework of the multilateral convention, and by the failure of the United States to pass the necessary implementing legislation. The US ability to lead in The Hague, the site of the Organization for the Prohibition of Chemical Weapons, has been impaired by ambivalence in Washington regarding the merits and viability of the regime, and indeed about America's stake in combating the proliferation of chemical weapons through arms control approaches.

The effort to strengthen the BWC has also proven more difficult and time-consuming than many had anticipated. Technical and operational factors have been important, as negotiators have found it difficult to find treaty-based mechanisms 
sufficient to the monitoring and compliance need, but not counterproductive of other interests, including the protection of commercially sensitive information. But political factors have also been important, not least deep divisions between the non-aligned states and the West, and indeed within the Western group.

What can we know today about the path ahead, between now and the year 2005? The 2000 review conference for the NPT is likely to be fractious. This in combination with proliferation development in South Asia and elsewhere is likely to lead to a more fundamental debate at the 2005 review conference about the long-term viability of the regime. In 2005, CWC implementation will be entering a new phase, as the ten-year destruction period gives way to the period of extended monitoring, and with it rising debate about hold-outs, drop-outs, and delayed implementation by Russia (and perhaps the United States). In 2005, the BWC is likely to have some new protocol, which has been opened for signature by State Parties but has actually been ratified by a relatively small number of the states of special concern to the regime, in other words, a two-tiered system.

What departures are possible? Collapse of the regime over the coming decade certainly appears unlikely, but the alternative may be something as troubling in its own right. If the effort to strengthen the global treaty regime is widely perceived to have lost its momentum, an increasing number of countries are likely to position themselves for a rapid material response to a collapse of the regime. As latent capabilities are increasingly shaped into 
virtual weapons programs, there would be a heightened risk of wildfire-like proliferation in response to some catalytic event. Absent such an event, we may well find ourselves in a world in which the writ of arms control appears broad, but its actual effect is quite circumscribed.

\section{The looming crisis of confidence}

The third fork lies on the path of treaty implementation. A major crisis of confidence in arms control is brewing. That crisis has its seeds in the so far incomplete efforts to restore Iraq and North Korea to full treaty compliance. If the arms control architecture is shown incapable of dealing with extant noncompliance, the entire edifice may come tumbling down.

Let us not write-off the possibility of success in either Iraq or North Korea, but let us also consider the consequences of failure. The Iraqi and North Korean cases have emerged as a test of the UN Security Council - which, after all, is final arbiter and enforcer of the global treaty regime. The Council has not yet failed this test; but its interim grades are not encouraging. Its effectiveness has been hindered by the absence of strategic consensus among its permanent members, and by continued doubts about Russian and Chinese compliance with their BWC obligations. Successful resolution of the situations in Iraq and North Korea (and of the BWC problems) could go a long way to sustaining the viability of arms control. 
But Russian and Chinese voices, along with many others, are quick to argue their case for how US actions, too, have impaired the ability of the Security Council to act as it might have to protect the global treaty regime. As they would argue, US disinterest in CWC implementation and compliance; its corruption of the UNSCOM process through the introduction of independent spying activities; its reluctance to fulfill its part of the Agreed Framework with North Korea; its hard line in BWC negotiations; and, its failure to pay long-tardy dues to the United Nations - in conjunction with the obvious executive-legislative gridlock in Washington on arms control - only exacerbate the problems confronting the Security Council in its enforcement role.

The perception that the Security Council has proven incapable of delivering arms control compliance when the chips are down - when noncompliance has been proven, as in the cases of Iraq and North Korea; and, when it has explicitly committed itself to serve as the final arbiter of compliance disputes, as its members have agreed in each of the treaty regimes - would likely have repercussions well beyond the arms control domain. The perception that the major powers are paper tigers (or perhaps tougher tigers, but who can be counted upon to fall out among themselves) could unleash a new wave of proliferation by states that either wish to contest their guarantees, or to protect themselves from such challengers with something more tangible than a guarantee of doubted viability. 
In short, there is a crisis of confidence brewing about the enforceability of the treaty regime, a crisis magnified by the politics of collective security in the post-cold war era. Confidence restored would have a salutary effect on arms control by demonstrating the efficacy of the regime and the reliability of the system in protecting the security of its adherents. Confidence lost would have a highly damaging effect, by demonstrating that arms control is worth nothing more than the paper on which it is written. To be sure, not all countries would be immediately concerned about the loss of confidence in the enforceability of the treaty regime. After all, many states have signed these treaties and adhere to them because they had no interest in banned weapons in the first place. However, there are a large and growing number of countries that have foresworn certain categories of weapons on the bet that a cooperative approach to international security would do more for their national security than unilateral reliance on mass destruction weapons. For those countries, the viability of a regime is critical. Moreover, they watch its functioning carefully, regularly questioning the necessity of revisiting their original decision. The degree to which these states develop hedging strategies against the collapse of a regime ought to be an excellent indicator of the health of the regime.

The path ahead, then, for the compliance issue, is thus very unlikely to be "more of the same." Muddling through for nearly a decade has not brought resolution of the problem. Sooner rather than later, success will be necessary or failure will be assumed. 


\section{The leadership agenda}

These three paths run along the same road. Thus, there are synergies among them.

The positive synergies should not be discounted. Continued or even accelerated strategic nuclear reductions, whether of the two, three, or five, could have a quite positive impact on the politics of NPT implementation. A strengthening of the global treaty regime could help to reinforce the commitment to arms control approaches more generally in Washington, Moscow, Beijing, and elsewhere. Success in dealing with compliance challenges in Iraq and North Korea could dampen proliferation fears more generally.

Nevertheless, the potentially negative synergies are numerous. Collapse of the bilateral US-Russian agenda probably doesn't preclude new modes of negotiated restraint in a new trilateral or P-5 context; though, of course, we have no notion of how to navigate from here to there, or of how to incorporate defenses into the new arms control architecture. Collapse of the bilateral process could have a very negative impact on the multilateral treaty regime, accelerating the collapse of the NPT consensus, reinforcing growing international fears about collapse of the chemical and biological regimes, and eroding the viability of multilateral institutions. Collapse of the multilateral treaty regime could weaken the bilateral impetus to further reductions. If treaty implementation does not weather its crisis of confidence, the 
political will to carry forward the bilateral and multilateral agendas seems likely to wane.

It would be hyperbole and overstatement to deem arms control to be in crisis, but the obstacles on the road ahead appear to be fairly substantial. Moreover, to have commanded relatively little thought or preparation from policymakers. Let us consider for a moment the possibility that arms control might collapse that the treaties as such will be formally abrogated by a significant number of states, and that the political will not be found to put them back together. What then? Does this actually matter to the United States? There are at least three good reasons to think that it would.

First, the collapse of formalized restraint would come at a time of unprecedented diffusion of the technologies, material, and expertise to make Weapons of Mass Destruction. More than ever before, developed and developing countries possess the indigenous capabilities necessary to produce these weapons, and to do so relatively quickly. A rush to break out, to turn latent capabilities into deployed ones, would likely prove deeply unsettling within regions and, given the concomitant proliferation of long-range delivery systems, across them as well. Such a process would sorely test the Ken Waltz proposition that "more is better" - that proliferation would be stabilizing.

Second, the proliferation of Weapons of Mass Destruction to more states, and the quantitative and qualitative improvements to those capabilities that would follow, would pose new military 
operational challenges to the United States. It is one thing to prepare for a world in which a handful of states have banned weapons produced in the basement and untested in war. It is another to prepare for a world in which many states have not fission but fusion weapons, not handfuls of chemicals but arsenals full, not a bit of anthrax but a diverse arsenal of bioengineered organisms, as well as a proven arsenal of precision delivery systems. Protecting US interests abroad and guaranteeing the security of others is likely to prove far easier in the first world than the second.

Third, a collapse of arms control would likely prove politically unsettling to Americans. It would signal to many the abrupt termination and abject failure of the nation's historic mission to create an international system based on the rule of law and political consensus, and the drift toward a "dog-eat-dog" world, in which the "dogs" - and their terrorists - can inflict mass suffering in America. At the very least, there would likely be a domestic, political price to be paid by those who permitted this to come to pass.

If the United States would prefer not to live in a world in which the challenges ahead combine to collapse the treaty regime, what should it do? What does it mean to lead the process and the community to a world free of these proliferation consequences? 


\section{Conclusion}

The three paths sketched out above suggest something about the leadership agenda ahead. We must know where we want to go on each of those paths -- which directions best serve the US national interest, and the interests of the larger international community. This is not a business for platitudes - it requires hard choices on the hard problems that others would call too hard to solve. This requires close collaboration with our partners, and listening when they want to move the dialogue in ways not always welcomed in Washington. Implementing those choices requires creating and sustaining political coalitions. It requires also brokering the necessary measure of domestic consensus in support of unpopular steps. It requires paying attention, rather than engaging only episodically. It requires that self-accepted commitments be honored. To lead, others must want to follow. This arms control agenda affords leadership opportunities for many countries, especially within the existing treaty regimes and their associated implementing bodies, but the opportunities are especially salient for the United States. Without Washington playing its proper and necessary role, it seems unlikely that others can pick up the slack adequately to navigate the difficult challenges ahead.

Arms control's continued relevance to the evolving strategic landscape cannot be taken for granted. If arms control approaches are to play some constructive role in managing the international security environment of the next decade, then care 
must be taken to navigate our way down the right forks on the road ahead. 


\section{.}


Chapter 2

\title{
Arms Control at the New Millennium: The Dilemmas
}

\author{
John D. Holum
}

Contemplating the arms control dilemmas we face on the brink of the new millennium is particularly apropos from my current vantage point. Indeed, it is almost bittersweet, capturing both the passing of an era and the challenge and inevitability of transition. "Transition" is the watchword in every aspect of our arms control endeavors as we gaze ahead. The challenges are not only profound, but messy and complicated.

The trend reflects the growth and spread of dangerous technologies and the possibility, appealing for many state and nonstate actors alike, of mounting "symmetric" threats against larger, more capable states. Recent events make it clear that we face dangers from many directions and in many forms that oblige us to greatly expand our field of vision.

- When they shattered the silence at nuclear test sites, India and Pakistan stepped into a profoundly more dangerous relationship, taking the rest of the world with them.

- Iraq continues its Weapons of Mass Destruction (WMD) ambitions and stepped-up defiance of the United Nations. 
- Iran's intermediate range missile potential threatens throughout and beyond its own region, and its nuclear ambitions are ominous.

- Beyond the issue of the suspect nuclear site, North Korea's three-stage missile capability potentially could land payloads on the United States.

- Despite inducements and its own best interests, Russia has failed, yet again, to ratify START II.

- We now see the potential for entirely new forms of debilitating threats, such as information-based attacks on critical national infrastructure.

More broadly, after great strides forward on arms control - among them the NPT made permanent, the CTBT completed, the CWC up and running, IAEA safeguards strengthened - it is probably generous to describe the pace of progress today as a crawl. Negotiations to strengthen the Biological Weapons Convention (BWC) are making little headway. With an opportunity to advance on both the fissile material cut-off and landmines, the Conference on Disarmament seems bent on showing it can neither walk nor chew gum, but only stand in one place and bicker.

As difficult as our diplomatic tasks are, they are made more onerous by a political context rife with internal division and second-guessing, which seems to succeed only in permitting our adversaries to play us off against one another. The Arms Control 
and Disarmament Agency (ACDA) disappeared at least in part because understanding of its goals and mission was flawed and had become controversial. At home, we seem mired in bitter struggles over virtually every element of policy, whether ratification of the test ban or nonproliferation engagement with China. Internationally, the common pursuit of security through arms control too often takes second place to the selective pursuit of political or military advantage.

Thus, we will carry with us into the new century much unfinished business, as well as the harbingers of new threats to come. These challenges warrant a serious response. Let me suggest three broad areas that will be critical to our chances for renewed success: how we organize to do this work, how we define and explain it, and how well we identify and address the hardest issues.

On the first, we will make reorganization work and maximize its benefits. At midnight March 31, 1999, we retired the colors of the small but proud agency, ACDA. For 38 years ACDA had been this nation's greatest independent voice for a policy perspective which seeks to reduce threats to national security by means other than war or the accretion of weapons.

While I bear the sad distinction of having served as ACDA's last Director, to paraphrase a popular playwright, I have come to praise ACDA, not to bury it. For indeed, ACDA's accomplishments are legion. 
For 38 years, ACDA tenaciously led a sometimesrecalcitrant group of US government agencies to champion major arms control achievements that we have all come to take for granted - nuclear test bans from partial to comprehensive; the NPT and the decision to make it permanent; strengthened IAEA safeguards; SALT, START, and INF; the BWC and the CWC; limits on conventional forces, including landmines; confidencebuilding in Europe and elsewhere; and many, many others.

ACDA also led in the interpretation and implementation of those treaties - assuring that the benefits recorded on paper were realized on the ground. ACDA offered the unvarnished facts, even when it was politically inconvenient or unpopular - whether on treaty compliance or verifiability, or on treaty interpretation.

Deservings of special praise are the public servants in ACDA's ranks that $I$ had the pleasure to lead. They are some of the most gifted found anywhere - experts who showed their mettle by refusing to be distracted from their mission over the last decade even as their agency seemed perpetually poised on the edge of oblivion.

Despite these attributes, or perhaps because of them, by 1997 it became clear that ACDA was losing the battle to retain its independence. We faced a choice: we could go down in flames, literally and risk losing the agency, its professional assets, and its vital advocacy role; or we could try to negotiate a soft, upright landing that would preserve not only ACDA's expertise, but an 
independent voice for arms control within a strong organizational framework.

In principle, in plan, and in law, we have accomplished the latter. The independent advocacy role ACDA was created for is preserved. The Under Secretary of State for Arms Control and International Security will also serve as Senior Advisor to the President, with authority to attend deputy and principal level NSC meetings, and even go directly to the President to express an independent view. Secretary Madeline Albright agrees that such independence on arms control matters is crucial. It will, however, fall to those of you who support arms control and follow it closely to be vigilant to sustain that commitment through successive administrations.

There are other pluses. The plan includes steps to preserve ACDA's unique technical verification, and legal expertise. The new organizational framework combines that expertise and memory with State's institutional authority and diplomatic capabilities. Although the process of merger has just begun, I believe the perspective ACDA brings will also challenge State to think more globally, less regionally, and to see issues systemically, rather than episodically.

Effectively fulfilled, this merger will give us an opportunity not simply to blandish, but to lead; not just to make points, but to shape events. Secretary Madeline Albright intends to make arms control and nonproliferation even more central to our international efforts. We are turning reorganization to precisely that purpose. 
But more and more of our efforts in arms control and nonproliferation are ensnared in unrelated political and diplomatic differences. More and more the political argument is not about who can do this work best, but about whether it should be done at all.

To me that means we need to renew our efforts to define the vital security role these policies play. With the public and Congress, in particular, we need to return to first principles and explain how critical these activities are to US national security.

Once again, we must correct the popular misconception that arms control is somehow the soft, altruistic, trusting part of our international strategy - that we negotiate agreements and then simply hope the miscreants of the world will sign up and play along. In fact, our arms control and nonproliferation efforts comprise a series of hardheaded interconnected strategies that, when they are most effective, enable us to confront and dispense with threats to our security without a single shot being fired. The full panoply of tools is essential to a consistent strategy capable of seeking out proliferation and firmly and verifiably containing it.

The essential tools include, in particular, strong nonproliferation regimes and "supply side" controls. We need the Comprehensive Test Ban Treaty in force, a Fissile Material Cut-off Treaty concluded, and the Biological Weapons Convention strengthened, to accompany other, existing elements of the international nonproliferation regime. These are needed not out of a naïve belief that everyone will obey the rules, but first, because 
they add to our ability to detect proliferators; and second, because international standards, including the legal obligation not to assist others acquire these weapons, can impede noncompliant behavior, justify sanctions, and dry up sources of supply.

Common political undertakings, such as the various supplier regimes with common export controls, serve the same essential purpose, which is why we want China to take the nonproliferation and export control steps necessary to join the Missile Technology Control Regime (MTCR) and the Nuclear Suppliers Group.

Positive inducements to shrink the "demand side" of the equation complement supply-side controls. US activation of the 1985 Sino-US peaceful nuclear cooperation agreement led China to phase out even peaceful nuclear contacts with Iran. The President's Enhanced Threat Reduction Initiative will enhance our nonproliferation efforts in the New Independent States. Technical support to those with commitment to control sensitive technologies and goods, but an absence of expertise, helps reinforce demandside goals.

We also need tools with sharper edges. Where we find noncompliance, sanctions can play a key role. The conventional wisdom that they never work is wrong. They can and do influence conduct.

These tools are supported by diplomacy at all levels, whether admonitions at the presidential level, démarches to interrupt problem shipments and everything in between, and they 
are employed in varying proportions in country-specific strategies - whether addressing loose nukes in Russia, or Russian and Chinese technology transfers, or North Korean nuclear and missile capabilities, or the budding arms race in South Asia.

When properly designed, the strategies I have outlined, even when only partially successful, can close off a proliferator's options, complicate his efforts, delay his ambitions, and thus ultimately ease the task of the defender.

Because they are much in the news these days, I want to say a word about the role of our labs, particularly Sandia and Los Alamos, in these efforts - and not only their contributions, which are legion, as enablers of arms control, through advances on the cutting edge of detection and other related technologies.

Serious security problems require appropriate responses. But we also need to keep other realities in mind: Unless China deepens a practical commitment to nonproliferation standards and practices, we will loose ground in the high stakes effort to contain WMD and missiles. Unless sensitive materials and expertise in Russia are protected, we will face more nuclear weapons in more unstable places.

One of the very best, proven ways to attack these problems is through direct contacts by scientific and technical counterparts - instilling both the methods and the culture of responsibility and protection that is so well developed and comprehensively practiced at our labs. Sweeping steps to sever these links in the heat of the moment could turn out to be a blunderbuss cocked and aimed 
somewhere between the middle and third tows of America's own foot.

While explaining the strategy at home, we also need to do a better job reminding the international community of the tangible benefits that all reap from these various arms control agreements and regimes. Rhetoric and frustration about the pace of disarmament has led to a loss of perspective. If we fail to make progress, and if the existing agreements do not remain strong and viable, everyone's security will suffer.

We need to renew more broadly that strong, palpable collective recognition demonstrated by the international community at the 1995 NPT Review Conference that, in affirming the Treaty's indefinite extension, they were doing so not as a favor to the Nuclear Weapon States, but because the NPT is a vital security instrument for each of its members.

It bears repeating that, without these nonproliferation efforts, the world would be a far more dangerous place. We arms controllers may differ over the nuances of one policy or another, but those differences are far less relevant to our future success than our renewed efforts, domestically and internationally, to explain what this work is about and why it is indispensable.

As we reinforce and apply these tools, we must also address some of the hard questions that arise as we approach the new millennium - questions that can no longer be relegated to the 
"too hard" pile. For example:

- How can we effectively enforce nonproliferation regimes in places like Iraq, where the national leadership is prepared to subject its people to any level of privation in order to maintain its WMD objectives? The related question Ambassador Richard Butler raised of how can we make the UN Security Council a more reliable instrument of enforcement?

- How can we create greater synergy between our arms control, nonproliferation, and defense strategies?

- How can we insulate arms control measures clearly in the interests of all parties, like START II, from the effect of unrelated political differences?

- What strategies will be effective in managing the effects of emerging technologies that may be easily weaponized by state and nonstate actors alike, and that can seemingly be used with impunity against large parts of the increasingly interconnected global community?

These and other questions deserve the thoughtful analysis and discussion. I don't have comprehensive answers to them all, but let me offer you a few thoughts.

That we cannot guarantee success on the hardest cases, for example, brings us precisely to the intersection between arms control and defense. In light of the Taepo Dong launch August 1998 by North Korea, the possibility of WMD - armed rogue 
state ICBMs aimed at the continental United States may be, at the outside, just a few years away. Deterrence will still play an essential role in safeguarding our security. Should deterrence fail, technology now may offer us other options, in the form of active missile defenses. Out of absolute necessity, then, a National Missile Defense (NMD), if proven, may become an integral part of our strategy against proliferation.

Of course, any decision to proceed with deployment will hinge on evaluation of system effectiveness, the threat, cost, and progress on our arms control objectives. We expect such an evaluation to be possible by the middle of the year 2000 .

This does not signal an intent to abandon the $1972 \mathrm{ABM}$ Treaty, nor will we develop a capability to undermine the Russian strategic deterrent. The ABM Treaty retains value. It contributes to strategic stability and enables continued deep reductions in strategic arsenals. So chief among our arms control objectives is an intent to negotiate whatever $A B M$ Treaty amendments are required if the US decides to proceed with a limited defense. Indeed, I would argue that amending the Treaty would protect and renew its essential purpose, by underscoring that arms control does not have to be the enemy of measured defenses responding to real threats.

Lastly, I would like to mention an emerging challenge that appears truly a harbinger of the new millennium. Of increasing importance to international security will be thoughtful approaches to managing the less desirable consequences of the global 
information revolution. As breathtaking as our combined technological progress in this area has been, our increasing dependence upon information technology has given the unscrupulous and the dangerous, yet another target, creating the very real possibility of highly disruptive attacks on key segments of national critical infrastructures.

Used in a hostile manner, information technology has attributes unique among the threats we have previously faced. It is a threat that does not recognize borders or observe traditional national distinctions: any state or nonstate actor anywhere can concoct some manner of attack and unleash it at any system. Neither perpetrator nor point of origin of attack is easily identifiable at this stage of technology and international law. Information technology, of all the technologies for which we have laboriously contemplated controls over the past decades, is the least susceptible to control or verification. It changes at lightspeed with no concomitant requirement for long-lead-time hardware development - all attributes, which would make offensive controls, no matter how well intended, obsolete before the ink was dry.

The strategic implications of this problem demand keen analysis and unconventional insight. With increasing global connectivity, the international risks are becoming our domestic risks. Indeed, our best strategy at this time is reflected in the President's initiative of last spring and reaffirmed recently: to take 
steps to assess and protect our critical infrastructures and to enjoin the international community to do the same.

As we peer ahead to the new millennium, we see grave challenges both old and new. We have the task of advancing these difficult agendas: on nonproliferation, through the strategy I outlined; on arms control, by pursuing START and related initiatives; on defense, by considering further modernization of the ABM Treaty; and on emerging threats, the dynamics of which beg to be better understood. Moreover, we will confront these challenges from the perspective of a new, as yet unproven, structure.

These are not endeavors for the faint of heart, or for those easily discouraged. But that only confirms what you already know - that we live in complex times, in a dangerous world - one in which the preventive medicine of arms control is both more important than ever before and harder.

We had better be up to the task. 
Chapter 3

\section{A Troubled Era for Leadership and Arms Control?}

\section{Thérèse Delpech}

Complaints concerning the lack of leadership in the arms control community are now commonplace, not only in the West, but also in the rest of the world. Is it due to a weaker psychological foundation than what existed during the Cold War? To some this phenomenon can be described as the fin de siècle's fatigue of leaders. To others, this lack of leadership may be attributed to the twin challenges of national identity crises and contested sovereignty. Additionally, globalization has enhanced this lack of leadership contributing to its death, thus creating a vacuum in international affairs.

Whatever the explanation, the leadership crisis is real and can be described in three different ways. The historical dimension of the problems is obvious: leadership has led to momentous disasters in this century, particularly in Europe and Asia, reversing Clausewitz's formula, that politics has often been a continuation of war by other means. Decades later, after witnessing the most extreme political experiences (World War II), the world is now producing more politicians than leaders, especially within liberal democracies.

Another way of describing this crisis is to consider the current sharp deterioration of relations among the major powers, 
whose leadership is critical to world order or disorder. This is particularly true for the United States and Russia. The growing imbalances, politically, economically, and militarily between these two countries has contributed to heightened tensions between them. Both disagree over issues regarding NATO's expansion, developing missile defenses, a Balkan strategy, and the roles of Iran and Iraq in the international community. The US is perceived as an increasingly unilateral power, and Russia doing too little in the area of international security. Russia, it would appear, is obsessed with its lost status as a "super power."

This deterioration among the major powers is further evidence, and perhaps even more serious, in the relations between the United States and China; which relationship will likely affect disarmament discussions. Strong disagreements exist in US-Sino relations on major matters, such as human rights, Taiwan, and Japan.

Furthermore, relations between China and Russia are equally important in shaping the international system. The rivalry between these two countries, as it existed during the Cold War, is now over. However, the very nature of their future relationship is still unclear. Russia's transformation toward a more democratic state and in westernizing its economy will take at least two decades to complete. Meanwhile, the asymmetries between Russia and China will likely continue to grow.

Finally, a major sign of the current crisis is the absence of a "driver." None of the P-5 countries is a forceful driver. It is quite 
evident that rhetoric and goodwill will not suffice in dealing with international issues because there exists in the world community a fetishist for non-interference.

It, therefore, appears that a troubled era is more than likely for arms control in the next millennium. This in part is a consequence of the reasons stated above. In the absence of political leadership, what remains is the "economization of politics" and a push toward a "technological drive." Yet, a good economy and good governance are not identical. They in fact can have the opposite affect, if security issues significantly overshadow the primacy of trade. As far as the technological drive is concerned, it may be viewed as a possible substitute to arms control, and thus become a decisive and complicating factor (e.g., ballistic missile defense). In addition, at a time when nation/states are reshaping their relationships, with no clear vision of what the future might hold, the States Parties' calculations of the effect of arms control on their role, in their region, and in the world arena appear essential. In a sense, everyone is waiting. How do the P-5 see their role in tomorrow's world? Cooperation or confrontation among the P-5 will be decisive. It is not enough to want cooperation and to obtain it, as the US-China relationship clearly shows. In many regions, however, the strategic withdrawal of the major powers that came about with the end of the Cold War has left instabilities, (e.g. Central Asia and the Caucasus). Internal and regional conflicts are now being seen in their proper context instead of being distorted and viewed as episodes in the global 
confrontation of the superpowers. No doubt shifts in regional power balances will have global implications. Additionally, the future of nationalism in both failed states and rising powers will be a key factor. Efforts in dealing with Weapons of Mass Destruction (WMD) and in evolving arms races should not rely only on traditional tools that have been previously used, but on efforts that encourage moderation in domestic politics. No doubt the current period is not an easy one for arms control and nonproliferation, because the problems that remain are also the toughest to solve. This is true for the countries affected, Iraq, Iran, and North Korea, in terms of verification (e.g., Biological Weapons Convention), and in terms of enforcement when disagreement among the P-5 members exists.

Against such a background, no wonder procrastination prevails. The ratification processes of already concluded major treaties appear to be endless. The START process is the most prominent example. The Comprehensive Test Ban Treaty (CTBT) is another important case. This latter Treaty will not enter into force in the foreseeable future. Thus, it is not out of the question that the resumption of some testing by a defiant country wishing to assert its nuclear power is conceivable. Such a possibility would have far reaching implications for regional and global stability in an already troubled world. Concerning expected negotiations, deep disagreements remain regarding the substance and scope of such conventions as the Fissile Material Cut-off Treaty. There are still other reasons to worry: the consequences that will come about 
regarding nuclearization in South Asia; the relative failures of policies adopted by the international community, vis-à-vis Iraq and North Korea; the possible introduction of missile defense systems risk legitimizing a new arms race; the Security Council inability to function properly; and, the P-5's disagreements on major arms control issues. Additionally, the mere maintenance of existing regimes into the next century will prove to be very difficult.

In general terms, however, the case for arms control is better than ever. The threat situation in many regions of the world could drastically change because of the various regimes, be they unilateral (e.g., Iraq or North Korea), bilateral (US-Russia process), or multilateral (the break-up of the NPT, challenges to the MTCR, and violations of the CWC and the BWC). Weapons of Mass Destruction exacerbate not only regional but global instabilities. Huge regions lack preventive mechanisms, notably among the countries in Africa and Asia. Negotiation, transparency, and compromise continue to remain appropriate responses to the increased risks of misunderstanding that might come about among nations or group of nations.

What should the major powers be doing to initiate a new era of arms control? The first step is to draw from the appropriate lessons of the last decade. What went right and what went wrong? For example, a positive lesson from the past was the expansion and the strengthening of international cooperation in the 1990s. To be able to react quickly and decisively against violators of international law and international community standards has 
always been problematic. Secondly, political interest in maintaining the existing arms control regimes should be sustained. The stakes for international security are high in the case of regimes collapsing requiring continuous efforts in placing stronger emphasis and commitment to nonproliferation and to arms control. Finally, accepting some changes in current policies is of necessity. For example, more transparency and less rhetoric from China; more emphasis for multilateralism from the United States; more concern for international security from Russia; and, more responsibility from the European countries. These suggestions would help to mute a rather cacophonous "concert of nations."

The XXth Century has been the most violent in human history and the technology of destruction is still advancing and spreading. Civilians are the principal victims of modern war. As a result, there is no longer a clear distinction being made between combatants and noncombatants. The XXth Century sends a very clear message to the XXIst Century in this respect. The inability of governments to contain violence, or to channel tensions that are generated in many parts of the world, might lead to unexpected turns. The danger is not a clash between civilizations, but a clash between increased violence and the failure of politics. The triumph of hope over experience should be a long-term view. This provides a guide to the setting of priorities, and to ensuring that future challenges will be met when they arise. Arms control is part of this long-term view. 


\section{Chapter 4}

\section{Rethinking Security and Disarmament Agenda for the NewMillennium}

\section{Sola Ogunbanwo}

"Arms Control and Leadership: Entering the New Millennium" is a forward-looking theme and confirms the fact that leadership can play an important role in disarmament efforts. This raises the question of what characteristics of leadership should the international community desire as we enter the new millennium. At the outset, it should be stated that it is not necessary to be a Nuclear Weapon State (NWS) or a technologically advanced country in order to lead. It is enough, however, if leadership has the vision, talent, and credibility to play a foremost role. Several attributes of good leadership follow:

- Leadership is creative thinking that sets the tone and direction;

- It means willingness and ability to lead;

- Leadership costs money and commits resources to achieve disarmament goods;

- It cultivates and maintains good relationships which are important for progress in disarmament negotiations; 
- Leadership has no isolationist illusions and believes that national interests can be served by international engagements;

- Leadership adjusts to the broader concept of global security and understands that in addition to national interests there are the vital interests of the international community; and,

- Leadership leads by example and should not be tainted and constrained by its own acts.

\section{Examples of leaderships that have advanced disarmament goals}

Below are a few examples of marked leadership that have made differences in advancing the cause of disarmament. Undoubtedly, the United Nations and the United Nations' Secretary General are the global leaders that played and continue to play leading roles in advancing the cause of disarmament through inter alia, the United Nations General Assembly (UNGA), the United Nations Security Council (UNSC), the Conference on Disarmament (CD), the United Nations Expert groups and meetings, and the United Nations Department of Disarmament Affairs. It is expected that the United Nations will demonstrate this leadership effort during the United Nations Millennium Assembly next year.

The United Nations needs and seeks leadership partners for disarmament. The international community has witnessed how the 
persistent efforts of the combined leadership of civil society, governments, and the United Nations resulted in the adoption of the landmark Ottawa Landmines Convention. Such leadership is currently at work in the efforts to control the scourge of small arms in their proliferation.

Outstanding leadership came to the rescue and transmitted the text of the Comprehensive Test Ban Treaty (CTBT) to the UNGA when the $C D$ failed to act at the crucial moment. The Canberra Commission's leadership has been recognized for its plans on the elimination of nuclear weapons. Other entities have emerged bringing with them new initiatives that include:

- $\quad$ Eight-Nation New Agenda coalition;

- $\quad$ Middle Powers' initiative;

- Canadian Parliament Report on reducing the political value of nuclear weapons for the $21^{\text {st }}$ Century;

- The advisory opinion of the International Court of Justice (ICJ) on the "legality of the threat or use of nuclear weapons;" and,

- Kampala Document which proposed the launching of a conference on security, stability, development, and cooperation in Africa. (The Kampala Document emerged from a conference organized by the Africa Leadership Forum).

Similar leadership traits and new actors will be required to contribute fresh ideas for the new Millennium Security and Disarmament agenda. 


\section{Future disarmament efforts require a new vision of the future}

What the international community needs to do is to capitalize on the positive trends that these new initiatives provide, and to use them to address the expanding range of security and disarmament challenges of the $21^{\text {st }}$ Century. In this connection, future disarmament efforts will require innovative designs, concepts, and approaches to meet these new objectives. It is advisable at this point to heed the observation of Einstein. He observed that the unleashed power of the atom changed everything, except our way of thinking. He warned this planet's population and its governments that they would bring unprecedented disaster upon themselves unless there were some fundamental changes made in their attitudes toward one another, as well as in their concept for the future. The element of change, as represented by the unleashed power of the atom, and the need to evolve a new peaceful concept for the future, forms the core of any security, and disarmament agenda. Thus, the agenda ahead calls for a new thinking, a new creative vision of the future based on common security, and a deep reassessment of the many traditional concepts, doctrines, and values, particularly as they pertain to peace and security. 


\section{The need for a new international conference to produce a new security and disarmament agenda}

With the above background, what should be the framework of the agenda ahead? What realistic goals should we set for ourselves? What programmatic steps should be taken as we face a wide range of opportunities and challenges in the new millennium?

The current global disarmament agenda is contained in the 1978 Final Document of the First Special Session of UNGA Devoted to Disarmament (SSOD-I). This agenda needs to be reviewed. For the moment, we are faced with the uncertain prospect of when the Fourth Special Session (SSOD-IV) will be convened to review the twenty-one year old agenda. Accordingly, given the positive effects of the above-mentioned issues, perhaps some thoughts should be given to the idea of convening a new international conference as the millennium approaches. Such a conference should be given the mandate of producing a farreaching and comprehensive report/agenda not only on nuclear disarmament, but also on the other aspects of security and disarmament affairs.

Preparing a new agenda for a new era requires the participation of the United Nations, governments, and civil society. Therefore, conferences such as the ones being held in Albuquerque, New Mexico; Washington, DC; Monterey, California; and in other regions of the world can generate new and 
useful ideas for the new millennium agenda for security and disarmament.

4. Generating ideas for the new millennium security and disarmament agenda

\subsection{Building on post achievements of disarmament treaties and agreements}

The various disarmament treaties and agreements provide the framework for the international legal order in dealing with security and disarmament matters. They especially contain Confidence-Building Measures among the parties concerned. It is essential to build on these past achievements, including the provision of assistance to needy countries in order to meet their treaty obligations.

\subsection{Roadmap to a nuclear-weapon-free world}

Priority should also be given to the creation of a roadmap to a nuclear-weapon-free world. Utilizing the NPT as a starting point, the international community needs to remember that the central and inseparable commitments in that Treaty are nuclear nonproliferation and nuclear disarmament. On nuclear nonproliferation, 182 of the 187 States Parties to the NPT are 
Non-Nuclear Weapon States, and they have given-up the option of possessing nuclear weapons, thereby demonstrating that security is possible without nuclear weapons. These same Non-Nuclear Weapons States have gone further by establishing NuclearWeapon-Free Zones (NWFZs) in their various regions.

The NWFZs created in Latin America and the Caribbean, the South Pacific, Africa, and South East Asia together form a nuclear-weapon-free mantle over vast and densely populated areas of the Southern Hemisphere. Proposals to establish additional NWFZs in Central Asia and the Middle East would represent a further step in the direction of a nuclear-weapon-free world.

It is clear from these developments that nuclear nonproliferation is proceeding well and that Non-Nuclear Weapon States are fulfilling their share of the obligations under the NPT. We should, therefore, be clear where the problem lies. The problem resides in the continued existence of, and reliance on nuclear weapons, and how to achieve nuclear disarmament. Having given up the nuclear option, it is natural for the NonNuclear Weapon States to fulfill their share of obligations under the NPT, especially Article VI of the NPT.

There is no doubt that the Nuclear Weapon States (NWS) bear primary responsibility for taking tangible steps toward the elimination of nuclear weapons which exist in the thousands, some of them lacking adequate, safe, physical protection with the risks of accidents and possible sale to suspect countries. At the bilateral level, the START process between the United States and the 
Russian Federation that has been stalled should be revived and reinvigorated. The other three NWS should be encouraged not to continue to sit on the sideline but to join in the negotiations to reduce their own nuclear arsenals. Measures to enhance transparency should be instituted, and reporting on such measures should become a regular feature in disarmament meetings.

Efforts to achieve nuclear disarmament cannot be left to the NWS alone. The international community has a role to play. Since the efforts during the outgoing millennium have been characterized at times by confrontation, it is incumbent upon the international community to make the new millennium a period of cooperation in preparing a roadmap to a world free of nuclear weapons. Such a roadmap should be based on a pragmatic approach and should contain realistic step-by-step measures leading to the total elimination of nuclear weapons. The roadmap should be open for inputs from all concerned countries. Indeed, there are already new ideas and initiatives that are being proposed through the United Nations, the Conference on Disarmament, the Canberra Commission, the 18-Nation New Agenda Coalition, and the Middle Powers' initiative and declarations from civil society.

As part of drawing-up a roadmap to nuclear disarmament, the NPT Parties should further examine the management of the NPT. The NPT is the cornerstone of the global nonproliferation regime. And yet, it is without a management mechanism. Management questions have too often been at the core of the problems of the NPT review processes. Indeed, during the long 
intervening periods between review conferences, NPT parties have not had an NPT-based management mechanism to turn to for their frustrations, concerns, complaints, or difficulties. In the past, such frustrations have been allowed to reach boiling points and then dumped on the review conferences or PrepComs, resulting in inconclusive results. As a response to the management problems facing the NPT, the parties may wish to consider the desirability of creating an "Informal Management Group for the NPT."

With regard to non-NPT Parties, there is a need to also address their concerns so as to encourage them to join the NPT. In this connection, the extension of NWFZs to the Middle East and South Asia will represent a significant contribution to the goal of a nuclear-weapon-free world.

The work of UNGA on the establishment of a NWFZ in the Middle East is very pertinent. It has been noted that the various UNGA resolutions on this topic have been adopted by consensus. What remains now is to implement these resolutions. When the States of the Middle East are ready to implement UNGA resolutions on the establishment of a NWFZ in the Middle East, they will find that there are lessons to be learned from the way the African States successfully concluded the African NWFZ Treaty (whose members also include certain States in the Middle East). Those lessons learned include:

- the positive and catalytic political effects that were engendered from Apartheid, led South Africa to a 
successful peace process with the frontline and neighboring African States;

- unique features in the text of the African NWFZ Treaty which are not found in other existing NWFZ Treaties;

- the imperative of acceding to the NPT; and,

- the necessity of placing all nuclear facilities under IAEA full-scope safeguards.

\subsection{Ban on nuclear tests}

The CTBT has increased the momentum towards nuclear disarmament; however, the international community should consolidate its ban on nuclear tests by the CTBT's entry into force and the inauguration of its Permanent Verification Organization.

\subsection{Fissile Material Cut-off}

The process of reducing nuclear weapons can only have meaning if we can be assured that there is no parallel build-up of weapons-usable fissile material. Therefore, negotiations should immediately begin, without delay, on a Fissile Material Cut-off Convention.

\subsection{Other Weapons of Mass Destruction}

The seriousness of biological weapons' threats has been widely reported. A two-track approach needs to be adopted in 
dealing with such threats. While states prepare for defenses against possible terrorist attacks, they should also invigorate their efforts to find solutions to the outstanding issues delaying the conclusion of a credible inspection regime for the Biological Weapons Convention (BWC).

\subsection{Compliance and enforcement}

There is a need to revisit issues relating to compliance regimes in disarmament agreements; in particular as they pertain in how to deal with challenges to such regimes. For example, UNSCOM/Iraq developments, the North Korean situation, and the India/Pakistan nuclear tests have serious implications for global security and compliance regimes, including the mandatory enforcement decisions of the United Nations Security Council. Experiences from such challenges underscore the need to devise stronger responses from the international community, such as imposing effective sanctions and improved procedures for dealing with acts of noncompliance.

\subsection{Universality}

Despite the conclusion and entry into force of the NPT, BWC, Chemical Weapons Convention (CWC), and others, these treaties still fall short of having universal memberships. Building on past achievements include engaging in strong advocacy for universality in memberships of these treaties. 


\subsection{Regulation of missiles}

Notwithstanding the values of the Missile Technology Control Regime (MTCR) and the Anti-Ballistic Missile Treaty $(A B M)$, the recent tests of missiles in South Asia, North East Asia, and the Middle East demonstrate the urgent need for a multilaterally negotiated agreement to regulate missiles. As stated by the UN Secretary General, "there are reasonable fears that without such norms, missiles carrying Weapons of Mass Destruction will proliferate and further jeopardize international peace and security."

\subsection{Civil society and disarmament efforts}

In 1997, the creative coalition of the UN, governments, and civil society accomplished the landmark Ottawa Landmines Convention. In the wake of their success in the Ottawa Landmines Convention, civil society has begun to forge partnerships with some states to find ways of tackling other problems including small arms and light weapons. In the future, civil society should assume a greater role in advancing the cause of disarmament. Accordingly, their status should be enhanced in international disarmament meetings. 


\subsection{Proposal for the establishment of an international} disarmament fellowship program for civil society

One of the reasons that inspired the creation of the UN disarmament fellowship program two decades ago was the desire to promote expertise in disarmament in more UN member states. Indeed, the barrier to effective participation in disarmament negotiation and deliberation was the lack of trained manpower in many countries, especially from the developing countries. It was, therefore, necessary that specialized training was needed to involve as many countries as possible in disarmament discussions. Since its inception, the UN program has fulfilled the function of preparing tomorrow's government leaders to have a better understanding of the concerns of the international community in the fields of disarmament and security. The program has created an informal network of former UN Disarmament Fellows spanning the various regions of the world, working cooperatively and constructively in the pursuit of disarmament goals.

By its own guiding principals, the UN disarmament fellowship program is open only to government employees and nominees, and excludes civil society. It has been widely acknowledged that disarmament is a continuous process which should involve the full participation and understanding of not only governments, but also of civil society. The reasons that inspired the establishment of the UN disarmament fellowship program should also inspire the creation of something similar for civil 
society. Accordingly, as part of the new millennium initiatives, an international disarmament fellowship program that is open to members of the civil society should be established. This will be one way of strengthening the partnership between the UN, governments, and their citizens.

4.11 Security, development, small arms, and conflict resolution

Disarmament cannot be pursued in isolation from the broader concerns of international security, and these broader concerns are themselves inextricably linked to economic and social issues. The international community needs to work harder to curtail the alarming proliferation of small arms used in regional conflicts. Small arms continue to devastate civilian populations, create humanitarian crises, and impede progress. How to control or regulate the worldwide tide of small arms and light weapons should occupy a prominent place in the security and disarmament agenda of the new millennium.

Developing a single worldwide regime like the NPT for controlling small arms will be difficult, but it is, however, possible to rectify the situation and find cooperative ways of tackling the problem through international and regional initiatives, inter alia:

- The West Afrian Economic Community (ECOWAS) Moratorium on the import, export, and manufacture of light weapons; 
- The collection and destruction of light weapons (as was done in Mali and Liberia as part of post-conflict disarmament process or as part of peace settlement agreements);

- The report expected by $54^{\text {th }}$ UNGA Session in 1999 from the UN Group of governmental experts on small arms; and,

- The OAS "Inter-American Convention on Transparency in Conventional Weapons Acquisitions," which paved the way to regional arms reporting, as well as highlighting goals of increasing confidence and security, thus setting a precedent as the first comprehensive regional register of arms transfers.

In the area of disarmament and conflict resolution and using Africa as a case study, new efforts and new roles have been undertaken in resolving conflicts through regional and subregional mechanisms, such as the Organization of African Unity (OAU), Economic Community of West African States (ECOWAS), the Southern African Development Community (SADC), etc. The trend toward creating African indigenous mechanisms are confirmed by several developments, including:

- The establishing of an OAU Mechanism for Conflict Prevention, Management and Resolution within the OAU Secretariat;

- The successful operations mounted by the Economic Community of West African States' Monitoring Observer 
Group (ECOMOG) in dealing with the conflict situations in Liberia and Sierra Leone;

- Leaders from SADC attempting to find ways of preventing war in Angola; and South Africa (supported by a decision of SADC) offered assistance to Botswana when elements in Botswana's Armed forces rebelled against the legitimate government of Botswana; and,

- A group of neighboring States offering assistance to the government of the Democratic Republic of the Congo in its conflict with rebels in that country.

ECOMOG's success in Sierra Leone marked the first time in Africa's recent history that a democratically elected government, overthrown by a military group, had been restored to power as a result of collective action by a subregion of a continent. It is also an important milestone in the development of an indigenous African Peacekeeping Capability. As a result of ECOMOG's successess in Liberia and Sierra Leone, a meeting of ECOWAS Ministers of Defense and Foreign Affairs, held in Côte d'Ivoire in March 1998, directed experts from member States to work with the ECOWAS Executive Secretariat to prepare a mechanism for conflict prevention, management and resolution and for peacekeeping.

African states have also taken steps to begin an African equivalent of the "Helsinki Process." In this connection, African leaders have realized that the problems of security and stability in 
many countries in their continent have impaired their capacity to achieve the necessary level of intra-African and inter-African cooperation so as to obtain the integration of the continent, which is critical to the socio-economic transformation of the African countries. This realization was reached against the background of a historic gathering at the Kampala Forum of May 1991, which deliberated on a proposal to launch a conference on "Peace, Security, Stability, Development, and Cooperation in Africa." The Kampala Forum adopted the Kampala Document, which effectively maps out a framework for governance and development in Africa into the $21^{\text {st }}$ Century. The underlying factor behind the Kampala meeting was that Africa needs to learn from the "Helsinki Process," and to work out for itself a continent-wide agreement dealing positively with its own problems. Confidence-Building Measures (CBMs) between the African countries are called for under the Kampala Document to cover:

- exchange of information on troop locations and movements;

- $\quad$ joint military training;

- $\quad$ joint military maneuvers;

- $\quad$ joint naval patrols;

- joint studies and seminars on regional security issues;

- non-aggression pacts; and,

- lowering of military expenditures. 
The Kampala Document represents a first-step in planning and its example needs to be taken further. While there are some delays in furthering the process, the continent of Africa is clearly on the move to achieve its own "Helsinki Process," within itself and between itself and the outside world that effects and impinges on it.

By these developments, the African States have begun to craft aspects of an African agenda in which regional cooperation and institutions can contribute to meeting the security challenges that lie ahead in the $21^{\text {st }}$ Century. 


\section{Part II}

Formalizing Restraint:

The Case of South Asia 


\section{.}




\section{Chapter 5}

\section{Formalizing Restraint in South Asia}

\section{Amit Gupta}

The May 1998 nuclearization of South Asia has created several problems for India and Pakistan. There is the danger of an expensive and destabilizing nuclear arms race. There is the concern that a conventional war between the two countries might escalate into a nuclear conflict. The warfare in the Kargil and Drass areas of Indian Kashmir in the summer of 1999, being the type of flash point that observers are worried, might escalate into a more serious war. Both sides have had sanctions imposed on them, leading to an adverse effect on their economies and their plans for economic development. On the Indian side there is also concern that China, with its illegal acquisition of American nuclear weapons and related technologies, will transfer more advanced weapons technologies to Pakistan. At the international level the major powers are worried that either South Asian nation might transfer nuclear and missile technologies to other countries. What this chapter argues is that for political, economic, and militarystrategic reasons it is necessary for both South Asian states to formally restrain their nuclear rivalry. It goes on to suggest some ways that this could be achieved.

In addition, the chapter argues that formal restraint will have to be carried out at both the regional and international level. 
To achieve the latter, however, the international community will have to consider reshaping existing international regimes or facilitating the creation of new ones that would allow de facto Nuclear Weapons States like Israel, India, and Pakistan to become participating members.

\section{The limits of South Asian nuclearization}

India's decision to conduct nuclear tests in 1998 was driven by a deteriorating security environment in South Asia and by the desire to use its nuclear capability to enhance its international status. The Indian government felt the security environment in South Asia had deteriorated because of Pakistan's growing nuclear and missile capability, and by China's role in assisting it. There was also disquiet regarding China's own intentions, particularly because the Sino-Indian border issue was still unresolved, and due to the significant growth in Chinese military capability in the 1980s and 1990s. Once the tests were conducted the Indian government also reportedly believed that its new nuclear capability could be used to leverage permanent membership on the United Nations Security Council, and to be admitted as one of the declared Nuclear Weapons States in the Nuclear Nonproliferation Treaty (NPT). In response to India's tests, Pakistan detonated its own devices to display the credibility of its nuclear deterrent.

The initial expectation was that the two countries would rapidly develop and deploy nuclear weapons and associated 
delivery systems. Instead, domestic, regional, and international constraints have constrained the goals both countries sought to achieve through overt nuclearization.

Domestically, both countries have felt the economic effect of nuclearization. The Pakistani government, with an outstanding debt of $\$ 42$ billion, recognizes that its attempt to secure international assistance is linked to the position it takes on the nuclear issue. ${ }^{1}$ India, similarly, has witnessed a drop in international investment, sanctions, and the cutback of technology transfers in areas that are crucial to both its civil development and military programs. ${ }^{2}$ As the Governor of the Reserve Bank of India stated:

In addition to the unfavorable external situation after the Pokhran test last year, India was also confronted with certain other developments. Among these developments were: the economic sanctions imposed by several industrial countries, the suspension of fresh multilateral lending (except for some sectors), the downgrading by international rating agencies, and the reduction in investment by Foreign Institutional Investors (FUs). ${ }^{3}$

Nor did nuclearization translate into political benefits for the ruling Bharatiya Janata Party (BJP) in India. Instead the BJP lost a series of state elections because of the decline in the domestic economy. 
Regionally, the tensions between India and Pakistan continue to flare in the conventional theater. Following the 1998 tests, the two countries engaged in heavy shelling of each other's territories. In 1999, India and Pakistan once again clashed along the Line of Control in Kashmir as Pakistan backed guerrillas established positions in the Kargil sector. In both cases, the governments of the two countries sought to localize the conflict and attempted to enter into diplomatic negotiations. For Pakistan, the expectation was that it could use its new nuclear capability to wage a low-intensity conflict in Kashmir and to internationalize the issue. This was done in 1998 and in 1999. India would not retaliate with a full-scale war, as it did in 1965, for fear of triggering a nuclear exchange. The problem with this approach is that India has shown that it will protect its vital interests in the state of Kashmir, and given its own nuclear capability, this may lead to a miscalculation by either side. The fact is that while a nuclear war would be disastrous for India, it would definitely destroy the political entity called Pakistan.

Internationally, neither side has gained a visible or formal increase in status by going nuclear. India has hoped to use its new nuclear status to become the sixth nuclear power in the NPT as well as a permanent member of the United Nations Security Council. ${ }^{4}$ Both goals were not achieved because the major powers did not view nuclear weapons as the determining currency of power in the changed international system. Nor did they accept the idea that the NPT could be revised to change the number of 
declared Nuclear Weapons States in the treaty. India, therefore, has found that nuclearization, instead of opening doors in the international system, has actually closed them. On the other hand, the international community has shown that it will encourage efforts to stabilize the nuclear rivalry in South Asia. The United States Senate recently passed a resolution that waived sanctions against India and Pakistan for five years. The assumption was that both countries would work to bring about substantive arms control measures in the region and limit a potentially dangerous situation from escalating.

Further, the United States, as the global leader in nonproliferation efforts, made a significant change in its declared policy towards proliferation in South Asia. The United States's original objective was to cap, reduce, and eventually rollback the nuclear weapons programs of both India and Pakistan. ${ }^{5}$ Instead, the United States has accepted quietly the new nuclear reality in South Asia, and Deputy Secretary of State, Strobe Talbott, has argued that, "Having India and Pakistan stabilize their nuclear competition at the lowest possible level is both the starting point and the near-term objective of the US diplomatic effort... . The Clinton Administration does not expect either country to alter or constrain its defense programs simply because we have asked them to." At the same time, the United States would like both countries to unconditionally sign the CTBT, join FMCT negotiations, and commit themselves to not transfer nuclear and delivery system related technology. ${ }^{7}$ While the US objective may be to achieve 
wide-scale arms control measures in the region, what sort of agenda could be realistically used to formalize restraint in the South Asian region?

\section{Regional conditions for arms control}

In order to bring about formal restraint, it is necessary to specify the crucial issues that need to be addressed. First, arms control must work to stabilize the nuclear rivalry. Second, it should work to prevent the escalation of conventional conflicts. Third, there should be an attempt to remove uncertainty regarding each other's nuclear and conventional doctrines. Fourth, a coherent Command, Control, Communications, and Intelligence $\left(\mathrm{C}^{3} \mathrm{I}\right)$ system has to be created to prevent accidental and unauthorized launches. Coupled with a $C^{3} I$ system is both countries' requirement for Permissive Action Links (PALs) in order to prevent unauthorized use of their nuclear arsenals.

In the nuclear realm, the ability to stabilize the rivalry is constrained by mutual suspicions by India and Pakistan's reluctance to open their nuclear arsenals to outside monitoring, and to the reluctance of the major powers to pass on technologies to make these arsenals safer. Mutual suspicions make it difficult for either nation to engage in open discussions about their nuclear doctrines. In fact, an Indian official was quoted as saying that it was unlikely that significant progress would be made on the issue of nuclear doctrines given the hostility between the two states. 
This naturally has serious implications for the attempt to stabilize the nuclear rivalry because of the uncertainty it leaves in both countries about the size, deployment, and usage of the other side's forces. The situation is further complicated by the Vajpayee government's assertion that the Indian minimum credible deterrent would not be quantified. Instead, it would remain flexible and be decided unilaterally by the government of the day. ${ }^{8}$ An additional problem is the high cost for establishing secure $C^{3} I$ on either side. Yet, without a secure and working system it would be impossible for both sides to credibly and fruitfully exchange information.

The alternative would be to seek assistance from the declared nuclear powers to secure $C^{3} I$ technology as well as PALs. The major nuclear powers, however, have been unwilling to pass on $C^{3} I$ technologies to either side because it would only help to consolidate the nuclear arsenals of both nations. As for PALs, to acquire such technologies both the Indian and Pakistani nuclear establishments must be willing to disclose their bomb designs, something that neither side is likely to do at present.

Given these limitations, the most likely approach would seem to be one that George Fernandes, the BJP government's Defense Minister called "recessed" deterrence. What is meant by this is that both sides would develop and flight test their ballistic missiles and produce nuclear weapons, but would not mate the warheads to the delivery systems. The warheads and the delivery systems would be stored separately and only assembled in the event of a crisis. ${ }^{9}$ While the Vajpayee government subsequently 
asserted that it would proceed with deployment, a recessed deterrence doctrine helps remove some of the dilemmas that technological limitations and external pressure create for the nuclear forces of India and Pakistan.

Recessed deterrence provides a breathing space for both nations as they seek to establish a coherent doctrine and acquire the technology to safeguard it. While analysts in both countries have acknowledged the need for a $\mathrm{C}^{3} \mathrm{I}$ system, they also realize that the costs are too prohibitive to quickly install and incorporate it into their force structures. ${ }^{10}$ In the meantime, conventional conflicts, like the Kargil and Drass operations, create uncertainties regarding the use of nuclear weaponry. In such a situation, the existence of a doctrine of recessed deterrence sends a clear signal that the decision to escalate would not happen due to miscalculations by local military commanders or by human error. This is especially the case because short-range missile deployment has already taken place in South Asia, albeit without any evidence of nuclear warheads being deployed. A conditional doctrine of recessed deterrence would also allow both countries the time to carefully work out what objectives they seek to achieve through the development of a nuclear force and the numbers required to fulfill these missions. On the other hand, open deployment, without a carefully thought out and publicly articulated doctrine, would only lead to an escalating arms race as both countries sought to blindly gain numerical and qualitative superiority over the deployed forces of the other. 
Both sides could also agree to restrictions on a particular class of nuclear weapons or, at the least, prohibiting their deployment. Tactical nuclear weapons and a naval nuclear deterrent come to mind. As K. Subrahmanyam has pointed out, the use of tactical nuclear weapons along the India-Pakistan border is unlikely because of the proximity of large population centers on both sides of the border - Lahore and Amritsar. ${ }^{11}$ A treaty that eliminated this class of weapon would, therefore, serve as a major confidence-building effort and help remove weapons that have the potential to escalate a nuclear exchange.

India has focused on the creation of a nuclear navy with the development of the Sagarika submarine launched cruise missile, the Dhanush short range ballistic missile (the naval version of the Prithvi SRBM), and ongoing research for an Advanced Technology Vessel - a nuclear submarine. ${ }^{12}$ At present Pakistan has given no indication of building its own nuclear navy and given the high cost of doing so, as well as the technological limitations of its arms industry is unlikely to do so for some time. Furthermore, India's nuclear development in this area is not primarily needed against Pakistan, but instead against China because Indian landbased missiles currently do not have the range to reach China's eastern seaboard. However, the extent to which India is able to weaponize to meet the China threat will be constrained by a couple of factors. China's lead in the nuclear field would make an Indian attempt to develop a credible deterrent: a costly, long-term, and potentially futile effort. India's arms industry and defense science 
community will have to build a new set of weapons to achieve this deterrent capability. Given the country's track record in developing new conventional and strategic weapons, this may take a long time. It would be considerably easier for China to target India and that would exacerbate the Indian security dilemma.

Further, the June 1999 China visit by the BJP's foreign minister, Jaswant Singh, led to both countries agreeing to carry out a security dialogue. ${ }^{13}$ If the relationship with China was to improve, or at least not get exacerbated to the point where the two countries needed to deploy nuclear weapons against each other, Indian development of naval systems could be slowed down. However, in the case of South Asia, the two countries could agree to not deploy naval weapons against each other, or at the very least, leave the Arabian Sea as a naval nuclear-free zone.

The second crucial challenge is to prevent the escalation of conventional conflict into a nuclear one. Since the 1980s, the nature of conventional conflict between the two countries has changed with the emphasis shifting to providing support to insurgencies. India has accused Pakistan of funding, training, and providing logistical support to insurgents in Kashmir and Punjab, while Pakistan accuses India of supporting ethnic separatists in Sind. On three separate occasions (1987, 1990, and 1999), such internal insurgencies have had a spillover effect by mobilizing the armed forces of both countries and almost precipitating a war. Both countries, of course, deny involvement in each other's internal affairs. The way to resolve this issue and provide a 
firebreak for nuclear escalation is to work towards a formal treaty where both nations agree to respect the internal sovereignty of the other. As members of the United Nations, both are already committed to such foreign policy behavior, but negotiating a treaty would help formalize it.

Pakistan is likely to be reluctant to endorse such a treaty because it would take away its ability to draw attention to, and to internationalize the Kashmir dispute. This is particularly the case because Pakistan views the Kashmir dispute as a core issue that vitiates India-Pakistan relations. There are several problems with this approach. India has shown that it will not permit the internationalization of the issue, and it is unlikely that any Indian government in the near future will change its position. Moreover, the international community has displayed an unwillingness to get actively involved in this dispute in the way that the North Atlantic Treaty Organization did in Bosnia and Kosovo. The other problem is that even if Kashmir was resolved to Pakistan's satisfaction, it would not reduce Pakistan's security dilemma, a dilemma caused by the asymmetry in size between the two countries. As early as 1948, Aslam Siddiqui argued that the physical disparity between the two countries created a security dilemma that Pakistan could not hope to counterbalance. ${ }^{14}$ Detaching Kashmir from India would not redress the huge, physical disparity unless the belief in Islamabad is that an independent Kashmir would signal the break-up of the Indian union in the way that a multi-ethnic USSR and Yugoslavia collapsed. The danger with such a strategy is that 
it would antagonize the government in New Delhi and lead to both a large-scale conventional build-up, as well as a demand for an extensive and deployed nuclear arsenal.

\section{Restraint at the international level}

At the international level the success of formal restraints will rest in the ability of the international community to accept the changed reality of the global system and reshape existing regimes or create new ones to stabilize South Asia's nuclear rivalry. The history of nonproliferation efforts shows mixed records of dealing with potential proliferators. On the one hand, the Nuclear Nonproliferation Treaty (NPT) and associated treaties, like the Missile Technology Control Regime (MTCR) have slowed down the proliferation of nuclear weapons and associated delivery systems. Furthermore, preventive diplomacy by the United States led to a rollback of several programs. Thus, South Africa, with the transition to democracy, rolled back its nuclear program, as did Argentina and Brazil. ${ }^{15}$ The United States was able to persuade Ukraine, Belarus, and Kazakhstan to return their nuclear weapons to Russia. It was also able to place a break on the North Korean nuclear program with a $\$ 4.7$ billion deal. ${ }^{16}$

At the same time, international regimes and regional diplomacy were unable to prevent the growth of Israel, India, and Pakistan's weapons programs. Further regimes, such as the NPT and the MTCR, have witnessed the establishment of national and 
international bureaucracies that have a vested interest in maintaining them in their current form. A good example of this attitude was the almost immediate decision by the nuclear powers to not grant India and Pakistan the status of declared Nuclear Weapons States. Any discussion of widening the NPT to accommodate the three de facto nuclear states has also been a nonstarter with the argument being made that this would encourage future proliferation.

Furthermore, post-Cold War nonproliferation strategy has been primarily targeted at rogue states. States that former US National Security Advisor, Anthony Lake, described as ones that suppressed human rights, promoted radical ideologies, were averse to market reforms, and procured Weapons of Mass Destruction. ${ }^{17}$ India and Pakistan are democracies that have pursued status quo policies in the international system. Dealing with them, therefore, requires a different approach. In part, a different approach has been pursued. US policy has already been described, but even China, Russia, and France have taken different approaches. China, while continuing to call for India and Pakistan to sign the NPT, has entered into a security dialogue with India and maintained its strategic relationship with Pakistan. Russia did not impose economic sanctions on India and continues to be the major supplier of weapons and space technology to New Delhi. France entered into an agreement to increase technology and military sales to India. 
In these changed circumstances, what policies are likely to lead to significant arms control measures? The United States's objectives are to get both states to sign the Comprehensive Test Ban Treaty (CTBT) and a future Fissile Material Cut-off Treaty (FMCT). It is also concerned about the potential for transfers to third parties of nuclear and missile technology. Such transfers are less likely to happen because of a state policy that prescribes technology transfers, but are more likely to happen inadvertently through theft and terrorist actions. In attempting to get both countries to the bargaining table, the US has used direct talks with India and Pakistan as a tool to understand what they want to achieve. Washington has also lifted some of the sanctions imposed in May 1998. However, some of the more significant measures, like transferring PALs and $C^{3} \mathrm{I}$ technologies, remain nonstarters.

For India and Pakistan, several factors make it difficult to meet all the stated objectives of the international community. India refrained from the CTBT because it saw the treaty as discriminatory, and because it needed further tests to confirm its bomb designs and yields. The 1998 tests should have taken care of the latter concern and, thus, permitted the signing of the CTBT, but it is unlikely that any Indian government would do it without some political concessions. In the past, even politically formidable Indian governments with large majorities in parliament have found it difficult to make concessions on security issues. The border dispute with China, for example, has not been resolved in part due to the fear of successive governments that they would be accused 
of betraying the national interest. The CTBT has now fallen into the category of vital national interests; and, therefore, any government signing, China would face a barrage of criticism unless it was able to show that significant concessions had been obtained from the international community.

Pakistan's willingness to sign the CTBT was contingent on India's entry into the regime. More recently, however, Islamabad has also recognized the value of negotiating concessions for its adherence to the treaty. The $1998 \mathrm{IMF}$ loan made it apparent that the international community was unwilling to allow the economic collapse of Pakistan because of the negative political, economic, and nonproliferation consequences that would ensue. For Pakistan to now unconditionally sign the CTBT would be giving away the leverage it has gained from the May 1998 tests. With the international community as yet unwilling to make concessions on technology transfers or a series of long-term loans, neither country is likely to tamely endorse the CTBT.

The present international situation, therefore, is one where there is a reluctance to change or modify existing international regimes. At the same time, neither India nor Pakistan is going to move towards joining the NPT as a non-nuclear state or sign the CTBT and FMCT without any significant and face-saving concessions. In the light of these facts, certain steps can still be taken to bring about arms control and Confidence-Building Measures that include the two South Asian states. 
These steps have to be based on the recognition that both countries are different from the nations targeted by recent nonproliferation and counterproliferation. India and Pakistan are states that seek to maintain the status quo in the international system. India is a long-standing democracy and Pakistan is a fledging one, and this leads to a different approach to thinking on international affairs. One step that can be easily taken is to create a new set of formal arrangements that achieve the goals of the NPT without going through the tricky process of getting either side to sign the treaty. The most important objective is to prevent intentional or unintentional transfers of nuclear and delivery technologies to other states. The international community can call for a treaty where both countries commit themselves to the nontransfer of sensitive technologies. Such a treaty would not compromise the security agendas of either state, nor would it require a shift in foreign policy behavior.

Both countries have refrained from transferring weapons and technology to other nations because it would be considered internationally provocative. India's conventional arms transfers policy has typically been very restrictive, and New Delhi has, on several occasions, given up opportunities to sell weapons to regions where there are ongoing conflicts. In the 1980s, it refused to sell MiGs to Zimbabwe because New Delhi viewed the latter country as a frontline state in the South African crisis. Later, India refused to sell weapons to Libya and enter into missile technology collaboration with Iraq because of the potential for incurring the 
wrath of the international community. ${ }^{18}$ Similarly, after the Pakistani nuclear tests, the father of the Pakistani bomb, A.Q. Khan, made it clear that while Pakistan was a Muslim country, it should not be construed that the country had developed an Islamic bomb. Pakistani officials have denied that they have entered into collaboration with other Islamic states and have ruled out any form of collaboration with Iran, one of the nations the Clinton Administration has branded a rogue state. ${ }^{19}$ A nontransfer treaty, therefore, would remove one of the immediate dangers of South Asian proliferation and prove the bona fides of the two states to the international community.

Another possibility may be to create an auxiliary treaty that removes one of the legal fictions of the international system, that there are only five nuclear powers. Since the NPT was negotiated, three nations (Israel, India, and Pakistan) have crossed the nuclear threshold, but the existing regime maintained a legal fiction that these are not nuclear states. After the May 1998 tests, the major powers refused to call the two South Asian nations declared weapons states because it would, for other reasons, jeopardize the NPT; but a new treaty that includes the two South Asian states and Israel should be considered. Mainly due to the policies of the United States, the Israeli nuclear weapons program has not received the international attention it deserves; but without including Israel, any new treaty would have limited value. So as part of a new approach, it might make sense to propose an 
auxiliary treaty that brings the three de facto weapons states into the nuclear club.

In this context there are two issues that need to be addressed. First, how does one bring new nuclear states into an international regime given that stated nonproliferation policy for the last three decades has been one of preventing the emergence of another nuclear state? The fear is that once a new state is allowed to enter the club, a number of other nations will test devices with the expectation of being granted membership. One way around this dilemma may be to suggest that new membership be based on adherence to a particular code of international behavior. The Clinton Administration laid out the criteria by which certain nations were labeled rogue states. One could formulate a different set of criteria to allow the three de facto states into a new international regime. Specifically, membership into a new regime could be based on fulfilling certain criteria that are exhibited by responsible states in the international system. These would include having democratic forms of government, a commitment to support and participate in international organizations, a willingness to participate in multinational peacekeeping efforts, and to specifically adhere to the goals and objectives of nonproliferation. A country would have to display a long-term pattern of such behavior in order to be admitted. Such a distinction, therefore, would keep nations that were not committed to maintaining order in the international system, and were anti-democratic in their internal structure out of the new regime. Being rejected from 
membership would mean that not only would a state be denied the benefits of inclusion, but it would also face any sanctions that the international community could impose.

Such a policy would have the advantage of bringing de facto nuclear states into the club and working to uphold the rules of membership, preventing proliferation, and maintaining order. Not allowing such states in, however, might force them to form their own club with looser rules of membership and thus lead to the proliferation of weapons and consequent escalation of regional rivalries.

Which brings up the second issue of what privileges and obligations would the de facto states have in a new treaty? One advantage for the de facto states is that it would legitimize their nuclear weapons programs and remove the fear of future sanctions. This would be a major concession to both India and Pakistan and allow them to continue indigenous economic and technological development. Further, given the mixed international response to the May 1998 tests, it would be a fairly accurate reflection of the international community's differing views on the usefulness of sanctions in this particular case. Legitimization would also permit these states to contribute to disarmament and arms control efforts in a way that being kept out of the club would not. It would indeed provide the incentive for these nations to help build stronger regimes and more effective enforcement measures.

A new treaty would not, however, automatically include permanent membership of the United Nations Security Council. 
Any expansion of the council would have to be made in a broader context and reflect the changed power differentials in the international system. If initial membership of the UN Security Council was based on a pre-Cold War conception of what constituted power in the international system and which countries qualified, a post-Cold War permanent membership cannot be based on a Cold War conception that nuclear weapons are the primary basis of international power. Obviously economic and other criteria that make countries like Germany and Japan global powers in the post-Cold War international system would have to be used.

The de facto states would have to fulfill a set of obligations as part of this arrangement. They would have to commit themselves to not transferring technologies to other countries. They would also have to seek assistance to make their own nuclear forces safer from both accidental use and from threats and acts of terrorism. Furthermore, the de facto states would have to commit themselves to participation in the construction of new arms control regimes and disarmament initiatives.

There may also be an indirect advantage to legitimizing the status of de facto Nuclear Weapons States. First as undeclared Nuclear Weapons States, and now as de facto but not declared Nuclear Weapons States, these nations have had little reason to initiate debates about the nature and size of their nuclear force structures. In Israel there has been little public debate about the issue even though several thoughtful books have dealt with the origins, rationale, and consequences of an Israeli nuclear force. ${ }^{20}$ 
In Pakistan, the debate has been minimal. In India, although several books have been written on the subject, the government only recently issued a statement on what shape a future nuclear force would take, and even that was kept deliberately vague. ${ }^{21}$ In part, the lack of a debate was associated with the need to keep the programs secret and the fear of ensuing sanctions if the full extent of these programs became public knowledge.

With a public nuclear force, there has been some discussion of what type of nuclear doctrine should be followed in India and Pakistan. Both countries have committed themselves to a policy of deterrence, although, with significant differences. The Indian government has signaled that its conception of deterrence includes the no-first-use of nuclear weapons, in part due to its advantage in conventional forces. Pakistan's government, while stating that deterrence is its declared policy, has not ruled out the use of a first strike to defend the country from India's conventional superiority. ${ }^{22}$ But in both countries, there has been a reluctance to quantify their proposed nuclear forces. In part, this reluctance comes from ad hoc decision making and the consequent lack of a coherent plan of force development to follow nuclearization. But it is also a response to the actions of the international community, because spelling out a force structure without being a legitimate nuclear power might lead to pressure for significant cutbacks and termination of programs. On the other hand, legitimization would possibly permit the public debate and quantification of force 
structures because both countries were secure in the knowledge that their nuclear forces had been internationally accepted.

Over the past decade the focus of confidence-building, arms control, and disarmament measures has been on achieving solutions at the regional level, and these measures have partially succeeded in Latin America, Southern Africa, and the former Soviet Union. The South Asian case, however, is different from those in other regions because of a serious regional rivalry. It makes both nations unwilling to forgo the nuclear option because of the adverse effect it would have on their perceived security interests. It is also clear that India views its nuclear force as not simply existing to counter regional threats. It also views it as a tool to assert its own status in the international system. Furthermore, the other cases were those where the nuclear programs had not reached fruition; or the bomb was in the basement; or as in the case of the former Soviet Union, it was a security dilemma inherited by a successor state. Overt nuclearization had not taken place, and economic and political incentives could be offered to terminate the programs or to hand back weapons. Dealing with the South Asian case, therefore, requires not only regional options, but also some fundamental rethinking of nonproliferation measures at the international level. It also requires a vision for world order in the next millennium, and the role different states at varying levels of economic and military power can play to maintain a new international system. 
Nonproliferation policy, like broader foreign policy, needs to be reoriented to achieve success in the reality of a changed international system.

\section{Notes}

1. This figure is an estimate of Pakistan's total external debt see, "UK Firm Fears Debt Default by Pakistan," Dawn, August 10, 1998. If the internal debt is included the country may owe between $\$ 60$ to $\$ 80$ billion. See Manzur Ejaz, "Redefining State Priorities," The News International Pakistan, August 3, 1998.

2. For the impact of sanctions on technology transfers to India see R. Ramachandran, "Sanctions: The Bark and the Bite," Frontline, Vol. 16, No. 10, May 8-21, 1999.

3. "Statement by Dr. Bimal Jalan, Governor, Reserve Bank of India on Monetary and Credit Policy for the Year 19992000." Reserve Bank of India Web Site, http://www.rbi.org.in/index.dll/7029?OpenStory?fromdate $=04 / 29 / 98 \&$ todate $=04 / 20 / 99 \&$ s 1 secid $=1001 \&$ s 2 secid $=100$ $\underline{1 \& \text { secid }=17 / 0 / 0 \& \text { archivemode }=0}$.

4. N. Ram, "The Perils of Nuclear Adventurism," Frontline, June 5, 1998 and Achin Vanaik, "The BJP's calculations," The Hindu, July 30, 1998, p. 12. 
5. US Department of State, Report to Congress on the Progress Toward Regional Nonproliferation in South Asia, (Washington, D.C.: Department of State, 1993).

6. Strobe Talbott, "Dealing with the Bomb in South Asia," Foreign Affairs, Vol. 78, No. 2, March/April 1999, pp. 116117.

7. Ibid., pp. 120-122.

8. T. Jayaraman, "Nuclear Issues: A Destabilizing Misadventure," Frontline, Vol. 16, No. 4, February 13-26, 1999.

9. "Fernandes: US Nuclear Policy is Hypocritical," The Hindustan Times, June 19, 1998.

10. For a discussion of this problem see Jayati Ghosh, "The Bomb and the Economy," Frontline, Vol. 16, No. 10, May 8-21, 1999.

11. K. Subrahmanyam, "Past Imperfect: Time for New Nuclearspeak," The Times of India, August 3, 1998.

12. Rahul Roy-Chaudhury, "Equipping the Navy for War on Land," The Times of India, July 13, 1998 and "India Buckles, Test-Firing of Agni Put off Indefinitely, The Hindustan Times, January 21, 1999.

13. Jyoti Malhotra, "China's No Threat; Talks Clear Bad Air," The Indian Express, June 16, 1999.

14. Aslam Siddiqui, Pakistan Seeks Security, (Lahore: Progressive Press, 1960), p. 61. 
15. For a discussion of the reasons behind the South African decision see Andre Buys, and for the Brazil-Argentina cases see Amit Gupta, Building an Arsenal: The Evolution of Regional Power Force Structures, (Westport, CT. and London: Praeger Publishers, 1997), pp. 148-162.

16. Leon V. Sigal, Disarming Strangers: Nuclear Diplomacy with North Korea, (Princeton; Princeton University Press, 1998), p. 191.

17. Anthony Lake, "Confronting Backlash States," Foreign Affairs, Vol. 73, No. 2, March-April 1994, p. 45.

18. Amit Gupta, Building an Arsenal: The Evolution of Regional Power Force Structures, (Westport, CT and London: Praeger Publishers, 1997), p. 68.

19. Amit Gupta, "After the Bomb: US Policy toward a Nuclear South Asia," Mediterranean Quarterly, Vol. 10, No. 2, Spring 1999, pp. 59-60.

20. See for instance, Avner Cohen, Israel and the Bomb, (New York: Columbia University Press, 1998), Fuad Jabber, Israel and Nuclear Weapons: Present Options and Future Strategies, (London: Chatto and Windus, 1971), and Seymour Hersh, The Samson Option: Israel's Nuclear Option and American Foreign Policy, (New York: Random House, 1991).

21. Vijay Nair, Nuclear India, (New Delhi: Lancer International, 1992) and Amitabh Mattoo (Ed.), India's 
Nuclear Deterrent: Pokhran II and Beyond, (New Delhi: HarAnand, 1998) are two good examples.

22. Hasan Akhtar, "First Strike: No Change in Pakistan's Nuclear Strategy," Dawn, June 20, 1999. 


\section{Chapter 6}

\section{A Restraint Regime for South Asia}

\section{Ahmad Kamal}

The Indian nuclear tests of May 1998 have radically altered the South Asian strategic landscape. These Indian tests, and the subsequent tests by Pakistan, have had a definite impact on the global nonproliferation regime, the full force of which has yet to be gauged. While the tests merely confirmed an existing reality, in strategic and operational terms, a new and dangerous threshold was crossed. In the process, new challenges were opened for threat reduction, arms control, crisis management, etc. The tests also brought home the need for evolving some sort of a nuclear restraint regime for South Asia. This paper attempts to put the South Asian situation in a proper historical context in order to identify the contours of a credible restraint regime for South Asia.

Any policy analysis of the nuclear situation in South Asia without reference to the historical evolution of events will be lopsided. An examination of events that propelled the nuclearization of South Asia will help us to avoid the mistakes of the past and arrive at some realistic options for the future.

This looking backward into the past will also help us focus on one of the important questions: How did the US intelligence estimates and political judgement fail so miserably in forecasting and predicting 
the Indian nuclear tests? In fact, what surprised Pakistan most was President Clinton's sense of shock at the Indian tests. Had the US heeded Pakistan's warnings or correctly estimated the Indian intention in time, it could have played a meaningful role in stopping the new Bharatiya Janata Party (BJP) Government from nuclear tests and, thus, saving the region from the subsequent conflagration.

Back in the 1960 s, if the major powers had paid more attention to check the supply of unsafeguarded nuclear material and technology to India by various countries, particularly Canada, things would have been different today. This technology was subsequently used for the 1974 Indian nuclear test. Pakistan's protests about the Indian nuclear test in 1974 were ignored and dismissed by the major powers. Most countries lulled themselves into believing that it was merely a peaceful nuclear explosion devoid of any strategic significance.

Indian nuclear ambitions became clear by its refusal to sign the Nonproliferation Treaty (NPT) in 1968. Pakistan fully supported the NPT negotiations, hoping that this treaty might check the growth of the Indian nuclear weapons program. Subsequently, during 1970s and 1980s, Pakistan attempted to halt nuclear proliferation in South Asia through diplomatic means by offering India a whole range of innovative proposals, like the establishment of a Nuclear-WeaponFree Zone in South Asia; the simultaneous accession by India and Pakistan to the NPT; the mutual acceptance of full scope IAEA safeguards; a Regional Test Ban Treaty for South Asia, etc. To deal 
with the problem of missile proliferation in South Asia, Pakistan proposed the establishment of a Zero Missile Regime in South Asia.

The Indian obdurate refusal even to consider any of these proposals should have served as a warning regarding India's real intentions. Regrettably, these telltale signs were ignored. Following the Indian nuclear tested in 1974, the Western nonproliferation efforts exclusively focused on Pakistan by aborting the existing agreements on the transfer of nuclear technology under IAEA safeguards, and the initiation of Pakistan specific nonproliferation legislation.

Similarly, Pakistan's warnings that the true reasons for Indian opposition to Comprehensive Test Ban Treaty (CTBT) were based on operational assessments and not on any moralistic grounds were ignored. Some important countries assured India that their nonacceptance of the CTBT would not affect their bilateral relations.

In the field of ballistic missile development, Islamabad had a sense of dé jà $v u$ when the US, having ignored the Indian missile program for more than two decades, made Pakistan a target of Missile Technology Control Regime (MTCR) sanctions. It is ironic to note that while the Pakistani leadership attempted to warn the US-led international community about the possibility of Bharatiya Janata Party Government's nuclear tests, the US imposed MTCR Category I sanctions against a Pakistan Government entity just weeks before the Indian nuclear tests of May 1998.

In fact, during his visit to India in April last year, which was the first high-level US contact with the newly elected BJP 
Government, the US Assistant Secretary of State for South Asian Affairs, when asked about BJP's announcement to conduct nuclear tests, stated, "What is most important is actions taken by governments... . We see our relations with India going beyond security issues... . We believe we cannot let anyone issue dominate our agenda with India." In the face of clearly evident indications regarding the direction of Indian nuclear policy one only wonders what would have been the source of such failure of political judgement. Either the reality of Indian nuclear ambitions did not blend with the "liberal image of a poverty-stricken India, the home of Mahatma Gandhi, and a country once in the forefront of global disarmament effort;" or as some commentators in Pakistan believe, had it not been for Pakistan's nuclear program, India would probably have been accommodated as a Nuclear Weapon State a long time ago.

Pakistan was the primary victim of the situation arising out of India's nuclear tests. During the 17 days following the Indian nuclear tests, Pakistan agonized over the possibility of exploring alternative options that could have obviated the need for conducting nuclear tests. Unfortunately, each passing day made it increasingly clear to the Pakistani decision-makers that Pakistan had no option but to carry out its own nuclear tests. The international reaction to the Indian tests did not go beyond some flaccid statements of condemnation and US sanctions mandated by its national law. In the backdrop of a world apparently adjusting to the reality of a nuclear India, all Pakistan was offered were some conventional weapons, which had in any case been 
unjustly embargoed by the US, and indirect threats of an economic disaster if it decided to test. An indication of the general Western apathy bordering on callousness was when, during the Birmingham G-7 Summit on 15 May 1998, the leader of a major Western country on hearing a mere rumor about Pakistan's nuclear tests remarked that, "we cannot let Pakistan go unpunished," without even checking the facts.

Added to these were provocative and threatening statements from the highest echelons of the Indian leadership, disturbing movements of Indian conventional forces, and public threats that "Pakistan should realize the change in the geostrategic situation in the region following India's bold step to become a Nuclear Weapon State." It was becoming increasingly clear to Pakistan that there was a real and present danger that the BJP-led Indian Government would engage in some form of aggression against Pakistan. These factors were more than enough to convince Islamabad that the existential deterrence operative in South Asia for the past two decades had collapsed. There was no Security Council resolution against India, no P-5 declaration, and no G-8 sanctions. These actions came about only after Pakistan's nuclear tests. Pakistan was left with no choice but to go ahead with its own nuclear tests. Perhaps the NATO member countries can better understand and appreciate the logic motivating Pakistan's nuclear tests as NATO's current strategic concept states, "the fundamental purpose of (the) nuclear forces (of the allies) is political: to preserve peace and prevent coercion and any 
kind of war."

The following important points can be concluded from this brief overview:

- The Indian nuclear program is driven by considerations of prestige and power whereas Pakistan's efforts in the nuclear field have been motivated by its quest for security;

- It is India which incrementally has crossed new thresholds with Pakistan reacting to every escalation; and,

- While the important states have tried to adjust to the Indian progress in the nuclear and ballistic missile field, it is mainly Pakistan that has been the target of discriminatory nonproliferation policies.

Future diplomatic historians will debate whether the failure of US nonproliferation policy in preventing Indian nuclear tests was a result of lack of political judgement or some more fundamental flaw in the policy itself. The point to be made here is that in the future any successful policy must be balanced and evenhanded. It must be realistic and must take into account the fact that South Asia is nuclearized, and that the traditional nonproliferation framework is no longer relevant to the South Asian situation. No matter what the position is in a legal sense, any future policy has to confront the fact that India and Pakistan are, in an operational sense, Nuclear Weapon States.

In other words, you have in South Asia two nuclear armed 
states which share a common border, have fought three wars, are parties to a live and potentially volatile dispute, yet do not fully possess the technical wherewithal to manage a complex deterrence equation.

The threat here may not emanate from a deliberate strategic design but from possible miscalculations. In this regard, it is important to assure that strategic choices for Pakistan and India do not narrow down to "launch-on-warning" or "use them or lose them" policy. The challenge in short is to evolve a stable deterrence relationship between the two countries at the lowest feasible level of nuclear weapons and ballistic missiles, induce crisis stability, reduce tensions, and ensure conflict avoidance. In other words, work out a restraint regime for South Asia.

Keeping in view, the peculiarities of the South Asian nuclear puzzle, a nuclear restraint regime for the region will need to be based on thorough discussion of the following issues.

\section{Conventional imbalance}

Any student of strategic studies or international relations would know that one of the factors motivating Pakistan's search for a nuclear deterrent has been its inferiority vis-à-vis India in conventional forces. Although India officially portrays China as the primary threat to its security, the fact that more than $75 \%$ of its conventional assets, and especially its strike formations, are deployed on Pakistan's border belies this claim. This imbalance has been 
further exacerbated over the last decade due to various official and non-official embargoes on conventional weapons sales to Pakistan. In view of its enormous indigenous defense production and the rate at which it is procuring weapons from a variety of sources, especially Russia and France, India is likely to gain a decisive edge in the conventional field in the near future.

As this asymmetry becomes definitive, the role of nuclear weapons in Pakistan's security policy is likely to increase proportionately. Given Pakistan's lack of "strategic depth," any threat of India launching a decisive and lightning conventional strike due to its overwhelming preponderance in conventional weapons will force Pakistan to adopt a more proactive nuclear posture. This vulnerability is further exacerbated by the fact that all of Pakistan's vital communication links and most of the industrial sites are perilously close to the Indian border. The strategic logic inherent in such a scenario is somewhat reminiscent of NATO's dilemma vi-à-vis the Warsaw Pact during the Cold War.

The imbalance is most striking in the field of air power. As opposed to around 300 Indian frontline aircraft, Pakistan can field only 40 . This yawning gap in capabilities in this pivotal area would mean that Pakistan's reliance on its missile capabilities as a substitute to the air force's conventional role in disrupting the enemy's line of communication, attacking armored formations, force concentrations, etc., is likely to increase. Secondly, such Indian air superiority will keep Pakistan under the constant fear of India launching a preemptive 
surgical air strike against its strategic assets. Moreover, the perception of such decisive advantage may tempt the more bellicose elements in the Indian leadership toward miscalculation and misadventure.

As such, this serious conventional imbalance is bound to impact on the Indo-Pakistan nuclear equation in more than one way. This situation carries within it the seeds of instability, and the possibility of a conflict that could spiral out of control. Therefore, any restraint regime must put into place mechanisms to address this aspect of the conventional imbalance inherent in the South Asia strategic picture.

To begin with, Western and especially the US arms sales policy toward Pakistan, needs to be rationalized. Of course, the motive here is not to trigger an Indo-Pakistan conventional arms race, but to provide Pakistan with at least some breathing space and confidence in its conventional capabilities. Such confidence will help Pakistan to robustly engage in evolving a restraint regime.

Secondly, steps could be worked out to arrange the peacetime deployment of strike forces in a manner which is less threatening. It is also important to evolve mechanisms to ensure that any large assembly of conventional forces for military exercises does not create a crisis situation akin to the one created by the Indian military exercise in 1987.

Finally, such steps should form part of a broader effort toward a Mutual Conventional Force Reduction Agreement between the two 
states on the pattern of Conventional Forces in Europe Treaty (CFE).

\section{Comprehensive Test Ban Treaty and Fissile Material Cut-off Treaty}

Progress on the above issues lies at the heart of efforts to make the security interests of India and Pakistan compatible with the global nonproliferation concerns.

While reaffirming its support and commitment to the CTBT, Pakistan has made it clear that its adherence to the Treaty would take place only in conditions free from coercion or pressure. Similarly, there are some positive indications about India's stance on the CTBT. Both States joining the CTBT will, in effect, formalize the moratorium on nuclear testing which they announced separately and reaffirmed during the Summit between two Prime Ministers in February this year. This would constitute an essential barrier against a qualitative nuclear escalation in South Asia.

On fissile material production, Pakistan has joined the negotiations for a multilaterally negotiated, nondiscriminatory and verifiable Fissile Material Cut-off Treaty (FMCT) at the Conference on Disarmament in Geneva. As in the case of Pakistan's participation in negotiations for other multilateral treaties, like the Chemical Weapons Convention (CWC) and the CTBT, Islamabad has joined the negotiations for a FMCT with an open mind and plans to contribute positively to the negotiations for this important Treaty. However, Pakistan cannot accept the demands from certain quarters 
to cease the production of fissile material pending the conclusion of such a treaty. Islamabad certainly cannot assume any international legal obligations before such a legal instrument enters into force.

It needs to be mentioned here that Pakistan may be forced to reassess its requirements of fissile material if India proceeds with its planned acquisition of S-300 Theatre Missile Defense Systems from Russia and its collaboration with Israel for the development of an Anti-Ballistic Missile (ABM) capability.

\section{Export controls}

On export controls, Pakistan has an impeccable record, and has always acted with a great sense of responsibility in this regard. Pakistan is in the process of formalizing its existing policy of not exporting sensitive technology and knowledge, to appropriate legislative and administrative steps. The US can assist both Pakistan and India in formalizing strict export control policies.

\section{Missile development}

There is no international legal instrument to control or ban the development or deployment of ballistic missiles. The MTCR based technology denial approach did not work in South Asia. Pakistan and India have successfully tested various missile systems. While the two countries are in possession of land-based ballistic missiles, steps should be taken to discourage and eventually ban the development 
and production of Air Launched Ballistic Missiles (ALBMs) and Submarine Launched Ballistic Missiles (SLBMs). This is an attainable goal as at present because both Pakistan and India are lagging far behind in this field. The recent announcement by the two countries to give prior notification of missile tests will go a long way in addressing this essential aspect. Similarly, in view of the destabilizing impact of Theatre Missile Defense Systems, India should be persuaded not to procure these systems.

\section{Transparency in doctrines}

The policy governing the deployment of nuclear weapons, their use, production, the choice of delivery systems, and targeting plans, are largely determined by the nuclear doctrine a state adopts. If two nuclear rivals have a somewhat clear understanding of the opponents threat perception and strategic concepts, this can act as a filter for many incipient fears and misperceptions.

It is a fact that while India and Pakistan have developed nuclear weapons, they are still in the process of evolving their respective nuclear doctrines. The degrees to which the aspects of a nuclear doctrine could be discussed in public vary from one military culture to the other. However, an institutionalized discussion between the two countries at various levels on such issues will prevent them from being lured by the logic and jargon of more extreme schools of thought harking back to the Cold War era. This 
will induce greater trust and bring more rationality to force planning. A regular institutionalized exchange on these matters, as agreed to in a Memorandum of Understanding (signed by the Foreign Secretaries of two countries in Lahore in February 1999), will assist Pakistan and India in evolving a common strategic vocabulary that will play an important role in more meaningful arms control measures in the future. For example, such a discussion could pave the way for developing a more tangible definition of the concept of "minimum nuclear deterrence." This like any other strategic concept is essentially vague and subjective. Lawrence Freedman in his book "Evolution of Nuclear Strategy" defines minimum deterrence as "the possession of sufficient nuclear weapons to inflict grievous harm on the enemy in retaliation and no more." In formulating a state's doctrine issues like defining "sufficient" and "grievous harm" is open to question.

This ambiguity and confusion is reflected in the way the Indian Foreign Minister has defined this concept. "Minimum credible deterrence is not a physical quantification which is finite or fixed and limited in time... . That policy has certainly a physical shape when translated physically; but that physical shape is determined by the security requirements of the time and that certainly is something which cannot be spoken out." This definition is practically openended and does not even remotely define anything concretely. Therefore, it is necessary to have a sustained and institutionalized exchange of views on doctrines and concepts. Such an exchange of 
views will help in removing these ambiguities and confusions.

\section{Crisis stability}

Measures to create crisis stability lie at the core of efforts to evolve a stable and predictable nuclear equation between Pakistan and India. An illustrative list of such measures would include: open lines of communications at various levels of governments; concrete steps to arrange for the security and safe custody of strategic weapons; eliminating any possibility of accidental or unauthorized use (or reliable command and control systems); and, early notification of military exercises and large troop movements, etc.

The United States can make an important contribution by allowing India and Pakistan to learn from its vast expertise in the areas of Confidence-Building Measures (CBMs) and cooperative threat reduction. The US role would especially be instrumental in assisting Pakistan and India to put effective command control systems in place, including the transfer of technology in the field of Permissive Action Links. Secure command control systems will go a long way in fostering trust between two sides.

\section{Bilateral dialogue}

Regular bilateral dialogue is indispensable in the smooth working of any restraint regime. The Pakistan-India Foreign Secretary talks have become regularized. It is hoped that the Foreign Ministers of both countries will meet on a more regular basis. The 
recent Summit meeting between the Prime Ministers of India and Pakistan was an important landmark in terms of addressing some of the issues raised above.

It is necessary to underline here that any nuclear restraint regime in South Asia will have to walk a delicate tight rope. The stability of such a regime will remain contingent on the political will of the parties and their commitment to addressing the core issues that bedevil peace in South Asia. Nuclear risk reduction and strategic restraint cannot sustain themselves in a vacuum. Measures in this direction will not go very far without a movement toward a broader settlement of the Kashmir dispute. It is, therefore, vital that a comprehensive and result-oriented dialogue on Kashmir be initiated and sustained. The international community can assist in creating a climate for such a dialogue to flourish with the aim of easing both the threat of conflict as well as the suffering of Kashmiri people.

A final word of caution: The international community should avoid any idea of rewarding India in some other critical field on the basis of supposedly good nuclear behavior. Such a linkage would be repeating the mistakes of the past, which is what led to the nuclearization of South Asia in the first place. Appeasement just does not work, never has, and never will.

The success of a nuclear restraint regime in South Asia clearly depends on the commitment of the two nuclear-armed states, as well as the sustained engagement of the international community. This 
does not just mean commitment to stabilizing nuclear deterrence in South Asia, but also to respecting each other's sovereignty and curbing hegemonic ambitions in the region. The international community has an indispensable role to play in this regard, and as such it must also be wary of regressing into the past patterns of neglect, combined with a misplaced zeal to push a nonproliferation policy which has failed and become redundant for South Asia.. 


\section{Chapter 7}

\section{Formalizing Restraint: The Case of South Asia}

Dilip Lahiri

The meaning of restraint is "to hold back." In the context of national security, particularly its nuclear dimension, restraint on the part of a government implies the holding back from measures that go beyond what could reasonably be regarded as essential requirements, while at the same time, exercising due care to avoid affecting adversely the interests of countries not involved in its security calculus. Formalizing such restraint could extend from unilateral articulation to bilateral, regional, or multilateral dialogues and agreements.

In national security matters, a responsible democratic government can scarcely be expected to hold back from the minimum steps necessary to guard against the kind of threat and challenges emanating from its security environment that have been part of its historical experience. The degree of restraint that can prudently be exercised will, therefore, naturally be affected, at the very least, by the behavior of all the major actors whose actions impinge on its security. Taking into account the reach of nuclear weapons and ballistic missiles, India's perimeter of security concerns clearly extend well beyond the confines of the conventional geographical definition of South Asia. This sub- 
region by itself cannot accordingly be an appropriate construct in attempting to formalize a restraint regime involving India.

The global context of nuclear restraint inevitably affects what is possible in a certain region or among a group of countries. This would be of particular relevance in the formalizing of restraint in South Asia, where a number of extra regional players apparently expect to be involved. The record of these countries in exercising restraint in security and nuclear matters, and of their past role in contributing to stability in South Asia, obviously, are relevant in determining whether or not their involvement in the formalizing of restraint is useful. Apart from this, it would clearly be unreasonable to hold India to a higher standard of restraint in national security matters than the rest of the world.

These caveats, which seek to broaden the scope of the title of this paper, enables us to have a meaningful treatment of this subject. It is only reasonable to recognize and to accept the wellintentioned, even if somewhat misplaced, expressions of concern about nuclear stability in South Asia since the May 1998 tests. The consequences are of an unrestrained nuclear arms race between India and Pakistan, possibly involving China, and the dangers of further proliferation. India, on its part, has shown a readiness to engage in dialogue with important and interested interlocutors with a view to reconciling the national security considerations that constrained India to weaponize, with the legitimate concerns of other countries, pertaining, inter alia, to proliferation, which India shares. 
Neither India nor Pakistan possess the economic resources or the fissile material stockpiles and manufacturing capabilities to engage in an unrestrained nuclear arms race. Restraint is, therefore, in a sense, built into the circumstances in South Asia. Beyond this, India has also shown great voluntary restraint in its defense expenditure, as evidenced by its declining defense budget, amounting to only $2.44 \%$ of its Gross Domestic Product (GDP) this year, by far the lowest among relevant countries in Asia. India has, of course, had her share of armed conflict, but the more bloody manifestations of 20th century warfare in terms of the fire bombing of cities and civilian targets, unrestricted aerial bombardment of economic infrastructure, etc. has never been part of her war-fighting culture. This is not to dismiss the existence of any nuclear danger in South Asia resulting from nuclear weapons, but only to suggest that this is probably much less than generally assumed, and ironically, more acutely felt and expressed by sources outside the region than in India and Pakistan.

Why should this be the case? A part of the explanation probably has to do with the evolution of Western, primarily US, thinking on nuclear doctrines. Since at least the mid-50s, the US had prepared for a "bolt from the blue" scenario, a nuclear attack without prior warning. Nuclear doctrines postulated that deterrence was safest from breakdown if credible preparations for all contingencies in fighting a nuclear war were convincingly demonstrated to the adversary. A mirror image of this doctrine in the Soviet Union created vast super power arsenals, approaching 
100,000 warheads at its peak, a substantial part of it permanently on hair-trigger alert to avoid being destroyed by a bolt from the blue. Much of the nuclear danger of the last half century, a danger which persists even today because of the continuance of launch-on-warning posture, 10 years after the end of the Cold War, is the legacy of this nuclear theology. It does not necessarily follow that South Asia's nuclear future is condemned to follow this same trajectory.

An element of nuclear danger is, of course, unavoidable as long as nuclear weapons exist, and this element of danger is present in South Asia, just as it is in every part of the world that hosts nuclear arms. The only true solution to this danger is the complete abolition of nuclear arms, which India has long campaigned for, and to which India has recommitted itself in the aftermath of the tests of May 1998. But this is an objective that is unlikely to be realized as long as the Nuclear Nonproliferation Treaty (NPT) Nuclear Weapon States continue to reaffirm the indispensable role of nuclear weapons for their national security, and refuse to engage in any serious multilateral negotiations for the elimination of nuclear weapons.

If global nuclear disarmament remains a distant dream, nuclear weapons in South Asia are there to stay. What then can be done to reduce the nuclear danger in South Asia? The first principle in any effort to achieve a stable and restrained nuclear order is the willingness of the parties to commit themselves to a common goal of stability. This might appear obvious, but such a 
commitment has not always been forthcoming from NPT Nuclear Weapon States. To mention only one example, proponents of nuclear superiority in the US at one time argued against nuclear arms control agreements with the Soviet Union because of the perception that it gave the Soviets nuclear "parity". In this regard, the South Asian scene presents a far brighter picture. Both Indian and Pakistani leaders have repeatedly emphasized their intent to search out mutually acceptable solutions so as to build a stable nuclear order in South Asia. The Lahore bus trip, and the Lahore Declaration that followed, are excellent indicators of the mood in both capitals, and of the willingness and commitment of both governments to manage their nuclear responsibility.

Nuclear doctrines both determine the conditions under which nuclear weapons could be used, as well as outline the procedures for the handling and use of these weapons. Nuclear doctrines, therefore, significantly influence the risks associated with maintaining a nuclear arsenal. Some nuclear doctrines are inherently more dangerous than others, because they increase the chance of accidents and inadvertent use of nuclear weapons. India has adopted a no-first-use doctrine and has firmly rejected concepts and postures based on Cold War models or arms races of any sort. If India will not use nuclear weapons first, the logical conclusion is that India must have an invulnerable, passive, retaliatory nuclear capability. The political commitment to no-first-use, combined with assured retaliation, has a technical corollary - the rejection of the launch-on-warning postures. This 
should be kept in mind when we contemplate scare scenarios of short ballistic missile flight times, since Indian nuclear forces do not have to be on hair-trigger alert. This substantially reduces the burden on any Indian nuclear command and control system and lessens the risks of an inadvertent nuclear war.

Confidence-Building Measures (CBM) must, therefore, be an integral part of a nuclear restraint regime in South Asia. However, such a regime should go beyond just CBMs, and eventually address itself to the kind of nuclear forces that are developed and the nuclear doctrines that determine their employment. Neither India nor Pakistan has well-developed nuclear forces. Both are in the preliminary stages of determining their strategic requirements. This creates difficulties for a restraint regime based on nuclear force planning because of the necessary secrecy surrounding these developments. A restraint regime that leaves one or both sides vulnerable will do more harm than good. Pakistan's concerns in this matter are focused almost entirely on India. But India's worries are not centered on Pakistan alone, but also on China, and equally important, on the alliance between the two. Any force restraint proposal that does not also consider these complexities is bound to leave India vulnerable, and is thus doomed to fail. This is not an unreasonable position, in a situation where the United Kingdom (UK) claims that the Indian and Pakistani nuclear tests will be a factor in its future decisions regarding nuclear weaponry, or that maintaining a degree of 
uncertainty about precise UK nuclear capabilities is a necessary element of a credible deterrence. ${ }^{1}$

India has taken the lead in initiating discussions at the bilateral level on formalizing restraint in its neighborhood, both in the India-Pakistan and the Sino-Indian contexts. Measures to build confidence with China were initiated during the visit of Prime Minister Rajiv Gandhi to China in 1988. The dialogue with Pakistan during the 1990s also testifies India's commitment to confidence-building.

Before we proceed to examine formalizing restraints in the Sino-Indian context, it is useful to recall that China is India's largest neighbor and features prominently in the security calculus in the Southern Asian region. It is India's sincere desire to improve relations with China and enhance economic and other interactions. Nonetheless, India cannot but take into account the realities on the ground. First, China remains in occupation of large tracts of Indian territory as a result of the 1962 war and maintains substantial claims over additional parts of India. Second, China's military modernization program will enhance the force projection capabilities of its armed forces into India's security perimeter. Third, China's assistance to Pakistan's nuclear weapons program and the transfer of missiles and missile technology to Pakistan complicates the nuclear dimensions of India's security environment. China's military collaboration with Myanmar is also well known. It is said that countries can choose their friends, but not their neighbors. India would like to develop mutually 
beneficial and friendly relations with all its neighbors. However, India cannot be blind to the existing and future military capabilities of the neighboring countries that have a bearing on its security.

The Agreement on the Maintenance of Peace and Tranquility Along the Line of Actual Control (LAC) in the IndiaChina Border Areas signed on September 7, 1993, and the Agreement between the Government of the Republic of India and the Government of the Peoples' Republic of China on ConfidenceBuilding Measures in the Military Field Along the Line of Actual Control (LAC) in the India-China Border Areas signed on November 29, 1996, provides a framework for CBMs in the conventional arena. Regular consultative arrangements exist between the Foreign Offices of India and China, as well as the institution of a Joint Working Group on border issues. Some of the CBMs agreed to under the above two agreements include:

- $\quad$ limiting military forces within agreed geographical zones along the LAC;

- $\quad$ avoiding large-scale military exercises involving more than one division (15,000 troops) and giving the other side notification of any exercise involving more than one brigade (5,000 troops);

- prohibiting the flight of combat aircraft within $10 \mathrm{~km}$ of the LAC without prior notification;

- $\quad$ prohibiting firing, blasting and hunting within $2 \mathrm{~km}$ of the LAC; 
- expanding the number of flag meetings between border commanders and authorities at designated points; and,

- exchanging information on natural disasters and diseases along the border.

It is evident that a number of conventional CBMs already exist and they need to be updated to cover the nuclear and ballistic missile fields. This may not be difficult given the commitment of both countries to no-first-use doctrines, and given that India and China do not have the kind of complex command and control apparatus that exists in the US and Russia. India has also stated that its "credible minimum nuclear deterrent" would not be shaped by considerations of parity with any particular Nuclear Weapon State and would be guided solely by considerations of sufficiency and survivability. The above combined with a mutual no-first-use policy makes the India-China nuclear equation a relatively stable one.

India signed an agreement on Prohibition of Attack on Nuclear Installations and Facilities with Pakistan in December 1988. The agreement entered into force in 1991 and the first lists of such facilities were exchanged in January 1992. Since then, these lists have been exchanged every year. Two more agreements were agreed to in April 1991 on the Advanced Notice of Military Exercises, Maneuvers and Troop Movements, as well as an Agreement on the Prevention of Airspace Violations and for Permitting Overflights and Landings by Military Aircraft. A 
dedicated communication link exists between the Director Generals of Military Operations of both sides since 1971, and earlier sporadic contacts, were elevated to regular weekly conversations after 1990.

India and Pakistan have been quick to recognize that the fundamental strategic objectives of the two nations must now be the avoidance of any war - either nuclear or conventional between themselves, and that existing conventional CBMs need to be updated and supplemented with nuclear and missile related Confidence-Building Measures.

It should be remembered that it took nearly 40 years for the US and the Soviet Union to discover that "a nuclear war cannot be won and ought not be fought." The hotline between the US and the USSR was established in 1963, fifteen years after the commencement of the Cold War, and the Nuclear Accidents Agreement was signed in 1971 and Nuclear Risk Reduction Centers were established only in 1987. All this while the two countries were engaged in an arms race with expanding nuclear capabilities, combined with doctrines of first strike and launch-onwarning postures. In contrast, the Heads of Governments of India and Pakistan have met three times in the last 10 months - at Colombo in July 1998, New York in September 1998, and in Lahore in February 1999. In between these meetings, they have spoken by telephone and exchanged letters. What is of greater significance is the agreement between India and Pakistan that negotiated a varied menu of Confidence-Building Measures to 
prevent the outbreak of a nuclear or conventional war in the subcontinent.

In September 1998, the Prime Ministers of India and Pakistan confirmed their common belief that an environment of peace and security was in the supreme interests of both India and Pakistan, and for the region as a whole. They also expressed their determination to renew and reinvigorate efforts to secure such an environment. They commenced a composite dialogue covering a number of bilateral issues with Foreign Secretary level talks in Islamabad in October 1998. The two sides exchanged various ideas on confidence-building and proceeded to build on the many common elements of the two sets of proposals.

The Lahore Summit of 1999 gave a special thrust to the immediate negotiation of measures for nuclear restraint. The Lahore Declaration calls for "immediate steps" to reduce the risk of a war - accidental or otherwise - between the two nations. The proposed CBMs, identified in a memorandum of understanding signed by the two Foreign Secretaries, range from a reaffirmation of their commitment to a moratorium on nuclear testing to strengthening of communications. The CBMs, to be finalized in the coming months, are likely to help stabilize the nuclear deterrent relationship between the two countries, and to provide a more secure environment to resolve outstanding political differences and promote economic cooperation.

An agreement on specific measures by each nation to prevent an accidental or unauthorized use of nuclear weapons, and 
quick reporting of dangerous incidents to each other, will be an important step towards preventing the escalation of tensions. The agreement to notify each other of impending missile launches will also help to avoid the kind of tensions that arose last year in April 1998 when Pakistan tested the Ghauri missile.

The decision to engage in bilateral consultations on security concepts and nuclear doctrines is significant, and therefore, should facilitate in a better understanding of each other's positions. India has articulated a broad outline of its nuclear doctrine and the recently established National Security Council is engaged in fleshing it out. Though Pakistan has said little in public about its nuclear doctrine, some Pakistani leaders have stated that they will keep open their option of the first use of nuclear weapons, inter alia, to off-set what they consider to be India's conventional military superiority.

A replication of the offensive orientation of Pakistan's conventional military doctrine in the nuclear field would imply that Pakistan will need to keep its nuclear forces, small though they might be, in a constant state of readiness. Pakistan would also need to acquire all the paraphernalia required for such a doctrine and force posture, such as early warning and command and control systems. Existing Pakistani capabilities in this area evidently leave a lot to be desired. They were unable to detect the dozens of US cruise missiles that violated Pakistani airspace during the US assault on the terrorist camps in Afghanistan. On the other hand, they "detected" non-existent Indo-Israeli attack preparations the 
night before the Pakistani nuclear tests. This situation, married with a dangerous first-use doctrine, is cause for serious concern.

The public acknowledgement by Pakistani leaders that each of the three major military conflicts with India in the past were initiated by Pakistan, combined with their recognition that India does not need nuclear weapons to manage a conventional threat from Pakistan, provides us hope that a bilateral dialogue could result in rethinking in Pakistan of the utility of its first-use posture. Through discussions on security concepts and doctrines, India intends to dispel the misperception that the link between conventional and nuclear weapons forms a continuum and, thereby, reassures Pakistan that it can ensure its own defense in terms of its own requirements and resources without becoming entangled in notions of parity.

India and Pakistan have agreed to review the existing communication links between the two security establishments, such as those existing between the two Army Directors General of Military Operations, and to upgrade them to modern standards of safety and security.

Among the other CBMs is a proposal to prevent incidents between the two Navies and Air Forces, and to expand consultations between the two nations at multilateral fora, such as the United Nations and the Conference of Disarmament in Geneva. Furthermore, the two sides are to establish "consultative mechanisms to monitor and ensure effective implementation" of the many existing CBMs. 
In the context of CBMs and nuclear doctrines, a word is necessary regarding Jammu and Kashmir, which has frequently been portrayed as a potential nuclear flash point. Some Pakistani security experts have even argued that nuclear deterrence provides an umbrella for Pakistan to press its aims in Jammu and Kashmir through low intensity warfare such as terrorism and insurgency. It is, of course, common wisdom that a nuclear deterrence umbrella might facilitate the quick exploitation of a localized conventional superiority, although it is not credible that a rational decisionmaker will resort to nuclear escalation to reverse a localized setback. On the other hand, the party that took such a step would then be required to maintain a defense in depth at a high level of alert status along the entire Line of Control, since it would otherwise be vulnerable to a similar localized conflict in a different area. As regards to Pakistan fomenting terrorism in Jammu and Kashmir through the induction of mercenaries, etc., India has already declared its intention to control this kind of a situation through counter terrorist and counter insurgency operations, instead of resorting to a conventional attack across the LOC on terrorist sanctuaries in Pakistan held territory, despite the many precedents for such action which exists in other parts of the world. The steady normalization of the situation in Kashmir demonstrates that this is successfully being done. Pakistan's nuclear capacity and its first use doctrine can have no relevance at all, in a situation of deterrence, in assisting Pakistan to further its aims in Jammu and Kashmir. Barring acts of total irrationality, and we have no 
reason to expect this from Pakistan, suggestions that Jammu and Kashmir could become a nuclear flash point have no basis whatsoever. Indeed, the more this is repeated, the more it gives the appearance of protesting too much, and perhaps with motivations that are quite different. It has echoes of the saying coined by a US expert some years ago that the road to nonproliferation in South Asia goes through Jammu and Kashmir.

At the regional level, India has participated since 1996 as a Full Dialogue Partner in the ASEAN Regional Forum (ARF) which brings together the ten ASEAN countries, Australia, Canada, China, India, Japan, Mongolia, New Zealand, Republic of Korea, Russia, the United States, and the European Union (EU). Unlike the Organization for Security and Cooperation, Europe (OSCE), the ARF is not a treaty based organization, but is best described as a framework for first order Confidence-Building Measures. The ARF process is three-tiered: Track I includes activities to be discussed and addressed by member states; Track I and a half with activities which are pursued by representatives from member states in their individual capacity; and, Track $I I$ which brings together academics, scholars, and government servants in their private capacity. An inter-sessional working group on Confidence-Building Measures acts as a clearinghouse for CBM proposals. The importance of the existence of such a forum that attempts to build trust and confidence through dialogue 
and consensus in a region which has complex security problems and divergent experiences cannot be over-emphasized.

To summarize the Indian perspective of formalizing restraint and its unilateral, bilateral and regional aspects, I would reiterate that it is inappropriate to examine restraint in security matters in an arbitrarily defined sub-region such as South Asia. The security concerns of at least one of the countries of South Asia extends well beyond that sub-region. The reach and effect of nuclear weapons and missiles inducted into service or under development envisage contingencies that have their origin beyond the geographical confines of South Asia. Unlike in the East-West bipolar context, formalization of restraint for India is a much more complex issue, because of the wide variation in the security concerns of different countries in the perimeter of India's security concerns. $\mathrm{CBMs}$ or other means of formalizing restraint need to be tailor-made to specific situations and be multi-dimensional, encompassing political, military, arms limitation, economic and cultural aspects. Examples of unilateral restraint, practiced by India, include a defensive orientation of security concepts and force postures, and strict control and reduction of the defense budgets. In the nuclear field, commitment to no-first-use, moratorium on nuclear testing, minimum credible nuclear deterrence, and the rejection of an arms race or concepts and postures from the Cold War era.

Bilateral formal restraint has taken place both in the IndiaPakistan and the Sino-Indian context. With Pakistan, conventional 
CBMs have now been supplemented with nuclear and missile CBMs in the framework of the Memorandum of Understanding (MOU) signed between the Foreign Secretaries of the two countries at the February 1999 Lahore Summit. Updating of conventional CBMs in the light of new realities is also envisaged. As regards to China, the hiatus in dialogue after May 1998 has been resolved. The question of bilateral restraint arrangements in the nuclear field could easily be included in the Indo-Chinese dialogue, subject to mutual agreement. At the Asia-Pacific level, the only arrangement for a regional security dialogue is the ASEAN Regional Forum. ARF has been focusing on building confidence and trust and has put forth a number of proposals on CBMs that can now be negotiated.

At this stage, it will be useful to examine the global context of restraint. India's position on the Comprehensive Test Ban Treaty (CTBT) has evolved since 1996, particularly after the limited series of nuclear tests conducted in 1998. Not only did India declare a voluntary moratorium on May 13, 1998, but it has also indicated that it was prepared to bring the ongoing bilateral discussions with various interlocutors on a range of securityrelated issues, including the CTBT, to a successful conclusion so that the entry into force of the CTBT is not delayed beyond September 1999. In addition, India is engaged constructively in the negotiations in the Conference on Disarmament (CD) towards a Fissile Material Cut-off Treaty. India's own export control procedure to prevent the leakage of materials and technology 
relating to Weapons of Mass Destruction are recognized as among the most stringent, with a record superior to that of most NPT Nuclear Weapon States.

India believes that nuclear weapons are not weapons of war fighting, and there is no continuum between conventional and nuclear weapons. That is why India has voluntarily announced a policy of no-first-use. It has also announced a readiness to formalize this undertaking bilaterally or multilaterally. An international agreement on no-first-use will be the first step on the road to the de-legitimization of nuclear weapons, a path that was followed with respect to chemical and biological weapons in 1925 with the Geneva Protocol. Furthermore, India has taken another initiative at the UN General Assembly that calls for a review of doctrines and postures with a view to reducing the danger of accidental and inadvertent nuclear conflict. Despite growing NGO and academic support for de-alerting and other measures of "horizontal disarmament," its allies and the US voted against this resolution in the United Nations. This reluctance to embrace even modest global measures to demonstrate restraint greatly contrasts with the West's own vocal demands for restraints on deployment in regional situations. Similarly, what is India to make of the uneasy co-existence of patterns of increasingly frequent unilateral military actions, in contravention of the provisions of the UN Charter, however seductive, may be the excuses to justify such initiatives? 
The Cold War ended almost a decade ago, and the notion of a deliberate and massive nuclear attack by the Cold War protagonists is an unrealistic proposition today. India welcomes this development, and further welcomed the statement, made more than a decade ago, by Presidents Reagan and Gorbachev that a nuclear war could not be won and must not be fought. Yet, the nuclear arsenals and the attitudes of these countries still reflect Cold War postures. Thousands of nuclear weapons remain on hair-trigger alert increasing the risk of an accident or unintentional nuclear exchange. The multilateral negotiating process on nuclear issues has remained blocked. Only a few partial efforts have not moved the international community towards the objective of a nuclear-weapon-free world. The Canberra Commission report, the advisory opinion of the International Court of Justice, the report of the Stimson Center, the appeal by the group of retired senior military generals and commanders, the Pugwash Declaration, the initiative launched by the expanding network called Abolition 2000 , all these initiatives provide an insight into what is expected and more importantly, today, considered feasible, practical, and achievable. Thus far, these exhortations seem, so far, to have fallen on deaf ears.

This is evidently not an encouraging international backdrop, and imposes limits on what the NPT Nuclear Weapon States and their allies can suggest to others on restraint in terms of their own example. There is also a further self-imposed theological obstacle for the NPT Nuclear Weapon States, and their 
allies, and supporters in engaging in a serious dialogue with India on such issues. Starting from the premise that the role of the NPT, as the cornerstone of the international nonproliferation regime, was written in stone, the NPT priesthood decreed that there could be no Nuclear Weapon States outside of the NPT. Therefore, India and Pakistan, despite possessing nuclear weapons, cannot be Nuclear Weapon States. To continue to describe India as a Non-Nuclear Weapon State, which would be perfectly in accordance with NPT theology, might cause the priesthood to be accused of frivolity, the effort now is to describe us as "threshold" or "nuclear capable" states. The logical development from this illogical premise has been the prescriptions offered by the Permanent Five (P-5) and the Group of Eight (G-8) and some others that India should not develop nuclear weapons, or delivery systems, and should sign the NPT, participate in a South Asia Nuclear-Weapon-Free Zone, etc. But all this is water under the bridge, and railing against the waves, like King Canute, will not roll them back. In any case, it would not be reasonable to expect India to play along with such illusionary comments.

It should be emphasized that this global dimension in formalizing restraint and the practice of restraint cannot be ignored. India has consistently held, as a matter of principle, that issues of security cannot be arbitrarily compartmentalized. The importance of non-discriminatory and global instruments that further disarmament, and reduce the danger of conflict, especially nuclear conflict, cannot be over-emphasized. Conversely, a pattern 
of unilateral actions which contravenes the provisions of the UN Charter, destabilizing theories which provide for new contingencies for the use of nuclear weapons, and opposition to measures for the de-legitimization of nuclear weapons, will inevitably have adverse consequences for regional restraint arrangements.

\section{Notes}

1. Essay Five of the United Kingdom Strategic Defense Review (London: Stationary Office, 1998). 


\section{Chapter 8}

\section{The Obstacles to A Nuclear-Weapon-Free Zone in the Middle East}

\section{Gerald M. Steinberg}

The nuclear tests conducted by India and Pakistan during the past year, Iran's missile test, the continuing impasse over the arms inspection regime in Iraq, and other developments demonstrate the challenges faced by the nonproliferation regime. Despite intense efforts to increase the extent of the global nonproliferation regime, progress is slow.

One of the most important lessons of the past twenty years of nonproliferation initiatives is that each area faces its own security concerns, and global regimes need to be supplemented by regional frameworks. The Nuclear-Weapon-Free Zones (NWFZ) that have been negotiated and implemented in Latin America, the South Pacific, Africa, and most recently, the Asia Pacific region, provide important examples. Other areas in which multifaceted regional approaches will be required include South Asia, the Korean Peninsula, and the Middle East.

The examination and analysis of the requirements and conditions for the creation of a functioning NWFZ in these conflictual regions demonstrate that this will require the settlement of intense and ongoing conflicts. In cases in which nuclear 
deterrence, in some form (deployed or virtual), is viewed as essential for national security, without the settlement of these conflicts, the impediments will remain. In addition, in some areas a nuclear potential or capability is seen as a necessary response or deterrent to non-nuclear threats. Thus, in such instances a NWFZ must be linked to a wider set of regional agreements and limitations, encompassing chemical and biological weapons, ballistic missiles and other long-range delivery systems, as well as massive conventional forces. A regional arms control system, including a NWFZ, must also include stringent and reliable verification systems in order to meet the concerns of all the parties regarding possible cheating, or undetected preparations for "breakout" (in which one party secretly creates the basis for a rapid development of prohibited weapons, and when the "breakout" occurs, this does not leave sufficient time for a response). Together, these three sets of requirements present a major challenge; or, until these challenges can be met, obstacles, to the creation of zones free of nuclear weapons and other Weapons of Mass Destruction.

\section{Background}

Since 1980, the United Nations General Assembly has supported, by consensus, annual resolutions calling for the creation of a Nuclear-Weapon-Free Zone (NWFZ) in the Middle East. All the states in the region have supported this consensus, including 
Egypt, Israel, and Iran. In addition, the leaders of these states have consistently voiced support for a Middle East Nuclear-WeaponFree Zone (MENWFZ) in public statements.

However, this consensus has masked a number of fundamental differences in approach and substance. Initially, and throughout the 1980s, Israel and the Arab states were divided on major issues of process. While Israel insisted that the negotiations take place through direct face-to-face talks as part of a regional peace process, the continuing refusal of the Arab states (with the notable and very important exception of Egypt) to end the state of war with Israel created an impasse. This basic obstacle was reduced, to some degree, in 1991, following the Middle East Peace Conference in Madrid, in which many of the parties participated (with the exception of Iraq, Iran, and Libya). The conference led to the establishment of a number of multilateral working groups, including one on Arms Control and Regional Security (ACRS) which, for the first time, provided a format for direct negotiations on such issues. However, the refusal of Syria to participate, as well as the absence of Iran, Iraq, and Libya (who reject the peace process; and in the case of Iran, actively support rejectionist terror groups such as Hamas and Hizbollah) have limited the ability of ACRS to consider regional security issues such as the MENWFZ in any detail. Without the active participation of all of these states in this or a similar forum, it is difficult to proceed towards significant regional agreements. 
Beyond the procedural issues, there are a number of substantive differences and conflicts that will be difficult to resolve. The first issue in the consideration of a NWFZ in any region is the scope of the areas to be included. In conflictual regions, such as the Middle East, the core sector is defined in terms of potential or actual states that might be involved in military confrontation in which nuclear capabilities or threats could play a role.

In comparison with the other areas in which regional NWFZs have been created, the Middle East is particularly complex. ${ }^{1}$ This is an area plagued by a long history of intense and overlapping ethno-national and religious conflict, and there are many obstacles and difficulties to reaching agreement on a MENWFZ. To be effective, a Zone would have to include the 22 member states of the Arab League, as well as Iran and Israel, and stretch from Algeria in North Africa to Iran and the Persian Gulf. ${ }^{2}$ There are specific issues regarding some peripheral states, such as Turkey, which is a member of the NATO alliance, and as part of an organization that has a nuclear component (through its Nuclear Weapons State members), is an exception that must, at some point, be considered. The large number and diversity of necessary participants, in itself, is a significant obstacle to agreement.

In addition, there are wide differences between the various conceptions and mechanisms that have been proposed. These primary differences result from conflicting perceptions of the security requirements and threats posed to the states in the region, 
and the link between the establishment of a NWFZ and the regional peace process in the region. There are also related disagreements on the implementation of a wide network of Confidence- and Security-Building Measures (CSBMs). These include the links between changes in the status of Israel's ambiguous nuclear deterrence option and limitations on conventional, as well as other military-strategic capabilities; the relation of a MENWFZ to the global Nonproliferation Treaty/International Atomic Energy Agency (NPT/LAEA) regime; and the nature of verification.

Nevertheless, in terms of long-term goals, the concept of a MENWFZ, as part of a wider zone free of Weapons of Mass Destruction, is the best option for creating and maintaining longterm stability. Despite the opposing interests and positions on other issues, all the states in the region, including Israel and Egypt, have signed the CTBT, and this could serve as a basis for gaining experience in regional cooperation.

This paper will demonstrate efforts to find "short cuts" that fail to meet the essential security requirements of the key states in the region, including Israel, in the attempt to create a MENWFZ, and to address the basic factors that are necessary for such a zone, albeit these "short cuts" are unlikely to succeed. Indeed, such pressures could, in themselves, become sources of additional conflict and will actually setback the achievement of this goal. 


\section{The MENWFZ in the United Nations}

Egypt and Iran introduced the concept of a MENWFZ in the United Nations General Assembly (UNGA) in 1974. Until 1980 , Israel abstained in the annual votes on this issue, but since then, Israel has joined the consensus, and has thereby also had a voice in shaping the language and in determining the fate of various changes that Egypt and other states sought to introduce over the years. ${ }^{3}$

The emphasis on this issue increased in the wake of the United Nations Special Session on Disarmament in 1988. A number of leaders in the region, including Israeli Prime Minister, Yitzhak Shamir, and Egyptian Foreign Minister, Abdel Meguid, addressed this Special Session, and presented their views on disarmament, in general, and proposals for the region, in particular. ${ }^{4}$ Egypt also proposed that the Secretary General create an expert group to consider the "Establishment of a NuclearWeapon-Free Zone in the Region of the Middle East," and this group issued its report in 1990. This highly detailed report explicitly examined the terms required for "effective and verifiable measures" which would facilitate the establishment of a MENWFZ, as well as the necessary conditions and preliminary steps, including Confidence- and Security-Building Measures (CSBMs) and balanced reductions in conventional arms. ${ }^{5}$ The authors also noted that even under the most favorable conditions, the process would take several years. The Israeli position on this concept has been favorable. In a statement before the 1996 United 
Nations General Assembly, Foreign Minister David Levi declared that "after peaceful relations and reconciliation have been established among all states in the region, Israeli will endeavor to establish in the Middle East a zone free of chemical, biological, and nuclear weapons, as well as ballistic missiles, based on mutual and effective verification. Negotiations to establish such a zone will commence following the signing of bilateral peace accords between Israel and all states in the region."

Since then, the issue has been discussed and debated annually in the First Committee of the United Nations and discussed in other forums, including the meetings of the IAEA Board of Governors; the meetings of the ACRS multilateral working group, in the context of the 1995 NPT Review and Extension Conference; and in the Conference on Disarmament, which Israel joined in 1997. Examination of the positions taken by the various parties at these meetings and in other settings provide a basis for examining the differing positions in detail, and for analyzing the obstacles to the establishment of a MENWFZ. The intense political conflicts and efforts to obtain minor political and public relations; advantages in the wording of declarations and resolutions, particularly in the First Committee of the United Nations; and the meetings of the Board of Governors of the IAEA, are indications of the long period that will be necessary to overcome the substantive and political obstacles. ${ }^{7}$ 


\section{The central issues and conflicts}

\subsection{Links between a MENWFZ and the global NPT/IAEA regime}

The question of whether and how to link a regional NWFZ to the existing global regime is a central and perhaps the most conflictual issue facing the parties. The global system is based on universality (except for the five recognized Nuclear Weapons States), and differences in geography, demography, and regional threat situations (both conventional and non-conventional) are not taken into account. In contrast, a regional approach emphasizes precisely these specific issues, allowing for the development of a complex and tailor-made framework, as seen in the case of Latin America. ${ }^{8}$

In general, the Arab states and Egypt, in particular, demand that a regional zone be integrated within the global structure, while, for Israel, this is unacceptable and would defeat the purpose of the NWFZ for the reasons noted above. The Egyptian position on this issue was clearly stated in the 1990 Mubarak initiative, (formally presented in a letter to the UN Secretary General in July 1991). This proposal emphasized the demand that all states in the region accept the NPT and adopt IAEA safeguards on all nuclear facilities. In his letter, Mubarak also included a broad call for the major powers "to step up their efforts to ensure that all Middle East nations, which have not yet done so, adhere to the Treaty." 9 This position is stressed frequently. For example, the final communiqué 
of the June 1993 summit meeting of the Arab League in Cairo stated, "The Arab leaders stress the need for Israel to join the Nuclear Nonproliferation Treaty and to subject all their nuclear facilities to the inspection regime of the International Atomic Energy Agency. They also renew their call for establishing a zone free of mass destruction, especially nuclear weapons, in the Middle East."10

By attempting to link the MENWFZ concept to the global NPT/IAEA regime, the multifaceted threat environment that is particularly characteristic of the Middle East cannot be included, as the NPT deals only with limitations on nuclear weapons. Israel's "last resort" deterrence policy is a response to the threats posed by other weapons systems and technology, including massive conventional forces that threaten national survival, as well as chemical and biological warheads

The ACRS working group, in which Israel, Egypt, and Jordan were active participants, provided a framework designed to address many of these differences. ACRS is not linked to the UN, IAEA, or any international organization. In addition, this mechanism is not limited to any specific weapon or technology, and allows for discussion of the links between such capabilities and the threats that they pose.

However, the effort to produce an agreed framework or declaration of principles for the next stage of ACRS broke down in 1994, precisely over the differences regarding the role of the NPT. While Egypt insisted on obtaining explicit Israeli agreement to 
language linking the NWFZ to the NPT, Israel rejected this linkage. This disagreement also mirrored the confrontation over the impending NPT Extension Conference." ${ }^{11}$ Since then, the ACRS process has been stalled, reflecting both the importance attached to this issue, and the degree to which it constitutes a fundamental obstacle to progress in negotiating a MENWFZ. It should, however, be noted that the 1994 Jordanian-Israeli Peace Treaty calls for a Middle East free from WMD, "both conventional and non-conventional," without specific reference to nuclear weapons or the NPT and IAEA. ${ }^{12}$

\subsection{Verification and safeguards}

Any arms limitation regime, whether global, regional, or bilateral, is only as strong as the verification and safeguards systems that are implemented. For example, the 1972 Biological Warfare Convention (BWC) has been ineffective, reflecting the absence of any verification system. The NPT has failed in areas where verification and safeguards were too weak to deter violations, as in the case of Iraq and North Korea, and, it is increasingly feared, now Iran. The IAEA, in general, and the safeguards and verification system, in particular, are vulnerable to political influence allowing states to exclude inspectors from some areas and to manipulate the system in a way which would prevent or delay the "timely detection of violations" and allow states to produce weapons before a significant international response. The 
IAEA Board of Governors, which appoints IAEA officials and must consider whether to report cases of suspected safeguards violations for action to the United Nations Security Council, is a political body with representation based on politically defined groups. For example, for political reasons, Israel has been systematically excluded from these groups, and therefore from representation on the Board of Governors. This discrimination further complicates efforts to gain Israeli cooperation in the context of the IAEA.

The Middle East poses some very difficult verification requirements. There are a number of diverse political systems, ranging from open democracies to closed and tightly controlled dictatorships. In the case of closed societies, particularly those with relatively large territorial extents, it is possible to hide weapons development and production programs from international inspectors. This has been clearly demonstrated in the case of Iraq, where both IAEA and the United Nations Special Commission (UNSCOM) inspectors attempted to determine the extent of the Iraqi capability until the system collapsed in 1998. For over seven years, the Iraqi government was able to keep significant capabilities and information hidden from the international inspectors, despite the agreement guaranteeing access and cooperation as specified in UN Security Council Resolution 687.

These experiences are a strong argument for creating safeguards based on dedicated regional systems of mutual verification, negotiated and implemented by the parties, without 
the political aspects of the IAEA or other international body. This is the Israeli position, and is underlined repeatedly.

In contrast, the formal Arab position has consistently stressed placing regional verification under the control of the IAEA. Ambassador Mohammed Shaker placed primary emphasis on adherence to the NPT and to giving the IAEA a "major role" in safeguarding nuclear activities in the region and in the verification of a MENWFZ. ${ }^{13}$ This is also consistent with the overall Egyptian emphasis on linking the MENWFZ to the global structure and subordinating the regional regime to the global framework.

The development of a regional and mutual inspection system is also dependent on some form of recognition and cooperation among all the parties, including Syria, Iran, Iraq, and Libya. This requirement has two driving factors. First, the failures and lack of reliability of third-party verification on an issue critical to national survival lead-individual states that might be threatened by a clandestine nuclear program to have their own sources of information and verification with respect to the other states in the zone. If any one state were able to violate the agreement and suddenly "breakout" from the limitations by producing nuclear weapons, this would pose a grave threat. From this perspective, the best way to reduce and limit this possibility is through mutual verifications.

Second, mutual acceptance and recognition of legitimacy is a necessary requirement for peaceful relations on which an NWFZ is predicated, and in the context of which mutual inspection and 
verification can take place. If some states are not ready for mutual inspection, it can be argued that they are not really ready for regional peace, and the conditions necessary for a regional NWFZ do not yet exist. (See the detailed analysis of the links between the peace process and a MENWFZ below).

The experience in Latin America suggests that a regional monitoring system is feasible. The 1967 Treaty of Tlatelolco (which took almost 30 years to become operable) and the Argentinean-Brazilian system, known as ABACC, provides a model that has been studied in the Middle East. There are many differences between the conditions in each of these two regions, and while regional verification systems addressed to the needs of the Middle East would be quite different, the concepts are similar.

\subsection{Conflicts, threats, and last-resort deterrence}

Israel is not a signatory to the NPT, and operates a nuclear reactor at Dimona, which is reportedly capable of producing plutonium for the production of nuclear weapons. Since the $1960 \mathrm{~s}$, Israel has followed a policy of deliberate ambiguity, and Israeli leaders have consistently refused to acknowledge or deny the possession of nuclear weapons. ${ }^{14}$ For many years, they have simply repeated the ambiguous formula that "Israel will not be the first nation in the region to deploy nuclear weapons" (and sometimes, with the addition that it will also not be the second nation). 
The Israeli position is primarily based on deterrence considerations. A small state lacking strategic depth and threatened by very large conventional forces, the Israeli leadership views the ambiguous deterrent as provided a "weapon of last resort" against existential attacks. The threat of nuclear retaliation has been and continues to be seen as the key to national survival, and the ambiguous capability, option, or potential has provided this deterrence. This policy is supported by a consensus of the Israeli decision-makers and by the vast majority of public opinion, and is linked to the perception that this option is necessary to national survival. ${ }^{15}$ The late Shalheveth Freier, who served as the head of the Israeli Atomic Energy Commission, described the nuclear deterrent option as providing "a sense of reassurance to Israelis in times of gloom" and "as possible caution to states contemplating obliterating Israel by dint of their preponderance of men and material."16 In January 1996, the present Prime Minister, Ehud Barak, former Foreign Minister and Israel Defense Forces Chief of Staff declared that in the absence of proven and reliable regional peace agreements, "Israel's nuclear policy, as it is perceived in the eyes of the Arabs, has not changed, will not change, and cannot change because it is a fundamental stand on a matter of survival which impacts all the generations to come." 17 The same approach is reflected in the policies of the former Prime Minister Benjamin Netanyahu's government.

This policy is widely supported across the Israeli political spectrum, and is based on a national consensus. There are no 
differences between parties, ideologies, or perspectives on the peace process. On this issue, there is little to distinguish the public statements of late Prime Minister, Yitzhak Rabin; former Prime Minister, Benjamin Netanyahu's; former Foreign Ministers, Shimon Peres and Ehud Barak; and leading politicians in the Left such as Yosi Beilin and Yosi Sarid. This position is also supported by a consensus in the Israeli public, and polls showed that close to $90 \%$ explicitly approve of the continuation of Israeli nuclear policy. Unless and until there is a fundamental change in the threat environment, this public support is unlikely to change. ${ }^{18}$

The Israeli position is that any change in the status of Dimona, through international inspection, would reduce or end this ambiguity and, thus, weaken or destroy the deterrent and, thus, make the country vulnerable to renewed existential attacks. Israel has consistently rejected pressures that it accede to the NPT and accept inspection. At the same time, Israel has not tested any weapons or taken any steps that would turn the ambiguous capability into an acknowledged and visible capability. ${ }^{19}$ This is also the framework from which Israel has approached the discussions of a global Fissile Material Cut-off Treaty (FMCT). ${ }^{20}$

The policy of deterrence is inherently not susceptible to empirical testing, except in the case of failure, and there is always a great deal of uncertainty in any deterrence situation. ${ }^{21}$ However, although deterrence may be flawed, no better and realistic alternative is available, short of comprehensive peace agreements and fundamental political changes in the region. This position is 
also supported by recent examples in which deterrence and the threat of massive retaliation seems to have led to restraint. For example, some analysts argue that the Egyptian decision not to exploit initial breakthroughs in the Sinai in 1973 were due to the Israeli nuclear deterrent. In addition, it can be argued that while Iraq possessed and had tested Scud missiles and chemical warheads prior to the 1991 war, it did not use the chemical weapons against Israel in response to the potential Israeli retaliatory capability. In other words, from the Israeli perspective, the implicit threat of massive retaliation against existential threats or the threat to use Weapons of Mass Destruction seems to be effective. Under such conditions, Israeli leaders have declared that they will maintain this capability as long as the threats remain. On the other hand, the Israeli policy also emphasizes the long-term goal of banning all Weapons of Mass Destruction, when this form of deterrence is no longer necessary.

3.4 Links with other forms of arms limitation and regional security

As noted above, in the Middle East, the development of nuclear weapons or options are not isolated from other securityrelated factors and sources of military threats and capabilities. When there are fundamental asymmetries in land area and population, large scale conventional capabilities, as well as chemical and biological agents, the nuclear option designed as a deterrent is closely linked to the non-nuclear threats. In this 
particular case, the proposed limitations on nuclear capabilities are inseparable from the development and implementation of limitations on other military capabilities, both conventional and non-conventional. As numerous UN reports and related studies have concluded, a MENWFZ must be linked to or include such broad limitations, each of which are, in themselves, complex and difficult to implement. The development of an acceptable and stable level of conventional weapons, limited in terms of both quantity and quality, in order to prevent any state or group of states from threatening the survival of any other state, is a complex process. However, such limits are a necessary first step towards comprehensive arms limitation agreements in the Middle East, including a NWFZ.

The threat from wars and attacks involving conventional weapons in the Middle East has always been significant, and in spite of recent progress towards peace agreements, this threat remains, and in some ways, has even increased. The Israeli strategic situation is essentially unique. In the Arab-Israeli conflict zone, Israel is a small state, and geographic, demographic, military, and economic asymmetries have played a central role in the development of security policies and strategic culture. In area, Israel consists of less than 21,000 square kilometers (excluding the Judea and Samaria regions of the West Bank, and the Golan Heights), compared to 1 million square kilometers for Egypt and 186,000 square kilometers for Syria. This small size, and the extremely narrow area between the Eastern border and the 
Mediterranean (15 kilometers in the pre-1967 borders), leaves Israel without the strategic depth necessary for absorbing armored and air attacks, and without the ability to recover and respond. Israel's vulnerability to conventional attack was made clear in 1948, when forces from a number of Arab states (Egypt, Jordan, Syria, and Iraq) advanced rapidly and came close to destroying the nascent state. In May 1967, the preparations for war by the Arab states were seen as threatening national survival, and the combined Egyptian and Syrian attacks in October 1973, and the Yom Kippur War, also highlighted Israel's extreme vulnerability.

The massive conventional forces that can be fielded by Syria, Egypt, and Iraq are seen, particularly through the lense of history, as a continued existential threat to Israel. Although the Soviet Union no longer exists to provide low-cost and technologically advanced weapons, Syrian ground forces are continuing to grow, and include 4800 main battle tanks, of which 1400 were acquired in the past eight years. The Syrian standing army is twice as large as Israel's, and a surprise attack, based on forces in place, and supported by combat aircraft and surface-tosurface missiles (SSMs) with chemical warheads, could prevent mobilization of Israeli reserves. Three-quarters of the Israeli ground forces are in the reserves, and unhampered mobilization takes from 48 to 96 hours.

Although Egypt signed a peace treaty with Israel in 1979, the Egyptian military has continued to devote billions of dollars in American military aid to the purchase of modern M1A1 main 
battle tanks and F-16 aircraft, as well as tactical missiles and related systems. In September 1996, Egyptian forces held their largest combined exercises (Badr 96) since the 1973 war, in an area near the Sinai Desert. Egyptian officials announced that these exercises included simulated canal crossings. From an Israeli perspective, these exercises served as a reminder of the continued potential for an Egyptian surprise attack. ${ }^{22}$

Similarly, it has become increasingly recognized that nuclear weapons limitations must be linked to limits on other forms of Weapons of Mass Destruction (chemical and biological warheads). Indeed, in his 1990/1 initiative, President Hosni Mubarak included all forms of WMD, and Israeli Foreign Minister Levi also stressed the link between a ban on nuclear and other Weapons of Mass Destruction as well as ballistic missiles.

\subsection{The relationship to the peace process}

In any region of the world, arms control agreements, and regional limitation zones are dependent on the resolution and amelioration of existing conflicts. In the case of Europe, the success of the Helsinki process that contributed to the Stockholm agreement and the development of the OSCE resulted from the end of the Cold War and the break-up of the Soviet Union. In Latin America, the Entry into Force of the Treaty of Tlatelolco was delayed for thirty years, due to a series of low-level of conflicts involving Argentina, Brazil, and, to a lesser degree, Chile. In the 
case of the Treaty of Rarotonga, the absence of significant conflict was also a major factor in allowing the process to go forward.

In the Middle East, security, arms control, and the peace process are closely interrelated, and progress towards a MENWFZ is dependent on the establishment and implementation of peace agreements with all states in the region, from Algeria to Iran. In his address to the Conference on Disarmament in 1997, the Director General of the Israeli Foreign Ministry reiterated the longstanding Israeli position that the establishment of peaceful relations and reconciliation, and bilateral peace agreements with all of the states, including Iran and Iraq, is a fundamental condition for beginning negotiations. ${ }^{23}$

In contrast, the Egyptian and Syrian position is that the sequence should be reversed, with the negotiation of a MENWFZ, and/or Israeli accession to the NPT and the ending of the Israeli nuclear option or potential coming before major new steps towards a regional peace agreement.

After over 70 years of violence, in the form of both fullscale war and continued terrorism, it is unrealistic to expect that the establishment of a stable Middle East peace can be accomplished in the span of a few years. To have any chance of success, this process must take years and even decades. The process began with the historic visit of President Sadat to Jerusalem in 1977, and continued with the 1979 Egyptian-Israeli Peace Treaty, the 1991 Madrid Conference, the 1993 Oslo 
Agreement, the 1994 Israel-Jordan Peace Treaty, and the 1995 Oslo II Agreement.

However, it is also important to recognize that this is only the beginning of the process. No agreement has been reached between Israel and Syria, and war is still considered to be a serious possibility. A war of attrition and terrorism continue in the areas of Northern Israel and Southern Lebanon, with Iranian forces working with Hizbollah to attack Israeli positions, settlements, and forces. Tensions continue between Israel and Egypt, and while these can be explained in terms of jockeying for position, and playing to domestic audiences, particularly in Egypt, in the Middle East, events can often assume an independent path, pushing decision makers to take action over which they lose control. The series of brutal terrorist attacks and suicide bombings in Israel during February and March 1996, in which over 100 were killed, brought the Israeli-Palestinian process to a halt, and it has not yet recovered. In summary, as Leonard and Prawitz note in their analysis of the nuclear issue in the context of the peace process, "There is a great deal of skepticism in Israel about the ultimate intentions of others with regard to a true peace."24

As noted, the essential factor in the establishment of a MENWFZ is progress towards comprehensive regional peace and security. In the absence of peace and an alternative security framework, the obstacles to a NWFZ will remain. Failure of the peace process will mean an end to any possibility of a regional zone. With continued progress, and the participation of Syria, Iran, 
and Iraq, the basis for a regional security framework will be created. A new structure for regional security will have to be established to replace the existing conventional and nonconventional forces on all sides. This will require time and the development of a series of increasingly substantive CSBMs, including steps to prevent surprise attacks, thinning out zones for conventional weapons, the exchange of information, and most importantly, continuous exchanges of views, ideas, and perceptions. Efforts to rush this process by pressing for the establishment of a NWFZ in the Middle East in the absence of these necessary conditions will be counter-productive.

\section{Notes}

1. See, for example, Jan Prawitz and James F. Leonard, $A$ Zone Free of Weapons of Mass Destruction in the Middle East, (Geneva: United Nations Institute for Disarmament Research, 1996).

2. Ibid., pp. 63-65. These issues are also considered in Shalhevet Freier, "A Nuclear-Weapon-Free Zone in the Middle East and Effective Verification," in Disarmament: A Periodic Review by the United Nations, Vol. XVI, No. 3 (1993), pp. 66-91.

3. For a detailed history of the role of the United Nations in this issue, see Mahmoud Karem, A Nuclear-Weapon-Free Zone in the Middle East: Problems and Prospects (New 
York: Greenwood Press, 1988); Avi Beker, Disarmament Without Order: The Politics of Disarmament in the United Nations (Westport: Greenwood Press, 1985); and Avi Beker, "A Regional Nonproliferation Treaty for the Middle East," Security or Armageddon: Israel's Nuclear Strategy, Louis Rene Beres, ed., (Lexington, Ma.: Lexington Books, 1985).

4. Address of Israeli Prime Minister Yitzhak Shamir, UN General Assembly, June 7, 1988; and Address of Egyptian Foreign Minister Ismat Abdel Meguid, June 13, 1988, reprinted in Arms Control in the Middle East, Dore Gold, (ed.), Jaffee Center for Strategic Studies, Tel Aviv, 1990.

5. "Establishment of a Nuclear-Weapon-Free Zone in the Region of the Middle East: Study on effective and verifiable measures, which would facilitate the establishment of a Nuclear-Weapon-Free Zone in the Middle East." Report of the Secretary General, United Nations General Assembly, A/45/435, 10 October 1990. This report was the result of a study by James Leonard, Ben Sanders, and Jan Prawitz.

6. Statement of Foreign Minister David Levi, United Nations General Assembly, October 3 1996; see also Statement by H.E. Mr. Eytan Bentsur, Director General of the Ministry of Foreign Affairs of Israel, Before the Conference on Disarmament, Geneva, 4 September 1997. 
7. The political conflicts in these international organizations in the effort to obtain support from other participants are similar to the type of activity that took place in the UN during the 1950s and 1960s, between the US and the USSR.

8. Gerald M. Steinberg, "Nonproliferation: Time for Regional Approaches?" Orbis 38:3 (Summer 1994) pp. 409-424.

9. UN document $A / 46 / 329,5 / 22855,30$ July 1991, Letter from the Minister of Foreign Affairs of Egypt to the Secretary General of the United Nations.

10. Text of "Final Communique" issued by the Arab Summit Conference in Cairo on June 23; read by Egyptian Foreign Minister 'AMR Musa, FBIS-NES-96-122, 23 June 1996.

11. For a detailed analysis, see Gerald M. Steinberg, "The 1995 NPT Extension and Review Conference and the ArabIsraeli Peace Process," Nonproliferation Review, Vol. 4, No. 1, Fall 1996.

12. Bruce Jentleson, "The Middle East Arms Control and Regional Security (ACRS) Talks: Progress, Problems, and Prospects", IGCC, University of California, Policy Paper 26, September 1996.

13. Mohamed Shaker, "Prospects for Establishing a Zone free of Weapons of Mass Destruction in the Middle East," Director's Series on Proliferation, Lawrence Livermore National Laboratory, Vol. 6, 1994, p. 22. 
14. Although a flood of books and articles, both journalistic and academic, have been published on the Israeli nuclear option or potential, the technical nature of the capability is highly ambiguous. Estimates of this capability range from 50 weapons to over 200 , and these are all based on guesses (some more educated than others) regarding the capacity and operations of Dimona, and efforts to sift fact from fiction in the claims of Mordechai Vanunnu.

15. Gerald Steinberg, "Deterrence and Middle East Stability: An Israeli Perspective," in Security Dialogue 28, (2) March 1997.

16. Shalheveth Freier, "A Nuclear-Weapon-Free Zone (NWFZ) in the Middle East and its Ambiance," unpublished manuscript (1992). An edited version of this paper was published in Shalheveth Freier, "A Nuclear-Weapon-Free Zone in the Middle East and Effective Verification," in Disarmament: A Periodic Review by the United Nations, Vol. XVI, No. 3 (1993), pp. 66-91.

17. Aluf Benn, "Barak: Nuclear Policy has not and will not change" Haaretz 31 December, 1995, p.10a. A recent advisory ruling by the International Court of Justice on the legality of nuclear weapons, stated that while in most cases, the threat or use of such weapons would be illegal, this would not necessarily be the case when the deterrent threat was in a situation of use as a weapon of last resort. 
18. Asher Arian, "Israel and the Peace Process: Security and Political Attitudes in 1993," Jaffee Center for Strategic Studies Memorandum, No. 39, Tel Aviv University, February 1993, p.12.

19. For analyses of the NPT issue in Israeli-Egyptian relations, see Gerald M. Steinberg, "The 1995 NPT Extension and Review Conference and the Arab-Israeli Peace Process," Nonproliferation Review, 4,1 (Fall 1996), pp.17-30; and Fawaz A. Gerges, "Egyptian-Israeli Relations Turn Sour," Foreign Affairs, (May/June 1995) 74, pp. 69-78.

20. Statement of Israeli Ambassador Yosef Lamdan before the Conference on Disarmament, 11 August 1998, Final Record of the 802nd Plenary Meeting, CD/PV.802, Geneva; former Prime Minister Netanyahu's remarks regarding media reports concerning Israel's nuclear policy, August 11, 1998, (communicated by the Prime Minister's Media Adviser).

21. There is a vast literature debating the role of deterrence, particularly during the Cold War. For one of the most comprehensive critiques, see R. N. Lebow and J. G. Stein, We All Lost the Cold War (Princeton, N.J.: Princeton University Press, 1994).

22. In the past, Iraqi forces have joined in attacks on Israel, and despite the reduction of the Iraqi military capability, the capability to intervene in the Arab-Israeli theater continues 
and may grow following the end of the embargo against Saddam Hussein.

23. Statement by H.E. Eytan Bentsur, Director General of the Ministry of Foreign Affairs of Israel, before the Conference on Disarmament, Geneva, 4 September 1997.

24. Leonard and Prawitz, op. cit., p. 78. 



\section{Part III}

\section{Beyond START II}




\section{Deterrence and Arms Control: A View from Europe}

\section{Bruno Tertrais ${ }^{1}$}

France and the United Kingdom (UK), the two European nuclear powers, reviewed the role and the shape of their armed forces since the end of the Cold War, but the most significant evolutions occurred in the field of conventional forces and operations. The role of British and French nuclear forces has not significantly evolved and their fundamental strategies and operations remain the same. However, new issues have arisen creating potential "new nuclear roles" for these forces. The paper will examine the political and military functions of the European nuclear forces in the post-Cold War era, ponder French and British contributions to the nuclear arms control process, and discuss the compatibility of the new roles assigned to their nuclear forces with "minimum deterrence" type postures.

There is today a remarkable identity of views between France and the UK on the fundamentals of nuclear policies and doctrines. Each of the two claim that its nuclear force is a "minimum" one (France prefers the term "sufficiency"), that it has solely a deterrence function, a fundamentally political one, and that it is reserved for the protection of their "vital interests." The possibility of a future major threat against Europe remains the main, while not the sole rationale for their continuing possession of 
nuclear weapons, but neither country sees any immediate threat to its vital interests. Their forces have been detargeted; deterrence is addressed "to whom it may concern," as Sir Michael Quinlan stated. The necessity of these nuclear forces are to be in a position to inflict "unacceptable damage" to any major adversary. This is the main yardstick used for force sizing. The backbone of both the British and French arsenals is a modern force of four ballisticmissile submarine/nuclear-fuelled (SSB/N) with three in the operational cycle, and at least one on patrol at all times. France also maintains an air-based nuclear component. The production of nuclear warheads now happens in a closed loop, since both countries have completely halted nuclear testing and the production of fissile materials for explosive purposes. This is an irreversible decision on the part of France, which is dismantling its production and testing facilities.

The debate on a possible "delegitimization" of nuclear weapons has not had the same effect in Europe as it has in the United States. There is no realistic prospect for any of the two European powers to abandon their nuclear deterrent force any time soon. In this respect, France and the United Kingdom are keen to put forward Article VI of the Nonproliferation Treaty (NPT), which calls on all Parties for general and complete disarmament in addition to nuclear disarmament. In a 1998 speech, French Prime Minister, Lionel Jospin, stated that "for France, as for European security, and as long as general and complete disarmament will not be achieved, nuclear weapons will remain necessary."2 
The longstanding question of French and British participation in multilateral arms control negotiations remains open. But the context in which it is tackled is different from that of the Cold War era. There is, in fact, in this author's personal opinion, little chance that France and the UK will join the bilateral arms reduction process in the post-START II context. There are several reasons for this and they follow:

- First, both countries have unilaterally reduced their own arsenals, and these reductions are proportionnally close to the cuts made by the US and Russia; ${ }^{3}$

- Additionally, the order of magnitude of US and Soviet/Russian arsenals are disproportionate to the actual total of nuclear weapons currently in their inventories, when compared to the START accountable warheads targets. The UK Strategic Defense Review published in 1998 stated that "considerable further reductions [in US and Russian arsenals] would be needed before further British reductions could become feasible;",

- Furthermore, and perhaps most importantly, the mere quantitative comparison between US/Russian arsenals on the one hand, versus the French/UK ones on the other, misses the mark. Each of the two countries consider their own deterrent force as a "minimum" or "sufficient" one, and thus not determined by the size of other nuclear powers' arsenals. On the contrary, both countries view the US and Russian nuclear forces targeting each other, which 
was a process that fuelled the arms race during the Cold War; and,

- Finally, both France and the United Kingdom, since the early 1990s, have additional reasons for cautiousness because of the uncertainties in the future of the nonproliferation regime, and most importantly, the AntiBallistic Missile Treaty (ABM), which is traditionnally considered in Europe as a guarantee of strategic stability. A US decision to deploy a National Missile Defense system would most likely not enhance the chances of British and French participation in multilateral arms reductions.

Let us now consider the following scenario. What would be the conditions under which France and the UK would judge timely and appropriate to participate in multilateral negotiations? In this author's opinion, there are three conditions:

- Verified nuclear reductions would be a prerequisite, probably down to the level of 1,000 START-accountable warheads;

- The continued existence would also be necessary of the NPT and ABM regimes; and,

- The Chinese willingness to join these negotiation, thus, ensuring that all (P-5) official nuclear powers participate. This would certainly be an obligation, since China is almost certainly now the third nuclear power by the number of warheads it has in its arsenal. 
Even under these conditions, new questions arise:

- Would smaller, "non-official" arsenals of other countries be taken into account? If yes, it would mean a recognition of their nuclear power status. If not, France, the UK, and especially China might hesitate to engage in such reductions by the P-5; and,

- What exactly would be the goal sought by these negotiations?

a) One option would be a proportionate reduction in nuclear weapons. For example, a cut of $50 \%$ in the US and Russian arsenals. Such logic would assume that the "marginal" value of one nuclear weapon is constant, whatever the size of the arsenal and the reductions made in it. This is a notion that China, France, and the United Kingdom would certainly challenge.

b) A second option would be a "two-tier" goal, such as a reduction to 300 nuclear weapons for the US and Russia; and 100 each for France, the UK, and China. But would such a clear-cut division between "big" and "small" nuclear powers be accepted by the three smaller ones, most especially China? And would the two larger ones accept to having a nuclear force not much larger than the other three?

c) A final option would be an identical fixed target or ceiling for each of the P-5 (e.g., 200 warheads). This, however, would imply that the United States and Russia 
would bear the brunt of the reductions, and this might not be compatible with the continued existence of a US extended deterrent strategy.

Preparatory discussions for such talks would in fact bring to light the differences in the nuclear policies of the P-5 and would prompt renewed discussions about the notion of "minimum deterrence" - a notion that means all things to all men. Let us suggest that there are at least two criteria for defining what a minimum deterrent force would be in the post-Cold War period. First, it excludes counterforce targeting, and thus dampens the possibility of arms races. Second, it is sustained by a force where the difference between the number of operationally available warheads, and the total number of warheads in the inventory, is as close as possible to zero.

For France and the UK to participate in "strategic" arms reduction talks, given that their definition of what a strategic weapon differs from that of the US-Russian definition makes no sense. Especially at a time when the very distinction between strategic and non-strategic weapons is increasingly being blurred and questioned? It is very likely that France and the UK would only agree to participate in Nuclear Arms Reduction Talks, and not in Strategic Arms Reduction Talks.

By the time such negotiations take place, it is possible that the European integration process has moved to the point that the 
French and British forces are "pooled," and virtually constitute one single force. How would this dimension be taken into account?

In the meantime, there are prospects for serious cooperation among the P-5, notably in the context of the NPT enhanced review process. This could lead to further arms control measures being adopted at least by the US, the UK, and France in the form of a formal multilateral detargeting regime. The multilateralization of existing agreements, such as the Intermediate Range Nuclear Forces Treaty (INF), or the ABM treaty might also be considered. Further unilateral steps may not be precluded in the field of transparency or alert levels. Also, France and the UK might consider taking the lead in setting up a coherent European "cooperative threat reduction" package along with their European Union partners. Such an effort would build on existing plans such as the French-German assistance program to Russia which, in particular, aims at burning Russian plutonium in MOX reactors for civilian consumption.

In all likelihood, de-alerting will continue to be opposed by both countries, who consider such a measure to be irrelevant to, or incompatible with, their deterrence postures. Neither of the two is reported to have a "launch-on-warning" policy. Neither has landbased missiles or any kind of forces on a "hair-trigger" alert status. The permanent presence at sea of operational nuclear forces is viewed by both as the key element of a credible deterrent force. Furthermore, both France and the UK do not ascribe to the arguments put forward to support de-alerting, which are judged to 
be unconvincing. The Russian early warning system is indeed degraded, and it is true that portions of Russia's arsenal seem to be under a launch-on-warning (LOW) posture. If confirmed, such a combination would certainly not be the best recipe for strategic stability.

However, the Russian command and control system appears to be robust, and the risk of accidental/unauthorized launch might be vastly exaggerated. The much touted 1995 incident, where the launch of a Norwegian rocket reportedly brought the hands of the Russian leadership close to the nuclear "button," revealed that the political control of nuclear weapons in Russia worked, in fact, rather well. However, steps should be taken to improve confidence and stability, such as a multilateral ballistic missile and space launch notification regime. In order to avoid incidents as the one reported above, such a regime would have to ensure that notifications are delivered at the right time and the right place.

There are two new challenges for the United Kingdom and France, which potentially creates "new roles" for their nuclear arsenals. The first stems from the proliferation of Weapons of Mass Destruction (WMD). What is the exact role that nuclear deterrence plays, and what is the scope of "vital interests" in regional contingencies? Both the United Kingdom and France have attempted to reconcile the objectives of nonproliferation through negative security assurances, and of security through deterrence policy. Both use prudent and carefully crafted public 
language to this effect and avoid creating the perception of a contradiction between the two objectives.

The second challenge stems from the evolution of the European integration process. The post-economic and monetary union in Europe, and the vital interests of European countries will be increasingly intertwined. What role can the UK and French deterrence play? France has been adamant in promoting some form of European deterrence to ensure the strategic autonomy of Europe. The UK is open to this strategy in principle, but warns that no European deterrence strategy should undermine the Atlantic Alliance.

These new roles are compatible with the notion of minimum deterrence because they do not entail any change in the fundamental criteria used to decide whether nuclear deterrence is relevant in a given situation. It would be more appropriate to speak of "new dimensions of traditional roles," than to use the traditional criteria of defining what "vital interests" are at stake.

In October 1995, French President, Jacques Chirac, and British Prime Minister, John Major, (during a bilateral summit meeting held in London) publicly acknowledged for the first time that they did not see any situations where the vital interests of one country could be threatened without the vital interests of the other being endangered as well. This milestone declaration paved the way for enhanced operational cooperation between the two 
European nuclear powers and for a broader European role for their forces.

Both France and the UK retain conservative nuclear policies in the sense that the core concepts and structures that underpin their nuclear arsenals remain intact. These European nuclear powers are not looking for new rationales for their nuclear deterrent posture, and in some respects, their role has in fact been reduced. Neither France nor the UK presents its nuclear arsenal as an instrument of prestige or grandeur anymore. In the post-Cold War world, these arsenals are simply instruments of international stability and political autonomy.

Notes

1. Views expressed here are solely the author's own. This paper expands on Bruno Tertrais, Nuclear Policies in Europe, Adelphi Paper No. 327 Institute for Strategic Studies (Oxford: Oxford University Press, 1999).

2. Prime Minister, Lionel Jospin, speech at the Institut des Hautes Etudes de Défense Nationale, Paris, 3 September 1998.

3. One should also point out the other gestures made by the two European nuclear powers to promote nuclear stability, such as providing assistance to Russia in detargeting, in the reprocessing of radioactive materials, and in providing storage containers. 
4. The UK Strategic Defence Review (London: The Stationary Office, 1998), p. 19, para. 70. 
Chapter 10

\title{
UK Nuclear Policies Within and After the START Process
}

\author{
George William Hopkinson
}

The Strategic Arms Reduction Treaty (START) process may have reached the end of the road. That is not to say that further reductions in nuclear weapons by the US and Russia will not be made in the coming years; but political turmoil in Russia, the quarrel over Kosovo, and the difficulty in the United States and Russia obtaining ratification of further formal treaties may indicate that other ways forward will have to be found. In itself that will not affect the United Kingdom's (UK's) posture, nor its preferred way forward on nuclear issues.

The START process is bilateral, and has had major significance as a means of engagement between Russia and the US, as well as for direct nuclear security benefits. There are some who argue that the time is now ripe for multilateral nuclear negotiations. For reasons explained below, this does not appear likely to be a fruitful course. Another option is for each country to determine its own posture and nuclear holdings, introducing, it might be hoped, a larger measure of transparency. And still a further possibility would be to concentrate international political effort on the substance of the major nuclear security issue at the beginning of the new century, and to assist Russia to reduce and rebalance its 
nuclear holdings in a safe manner. The means by which this might be effected would be subsidiary to the achievement of the objective and determined in the light of Russian reactions.

At the end of the Cold War it was less than easy for any western state to define a precise rationale for the possession of nuclear weapons. That is not to say that there was no rationale, nor that these weapons were without utility. It was simply that there were a number of rather imprecise risks instead of one major nuclear threat. A nuclear posture cannot, therefore, be tailored as a precise response, within an understood security framework. The case for the smaller nuclear arsenals is particularly difficult to elaborate. Nevertheless, nuclear weapons are a part of the global security situation, and moving to remove them in accordance with Article VI of the Nonproliferation Treaty (NPT) requires taking account of that fact.

Deterrence, as part of a general posture to safeguard against problems arising in Russia, requires very careful articulation when attempts are being made to establish friendly relations with that country, and much western effort is going into supporting the Russian armed forces rather than destroying them. Despite attempts to justify the possession of nuclear weapons, there are major problems with such an argument. There are obvious difficulties in saying that western powers need nuclear weapons because of a potential nuclear threat from Iraq: if this is why the UK needs them, why not Iran, which is much nearer? Even more 
difficult is the articulation of a precise deterrent posture against other Weapons of Mass Destruction (WMD).

At present, nuclear weapons are embedded in world security structures that their instant abolition, even if it were technically feasible, so far from adding to world security, would be destabilizing. Instant abolition is not, of course, possible, nor does it seem credible to set a fixed deadline for the abolition of these weapons. This is not to deny that abolition of nuclear weapons might, overall, be a good thing, or that the states concerned should strive, in all good faith, to make progress with their obligations under Article VI of the NPT. The point is that progress must take account of the world as it is, and how international relations are actually conducted, and disputes resolved.

One has only to consider the five NPT acknowledged Nuclear Weapons States and the three known other possessors to note that no early date for universal abolition could be agreed upon at this stage. In the former group, Russia is faced with real security problems and the collapse of its conventional forces. Even though few of Russia's problems are a result of nuclear weapons, neither the Russian military, nor politicians, nor the Russian public are likely to feel that they can forego their protection in the immediate future. The US for its part has obligations in Asia to which nuclear weapons make a real contribution: the Korean peninsula, and probably Japan, would not be more stable if US nuclear weapons ceased to exist in the short term. 
On the other hand, the nuclear possessors not recognized by the NPT are even more difficult. Israel will cling on to its nuclear weapons, pending a fundamental rearrangement of Middle Eastern security issues, which at present appears very distant. Pakistan would probably give up its nuclear capability if India would do the same.

Of all the nuclear powers, official and unofficial, the UK is probably the least attached to these weapons. It has no burning security problems for which they are the only answer, nor obligations that can be discharged only with possessing them. There is no pressing chauvinistic sentiment for the possession of such weapons. Its nuclear holdings are very much smaller than the US and Russian ones, and significantly smaller even than the French and Chinese ones. (US and Russian warheads are numbered in tens of thousands. START II accountable warhead limits, i.e., strategic systems only are 6,000 for each side. French numbers are around 500 in total, Chinese probably about the same). If the UK had not just acquired its present sophisticated strategic systems, it would unlikely have a great desire to invest in them.

On the other hand, the Government, the political classes and the country as a whole, feel quite comfortable with nuclear weapons. There is no significant body of opinion in the UK pressing for nuclear disarmament, nor even for such measures as a no-first-use agreement. Past experience has shown that nuclear 
disarmament issues are election losers in the UK although that relates mainly to the Cold War period. Therefore, the UK's decisions on nuclear weapons are likely to be influenced by wider political considerations. These do not include the view that such weapons are a prerequisite for a permanent seat on the UN Security Council. They do, however, include the view that if a country is to be taken seriously by other Nuclear Weapons States in discussions of these weapons, its negotiators and commentators must have a thorough understanding of their capabilities and the security role which they can play.

In its 1998 Strategic Defense Review (SDR), the UK made unequivocally clear its commitment to full implementation of the NPT, ${ }^{1}$ including Article VI, but also expressed its view that at present it needs to retain nuclear weapons. Article VI, of course, sets nuclear disarmament in the context of general and complete disarmament. This does not mean that the last rifle and the last round of ammunition must be given up before there is progress on nuclear disarmament. However, consideration must be given to the overall national security situation, and the roles that nuclear weapons play in them at any stage. The question for all who wish to see the complete implementation of the NPT is how to move from where we are today to circumstances in which all nuclear weapons are prudently laid aside, and in which there are appropriate arrangements for dealing with any attempts at cheating, break out, or blackmail. In such a context, transparency and 
verification will have a role to play. In addition, unilateral or formal agreements will help pave the way toward the levels of confidence, which complete abolition will one day require.

As an early participant in multilateral negotiations on nuclear matters, the UK has thus far not engaged in any negotiations on limits on either warheads or delivery systems. It has not opposed the concept, and indeed has welcomed and encouraged US-Soviet (Russian) negotiations, but successive UK Governments have taken the view that their policy was to maintain a minimum deterrent force and that there was no scope for negotiated reductions. They have also pointed to the disparities in scale of nuclear holdings, acknowledging that as the major powers, nuclear arsenals were substantially reduced, there would come a stage at which the UK would join such negotiations.

This reflects the position also of the present Blair Government. In brief, the UK will consider joining the negotiations when the major arsenals of the US and Russia have been reduced to a level not out of scale with the UK's holdings. Given the size of the Russian and US arsenals in a post-START II or START II era, or in any follow-on agreements, the UK's joining such multilateral nuclear weapons negotiations appears very unlikely. In any case, quite apart from the minimum deterrent argument, until substantial progress had been made with the actual reduction of the US and Russian arsenals, any positive affect on global security arising from the reduction in the UK stockpile 
would be very limited, while the downside of such reduction could be disproportionately greater.

The SDR introduced greater transparency regarding the UK's warhead numbers and fissile material holdings. On the former, the UK undertakes to hold less than 200 warheads, strategic and sub-strategic. For all submarine based warheads, only 48 will be on patrol at any one time. ${ }^{2}$ This constitutes the latest scenario on a minimum deterrent force. Constituting such a small number of warheads, it is difficult to see the scope for further nearterm reductions, whether unilateral or negotiated. This being the case, it would be very difficult for the UK to participate in multilateral negotiations.

Moreover, having just completed the acquisition of the Trident system for both strategic and sub-strategic levels, there is relatively little resource incentive for the UK to seek reductions. The savings to be made by nuclear cuts or even total disarmament would be quite modest at this stage. When the time comes for replacing current systems (perhaps in thirty years), this view may change. The time for change may well coincide with the earliest date at which substantial Russian (and US) reductions are realistically implemented. For the foreseeable future, however, the UK is unlikely to join in negotiations on numbers of weapons or their delivery systems.

Of course this does not rule out either further unilateral changes in weapon numbers or participation in negotiations on 
other nuclear issues. On the former, substantial reductions in warhead numbers has been made over the years, although the lack of transparency has hindered these proposals. On the latter, there are the test ban and fissile cut-off measures to pursue, as well as, matters such as de-alerting, or reducing the frequency of submarine patrols, which are appropriate actions that can be taken unilaterally.

The ultimate reason for engaging in arms control negotiations is to enhance security. Reductions in arsenals should lessen the likelihood of conflict; while arms control may be considered the vehicle in reducing the damage caused by war, should it occur. At any rate the arms control process might reduce the resources that are necessary for preparing against the possibility of war. At the very least, arms control may be a useful lubricant in attaining wider objectives. For example, the Conventional Forces in Europe Treaty (CFE) was able to transform European security at the end of the Soviet era and the Cold War.

The most pressing security issue in the nuclear field today is the significant reduction in a safe and orderly manner, and with the effective disposal of the fissile materials of the Russian arsenal, including, in particular, the tactical systems. This is not an attempt to reduce Russian security, or to deprive Moscow of those systems that it requires as a safeguard in this difficult world. It is, however, in Russia's interest, as much as anyone else's, that weapons be properly disposed of when no longer needed and cannot be maintained. 
No one really knows the numbers of Russian tactical nuclear weapons. The figure of over 20,000 has been suggested. Any objective evaluation would set the number of required weapons at no more than 500 . The total of strategic warheads in Moscow's stockpile might be of the same order or a bit greater. It would be in everyone's interest for Russia to minimize its stockpile, whether this came about as a result of negotiation or not. It would be beneficial to the West, excluding Europe, to provide substantial assistance toward this end. This is a much more urgent matter, and is more likely to produce real security gains than if the UK engaged in multilateral negotiations as to whether its total number of nuclear weapons should be reduced from 200 to 185 .

Currently, the United Kingdom is committed to two things in the defense area: a continuing close relationship with the United States; and construction, in particular with France, of a more effective European Defense Capability. The latter defense arrangement will not extend for the near future to nuclear matters, but general Anglo-French relations. However, if this relationship proves fruitful, it could also affect nuclear arms control and nonproliferation issues. Experience has shown that the two countries are likely to maintain similar general policies in nuclear issues, despite past assertions of doctrinal differences. The UK will view its advantages in maintaining, so far as possible, joint AngloFrench approach as to nuclear arms control, and to withstand the pressures that will come from the Non-Nuclear Weapons States 
over progress on Article VI of the NPT. In strategic and in security terms it is difficult to discern any differences in the vital interests of the two countries. Therefore, given the real desire to consolidate a Common Foreign and Security Policy in the European Union, and for European countries to work together wherever possible in international fora, it can be expected that the same approach will be forthcoming in nuclear issues from the UK and France.

The arguments that were put forth against the UK's engaging in multilateral negotiations apply equally to France. There is no doubt that French public opinion is certainly more committed to nuclear weapons than that of the UK. Moreover, any reasonable judgement would conclude that the French government, faced with other major defense issues on NATO or in creating a European Defense Identity, would not be willing to risk domestic political complications by moving too swiftly to negotiated changes in its nuclear posture. Furthermore, if France declined to negotiate changes in its nuclear arsenal, it would be most unlikely if any UK government would willingly make changes in its nuclear holdings. Nor would the UK at all likely to relinquish its nuclear status while France remained a nuclear power.

Recently the UK took steps to further transparency in regards to fissile materials, ${ }^{3}$ and London is willing to work toward multilateral negotiations on a cut-off in fissile material production. The Government sees this as an essential first step toward the 
global elimination of nuclear weapons. It is in this area that the UK is most likely to make its next political demonstration, that it is serious in its commitment to the elimination of nuclear weapons.

In addition, the UK will seek to ensure that India and Pakistan join the Comprehensive Test Ban Treaty (CTBT). In fact, if they do not sign this Treaty, it will not enter into force. In the case of the Fissile Material Cut-off Treaty (FMCT), its actual direct security effects would probably be very limited. The issues, however, are political, and in particular the weight attached to progress in the context of the forthcoming NPT Review Conferences. Progress must be demonstrated if calls for disarmament are to be averted.

The strategy of no-first-use, which was raised in the review of NATO's Strategic Concept, is an unlikely scenario for the UK. Nor is there much scope for enhanced security assurances. In fact, with the spread of WMD, nuclear retaliation is diminished, and does not add to the UK's security needs, and in essence, makes the case for the retention of nuclear weapons even more difficult.

Assuming that India and Pakistan do adhere to the Comprehensive Test Ban Treaty in the near future and progress is made on FMCT, perhaps then in the long term, the UK must decide whether to make more unilateral reductions in its nuclear arsenal or join in negotiations. How all this plays out will depend on the positions of Nuclear Weapons States and how further reduction between Russia and the US are implemented. Whatever 
the strict logic may be to minimum deterrence, if the general security climate has improved, and if progress has been really significant in the reduction in the major nuclear arsenals, the UK and France will find it most difficult not to reduce its arsenals. The time for such a decision will not be early. The possibility of major reductions in the nuclear assets of the UK will coincide, most likely with the end of Trident's life, some thirty years hence. The factors that will affect this decision are improvements in how the international community handles crises and in the diminution in the importance of nuclear weapons in the international security structure.

Apart from the question of whether there should be a successor system to the Trident, the UK, before that, will be faced with two connected sets of questions regarding its nuclear posture: these issues will be concerned with Europe on security and the developments in the Trans-Atlantic relationship. By 2020, China may be the world's biggest economy, the European Union second, and the US third. In such a situation, will the US see itself committed to European security; and if so, on what terms, and will the commitment involve a nuclear dimension? Is it conceivable that in a world with a nuclear armed Russia in close proximity to Europe, China, and US, the Europeans would forego having nuclear assets of their own? The answer is that it is conceivable, but not likely, especially if major international instabilities exist, some involving possible nuclear powers in the Middle East. Even 
if the US commitment remains in tact, it is conceivable that the Europeans will feel a necessity to have some assurances of their own. Given the increasing signs of strain between Europe and the United States over a host of international issues, some Europeans might conclude that whatever words are emanating from Washington that there was no real US commitment, and they must proceed in their self interests

At present, there are two European nuclear powers and for reasons of internal politics, as well as treaty obligations, that number is unlikely to increase. It has, at times, been suggested that without the US nuclear guarantee, Germany could seek such a capability. Technically this is a possibility, but it seems to fly in the face of both internal and external political realities. The questions that must be considered is how would the two existing European nuclear powers manage their assets vis-à-vis each other and the European Union.

Given the extreme nature of nuclear weapons, full coordination of deployment and use are difficult tasks to attain. These systems are truly assets of last resort. They are to be used when a state's vital interests are threatened. To use such weapons calls for an extraordinary degree of engagement; hence, the doubts Europeans may have over the actual commitment of the US. Therefore, a fused Anglo-French force is not likely for many years to come. 
Even less likely would be a formal endowment of the European Union with a nuclear capability. This would probably run foul of the NPT regime. In practice, on any dimension, it will be a long time before the European Union is capable of producing coherent lines of strategy and policy for conventional wars. It is less likely on nuclear matters.

In order for Europe to attain a nuclear posture in the first quarter of the next century, it will require the development of a European defense identity along with intense diplomatic activity by the major actors on the European scene. Therefore, both France's and the UK's nuclear assets, doctrines and policies, will, out of necessity, be framed to take into account the needs of a European Defense identity and diplomatic initiatives.

If the Germans and others have any doubts about the US nuclear commitment, they will have even stronger concerns regarding the more amorphous UK-French arrangements, which certainly are not a commitment. These doubts may persist, but it is better to have a "partial loaf of bread" then none at all. Second, and more concretely, the UK-France nuclear commitment should take place in a context of an ever closer, and deepening European Union. Over time, confidence will develop that the states of Europe have whatever they need in the way of nuclear protection, direct and indirect, and this should grow. Furthermore, if tension and strife in the international community is ameliorating, and moves toward total or partial disarmament are taking place, then 
the need for nuclear arms and protective umbrellas diminishes. This then is a good foundation for French and British nuclear deterrence to enter into the new century.

Meanwhile, UK policies will be to pursue the Fissile Materials Cut-off Treaty; to assist as far as possible in ensuring that the conditions necessary for the implementation of the CTBT are met; and to respond in a positive manner to the real concerns expressed in such fora as the NPT Review Conference. Although not a party to the ABM Treaty, the UK regards this treaty of prime importance in contributing to stability and security, and will assist to ensure that it is not undermined. The loss or abrogation of this treaty could in principle undermine the effectiveness of the UK's own deterrence strategy. Of much more concern is the possible destabilizing effect of Russia which can afford neither major modernization of its offensive capabilities, nor the deployment of effective defensive ones.

There are four points to be made in terms of the international community moving toward total disarmament:

- Nuclear weapons are a part of the global security structures and cannot be dealt with in isolation;

- The western states have made enormous reductions in nuclear arsenals and others need to respond to Article VI of the NPT; 
- The most urgent need is to deal safely with the excesses of the Russian arsenal, in a way as to enhance Russian security; and,

- China needs to be much more forthcoming on its nuclear holdings, and plans. It should at least match the UK/French disclosures.

From a UK perspective, the ratification of START II and a subsequent move to START III are desirable, but they are desirable for the underlying motives, not for the technicalities of the treaties or proposed treaties themselves. The most important results are to improve the overall international security situation. Diminishing the salience of nuclear weapons and downsizing excessive stockpiles in a prudent manner, thus eliminating the possible risks of proliferation. This is the immediate objective.

Russia's problems are economic and political and are quite obvious, and they impede the successful implementation of the START process. If those difficulties prevent that implementation of the START process, then the substance of what START will attain will require new and more innovative solutions. There is no intrinsic reason why Russia cannot do what the UK, France, and presumably China will do, and that is to decide on her security needs and fix her force structure accordingly, at levels substantially below current nuclear holdings. If this were done, then the absence of a START II or III Treaty need not preclude Western assistance in safely dismantling Russia's nuclear weapons and fissile 
materials. Everyone's security would be improved, particularly with the elimination of tactical nuclear weapons.

As far as its own nuclear force structures are concerned, the UK will no doubt keep its needs under review. It will intensify its dialogue with France and develop the non-nuclear dimensions to the European Defense Identity. At some stage, perhaps fifteen years from now, the UK will need to consider whether improvements in the general international security situation requires the replacement for Trident system, some fifteen years ahead of its time. If all has gone well, the UK may be able to leave the nuclear club; if not, then full implementation of Article VI, though still being pursued in good faith, will have to wait.

\section{Notes}

1. The Strategic Defense Review (London: The Stationery Office, 1998). Supporting Essays Paragraph 22, pp. 5-9.

2. Ibid. Paragraph 9, pp. 5-2.

3. Ibid. Paragraph 26, pp. 5-10. 
. 


\title{
The Ballistic Missile Defense Challenge: Consequences of the National Missile Defense for Strategic Arms Control Regime
}

\author{
Sergey $M$. Rogov
}

The Clinton Administration's decision on a National Missile Defense can become the turning point in the development of the military-strategic conditions for international relations for the beginning of the 21st century.

For several decades, since the conclusion of the 1972 ABM Treaty, strategic stability in the nuclear sphere has been based on a mutual nuclear deterrence model providing a "balance of fear" that guaranteed the sides' mutual destruction in case of nuclear war.

\section{Strategic and tactical ballistic missile defense (BMD)}

To acknowledge the vulnerability of US territory has proved very difficult for Washington, which has lived for almost two centuries in the absence of such an immediate threat. The acceptance of strategic parity with the Soviet Union was imposed on the United States. The strange logic of mutual nuclear deterrence contradicts deep-rooted notions of America's "exclusiveness." It was in 1993 when President Reagan proclaimed the intent to ensure protection of US territory against a 
nuclear strike. The Strategic Defense Initiative (SDI; also known as "Star Wars") envisaged creation of a space missile defense, thereby providing the United States with "absolute security."

In a historical retrospective, "Star Wars" was seen as a grandiose psychological/propaganda bluff that was supposed to persuade the Soviet leaders that it was impossible for a country, exhausted by the Cold War, to withstand a new, costly, and destructive arms race with the United States. SDI was a political act for which there was no military-technical verification. The United States did not have, nor does it have, to build BMD systems capable of executing this mission effectively. After spending over $\$ 60$ billion of research and development monies (R\&D) for these purposes, the Pentagon has yet to create either strategic nor a tactical missile defense, some 15 years after SDI was proclaimed.

Unfortunately, to this day some in Moscow speak of "Star Wars" as if it is something real, without having paid attention to the actual US military programs. In contrast to its Republican predecessors, the Clinton Administration rejected SDI. In the early 1990 's, America's R\&D programs were reoriented toward tactical missile defense systems, inasmuch as the Persian Gulf war demonstrated that the United States possessed no reliable means to protect its troops against short-range and medium-range missiles which appeared in the inventory of a large number of countries. Approximately 80 percent of all the Clinton Administration expenditures are connected with developing theater missile 
defense systems.

This change reflects a substantial evolution of US military strategy since the end of the Cold War. It is not by chance that special importance in recent years has been attached to the distinction being made between strategic and tactical missile defenses at the Russian-American arms control talks. Both sides admit that a tactical missile defense does not contradict the 1972 ABM Treaty, but the technical parameters of the "demarcation" have generated sharp disputes. Finally, President Yeltsin conceded at the Helsinki Summit in March 1997, by agreeing to the proposed US parameters, which a number of experts believe overstated the facts for a tactical missile defense. On the whole, however, the 1997 Protocol, which has not been ratified until this day, either by Russia or the United States, does not affect the fundamentals of the ABM Treaty, nor does it undermine the model of mutual nuclear deterrence.

However, today's Russian Federation is not the Soviet Union. Russia's Gross Domestic Product (GDP) is 15-20 times smaller to that of the US GDP. By American estimates, Russia's 1997 military budget was seven times smaller than in 1990 (the US budget was reduced approximately by 35-40 percent). Clinton has proposed to increase the Pentagon budget by $\$ 110$ billion in the next fiscal year. In 1999, the Russian Ministry of Defense is being allocated only R93 billion rubles. This amount is $\$ 4$ billion according to the exchange rate, and $\$ 1-1.5$ billion according to its 
purchasing power. Moscow cannot take part in a new arms race with Washington, and the United States realizes this full well.

\section{US internal political struggle on $\mathbf{B M D}$ issues}

The question is being asked more often in US political circles: Can military-strategic parity be maintained between the United States and Russia if there exists no parity in the economic, political, and all other spheres of life? Washington is making a mistake when it overlooks such debates.

Unfortunately, Russia rarely takes into account how events are developing in the US domestic political scene, what the alignment of forces is in the US establishment, and where the Washington policy vectors are pointed. Thus, the then Soviet Union was carried away with emotion regarding the liberal Jimmy Carter in the late 1970 's. Moscow realized its lost opportunities only after the ultraconservative Reagan came into power. Conversely, Moscow believed too seriously in "Star Wars" and the other threats by the Reagan Administration in the 1980's, so that the Soviet Union did not notice that Reagan had frightened Americans themselves, and that the vector of US political life had swung in the opposite direction. It was in 1992 that the American electorate rejected George Bush, the winner in the Cold War, and gave preference to a little-known moderate liberal Bill Clinton, who placed emphasis on solving domestic problems. It was with the election of Clinton that serious reductions in the Pentagon 
budget were undertaken and SDI was buried.

However, a new conservative wave arose in 1994. In their "Contract with America" the Republican members of Congress demanded an expansion of NATO and the abrogation of the ABM Treaty. They attempted to change US policy priorities. In recent years, however, providing for a national (territorial) defense has become an idie fixe for the Republican Party, which historically has always gravitated to the concept of "Fortress-America."

In 1995, a Republican Congress passed the Defense of America Act, which required the rapid deployment of a strategic missile defense. Clinton did not implement it, but Congress doubled the R\&D expenditures for a National Missile Defense. In the proposal by Republican Senator William Cohen, who is regarded as one of the most moderate figures in the Republican Party, an amendment was passed that required the preparation of a territorial missile defense with interceptor missiles to be deployed at several bases. This is in contradiction of the ABM Treaty. In 1996, Republican presidential candidate, Robert Dole, made the $\mathrm{BMD}$ one of the central points of his campaign, but the voters paid little attention. Bill Clinton defeated his rival easily, again because of economic and not foreign policy issues. Nevertheless, the Administration announced the " $3+3$ " plan, which envisaged bringing R\&D on National Missile Defense to such a level in three years that it would permit deploying the system in another three years. 
Subsequently, the Republican Congress again attempted to pass the "Missile Defense Act," but to no avail. The Democratic minority in the Senate was able to block this vote. Today Clinton is attempting to deprive the Republicans of the opportunity to politicize in the upcoming 2000 elections on America's "lack of protection" against a missile-nuclear attack. The Clinton Administration speaks today only about a "limited" National Missile Defense system. The decision on deploying it is to be made next year, and deployment is now being postponed until 2005 (two years later than previously planned). The overall funding of National Missile Defense will be $\$ 10.5$ billion which is approximately 0.6 percent of the total Pentagon budget.

\section{Which way will America go?}

In case of a Republican presidential victory in 2000, the expectations are of a serious hardening of US policy, above all in the military-strategic sphere. If Reagan's spiritual heirs control both the White House and the US Congress at the beginning of the next decade, then a US attempt to overturn the strategic balance in all its components appears inevitable.

To begin with, the Republicans are attempting to increase military expenditures at the level of at least four percent of GDP. This level of funding will permit the elimination of the present twofold gap in both the procurement of fifth generation conventional arms, but will also allow for the increase, several 
times over, the expenditure for strategic systems, which today are only about 12 percent of the US defense budget.

Second, if the Republicans accede to power, decisions on creating a new generation of US strategic offensive systems may be made in the next decade. It is common knowledge that in the case of the ratification of the START II Treaty, the newest US Peacekeeper (MX) MIRV'd ICBMs will be eliminated and that the United States will be left with only Minuteman III missiles, which already have been continuously through the years modernized. Many Republican Party experts believe that the United States should not halt developing and producing new strategic offensive arms after completing its procurement of B-2 bombers and D-5 SLBMs. If a Republican Administration comes into power in 2000 , it is assured that it will make the decision to develop a new MIRV ICBM, if START II does not enter into force.

Additionally, a Republican Administration will not attempt to conclude a START III Treaty, assuming that unilateral reductions by Russia are inevitable. This will permit the United States to have at least a threefold superiority in the number of deployed strategic nuclear warheads by the end of the next decade. The so-called upload potential, which worries many of the START II opponents, will not be stored but will be deployed on combatready $\mathrm{MX}$ and D-5 missiles and on heavy bombers. Over 5,000 counterforce warheads will be deployed on the US's ICBMs and SLBMs, while the number of Russian ICBMs and SLBMs will not 
exceed 700-800. This creates the temptation of a disarming first strike, although the United States does not have a strategic missile defense.

Furthermore, the Republicans have already refused to ratify the 1997 Memorandum of Mutual Understanding, which recognizes Russia, Belorussia, Ukraine, and Kazakhstan as successor states to the USSR in the ABM Treaty. This enables Russia to take advantage of early warning system radars on the territory of these former Soviet Republics. According to the ABM Treaty, the USSR (Russian Federation) and United States must not have missile attack warning radar systems outside their national territory except for two US radars in Greenland and Great Britain. The Republican Party interprets the 1997 protocol as an acknowledgment that the Russian Federation is not a successor to the Soviet Union, and therefore, concludes that the ABM Treaty is invalid since one of the parties no longer exists. Thus, there is an extremely high likelihood that if the Republicans came to power, they will publicly condemn the ABM Treaty.

Finally, other agreements already in force, including the START I Treaty may also prove to be threatened. The Preamble to this Treaty rigidly links fulfillment of its provisions with compliance to the ABM Treaty. The US withdrawal from the ABM Treaty enables Russia to refuse to comply with START I. On the other hand, the Republicans' view that Moscow cannot be considered a successor to the ABM Treaty suggests that this 
reasoning can also be extended to the START I Treaty.

Evidently, it was not by chance that the Clinton Administration announced that deploying the BMD would be made in the summer of 2000 , when the Democratic Convention officially nominates a candidate for President and adopts an election platform. There are grounds to assume that present US leaders are attempting to force discussions to take place to modify the ABM Treaty without completion of tests on the BMD. Therefore, it is doubtful that in the summer of next year Clinton would take this unprecedented step to unilaterally denounce this essential arms control agreement.

In the author's view, the focus of Clinton's efforts will continue to be in establishing a theater missile defense. It appears that the United States cannot match Russia's missile developments such as the S-300V and S-400. Specialists estimate that 14 out of 18 tests of tactical missile defense systems being developed by the Pentagon were unsuccessful.

At the same time, the threat assessment changed last year. Previously, the Central Intelligence Agency (CIA) believed that potential US enemies would require at least 15 years to create ICBM capabilities of hitting US territory. However, in 1998 India, Pakistan, and Iran demonstrated new medium-range missile systems. In July 1998, the commission headed by the former Secretary of Defense, Donald Rumsfield, which included a number of prominent "Star Wars" critics, unexpectedly announced that 
potential US enemies soon might possibly develop long-range missiles. A few weeks after this pronouncement, North Korea conducted tests of a missile that the United States estimates can reach some areas of its territories, in particular, Alaska and Hawaii.

Under these conditions, in January 1999, the Clinton Administration announced a new approach to $\mathrm{BMD}$, and accelerated deployment of tactical missile defenses, albeit, the upper tier of this system is to be placed into service by 2007 . Certain other systems, including Aegis on Navy ships and a chemical laser on a Boeing-747, will possibly be deployed earlier. Cooperation most likely will be expanded with Israel, which successfully tested the Arrow interceptor missile, as well as with Germany and Japan.

Overall, however, the present degree or progress that the US is making in theater missile defense makes deployment likely only toward the end of the next decade. Technical characteristics of a future US tactical missile defense will limit its effect on the Russian-American strategic balance.

On the other hand, US deployment of a "limited" National Missile Defense can present an immediate threat to the model of mutual nuclear deterrence. There are different options possible for a US approach to the ABM Treaty. The first option may affect the 1974 Protocol and be limited to a transfer of the interceptor missile bases from Grand Forks in North Dakota to Alaska, where construction of a new radar is planned. The number of interceptors 
(100) may remain unchanged. This essentially will leave a considerable part of the US territory without protection, which in essence preserves the existing strategic balance.

In a second option, the United States will propose more serious changes to the Protocol affecting both the number of interceptors as well as the number of deployment areas, leading to a "thin" BMD system covering all US territory. By creating such a system, this will enable the United States to enlarge its holdings to several thousand interceptors by 2010's.

A third option suggests that the ABM Treaty may undergo revision and any kind of restrictions on the beginning deployment of a "thick" strategic missile defense system toward the end of the next decade will essentially be removed. However, such a system cannot be created any earlier than 2010 .

Finally, after the year 2000 the United States will announce a unilateral abrogation of the $\mathrm{ABM}$ Treaty and will begin deploying very quickly a National Missile Defense. However, such a system will hardly be effective earlier than in 10-15 years.

The first and second suggested options of a "limited" National Missile Defense are likely if the White House continues to be controlled by the Democratic Party in the next decade, and the third and fourth options if the Republican Party wins the elections.

As Clinton's critics in the Republican Party noted, the President has essentially rejected the " $3+3$ " formula which was 
announced in 1996 that envisages the deployment of a National Missile Defense in three years followed by three years of $R \& D$. Now the Administration has shifted deployment dates from 2003 to 2005. Even this date appears doubtful, inasmuch as tests of the booster, engine and warhead of the interceptor missile are now planned for 2001-2003. Hitches may also occur with the deployment of a group of low-orbiting satellites, which are to track the mid range flights of enemy missiles.

It should be emphasized that the architecture of missile defenses of the US's territory does not envisage deployment of space echelon weapons. These Reagan fantasies were forgotten long ago. True, the Republicans are attempting to conduct a demonstration test of a space laser in the year 2005, for which they are allocating money over and above the Pentagon's requests. Secretary of Defense Cohen has stated that the National Missile Defense must provide protection for all 50 states, and that the United States can take advantage of its right to withdraw from the ABM Treaty if Russia does not agree to the Treaties modification. Such statements cannot help but raise concerns. Both the White House and State Department hastened to correct the Pentagon chief, but this action does not provide any guarantee against a future hardening of the US position. The present US leadership is not striving to force the collapse of the ABM Treaty, which has provided the framework for Strategic stability over decades, but it 
is an attempt to gain substantial advantages within the framework of this Treaty.

The situation may conceivably change if Russia and the United States again enter into a protracted confrontation. The fact is that even a "limited" National Missile Defense contradicts the Treaty, which prohibits creating any territorial ABM defense (Article I) and the deployment of space-based sensors (Article V).

\section{How can Moscow respond?}

There is a need to assess Russian capabilities, and for Moscow to analyze its options for a diplomatic solution to this imminent problem. This can be done by identifying possible geopolitical maneuvers by calculating scenarios of an asymmetric response utilizing military-technical means.

Let us begin with the latter. A persuasive demonstration by the Russian Federation of its capabilities to penetrate the US BMD, in a retaliatory strike, is the sole guarantee for preserving strategic stability. Russia's capability to deliver 400-500 warheads to targets is fully sufficient to deter a nuclear war with any enemy. Considering that a counterforce strike against the United States is entirely senseless, an acknowledgment of countervalue targeting further lowers this bar even more (in the Cold War years, US experts figured that a nuclear strike against 200 cities would destroy the United States as a civilized state). However, the vulnerability of Russia's strategic forces to a preemptive strike and 
the deployment of a strategic missile defense will raise this ceiling several fold.

Considering the inevitable reductions in the composition of Russia's strategic nuclear forces in the next decade, it appears extraordinarily important for Moscow to improve the battle management system, and above all to create a unified operational command of its strategic nuclear forces. Penetrating the US's BMD will be very difficult without this. The refusal to ratify START II certainly weakens Russia's negotiating positions in future discussions. This deprives Moscow of an opportunity to rigidly link ABM Treaty compliance with elimination of MMRV'd ICBMs.

Nevertheless, the threat of abrogating the ABM Treaty can be countered by the threat to comply with the START I Treaty, which contains a corresponding linkage. At any rate, the 1997 Protocol on "deactivating" missiles and their destruction under the START I Treaty stated by 1 January 2003, proves to be doubtful if neither Moscow nor Washington ratify START I.

It is true that without the help of the Ukraine it will be quite difficult to extend the service life of the missiles. The recent reluctance, however, on the part of the Ukraine to ratify the Treaty on Friendship hardly permits Moscow to count on close RussianUkrainian cooperation. Furthermore, the deployment of a strategic missile defense begins in the latter half of the next decade, when Russia's heavy missiles will be removed from service. Thus, the 
United States will have additional incentives to deploy a "thick" $\mathrm{BMD}$. Under these conditions the question that faces Russia's strategic planners is the feasibility to equip the new Russian mobile ICBMs with multiple re-entry vehicles capable of maneuvering, and equipping these with anti-missile defense penaids, including decoy warheads and adaptive means of electronic counter measures (ECM).

In general, this entire set of "cheap" countermeasures was well researched some 15 years ago. Another proposal that requires some attention is to deploy long-range, nuclear-armed strategic cruise missiles capable of penetrating the US's BMD.

The Russian Federation, obviously, is incapable of offering a symmetric response to the US challenge. Russia is hardly in an economic position to create a territorial missile defense, although a ballistic missile defense of individual areas is possible in principle. Protecting some part of its strategic offensive forces, against a preemptive first strike, can probably be the goal of such a ballistic missile defense. In addition, forms of passive protection, such as maneuverability, have not lost their importance. The mobility of ground-based and rail-based ICBMs, combat patrolling by missile submarines and high combat readiness of strategic bombers, will enable Russia to increase the power of its retaliatory strike, and consequently, the burden on the enemy's BMD.

Nevertheless, an arms race response, even if asymmetric, is not the best strategy for today's Russia. There is no question that a 
collapse of the present strategic arms control regime is not in Russia's interests. Moscow will have great difficulty to come out of its present, very serious economic crisis, therefore, Russia does not need a new arms race. Moscow should not assume responsibility for the collapse of the strategic arms control regime, and to hasten to break existing treaty obligations. Of course, the US's inclination for unilateral actions is too great. Still, for now Washington intends to attempt to solve the BMD problem by negotiations, and this means, inevitably, compromises on the part of both sides.

It is time to begin preparing for the difficult and serious discussions, which may exceed the bounds of updating the ABM Treaty. Overall, these discussions may lead to a reinterpretation of the entire system of measures that ensure military-strategic stability.

In Russia's view, there are real opportunities, today, to preserve the regime of limiting an $\mathrm{ABM}$ defense, at least until the end of the next decade. There can be no doubt that the United States will attempt to deploy a strategic missile defense base in Alaska. It is a matter of Alaska's proximity to North Korea.

The second option is if the United States demands two bases with 200 interceptors. This will be a worse case scenario. In this instance, a build-up of what is really a National Missile Defense (NMD) system will be possible making it "denser". Building a denser NMD will take about five to ten years. 
Future discussions between Russia and the United States may require new, nonstandard decisions. If both parties begin to revise this regime which restricts strategic defensive systems, then it is impossible for previous provisions that pertain to strategic offensive arms control to also be reassessed.

For example, if the United States attempts to go outside the ABM Treaty, then Russia can fully request permission to deploy MIRVs on Topol-M missiles. Thus, MIRVs will be prohibited only on silo-based missiles, white mobile MURV'd ICBMs and MIRV'd SLBMs are permissible. Another option may require establishing an overall ceiling for all types of strategic offensive and defensive missiles, (i.e., ICBMs, SLBMs, and interceptor missiles). For example, each side will have no more than 500 or 600 missiles, and any increase in deployment of interceptors must be accompanied by the simultaneous destruction of the same number of ICBMs or SLBMs.

New proposals on arms limitation are possible, but in addition, cooperation in the strategic sphere is welcomed. At one time Reagan spoke of a joint Soviet-American "space shield," but no one took this gibberish seriously. Later Bush and Yeltsin spoke about cooperation in creating a "Global Defense System," but this proposal also consisted of empty words. Is it possible to return to these ideas now?

This will be difficult to do, inasmuch as everyone realizes that a strategic missile defense makes sense only if it is directed 
against Russia. But there are possibilities for the exchange of information on missile launches.

Furthermore, cooperation on tactical missile defense in certain theaters is of even greater importance. It is especially important in the Far East, where not only will a theater BMD be deployed in the next decade (in Japan and South Korea), but also a strategic missile defense in Alaska. It is not difficult to imagine that such American reaction to a North Korean threat may provoke a reaction both on the part of Russia as well as China. The fact is that such a combination is fraught with totally undermining the Chinese nuclear deterrence potential.

Perhaps it makes sense to think about a multilateral BMD in the Far East that will involve not only of the United States and its allies, but also Russia and China. This is conceivable since the Russian systems are capable of intercepting short-range and medium-range missiles.

Drawing China into these negotiations is especially important. The fact is that Beijing faces a challenge from the United States, but also from India. It cannot be precluded that the Chinese leadership will follow the path of building up their nuclear forces by initiating a massive deployment of MTRV'd ICBMs or of medium-range missiles. China's new economic capabilities permit doing both. Is Russia and the US interested in such a development?

A different version of coordination is required in the North 
Atlantic. The deployment of a tactical missile defense in this region is absolutely unacceptable to Russia. What guarantees can the US and its NATO allies provide when considering the high mobility of air-based and sea-based anti-missile weapons in this theater? Is it possible to prevent the Norwegian-American radar from being built in northern Norway, and if it is, from turning into a contentions issue? Moscow and Washington might use this radar to exchange information in real-time.

Moreover, the deployment in the future of a US strategic missile defense affects the interests not only of Russia, but also of certain other nuclear powers. China has already been mentioned, and it has no intention to neutralize its nuclear potential. This scenario also does not generate enthusiasm in India. France always has regarded BMD apprehensively, and continues to do so. Therefore, it is impossible to prevent the BMD from turning into one of the key issues in arms control negotiations. No doubt new mechanisms for maintaining stability will need to be discovered that will conform to the new balance of forces in the international arena. The creation of such a new system will be lengthy and complicated. It will be much more difficult to maintain equilibrium in a multipolar world than it was in a bipolar world.

One should not panic and conclude that strategic stability already has been irrevocably undermined once and for all. The Russia Federation must define its interests clearly. On the one hand, develop systems that are technically feasible and not 
economically burdensome; while on the other hand, develop wellconceived, echeloned tactics that will be the foundation for the extremely complicated upcoming negotiations. 


\section{Chapter 12}

\section{Jump-START: Retaking the Initiative to Reduce \\ Post-Cold War Nuclear Dangers}

Jesse James

The Berlin Wall fell a decade ago. The Cold War ended approximately nine years ago. The old nuclear standoff between the United States and the Soviet Union has been transformed. Nevertheless, the nuclear arsenals and attitudes of the United States and Russia still reflect Cold War postures. Worse still, terrifying new nuclear dangers have emerged as these postures are maintained in the face of Russia's on-going economic collapse.

If the notion of either side launching a deliberate, massive nuclear attack against the other is wildly unrealistic, why have the nuclear doctrines of the United States and Russia not changed? Why are thousands of nuclear weapons on both sides still on hair-trigger alert even though they no longer target each other's territory? If Presidents Ronald Reagan and Mikhail Gorbachev could agree that a nuclear war could not be won, and must not be fought, why have the United States and Russia not moved faster in the post-Cold War period to reduce the risk of a nuclear exchange precipitated by a breakdown of authority or miscalculation?

One answer may be that the formal treaty negotiation process, used by the United States and the Soviet Union/Russia Federation to 
manage their Cold War nuclear rivalry, has not dealt effectively with new post-Cold War realities. The START II Treaty, signed in 1993, aims at force levels (3,000-3,500 deployed strategic warheads) that are no longer appropriate for today, let alone for the 21 st Century. Russian Defense Minister, Igor Sergeyev, has stated publicly that Russia is likely to have no more than 500 deployed strategic warheads by the year of 2012 for economic reasons. Yet, START II still has not gone into force because of opposition in the Russian Duma where it has languished for the past six years. Moreover, formal negotiations for a follow-on START III pact (with further reductions to levels between 2,000 and 2,500) are likely to be time-consuming, and, according to the Clinton Administration, cannot begin until START II is formally approved by the Duma.

Treaties have served US national interests well, but the pace of this process simply has not kept up with the expansion of nuclear dangers inside Russia. Senior Russian officials have publicly acknowledged that 70 percent of Russia's early warning satellites are either past their designed operational life or in serious disrepair. Senior Russian military officials have also acknowledged that 58 percent of Russia's ballistic missiles are well past their operational life span. Vast amounts of bomb-making materials (plutonium and highly enriched uranium) are poorly protected. These grave conditions invite catastrophic accidents or proliferation.

Neither the United States nor Russia has been willing, in recent years, to complement the slow and cumbersome process of 
treaty negotiations with actions that could be implemented far more rapidly. The time has now come to supplement treaties with parallel, reciprocal, and verifiable steps to reduce these dangers, dangers that directly threaten vital US national interests.

Following a careful and painstaking examination over the past few months of the formal treaty negotiating process, the Committee on Nuclear Policy has concluded that the START process must be augmented with immediate, parallel, and reciprocal actions. The Committee strongly calls upon the Clinton Administration to: reduce nuclear forces to levels far lower than currently envisioned under a START III treaty; take the majority of US forces, alongside Russia, off hair-trigger alert; and, secure, monitor, and greatly reduce fissile materials and warhead stockpiles. Concerted effort to achieve these goals could pave the way for formal negotiations at a later date and lock in these initiatives with treaties.

The Committee acknowledges the Reagan, Bush, and Clinton Administrations' efforts to advance the START process. Even before the end of the Cold War, Presidents Reagan and Gorbachev acted prudently to end the US-Soviet strategic rivalry by declaring that a nuclear war must never be fought. They followed up that declaration with the elimination of an entire class of nuclear weapons in Europe by signing the 1987 Intermediate Range Nuclear Forces (INF) Treaty.

Presidents Bush and Gorbachev continued to pull back from the strategic competition by concluding the START I Treaty in 1991, obligating the United States and the Soviet Union to deploy no more 
than 6,000 strategic nuclear weapons. President Bush and Russian President, Boris Yeltsin, kept that momentum going, agreeing to further reduce deployed strategic forces by half in START II. The Clinton Administration has made great strides in implementing START I.

The US arsenal has now dropped below 7,000 accountable warheads. The administration persuaded Ukraine, Belarus, and Kazakhstan to allow ex-Soviet nuclear warheads to be removed from their territories, and to join the Nuclear Nonproliferation Treaty (NPT) as Non-Nuclear Weapons States. The administration worked hard to get START II ratified by the US Senate, and successfully engaged President Boris Yeltsin at Helsinki by outlining a START m framework in 1997. The Clinton Administration's efforts to secure the indefinite extension of the NPT and the completion of the Comprehensive Test Ban Treaty (CTBT) are equally laudable. All of these efforts have contributed to reducing nuclear dangers of the $21 \mathrm{st}$ Century.

These notable achievements can be nullified, however, if Russia's continued decline leads to vastly increase nuclear dangers. The Committee on Nuclear Policy believes strongly that more can and must be done to radically reduce the number of US and Russian nuclear weapons, reliance on them, and the political value attached to them. While the Committee supports effective nuclear treaties, and the START process, it believes that new impetus is required to reduce nuclear dangers. 
After meeting with Clinton Administration officials, and with Russian civilian and military leaders, the Committee crafted, and now proposes, a set of initiatives to serve as the basis for supplementing the formal treaty negotiating process - initiatives similar to those undertaken by Presidents Bush and Gorbachev in 1991. Keenly aware of the threat posed by a quickly disintegrating Soviet Union one nuclear power dangerously on the verge of splitting into multiple nuclear powers - President Bush moved creatively and boldly. In September 1991, he announced that the United States would withdraw to its territory US non-strategic or tactical nuclear weapons - artillery shells, short-range missiles, gravity bombs, and nuclear weapons aboard US surface naval vessels. He also ordered a thousand US warheads deployed on strategic bombers and ballistic missiles that were slated for dismantlement under START I be taken off alert, even before the treaty was ratified. He further proposed new negotiations on strategic reductions.

President Gorbachev responded in kind, withdrawing all tactical weapons from Warsaw Pact nations and non-Russian republics, removing most categories of tactical nuclear weapons from service and designating thousands of nuclear warheads for dismantlement, while taking several classes of strategic systems off alert. The Soviet president also agreed to the negotiations that President Bush proposed, which resulted in START II.

President Bush's action successfully paved the way for larger nuclear reductions by taking the initiative to reduce an immediate 
nuclear threat. So, too, should the Clinton Administration now take a similar leadership role in advancing creative and bold new steps to address newly pressing nuclear dangers within Russia. The Committee is convinced that such an approach provides the muchneeded flexibility for adapting to the pace of the political, economic, and military realities of the post-Cold War period.

\section{Nuclear dangers}

Russian strategic rocket force commanders, unable to reach their ailing president, come dangerously close to Iaunching Russian missiles because an aging early warning radar erroneously indicates their country is under nuclear attack by the United States. A Russian nuclear weapons designer, who has not been paid for nearly a year, sells his services to Iran or Libya. A worker at a facility in one of Russia's once-closed "nuclear cities," now suffering severe economic conditions, delivers enough bomb-grade plutonium or uranium for one or two weapons to a terrorist organization or a rogue state.

These are no longer the scenarios of science fiction. They are real and present dangers that are no longer improbable. The following anecdotes demonstrate just how imminent these dangers are.

- January 1995, a scientific rocket launched by Norway was mistaken for a missile attack on Russia by the West due to a malfunction of Russia's aging early warning system. The Russian President's nuclear briefcase containing Russian 
forces' launch codes was activated for the first time before the Norwegian launch was deemed peaceful.

- $\quad$ September 1998, five soldiers from the 12th Main Directorate at Novaya Zemlya — Russia's only nuclear weapons test site - killed a guard at the facility, took another guard hostage, and tried to hijack an aircraft. The soldiers seized more hostages before being disarmed by other Ministry of Defense forces and Federal Security Service commandos.

- September 1998, a 19-year-old sailor went on a rampage on an Akula-class nuclear-attack submarine, killing seven of his fellow sailors. He barricaded himself inside the torpedo bay for 20 hours, threatening to blow up the submarine with its nuclear reactor. He either committed suicide or was shot by Russian security forces. Russian officials insisted there were no nuclear weapons on board at the time, but unofficial accounts suggest otherwise.

- September 1998, a Ministry of Internal Affairs sergeant at the Mayak facility, where over 30 tons of separated weaponsusable plutonium is stored, shot two fellow soldiers and wounded another before escaping heavily armed. The incident led President Boris Yeltsin to order a review of nuclear security at the site.

- September 1998, a team of US experts visiting Moscow was shown a building containing 100 kilograms of highly enriched uranium (enough for several nuclear bombs) that was 
completely unguarded because the facility where the fissile material was stored could not afford the $\$ 200$-a-month salary for a security guard.

- $\quad$ September 1998 , some 47,000 unpaid nuclear workers joined in protests at various locations around Russia over what the workers' trade union said was over $\$ 400$ million in back wages owed to the nuclear sector.

- December 1998, the Chief of the Federal Security Service (FSB) in the Chelyabinsk region told the Itar-Tass that FSB agents had prevented the theft and illicit appropriation of 18.5 kilograms of nuclear materials suitable for use in nuclear weapons from one of the nuclear facilities in the Chelyabinsk region.

- Today, Ministry of Internal Affairs guards at several nuclear facilities has left their posts to forage for food. Others have been reluctant to patrol facility perimeters because they did not have winter uniforms to keep them warm on patrol.

- Today, at some nuclear facilities, entire security systems (alarms, surveillance cameras, portal monitors, etc.) have been shut down because electricity was cut off to the facilities for non-payment of bills.

- Today, in hundreds of silos across Russia, sit over 20-year-old ICBMs with service lives of only ten years that are so unstable, they pose risks of catastrophic proportion to life and the environment. 
These examples represent only the tip of a nuclear iceberg. Clearly, time is of the essence. Waiting on the START process not only exacerbates these dangers for Russia, but also increases the risks of a nuclear accident, unauthorized launch, or nuclear materials falling into hostile hands. Waiting for the Duma to ratify START II also weakens the NPT, which requires a good faith effort toward meeting nuclear disarmament obligations.

The Committee on Nuclear Policy calls on the Clinton Administration to lead and to engage Russia in parallel, reciprocal, and verifiable measures to reduce post-Cold War nuclear dangers. The Committee calls on the administration to establish a new nuclear relationship with Russia for the post-Cold War era.

\section{Recommendations}

\subsection{Deep reductions}

Russia can no longer afford to maintain the huge nuclear arsenal that it inherited from the former Soviet Union, and its civilian and military leadership have publicly acknowledged that Russia will not be able to deploy the forces allowed under START II or START III. Because of serious concerns over safety and control of Russia's arsenal as presented above, and because both Russia and the United States have arsenals well in excess of that needed to deter an attack, the United States should:

- Supplement formal arms control treaties with parallel, 
reciprocal, and verifiable reductions;

- Immediately declare US intention to reduce, alongside Russia, to 1,000 deployed strategic nuclear weapons within a decade;

- Offer cradle-to-grave transparency on the status of all US and Russian nuclear weapons as the basis for reciprocal reductions;

- With reciprocal verification, subsequently reduce to 1,000 total nuclear weapons on each side; and,

- $\quad$ Seek agreement from the other Nuclear Weapons States on a ceiling on their current deployment levels and begin multilateral talks on reductions once the United States and Russia reach 1,000 total nuclear weapons.

The formal treaty process is stalled. There is no telling when START II will be ratified by the Russian Duma. The Clinton Administration's posture of waiting for the Duma to act before proceeding to negotiate START III is untenable. Even if the Duma did act, it is highly unlikely that START III negotiations would result in a complete agreement before Presidents Clinton and Yeltsin leave office. That means more time lost.

Supplementing the formal treaty process with parallel, reciprocal, verifiable, and deep reductions serves US national security interests. By proposing reductions down to 1,000 deployed strategic weapons, well below currently proposed START III levels, the United States opens the door for Russia to move more quickly in the 
direction that it has to go anyway. Willingness by the United States to cooperatively reduce strategic forces down to this level sends a signal that Washington seeks a new post-Cold War nuclear relationship with Moscow. Consequently, Russia may be more likely to agree to greater openness and transparency on its weapons, which the United States must insist on for deep reductions. The Committee advocates this positive sum tradeoff: Russia secures rough parity at lower levels, while the United States secures transparency in Russia needed to make reductions irreversible.

Cradle-to-grave transparency, the tracking and accountability of every warhead from its production to its dismantlement and destruction, must be the linchpin of a deep reduction regime so as to make it maximally verifiable and irreversible. Russia has been less than enthusiastic about greater openness for its nuclear holdings. This must change and is more likely with the offer of parallel deep reductions.

Agreement between the United States and Russia to reduce to 1,000 deployed strategic weapons would also include an agreement to second stage reductions down to 1,000 total weapons, which would include the tactical nuclear weapons that concern the United States and our European allies. In return for addressing Russian concerns of asymmetry at the strategic level, Moscow must shed light on its inventory of tactical nuclear weapons, which are aging and reaching obsolescence, in any event. Reductions to 1,000 total weapons on each side coincides with the proposed limit called for in the 1997 
report by the National Academy of Sciences, The Future of Nuclear Weapons.

Moreover, bilateral reductions to this level would then pave the way for five power nuclear negotiations to deal with residual nuclear forces. This reduction regime could also reap major nonproliferation benefits. It moves the P-5 states significantly toward meeting their nuclear disarmament obligations under the Nuclear Nonproliferation Treaty.

\subsection{Removing the hair-trigger}

That a large, powerful and unstable Russian nuclear arsenal is also on hair-trigger alert, capable of being launched within a few minutes of an attack warning, greatly heightens the risk of an accidental or unauthorized launch. US forces are equally poised for quick launch. Neither the United States nor Russian can be secure with so many nuclear weapons on hair-trigger alert. No other single measure would more clearly signal the end of the mutual suspicion carried over from the Cold War than taking these weapons off quick launch status. The Committee calls on the United States to:

- Immediately stand-down, alongside Russia, nuclear forces slated for destruction under START II;

- Declare its intention, with a parallel, reciprocal commitment from Russia, to eliminate the launch-on-warning option from nuclear war plans;

- Begin discussions among the five Nuclear Weapon States on 
verifiably removing all nuclear forces from hair-trigger alert; and,

- Declare its intention, with a parallel, reciprocal commitment from Russia, to verifiably eliminate massive attack options from nuclear war plans.

Despite the 1994 Clinton-Yeltsin pact not to aim nuclear missiles at each other, US and Russian forces still are loaded with their wartime targets that can be reactivated within seconds for Intercontinental Ballistic Missiles (ICBMs) and minutes for Submarine-Launched Ballistic Missiles (SLBMs). Therefore, if a launch order were sent under current circumstances, 4,000 ICBM warheads ( 2,000 on each side) could be on their way to their targets within a few minutes and another 1,000 SLBM warheads could be en route to targets shortly thereafter.

Presidents Clinton and Yeltsin also agreed in 1997 at their Helsinki summit to "deactivate" missiles slated for destruction under START II by 2004. The dangers posed by having so many weapons on hair-trigger alert demand that these missiles be stood down immediately. An immediate stand-down would reduce the number of weapons on hair-trigger alert from 2,500 (on each side) currently to 500; the number Russia would retain on quick-launch under the START II provisions.

The stand-down could be monitored by national technical means, as well as by existing extensive right for random, short notice missile inspections under START I. Above all, the stand-down 
would benefit US national security interests and the safety of its citizens. This action would also achieve a major psychological benefit by breaking with the Cold War psyche. So, too, would the declaration to eliminate the launch-on-warning option. The declaration could be implemented by procedural changes similar to those that now preclude the launch of US missiles directed at China. Like the existing de-targeting declaration, these procedural changes could not be readily verifiable. Confidence in and verifiability of the declaration could be achieved gradually as transparency arrangements and other de-alerting measures, such as removing warheads from missiles, are implemented.

The alert levels of French and British nuclear forces are low. China does not appear to have strategic nuclear forces on alert. Including the forces of these Nuclear Weapons States in talks to verifiably remove all nuclear forces from hair-trigger alert is pivotal to Russia's acceptance of such a move.

The elimination of massive attack options goes to the heart of transforming Cold War postures. Taking this step would be the first material acknowledgment that a deliberate, premeditated, mutually suicidal bombardment is both implausible and unthinkable. The Committee on Nuclear Policy believes that launch-on-warning postures and massive nuclear targeting options are no longer suitable in contemporary circumstances. 


\subsection{Fissile material and warhead controls}

Central to US security is ensuring that nuclear weapons and the essential ingredients to make them do not fall into hostile hands. With the escalating economic crisis in Russia, immediate action is needed to consolidate, secure, and account for all stockpiles of nuclear warheads and weapons-usable nuclear materials. A comprehensive accounting and monitoring regime for warheads and fissile materials is critical to the verification of the deep reductions the Committee proposes, and, to making them irreversible. This regime would also provide an urgently needed defense against the proliferation of nuclear weapons and fissile materials to other states or sub-national groups. The Committee calls on the United States to:

- Help install modern security and accounting systems and provide resources and incentives for sustaining effective security at all Russian nuclear facilities;

- Help consolidate Russia's weapons-usable materials into the smallest possible number of locations;

- Help shrink the Russian nuclear weapons complex;

- $\quad$ Promote alternative employment in Russia's nuclear cities;

- $\quad$ Build a cradle-to-grave transparency and monitoring system for all warheads and fissile materials;

- Negotiate reductions in fissile material stocks in excess of that needed to support a 1,000-warhead stockpile; and,

- $\quad$ Triple current funding for fissile materials controls. 
With nuclear guards walking off their posts to forage for food and thousands of workers with access to fissile materials striking to protest months of unpaid wages, improving the security at Russia's nuclear facilities is warranted on an emergency basis. The expanded scope of assistance that the Committee proposes is essential not only to control missiles and launchers, as in the past, but also to expand controls over nuclear warheads and fissile materials.

Fissile materials are stored at over 100 buildings located in over 50 different sites throughout Russia and the former Soviet Union. It is essential to consolidate this material at as few sites as possible. It is equally essential that all remaining facilities are equipped with modern security and accounting systems, and are provided with the resources and incentives necessary to sustain security well into the future, including a new focus on the "human factor" to help instill a new safeguards culture.

The sheer size of Russia's vast nuclear weapons complex poses a monumental challenge in controlling and safeguarding fissile materials and warheads. In Russia's ten "nuclear cities," tens of thousands of nuclear scientists, engineers and technicians, are in dire economic straits. An investment of roughly $\$ 500$ million over the next five years by the United States - with Russian contributions as well - could be used to downsize this giant complex and provide alternative employment to its workers who might be tempted not only to steal fissile materials, but also sell their services to others.

Cradle-to-grave transparency needed to achieve deep 
reductions requires a credible, detailed exchange of data on stockpiles of warheads and fissile materials. Reciprocal monitoring of sites where warheads are stored pending dismantlement would be required as well. Relaxing nuclear secrecy would require a major change in psychology, particularly on the Russian side. Russian transparency will be difficult to secure unless the United States is willing to make the kinds of reductions in its arsenal that Russia is now forced to make because of its economic crisis, and to permit equivalent transparency.

Both to ensure that excess warheads are dismantled as rapidly and as safely as practicable, and to increase the incentive for Russia to accept cradle-to-grave transparency, the United States should provide financial assistance to defray Russian dismantlement costs, including costs to increase its dismantlement capacity if necessary.

To avoid having to secure vast stockpiles of excess fissile materials indefinitely, and to make deep reductions irreversible, the Committee on Nuclear Policy calls on the United States and Russia to agree on a level of plutonium and highly enriched uranium stocks sufficient only to maintain the maximum 1,000 total warheadstockpile. While en route to this fissile material stockpile, the United States and Russia should move as quickly as possible to establish arrangements to transform current excess fissile material stocks into forms that would make it far more difficult to ever convert them for use in weapons again. As a first step, the United States could offer to purchase additional amounts of Russia's highly enriched uranium 
(HEU) from weapons that has been blended down to non-weapons usable form, with the proceeds going back into consolidating and improving security at fissile material storage cites.

The United States could also offer Russia financial incentives to blend down all its excess HEU to less than 20 percent as quickly as possible, thereby reducing risks of proliferation. The United States could encourage the conversion of excess plutonium to forms that are no more weapons-usable than the plutonium in commercial spent fuel, using the method preferred by each side that could be implemented quickly and with stringent safeguards and security throughout the process.

As the United States and Russia reduce their stockpiles of fissile materials, it is vitally important to ensure that no new materials are being produced. The Committee calls on the United States and Russia to establish transparency at each other's enrichment plants to ensure that no additional HEU is being produced. The two countries should also complete the conversion of Russia's plutonium production reactors so that they no longer produce weapons-grade plutonium. These measures would provide valuable experience and impetus for concluding an international Fissile Material Cut-off Treaty (FMCT).

The expanded scope and level of effort proposed by the Committee would require a tripling of the funds currently spent on fissile materials controls in Russia. The cost to address this threat is small compared to the cost and risk of failure to control fissile 
materials in the former Soviet Union.

Finally, effective management of a new US-Russian nuclear relationship also involves addressing differences over the issue of ballistic missile defenses (BMD). Realizing that another significant debate over defenses and the Antiballistic Missile (ABM) Treaty is in the offing within the United States, the Committee agreed on a set of criteria by which to evaluate objectively any national missile defense (NMD) proposals and against which a deployment decision should be weighed. The Committee believes that national missile defense deployment proposals should:

- Have a clearly defined, achievable mission;

- $\quad$ Prove missile defense technologies under repeated, rigorous testing;

- Be affordable;

- Be cost effective at the margin;

- $\quad$ Be pursued in a balanced fashion along with other measures to reduce nuclear threats; and,

- Have an overall impact that should reduce nuclear dangers, taking into account their potential impacts on nuclear arms reductions and nonproliferation.

\section{Conclusion}

The Committee on Nuclear Policy does not believe that the START process of formal treaty negotiations is irrelevant, or that it 
should be jettisoned. The Committee believes, however, that the START process should be supplemented with new initiatives to directly address the new nuclear realities and risks of the post-Cold War period. The Committee calls on the Clinton Administration to break the current six-year logjam on START II ratification; radically reform the management of the US-Russian nuclear relationship; and, to take the lead in reducing both reliance on nuclear weapons and the political value attached to them.

To continue to rely solely on the stalemated START process is to needlessly increase the costs and risks of maintaining US and Russian nuclear arsenals at levels well in excess of what is needed to deter an attack. The Committee's initiatives for deep reductions, removing nuclear forces from hair-trigger alert, safe guarding fissile materials, and warhead controls, not only would reduce these costs and risks, but could also set the stage for a larger, more cooperative multilateral security framework for the 21 st Century.

Prior to the disintegration of the Soviet Union, President Bush responded quickly and successfully to an immediate nuclear danger. Immediately following the disintegration of the Soviet Union, Senators Sam Nunn and Richard Lugar acted quickly to harness US funds and expertise to consolidate scattered Soviet warheads under Russian control and to destroy the delivery vehicles for those warheads. Even more far reaching measures, to be implemented just as quickly, are now needed by the United States to respond to even greater post-Cold War nuclear dangers. 


\section{Part IV}

Regimes Under Assault: The Chemical And Biological Weapons Conventions 
. 


\section{Chapter 13}

\section{Arms Control Regimes Under Assault: Explaining the US \\ Position in the Negotiations to Strengthen the Biological \\ Weapons Convention}

Marie Isabelle Chevrier

As the $20^{\text {th }}$ Century draws to a close, a number of arms control regimes could be described as "under assault." Among these is Biological and Toxin Weapons Convention (BWC), signed in 1972 and entered into force in 1975. Although the BWC was the first multilateral arms control agreement to ban the possession of an entire class of weapons, it has been criticized from its inception for the inadequacy of its provisions to achieve its goals. Moreover, compliance with its provisions among the more than 140 parties to the treaty has often been questioned. The BWC has been under assault for several reasons.

First, the physical characteristics of biological agents and toxins, and the delivery systems which could turn the agents and toxins into weapons, are inherently more difficult to detect than comparable components of other weapons systems. These characteristics mean that the BWC cannot be verified in the manner that other arms control agreements can, particularly agreements controlling nuclear weapons. This will not change. The difficulty of verifying the BWC, however, is not an excuse for 
refraining from bolstering the prohibition against the possession of biological weapons (BW). Much can be done to strengthen the effectiveness of the treaty, and increase confidence among State Parties that the vast majority of its members are in compliance with its provisions.

Second, the Soviet Union ignored its obligations and developed an extensive, offensive BW program in defiance of the BWC from the time the treaty entered into force. Although the United States and other countries suspected the Soviet Union of violating the treaty's most fundamental strictures, definitive proof of its violations was elusive. Not until the end of the Cold War did Russian President, Boris Yeltsin, admit that the Soviet Union had an extensive offensive BW program. Details of the extensive program have come to light even more recently through the revelations of defectors from the program. ${ }^{1}$

Additionally, the audacity of the Soviet Union in so flagrantly disregarding its sworn promises has made governments and others wonder whether other countries have successfully hidden their own offensive weapons programs.

Finally, the absence of any mechanisms with the treaty to investigate instances of suspected noncompliance is a glaring omission. The importance of this omission has been reinforced recently by the inability to investigate, for example, Russian facilities. While this omission of on-site measures to investigate noncompliance could not have been avoided in 1972, international negotiators now have the opportunity through a protocol to the 
Convention to rectify some of weaknesses of the original treaty. Through the ability to investigate alleged noncompliance, checks on facilities with the capacity to be involved in noncompliant activities and other measures, the protocol would make noncompliance more difficult and more expensive for countries to undertake.

Since January of 1995 representatives of the countries who are party to the BWC have been meeting periodically at the United Nations in Geneva under the leadership of Chairman Tibor Toth of Hungary to draft a legally binding Protocol to the 1972 BWC. The Protocol will address, wherever possible, the problems that have led the regime to be characterized as "under assault." For three years, the United States took a back seat in these negotiations. The US, for example, put forward only four papers through the first ten sessions: a "non-paper" on international development programs introduced in the second session ${ }^{2}$ and overall four working papers. One on the potential of Article $\mathrm{X}$ measures introduced in the second session; ${ }^{3}$ one on computer networking introduced in the third session; ${ }^{4}$ one on the role of epidemiology in unusual/suspicious outbreaks of disease introduced in the fourth session; ${ }^{5}$ and one on the preamble submitted at the seventh session. ${ }^{6}$ The paucity of US contributions of working papers to the negotiations is in stark contrast to nations such as South Africa, which introduced forty-seven papers through the first ten sessions, and the United Kingdom, which introduced thirty-one. ${ }^{7}$ 
On January 27, 1998, however, President Clinton announced that "the United States would lead the effort to erect stronger international barriers against the proliferation and use of biological weapons."8 A fact sheet issued by the White House on the same day laid out the rough outlines of a new US policy in the negotiations for a Protocol to strengthen the effectiveness of the BWC. 9

The US policy would support four broad provisions:

- declarations of "facilities and/or activities that are especially suited for possible BW purposes;"

- voluntary visits to facilities declared in the above item;

- non-challenge visits to clarify an ambiguity, uncertainty, anomaly, omission, or other issues related to declarations; and,

- challenge investigations if there is evidence of noncompliance.

In addition, challenge investigations would be subject to a filter that would allow the challenge investigation to proceed only if a majority of the governing body approved. The fact sheet also set the end of 1998 as a goal for completing the framework of the protocol.

This paper will compare and contrast the stated policy of the United States and its further development in working papers submitted in 1998 with the policies of other active participants in the BWC protocol negotiations. In doing so, I attempt to lay out 
the reasons why the US policy might differ with those of its Allies. Secondly, the paper will assess what components of a "framework" have indeed been agreed upon and what components of the framework are not yet in place. Finally, the paper will assess whether the US succeeded in its leadership aspirations as stated by the President.

\section{Information sources}

To discern the US's negotiation position, I relied on a number of disparate sources. First, I obtained and systematically analyzed the official documents submitted by the United States to the Ad Hoc Group (AHG) negotiations. These working papers, together with the text of a speech by John Holum, former director of the US Arms Control and Disarmament Agency, to the AHG in October 1998 provided the most reliable, and most public, statements of the US position. In addition, I attended a meeting that included many of the members of the interagency working group of the US government that formulates US policy in these negotiations. The meeting sought the input of experts to comment on a draft proposal regarding one aspect of the US position, its declarations. Attending this meeting enabled me to listen to representatives of the US government from different agency perspectives describe their reasoning behind the position development and to ask them questions to clarify my understanding. I have discussed these issues on many occasions 
with members of the US delegation to the BWC negotiations, other participants in the US inter-agency process, and members of delegations from other countries participating in the AHG negotiations.

To ascertain the positions of other countries, my sources were somewhat more limited. They also included working papers submitted to the AHG. Whenever possible I also spoke with members of the country's delegation to the AHG. I did not, however, have any access to members of any other country's intraagency process. At times I checked my understanding of a country's position with other participants and observers of the AHG process.

As mentioned above, the most reliable sources are official documents. However, these documents have limitations as well. Working papers, with few exceptions do not cover the entire range of a country's position, but only a few specific areas. Second, working papers represent an affirmative statement of what should be included in the Protocol and as such do not specifically include the arguments a country makes in opposition to sections of the proposed protocol. Hence, discussions herein on what provisions the US (and other countries) oppose are ordinarily based on conversations rather than official documents and may, therefore, be somewhat less reliable. 


\section{The US position}

\subsection{Declarations}

In October 1998, the US submitted a working paper elaborating on what activities and facilities should be declared in the category of "Current Biological Defense." 10 Its working paper included a proposal for declarations of:

- Whether a country has conducted activities which directly protect or directly defend humans, animals, or plants against the use of agents or toxins for hostile purposes or in armed conflict (requiring a yes or no answer);

- If the first point is yes, a declaration of research and development activities including the purpose and a summary of activities on prophylaxis (protection against an agent), pathogenicity and virulence (ways to make an agent more or less harmful), diagnostic techniques, aerobiology (ways to disperse an agent through the air), medical treatment or toxinology/toxicology;

- Government and non-government facilities where such activities have taken place, if they are above a certain scale, measured in person-years of staff effort; and,

- If less than a certain number facilities met the criteria in scale criteria, the country would still need to declare general information about some facilities. 
It is difficult to determine the lower end of this scale from the working paper; nevertheless, the paper does include a minimum declaration requirement. In other words, if a country declares that it has conducted any defense activities, it must declare those of the greatest scale; if on the other hand it has only conducted small-scale activities, it must declare those.

The concern of the United States that led to the formulation of this working paper appears to be threefold. First, the US has a strong desire to create declaration obligations in such a way that the US can be certain that its declarations are complete and technically accurate. Second, the US wants the organization that will be created to implement the protocol to concentrate on the facilities of greatest relevance. It does not want the organization to be overwhelmed by a large volume of declarations of small, not particularly relevant, facilities many (if not most) of which would be located in the US. Finally, at the same time, it does not want a country that has a BW defensive program, however small, to be entirely exempt from declaring information about its program.

In addition, the US may want to limit intrusion into its own defense facilities, particularly those that may conduct a combination of biological defense activities and sensitive activities unrelated to biological defense. This interpretation of the US position is, understandably, not one that is presented by the US government. Nevertheless, it can be inferred from the stated US position. 
In light of these concerns, the US proposal is an attempt to require declaration of the largest - which would be a proxy for most relevant - defensive facilities in every country that has a program. The number of Full-time Equivalent Employees (FTE) would define the largest facilities or activities. In effect, this declaration provision would exempt countries that have a variety of biological defensive activities from declaring their small-scale activities, but would require countries who conducted only smallscale activities to declare them.

The advantage of this requirement is that it limits the amount of declaration information that the BWC organization would have to handle. It makes the implicit assumption that the largest scale activities are those that would be most relevant to the Convention - a reasonable, if not always, accurate assumption.

The disadvantage is that identical programs would be subject to declaration in some states but not others. Moreover, the FTE proxy for most relevant facilities could be manipulated. The amount of time someone spends on a project, which is usually selfreported, could easily be exaggerated or downplayed. Moreover, the most relevant defensive programs could be very secret, smallscale research programs that employed few FTEs. A calculating country could very well construct a larger scale defensive program in order to shield its most relevant programs from declaration.

Beyond defense facilities, the full scale of facilities and activities that the US thinks is appropriate for declarations was not spelled out in its Working Paper. Nevertheless, the fact that it has 
not directly commented on the "Rolling Text's" declarations implies that while it may find some of the declaration provisions in the text objectionable, other elements within it are likely to be acceptable on some basic level.

The latest "Rolling Text" (April 1999) ${ }^{12}$ contains fifteen pages describing the facilities and activities that would be declared under a Protocol. The following summary, therefore, is a very broad description. Declaration requirements are divided into an initial declaration and annual declarations. The annual declaration is further divided into 1) declarations of facilities that meet specific criteria, and 2) certain other activities. The initial declaration would cover offensive and/or defensive programs that existed in the past, and any national legislation and regulations concerning pathogens and toxins. Annual facility declarations would be required for programs to defend against $\mathrm{BW}$, vaccine production facilities, maximum and high containment facilities, facilities that work with listed agents or toxins, certain other facilities producing products relevant to the Convention, and facilities with aerosol capacities or those conducting certain modifications of agents or toxins. The activities portion of the annual declaration would include transfers of listed agents, toxins and certain equipment, actions taken to implement Article $\mathrm{X}$ of the Convention, and notifications of disease outbreaks that meet certain criteria.

Once all declarable facilities and activities are accurately specified (triggered), the question of what specific information about these facilities and activities should be declared still remains. 
Again, the US position is not explicitly put forward in a working paper. However, there are disagreements regarding what should be declared, specifically the degree of detail regarding a facility. Detailed declarations of a facility's activities and equipment would strengthen confidence in compliance, increase transparency, and deter countries from concealing prohibited activities within facilities also conducting legitimate activities better than more general declarations. On the other hand, detailed declarations would likely be more prone to errors leading to uncertainties, anomalies, ambiguities, or omissions that could lead to the need for a clarification process.

Beyond the concerns about which facilities and activities will be declared and what information about these facilities and activities will be declared, the United States would like the procedures in place to ensure that countries' declarations are complete and accurate. John Holum, at that time the Director of the US Arms Control and Disarmament Agency, ${ }^{13}$ made this point clearly when he addressed the AHG in October 1998. He stated that there "must be a means to ensure that all sites whose activities merit declarations are in fact declared, and that the declarations are accurate." The US answer as to how this goal is to be accomplished is through clarification visits. 


\subsection{Visits}

The US elaborated its position in support of clarification visits in a working paper submitted on the last day of the negotiations' $11^{\text {th }}$ session in July of 1998 and resubmitted it the first day of the $12^{\text {th }}$ session in September. ${ }^{14}$ Clarification visits are the end point of a clarification process that first attempts to resolve declaration concerns without resorting to an on-site visit to the location in question. The US working paper "Proposed Elements of Clarification Visits" describes a multi-step clarification process. The first step would be to resolve the issue arising from the declaration through correspondence between the BWC organization and the affected party or between two State Parties. The second step would be a meeting in the national capital of the State Party whose declarations are of concern. Only if theses two steps were unable to resolve the issue could a request for a clarification visit to the facility in question be initiated. As a consequence, several months could elapse between the initial identification of an ambiguity, uncertainty, anomaly, or omission in a declaration and the arrival of a visiting team on site.

The visits portion of the US working paper on the clarification process applies to both declared facilities and facilities that should have been declared but were not. The latter would constitute omissions in declarations. ${ }^{15}$ The US proposed elements for visits to the two types of facilities share some features:

- no annual quotas or limits on the number of clarification visits; 
- $\quad$ managed access procedures would be used;

- $\quad$ sampling would be prohibited;

- limits on the duration of the visit and the size of the visiting team;

- the mandate would be signed by the Director General and would be limited to clarifying the specific declaration issue or omission; and,

- the visiting team would prepare a factual summary and the State Party visited could comment on the summary.

The US proposed several important differences between clarification visits to declared and undeclared facilities. To begin with, only the Technical Secretariat could initiate the clarification process for declared facilities, while the Secretariat or a State Party could initiate the process for an omission in a declaration. Furthermore, the clarification visit would proceed presumably automatically to a declared facility if the previous consultations did not resolve the issue. While a clarification to a facility that was not declared, would be subject to a filter - a red light silence procedure of the Executive Council - according to the US proposal.

The Rolling Text reflects a number of changes to the sections of the text concerning clarification procedures that differ from the US working paper on clarification visits that it introduced in July of $1998 .^{16}$ For example, under the US proposal, the Technical Secretariat of the BWC organization would initiate the 
clarification process if it identified an uncertainty, ambiguity, anomaly or omission in a State Party's initial or annual declaration. That has been changed such that a State Party or the Technical Secretariat may initiate the process in both declared and undeclared facilities. Second, the US proposal established no limits on the number of clarification visits. The January 1999 Rolling Text contained a proposal to limit the total number of clarification visits to twenty in one year, with no more than two visits to any State Party. The language limiting the number of clarification visits, however, does not appear in the April 1999 Rolling Text. Finally, in the US proposal, clarification visits to declare facilities would occur automatically, that is without going through any type of political process in the Executive Council of the BWC organization. ${ }^{17}$ The April 1999 Rolling Text contains proposed language for three possible responses to a request for a clarification visit, following written attempts to resolve the issues and a consultative meeting. The responses include an invitation to visit, a refusal to be visited, and a request that the Executive Council reviews the request as a matter of procedure. Thus, clarification visits, even to declared facilities, could be refused or subject to a political filter.

The US approach to ensuring that declarations are complete and accurate seems to incorporate a criminal justice model. Only if there is evidence of a failure to comply completely with Protocol obligations, in the form of an ambiguity, uncertainty, anomaly, or omission in a declaration, will there be a procedure to look into the 
alleged breach of obligation. The consultation process could be considered comparable to questioning witnesses or possible suspects prior to an arrest. While the proposed procedure in the Executive Council approving a visit is somewhat analogous to a requirement to find probable cause before conducting a search of premises that may reveal relevant information about a crime.

A contrasting approach to ensuring that declarations are complete and accurate is to incorporate an Internal Revenue Service (IRS) ${ }^{18}$ approach of random audits of declared information. Citizens who earn income are obligated to submit income tax returns each year, analogous to declarations, which are subject to thorough, intrusive random audits. Randomly selected visits, which are supported by many delegations in the AHG, would occur in a small number of declared facilities every year as an incentive to submit complete and accurate declarations. Randomly selected visits are not intended to be intrusive, yet their purpose is analogous to IRS income tax audits.

The two approaches are not mutually exclusive. Certainly, if the $\mathbb{R S}$ discovers through its records that an individual has not declared all of its income, it can inform the taxpayer and initiate what is similar to a clarification process. This clarification does not preclude the IRS from conducting an audit at a later time. It is another method to promote accurate and complete tax returns.

The approach of randomly selected visits to ensure accurate and complete declarations is relatively straightforward. The Technical Secretariat of the BWC organization would select 
declared facilities for visits, balancing the visits among different types of declared facilities and among different geographical regions. ${ }^{19}$ The proposed purposes of randomly selected visits include four related to declarations:

- to confirm their consistency with Protocol obligations;

- $\quad$ to promote their accuracy;

- to enhance transparency of declared facilities and activities; and,

- to ensure that the Technical Secretariat is familiar with and up-to-date on all the types of facilities and activities that are declared.

An additional proposed purpose of randomly selected visits, not necessarily related to declarations, is to provide technical assistance and information, most likely associated with obligations under Article $\mathrm{X}$ of the Treaty.

Yet, another type of visit, which may be called "Familiarization Visits," is under consideration by several countries. Familiarization visits, as they are presently envisioned, have a number of significant differences from randomly selected visits. The most important difference is that the purpose of the visit would not be to confirm the accuracy of declaration information. Thus, there would be no standard to guide the inspectors on their visit. Second, the mandate of the visit would be different. In the case of randomly selected visits, the mandate would be to confirm that activities at the selected facility are 
consistent with information submitted in the declaration. The mandate of familiarization visits would be unrelated to declarations; it would be related to transparency, and training inspectors (see items 3 and 4 above). It is unclear how the purposes of transparency and training inspectors would be translated into a clear and narrow visit mandate. Additionally, notice to the visited State Party in a familiarization visit would increase to thirty days from the two to ten days proposed for randomly selected visits. Finally, access in familiarization visits would be at the discretion of the visited State Party and the facility would be under no obligation to satisfy requests of the inspectors. Randomly selected visits would carry managed access obligations for the visited State Party. This means that the facility would be under an obligation to provide an alternative means for satisfying inspectors' queries if the facility or the State Party concluded that the original request for information would threaten confidential proprietary information, trade secrets or national security. Because of these differences, Familiarization Visits would appear to be a poor substitute for randomly selected visits.

Table 1 compares characteristics of the three types of nonchallenge visits described above: clarification visits, randomly selected visits, and familiarization visits and the value of the different visits. Proponents of clarification visits argue that the clarification process, including visits, can resolve questions about declarations at a low political level. The clarification process is meant to be friendly and to resolve any questions regarding the 
completeness and accuracy of declarations at the lowest level possible: initially through correspondence, then through a consultation visit with interested parties at the nation's capital, and finally through a non-intrusive, friendly visit. Another value of clarification visits is to encourage countries to complete thorough, accurate, and timely declarations. As mentioned previously, the value of randomly selected visits is to promote thorough, accurate and timely declarations. Familiarization visits are not designed to promote accurate declarations and would not give inspectors any experience in using managed access techniques most effectively. A thorough working knowledge of managed access techniques could prove critical in any investigation of alleged treaty noncompliance. All three visits would have the value of training inspectors and keeping them up-to-date and aware of biological practices in different countries.

Finally, while promoting accurate declarations is mentioned as a possible purpose of familiarization visits, it is difficult to understand how this purpose could be achieved without a mandate for the inspectors to compare actual facility activities with declared information. Thus, it appears that the greatest value of non-challenge visits is to deter countries from placing prohibited activities under cover of declared facilities, and at best erode, and at worst evaporate completely the features of randomly-selected visits by replacing them with those envisioned for familiarization visits. 
TABLE 1

Comparison of Proposed Visits Under The BWC Protocol

\begin{tabular}{|c|c|c|c|}
\hline & $\begin{array}{c}\text { Clarification } \\
\text { Visits } \\
\end{array}$ & $\begin{array}{c}\text { Randomly } \\
\text { Selected Visits }\end{array}$ & $\begin{array}{c}\text { Familiarization } \\
\text { Visits }\end{array}$ \\
\hline Purpose & $\begin{array}{l}\text { Clarify an } \\
\text { ambiguity, } \\
\text { uncertainty, } \\
\text { anomaly, or } \\
\text { omission in a } \\
\text { declaration. }\end{array}$ & $\begin{array}{l}\text { Confirm } \\
\text { consistency of } \\
\text { facility or } \\
\text { activity with } \\
\text { declared } \\
\text { information OR } \\
\text { protocol } \\
\text { obligations. }\end{array}$ & $\begin{array}{l}\text { Enhance } \\
\text { transparency; } \\
\text { Train inspectors; } \\
\text { Promote } \\
\text { accurate } \\
\text { declarations (?). }\end{array}$ \\
\hline Mandate & $\begin{array}{l}\text { Limited to } \\
\text { clarifying the } \\
\text { ambiguity, } \\
\text { uncertainty, } \\
\text { anomaly, or } \\
\text { omission. }\end{array}$ & $\begin{array}{l}\text { Confined to } \\
\text { confirming } \\
\text { declared } \\
\text { information. }\end{array}$ & \\
\hline $\begin{array}{c}\text { Notice } \\
\text { before } \\
\text { arriving }\end{array}$ & $\begin{array}{l}\text { Up to several } \\
\text { months. }\end{array}$ & $\begin{array}{l}\text { From two to ten } \\
\text { days. }\end{array}$ & Thirty days. \\
\hline Access & $\begin{array}{l}\text { Managed Access } \\
\text { obligations. }\end{array}$ & $\begin{array}{l}\text { Managed } \\
\text { Access } \\
\text { obligations. }\end{array}$ & $\begin{array}{l}\text { At the discretion } \\
\text { of the visited } \\
\text { State Party. }\end{array}$ \\
\hline Value & $\begin{array}{l}\text { Resolve } \\
\text { declaration } \\
\text { questions at a low } \\
\text { political level. } \\
\text { Create incentives } \\
\text { for complete and } \\
\text { accurate } \\
\text { declarations. }\end{array}$ & $\begin{array}{l}\text { Deter countries } \\
\text { from using } \\
\text { declared sites } \\
\text { for prohibited } \\
\text { purposes. } \\
\text { Promote } \\
\text { complete and } \\
\text { accurate } \\
\text { declarations. }\end{array}$ & Train inspectors. \\
\hline
\end{tabular}


In conversations, US government officials imply that their opposition to the salient features of randomly selected visits namely confirming declared information with short notice, and using managed access techniques and obligations - is based on the pharmaceutical industry's opposition to nonchallenge visits. Yet, the Pharmaceutical Research and Manufacturers of America (PhRMA) opposes all mandatory non-challenge visits including clarification visits, which the US government supports and is actively promoting. Thus, the argument that the US government cannot support randomly selected visits because US industry opposes them is not convincing. This is an insufficient explanation, given the US's support of clarification visits in spite of the industry's vehement opposition to clarification visits. Indeed, although the US industry opposes all but voluntary nonchallenge visits, its opposition to clarification visits may be stronger than its opposition to randomly selected visits as they are defined in the current April 1999 Rolling Text. PhRMA opposes clarification visits because it views them as a form of challenge investigation with a lower evidentiary burden for the country wishing to conduct the visit. PhRMA worries that the reputation of its member companies might suffer damage from a clarification visit. The US refusal to support randomly selected visits may be as a result of its reluctance to expose its biological defense programs to international inspectors.

Voluntary visits, also supported by the US, are relatively non-controversial. Voluntary visits, as their name implies would 
be offered by the State Party or the facility. One type of voluntary visit could be as a response to a request for a clarification visit. While some delegations may question the value of voluntary visits, others see their value as training inspectors, and helping countries fulfill their declaration requirements more accurately. The State Party or the facility would determine access. There could be no guarantees that voluntary visits would adequately train inspectors because there may be no volunteers, and the conditions of voluntary visits bear little relation to the circumstances of noncompliance investigations.

\subsection{Investigations}

Prior to the President's announcement of the US policy in January 1998, the US was known to support investigations of alleged use of biological weapons and disease outbreaks that might raise suspicions that a country was not in compliance with the Convention. While the US has had little to say on the subject through working papers, it is known to support both field and facility investigations. Field investigations would be used to investigate alleged use of biological weapons, and/or the release of agents or toxins, or exposure of humans, animals, or plants to them, that has raised compliance concerns. Facility investigations would probe alleged treaty violations other than alleged use or the accidental or deliberate release of agents or toxins. 
While the principle of investigations of alleged use or other violations of the Convention is generally accepted, several of the details regarding how investigations are launched and conducted remain topics of controversy. For example, there is no agreement on the level of review necessary to launch an investigation. The Executive Council, composed of representatives of a subset of treaty parties, would filter investigation requests from State Parties. Some countries envision that on-site inspections would take place automatically after a country makes a request, unless the council denies the request. This principle, dubbed "red light," is incorporated in the CWC. ${ }^{20}$ Other countries support an alternative with subtle, but significant differences. The "green light" principle supposes that a request for an on-site inspection would proceed only if the council gave its approval, that is, gave it a "green light." The Rolling Text includes proposals for a "red light" three-quarters majority to stop an investigation and "green light" approval by a two-thirds or three-quarters majority. According to the January 1998 fact sheet, the US favors the "red light" procedure, albeit by a simple rather than an extraordinary majority, a departure from its support of the "green light" procedure to screen challenge inspections under the CWC.

The "red light" and "green light" procedures have differing effects on both the party lodging an allegation and the party responsible for convincing the Executive Council of the merits of its position. Under the "red light" procedure, the onus would be primarily on the accused country, which would need to convince 
the Council members that the challenge was frivolous or motivated solely by politics. Under the "green light" procedure, the burden would rest more heavily on the country requesting the investigation, to support the contention that its suspicions were realistic or based on valid information. Conceivably, an accusing country could face a dilemma under the "green light" procedure: it would either risk revealing sensitive sources of information from which the suspicions arose, or face the prospect of international embarrassment if its investigation request failed to gain sufficient support to proceed. The percentage of Council members needed to deny or approve a request is a secondary disagreement. Council voting procedures more complicated than simple "red or green light" procedures are also possible. ${ }^{21}$ Other aspects of noncompliance investigations, such as the rights and obligations under managed access, are under debate.

\section{What is absent from US policy?}

The four components of the BWC Protocol that the US supports contrast with other elements of the proposed Protocol upon which the US has not commented. The United States' relative silence is particularly noteworthy concerning the Protocol's treatment of Articles III and X of the Convention. Although two of the early US working papers concerned Article X, it has introduced no new proposals since 1995. Article $X$ of the Convention states that "States Parties...undertake to facilitate and 
have the right to participate in, the fullest possible exchange of equipment, materials and scientific and technological information for the use of ...agents and toxins for peaceful purposes." In establishing the Ad Hoc Group to draft a Protocol to the BWC, the State Parties instructed the AHG to consider "specific measures designed to ensure effective and full implementation of Article $\mathrm{X} . . . .22$ The US has generally regarded Article X-like measures, which appear in other arms control agreements, most notably the Nuclear Nonproliferation Treaty, as the price the US and its Allies must pay to induce lesser developed countries to join the Treaty. As such, the United States would generally prefer to wait and see what the Non-Aligned Movement countries and others request regarding Article $\mathrm{X}$ measures rather than affirmatively proposing measures. Such a position, which is unofficial, may miss the point. If Article $\mathrm{X}$ measures can be identified, which will benefit all BWC parties, the notion of an inducement from developed countries to lesser-developed countries is weakened. The US may miss an opportunity to introduce measures that would be to its benefit, rather than to its detriment, by receding and waiting for other countries to carry the ball on Article X measures. The 1995 US working paper on computer networking was a worthwhile effort in that regard. More attention to this aspect of the Protocol is likely to be beneficial.

Article III of the Convention outlaws the transfer "to any recipient whatsoever...any of the agents, toxins, weapons, equipment or means of delivery" for hostile purposes. The Article 
also prohibits State Parties from assisting or encouraging others in obtaining biological weapons. In part, the US has met its Article III obligations through the Australia Group, an informal group of countries that coordinate their export policies and share intelligence to prevent the proliferation of chemical and biological weapons. Countries that are targets of export restrictions want all export controls on biological agents, toxins, and equipment lifted. The US position is against supporting the lifting of export controls in the BWC negotiations, in large measure because of its experiences with the ratification of the Chemical Weapons Treaty. ${ }^{23}$ The Clinton Administration desires a Protocol that will be ratified by the US Senate. It is highly unlikely that the US Senate, as it is presently constituted, would ratify a BWC Protocol that weakened the Australia Group controls. Of course, the United States cannot dictate policy to the other members of the Australia Group, nevertheless, the executive branch is not in a position to propose or support positions in the negotiations that would raise difficulties in the Senate. The US's silence on Article III measures is thus understandable.

\section{Leadership}

Washington's position in the negotiations, to strengthen the effectiveness of the Biological Weapons Convention, became public three years after the onset of the negotiations. While the US contributions to the negotiations have increased, Washington has 
yet to fulfill the leadership role that the President proclaimed in 1998. Recognizing that leadership comes in many forms and that its recognition may be highly subjective, the US has lagged behind in two measures of leadership. The number of US authored working papers has increased since the President's January 1998 announcement, but it does not approach that of the most active participants. A second measure of leadership in the negotiations is to serve as a "Friend of the Chair" on a specific area of concern in the negotiations. The US has never served in this capacity. Although leadership can be exhibited in many forms, the US is not mentioned as a leader in any aspect of these negotiations. Nevertheless, the perception of leadership may be a two-edged sword. Some countries may be reluctant to become parties to the BWC Protocol if they believed the Protocol resulted from a process in which the US was at the helm. Thus, a more robust Protocol may emerge if countries, other than the US, continue as visible leaders of these negotiations.

\section{Conclusions}

The United States' statement on its position in the BWC Protocol negotiations was a long time in coming, and appears to be formulated with a number of primary concerns in mind. Foremost, the US is intent on drafting a Protocol that it can implement completely and accurately at the domestic level. Second, it wants to achieve a Protocol that it can bring to the US Senate with some 
confidence that the Senate will ratify it. Furthermore, in order to achieve a ratifiable treaty it must have the support of the US pharmaceutical and biotechnology industries. Thus far, the US has already fallen short of some of its goals. A Protocol was not completed in 1998 and is unlikely to be finished in 1999. Moreover, the US has not demonstrated the leadership that President Clinton pledged to provide. A number of serious disagreements await resolution. The Western Group must seek agreement on the types of visits to be included in the Protocol and elicit the support of other influential countries such as China and South Africa. Means of implementing Article $X$ without jeopardizing the strength of Article III need to be formulated. Other less-discussed disagreements, for example, the location of this Organization, need to be aired and resolved. The US furthermore needs to renew its efforts to be an active participant in the negotiations. Creativity, problem solving, and skilled diplomacy are needed in Geneva to truly strengthen the effectiveness of this important treaty.

\section{Notes}

1. See Ken Alibek and Stephen Handleman, Biohazard: The Chilling True Story of the Largest Covert Biological Weapons Program in the World-Told from the Inside by the Man Who Ran It, (Random House: New York, 1999); Judith Miller, “At Bleak Asian Site, Killer Germs Survive, 
The New York Times, Wednesday, June 2, 1999, p. A1, col. 1; and, "Renewed Concerns about Russia's Bio Weapons Program," CBW Chronicle, Vol. 2, Issue 4, May 1998, The Henry L. Stimson Center, available on the Web at http://www.stimson.org/cwc/bwissues.htm.

2. Ad Hoc Group of the States Parties to the Convention on the Prohibition of the Development, Production and Stockpiling of Bacteriological (Biological) and Toxin Weapons and on their Destruction, Second Session, BWC/AD HOC GROUP/CRP.2.

3. United States of America, "Discussion of Potential Article $\mathrm{X}$ issues," Ad Hoc Group of the States Parties to the Convention on the Prohibition of the Development, Production and Stockpiling of Bacteriological (Biological) and Toxin Weapons and on their Destruction, Second Session 10-21 July 1995, BWC/AD HOC GROUP/23, 13 July 1995.

4. United States of America, "Computer Networking as a Means of Strengthening the BWC," Ad Hoc Group of the States Parties to the Convention on the Prohibition of the Development, Production and Stockpiling of Bacteriological (Biological) and Toxin Weapons and on their Destruction, Third Session 27 November -8 December 1995, BWC/AD HOC GROUP/25, 1 December 1995. 
5. United States of America, "The Role of Epidemiology in Unusual/Suspicious Outbreaks of Disease," Ad Hoc Group of the States Parties to the Convention on the Prohibition of the Development, Production and Stockpiling of Bacteriological (Biological) and Toxin Weapons and on their Destruction, Fourth Session, 15-26 July, 1996, BWC/AD HOC GROUP/WP.73, 17 July 1996.

6. United States of America, "Preamble," Ad Hoc Group of the States Parties to the Convention on the Prohibition of the Development, Production and Stockpiling of Bacteriological (Biological) and Toxin Weapons and on their Destruction, Seventh Session, 14 July -1 August 1997, BWC/AD HOC GROUP/WP.176, 21 July 1997.

7. For a nearly complete list and the texts of most Ad Hoc Group papers see the Joint SIPRI-Bradford website at http://www.sipri.se/cbw/cbw-sipri-bradford.html.

8. The White House, Office of the Press Secretary, Fact Sheet, The Biological Weapons Convention, January 27, 1998, Washington D.C.

9. Ibid.

10. Ad Hoc Group of the States Parties to the Convention on the Prohibition of the Development, Production and Stockpiling of Bacteriological (Biological) and Toxin Weapons and on their Destruction, Twelfth Session, BWC/AD HOC GROUP/WP.319, 14 September - 9 October 1998. 
11. The "Rolling Text" is the working document that contains the proposed text for the Protocol. The text changes after each Ad Hoc Group session.

12. Procedural Report of the Ad Hoc Group of the States Parties to the Convention on the Prohibition of the Development, Production and Stockpiling of Bacteriological (Biological) and Toxin Weapons and on their Destruction, BWC/AD HOC GROUP/45, Fourteenth Session, 29 March - 9 April 1999.

13. Mr. Holum is presently Senior Advisor for Arms Control and International Security, Department of State.

14. Ad Hoc Group of the States Parties to the Convention on the Prohibition of the Development, Production and Stockpiling of Bacteriological (Biological) and Toxin Weapons and on their Destruction, Eleventh Session, Geneva, 22 June - 10 July 1998. "Proposed Elements of Clarification Visits" Working Paper submitted by the United States, BWC/AD HOC GROUP/WP.294, 9 July 1998.

15. The term "undeclared facilities" could have the connotation of all relevant facilities that have not been declared under the Protocol. In contrast, in this paper the term "undeclared facilities" refers specifically to those facilities that meet the requirements for declaration under the BWC Protocol and, therefore, should have been declared, but have not. 
16. The "Rolling Text" is a document prepared by negotiators containing all of the proposed language of the protocol. The text changes each session to incorporate countries' views. Inclusion of text in the "Rolling Text" does not imply that all countries agree to the language. To the contrary, the text contains alternative wordings, of phrases and entire paragraphs. Moreover, if any country objects to provisions in the text they can insert square brackets "[ ]" around the text to indicate its disagreement with the text. For this chapter, I used the most recent version of the "Rolling Text," that of April 1999. Ad Hoc Group of the States Parties to the Convention on the Prohibition of the Development, Production and Stockpiling of Bacteriological (Biological) and Toxin Weapons and on their Destruction, Fourteenth Session, Geneva, Procedural Report and Rolling Text, BWC/AD HOC GROUP/45, 29 March - 9 April 1999.

17. According to the US proposal, clarification visits to facilities that have not been declared would be reviewed by the Executive Council under a "red light" silence procedure.

18. The IRS collects US federal income taxes.

19. Balancing among regions and types of facilities would mean that the selection process would not be purely random among all declared facilities, but randomly selected within these groups. "Randomly-selected" is the 
designation for these visits in the "Rolling Text" of April 1999.

20. In the CWC, the request goes forward unless two-thirds of the Executive Council denies the request.

21. This argument is taken from my chapter "Strengthening the Biological Arms Control Regime" in Raymond A. Zilinskas, (ed.), Biological Warfare, (Boulder: Lynne Reinner Publishers, 1999).

22. Final Report, Special Conference of the States Parties to the Convention on the Prohibition of the Development, Production and Stockpiling of Bacteriological (Biological) and Toxin Weapons and on their Destruction BWC/SPCONF/1 (Geneva), 19-30 September, 1994.

23. See The Battle to Obtain US Ratification of the Chemical Weapons Convention. Krepon, Michael, Amy E. Smithson, John Parachini, (eds.), The Henry L. Stimson Center, Occasional Paper No. 35. July 1997. 
Chapter 14

\title{
Russian Approach to Strengthening the Regimes of the CW and BW Conventions
}

\author{
Gennadi A. Lutai
}

Historically, different incapacitating substances have been used as a means for conducting combat operations. The first attempts to limit their use can be found in the nineteenth century. However, the real basis for the global prohibition of the use of toxic substances in warfare was laid down by the signing of the Geneva Protocol in 1925. The Protocol's mechanisms were far from perfect because not all States adhered to it, thus the possibility remained that some States might use chemical and biological weapons. The experience of using chemical weapons (CW) in wars and conflicts in this century, where large stocks existed in various countries, confirmed the necessity of eliminating these types of mass destruction weapons. These weapons are easily produced, and consequently, their accessibility to terrorist groups led the international community to the conclusion that it was necessary to totally destroy them and to further prevent their production in the future. In addition, controlling the chemicals that may be used to produce chemical weapons was also restricted. All of these concerns resulted in 1997 in the Convention on the Prohibition of Chemical Weapons (CWC). 
Russia, and the former Soviet Union (USSR), participated actively in the work on the text of the Convention. In 1987, the cessation in the production of CW in the USSR was officially announced, which was in keeping with the principles of the future Convention. The Russian Federation fully adheres to the principles that have been laid down in the CWC.

Russia owns a stock of chemical agents in the amount of 40,000 tons. Because of domestic conditions, Russia did not become an original State Party. However, preparations are well on their way to eliminate its $\mathrm{CW}$ stockpile.

\section{Legal basis for CW destruction in Russia}

There are three basic Russian Federation documents that form the legal basis for the destruction of chemical weapons: the Special Federal Program "Destruction of the CW stockpiles in the Russian Federation" (which has been given a presidential status of extreme importance); Federal Law on the destruction of $\mathrm{CW}$; and the $\mathrm{CWC}$ ratification act.

The Federal Law defines the terms, concepts, and responsibilities of the bodies involved in $\mathrm{CW}$ destruction. This law also envisages the creation of special zones around $\mathrm{CW}$ storage and destruction facilities and the establishment of a network of laboratories and health institutions to monitor for signs of adverse health effects from the activities of such facilities and to further deal with their possible consequences. This law requires that $\mathrm{CW}$ 
destruction facilities be constructed in the areas where CW storage facilities are located.

The CWC ratification act outlines the responsibilities and obligations of the Russian President, the Government, and the Federation Council. The President is given the responsibility for overseeing the implementation of the destruction of chemical weapons and insuring compliance with the provisions of the CWC. This act also requires him to take into account the economic situation within the country when implementing the destruction deadlines and mandates and further requires that the safest available destruction technologies will be used.

The Government, on the other hand, is responsible for the implementation of activities such as coordinating international destruction assistance and overseeing the related health and safety measures. The Federation Council is to provide oversight. In particular, it reviews the annual report prepared by the Government and which the President submits. This report's focus is on the destruction activities, but also includes reports on the status of implementing the CWC, the amounts of chemical weapons destroyed, the construction of $\mathrm{CW}$ destruction facilities, the destruction or conversion of former $\mathrm{CW}$ production facilities, and the condition of the chemical weapons stockpiles. Also, environmental issues are highlighted, such as the $\mathrm{CW}$ storage and destruction sites, and the health of facility personnel and civilians living in the vicinity of these chemical weapons facilities. The act 
also explicitly leaves open the possibility of converting these production facilities into civilian industries.

\section{Implementation of the CWC}

Russia declared to the Organization for the Prohibition of Chemical Weapons (OPCW), seven chemical weapons storage facilities, 24 chemical weapons production facilities, and a dozen commercial chemical industry facilities. During the period of March-August 1998, the initial inspections were completed of Russia's chemical weapons manufacturing and storage sites, and the initial permission was given to conduct inspections of Russia's chemical industry.

For understandable reasons, the economics of implementing the CWC are of great importance to Russia, if Russia is to meet its obligation within the established time frame as set by Convention. Unfortunately, despite the willingness of the Russian Government to meet these obligations, the financial costs are prohibitive. Therefore, international assistance to Russia to meet its $\mathrm{CWC}$ requirements is quite crucial.

To destroy Russia's CW stockpiles, the cost is generally estimated at $\$ 3.5$ to $\$ 5$ billion. Monies that were allocated by the Government for CW destruction in the 1997-1998 budgets were insufficient. Because of insufficient funding to date, this has led to an estimated delay of two or three years in implementing the destruction activities that were planned for 1998. These delays 
also increase the overall cost. Furthermore, Russia expects financial assistance from the international community in order to meet its obligations under the CWC. The total amount of assistance provided by the United States, Germany, and Sweden since 1993 totals $\$ 303.4$ million. The Netherlands, Finland, and the European Union have allocated $\$ 30$ million to the destruction of Russia's chemical weapons and for conversion of its facilities.

Unfortunately, Russian domestic laws, at present, are an impediment to the prompt disbursement of international aid. Both the legislative and executive authorities are undertaking efforts to ensure the most favorable domestic conditions for such cooperation.

\section{Implementing the CWC obligations in other countries}

When the CWC came into force in 1997, its Parties were required to meet several important deadlines so that an effective verification regime could be established. For example, the CWC specifies that the State Parties are required to submit complete initial declarations within 30 days after entry into force. In addition, several verification deadlines must be met. A significant number of State Parties failed to meet these obligations. This is a matter of great concern for Russia. As indicated, Russia submitted its initial declarations in due time. However, some State Parties 
did not declare their facilities or submitted incomplete or partial declarations. Russia, on the other hand, was quite open in meeting all of the requirements, and therefore is justifiably concerned that the behavior of some State Parties will undermine the legitimacy of the CWC.

In this regard, Russia is anticipating the US's initial industrial declaration. There are some provisions of the US Chemical Weapons Convention Implementation Act that contradict the CWC Treaty requirements and obligations. These contradictions have raised serious concerns in the OPCW. It is anticipated that Washington will redress these concerns and comply with the CWC.

\section{Universality}

Universal adherence to the CWC contributes to its strength, and therefore is a key objective to be met. There are 121 parties to the Convention and 45 additional states have signed but not ratified the CWC as of April 1999. Critical to the overall credibility and long-term effectiveness of the CWC are the nations in the Middle East and North Africa (e.g., Israel, Egypt, Libya, Syria, etc.), where $\mathrm{CW}$ proliferation is acute, who have yet to sign the CWC, and who argue that they will not do so until Israel accedes to the NPT. The Russian Ambassador, A. Khodakov, at the Third Plenary Session of the Conference of the OPCW, stressed Moscow's concern, and urged the OPCW to continue its untiring efforts to expand the 
signatories to the Convention so that the CWC will acquire universality.

\section{Nonproliferation}

Among the other important provisions of the CWC Treaty have to do with control mechanisms, and requires the State Parties to report certain chemicals that appear in the Annex, Schedule I, II, and III. Article I of the Treaty commits State Parties never to "assist, encourage, or induce, in any way, anyone to engage in any activity prohibited" under the CWC.

Schedule I, of the three schedules, contains a list of chemicals that can only be transferred between two parties for nonprohibited purposes, in defined quantities. They cannot be retransferred to a third party, and both parties must notify the Technical Secretariat no later than 30 days before any transfer takes place. Furthermore, all parties must submit detailed annual reports on the transfer of Schedule I chemicals. Three years after the entry into force of the CWC, its State Parties will be permitted to transfer Schedule II chemicals only among themselves. Such transactions are not subjects to the stringent quantitative conditions and reporting requirements that apply to Schedule I chemicals. While the transfer of schedule III chemicals is only addressed in relation to non-parties, the end-users certificate is a prerequisite in such transactions. 
The categorization of chemicals under the $\mathrm{CWC}$ also requires the State Parties to establish a global treaty-based trade control regime. In addition, the verification and inspection regimes of the CWC further enhance the effectiveness and credibility of the trade controls imposed by the Treaty. There is no doubt that the future of the CWC is dependant upon achieving universality in ratification, and that the State Parties provide complete and accurate declarations.

\section{On the way to the $\mathrm{BWC}$ verification regime}

The Russian Federation, being one of the three depositaries of the BW Convention that prohibits biological weapons, supported from the outset efforts of the international community to strengthen it, and, in fact, Russia actively participated in the negotiations, using its extensive expertise in this area. A number of provisions that were developed by the Russian experts were included for further discussion in the "Rolling Text" of the Draft Protocol. On September 2, 1998, during the Russia/US Summit, a joint statement by the Presidents of Russia and the US was adopted. This statement called for the negotiations in the development of the Protocol and reflected the adherence of both countries to the purposes of strengthening the BW Convention and the desire of both countries to work jointly to ensure speedy progress in negotiating the BW Protocol. 


\section{Declarations}

Presently the State Parties participating in these negotiations have agreed that the Protocol will provide for annual mandatory declarations of facilities and activities related to the BW Convention. Complicated work is currently under way to agree to the scope and formats of such declarations. The task of the State Parties is to determine the facilities and activities that require declaration and verifications, and these, therefore, should be covered by a transparency regime. The criteria that Russia set forth that will "trigger" an inspection and verification follow:

- Facilities which participate in biological weapons defense programs and carry out work with any microorganisms and toxins as well as with materials imitating their properties;

- Facilities at which work is carried out with biological agents and toxins (a list that will be part of the Protocol) except for facilities that conduct only diagnostic and/or medical activities;

- Facilities which produce vaccines and/or anatoxins for human and animal protection against listed biological agents and toxins;

- Facilities with a BL-4 biological safety level according to the World Health Organization's classification; and,

- Facilities which have open-air aerosol dispersion equipment with particulates no greater than 10 microns. 
On the whole, the "triggers" proposed by the Russian Federation have raised no objections from the other State Parties. The inclusion of a number of other "triggers," in the opinion of Russia and other countries, would lead to an unjustified expansion of the declaration's scope. Discussions continue on this proposal.

\section{Investigations}

Another important element pertaining to verification mechanisms is the possibility of conducting on-site inspections of possible violations of the BW Convention. The Russian Federation considers such inspections as an important and effective instrument for verifying compliance of the BW Convention. The "trigger" mechanisms and the specific procedures for such investigations are now being developed. Any State Party to this Protocol will have the right to request an investigation concerning another State Party's facilities. The decision concerning the conduct of such investigation will be taken up by the Executive Council, which will consist, on a rotating basis, of State Parties representing different regional geographic areas. It is assumed that when a State Party requests an on-site inspection, it is obligated to include sufficient information to justify this action. This requirement is aimed at avoiding abuses of the investigative mechanisms for political purposes.

If suspicion arises that there has been a breach of the Treaty, the State Party will send a request for an investigation 
containing mandatory and supplementary information, in accordance with the format contained in the Protocol, to the Technical Secretariat of the proposed Organization on the Prohibition of Biological Weapons (OPBW). They will then investigate whether the request is in accordance with the format stipulated in the Protocol. The request will be considered by the Executive Council and will require a two-thirds vote of the Executive Council members to sustain such an action.

A number of the State Parties have suggested that the verification mechanisms should include field investigations of outbreaks of infectious diseases or the effect that certain microorganisms have on human beings, animals, and plants. In the opinion of Moscow, phenomena associated with releases or "exposure of humans, animals, and plants to micro-organisms" cannot be the subject of an investigation. Such situations are related to outbreaks that may occur by virtue of natural endemicity or a result of activities at enterprises that are not prohibited under the Protocol. Such events should not be subject to any prohibition under the Convention and consequently would not fall under the scope of the Protocol. Epidemiological analysis and evaluation of outbreaks of infectious diseases fall under the competence of national health and epidemiological surveillance bodies and the corresponding jurisdiction of the World Health Organization. Moreover, such investigations would lead to intrinsic inspection 
activity. This would inevitably lead to greater on-site inspection costs and duplication in activity of the World Health Organization.

\section{Definitions and objective criteria}

Russia assumes that in verifying compliance of the Convention, prohibited and allowed activities, along with the definition of terms, must be distinguished and clarified. These explications are necessary for defining only verification terms of compliance under the Protocol, and are not intended to revise Article I of the BWC. Finally, the Russian Federation is proposing of compiling a list of the most dangerous agents and toxins, updated periodically, and would apply to all elements of the Protocol.

\section{Non-challenge visits}

Russia, along with several other State Parties, opposes nonchallenge visits. It is Moscow's view that within the verification regime, there is sufficient flexibility to allow challenge inspections so as to verify compliance effectively. Any technical errors or omissions in declarations can be clarified through the process of consultation. In order to carry out routine inspections, this will lead to an increase in the number of inspectors and the accompanying cost in verification. Additionally, non-challenge 
inspections will affect the normal functioning of industries and could conceivably jeopardize commercial secrets.

\section{Organization}

It is anticipated that the implementation of the Protocol will be entrusted to the Organization on the Prohibition of Biological Weapons specifically established for this purpose. Most States share the opinion that such an Organization should be established, and will be small and cost-effective. It is the Russian Federation view that the size and configuration of the OPBW Organization, which must be independent, should be determined only after an agreement is reached on the functions of the verification regime, which takes into account the opinion of the State Parties.

\section{Prospects for the completion of the negotiations}

Overall, many difficult questions remain to be resolved before the Protocol is completed. It is necessary to affect a balanced verification regime that, on the one hand, ensures effective implementation of the BW Convention; and, on the other hand, will not be too cumbersome and expensive to implement, and therefore, not damage the national security interests and industrial developments of the States Parties. What will be required to achieve this goal is the political will of the State Parties in finding mutually acceptable solutions. 
. 
Chapter 15

\title{
OPCW: A Role Model for Peace in the New Millennium?
}

\author{
Sergei N. Kisselev
}

The Chemical Weapons Convention (CWC) entered into force just two years ago on 29 April 1997. The Organization for the Prohibition of Chemical Weapons (OPCW) came into being on the same day. It has now grown into an Organization of approximately 500 staff members, including over 200 inspectors. At the present time, 121 States Parties to the Convention represent the membership of the Organization. An additional 48 States have signed the treaty, but have not yet completed their internal preparations for the deposit of their instruments of ratification. Such States are nevertheless bound under international law not to undercut the provisions of the Convention unless they give formal notice that they do not intend to ratify it.

Such a level of adherence so early in the life of an international disarmament treaty is unprecedented. Given the intricate complexity of the Chemical Weapons Convention (together with its annexes, runs well over 150 pages of legal text) and the importance of the disarmament and security matters that it addresses, a high degree of formal adherence at such an early stage in the life of the Convention, demonstrates the importance that States attach both to the global elimination of chemical weapons 
and to the universal nature of the obligations that States assume when they become parties to the Convention.

The implementation of the Convention offers a dual challenge: arms control and the development of the commercial chemical industry. The arms control objectives consist of two complementary elements: disarmament and nonproliferation. The obligations the States Parties assume reflect the intricate nature of the Convention's goals. First, the States Parties must declare chemical weapons related information and activities, and permit the systematic monitoring of chemical weapons production, storage, and destruction facilities. The States Parties must submit information on old and abandoned chemical weapons sites and permit for their verification. They further agree to the declaration and verification by routine inspection of their industries that produce, process, and/or consume chemicals listed specifically or by family in the Schedules of Chemicals in the Annex on Chemicals in the Convention, and may agree in the future to routine inspection of plant sites producing discrete organic chemicals over certain quantity thresholds. Additionally, these States Parties have agreed to receive challenge inspections requested by other States Parties and accede to certain restrictions in trade of Scheduled chemicals with States not party to the Convention.

Without prejudice to the economic development aspects of the CWC, this presentation concentrates on the arms control side of 
the OPCW's activities. To better understand the approach in the practical implementation of the CWC verification requirements, it is useful to examine the structure of the OPCW, and the organization of its Secretariat that is mandated by the Convention the responsibilities for carrying out its verification regime.

\section{Organization's structure}

The principal organs of the OPCW are the Conference of States Parties, the Executive Council and the Technical Secretariat. The head of the OPCW is its Director-General appointed by the Conference of the States Parties upon the recommendation of the Executive Council and responsible to both for the appointment of the staff of the Secretariat, its organization and functioning. The Secretariat provides the administrative and operational components for the organization. Providing speciality advice and oversight are two additional bodies, the Scientific Advisory Board and the Confidentiality Commission. Together these components interact to accomplish the object and purpose of the CWC.

\{Figure 1: OPCW Structure

Following Page\} 
Figure 1

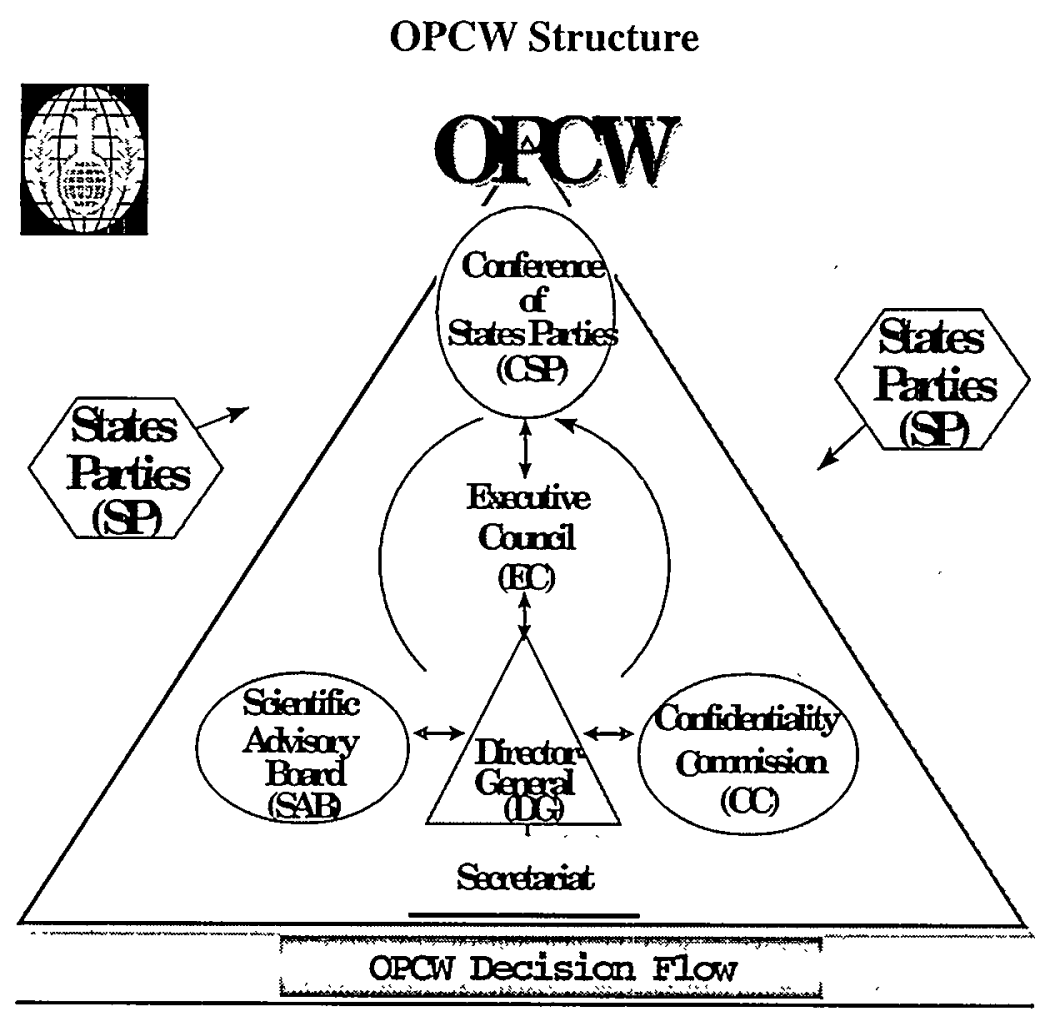

The Conference of the States Parties - the principal organ of the OPCW - is composed of all signatories to the CWC, and its purpose is to oversee the implementation of the Convention in order to promote its object and purpose. It has the power to make recommendations and take decisions on any matters related to the CWC raised by a State Party or brought to its attention by the Executive Council. The Conference meets on an annual basis and, when required, in extraordinary sessions.

The Executive Council is the Organization's executive organ. It has the responsibility for supervising the activities of the 
Secretariat, cooperating with National Authorities, and facilitating consultations and cooperation among States Parties. It reports directly to the Conference of States Parties. The Executive Council consists of 41 States Parties which are elected by the Conference for terms of 2 years from among the States Parties representing the seven geographical areas: Africa, Asia, Eastern Europe, Latin America, the Caribbean, Western European, and Other States. The Executive Council meets four times a year for its regular sessions with additional meeting when necessary.

The role of the Executive Council is extremely important. Its scope includes:

- drafting of the program of work and budget for the Conference of the States Parties;

- reporting to the Conference on the implementation of the CWC and on it own activities;

- $\quad$ arranging of the agenda for the Conference;

- concluding agreements or arrangements with States Parties and international organizations on behalf of the Organization subject to the Conference's approval, including on Article $\mathrm{X}$ issues;

- approving agreements or arrangements relating to the implementation of verification activities negotiated by the Technical Secretariat with States Parties;

- issuing of compliance and noncompliance reports; and, 
- in cases of particular gravity and urgency, referring compliance issues to the attention of the United Nations General Assembly and Security Council.

The Scientific Advisory Board is composed of independent experts in a variety of fields. The Director General appoints the members of the Board. They render advice in the areas of science and technology relevant to the Convention to the Conference, Executive Council, or States Parties.

The Confidentiality Commission consists of 20 representatives from the States Parties. Its function is to consider breaches in confidentiality involving both a State Party and the Organization. The existence of this Commission operating with high visibility in the top structure of the Organization is a clear signal to all of the seriousness with which confidentiality is taken by all connected with the OPCW.

\section{Secretariat}

The Secretariat is primarily focused on carrying out the verification measures required by the Convention. The Secretariat consists of five Divisions: The Office of the Director-General, 
Office of the Deputy Director-General, Office of Internal Oversight, Office of the Legal Adviser, Office of Special Projects, and Secretariat for the Policy-Making Organs. The Deputy Director-General is responsible for the Verification Division, the Inspectorate, the External Relations Division, the Administrative Division, and for the International Cooperation and Assistance Division.

\{Figure 2: OPCW Secretariat Following Page 
Figure 2

OPCW Secretariat

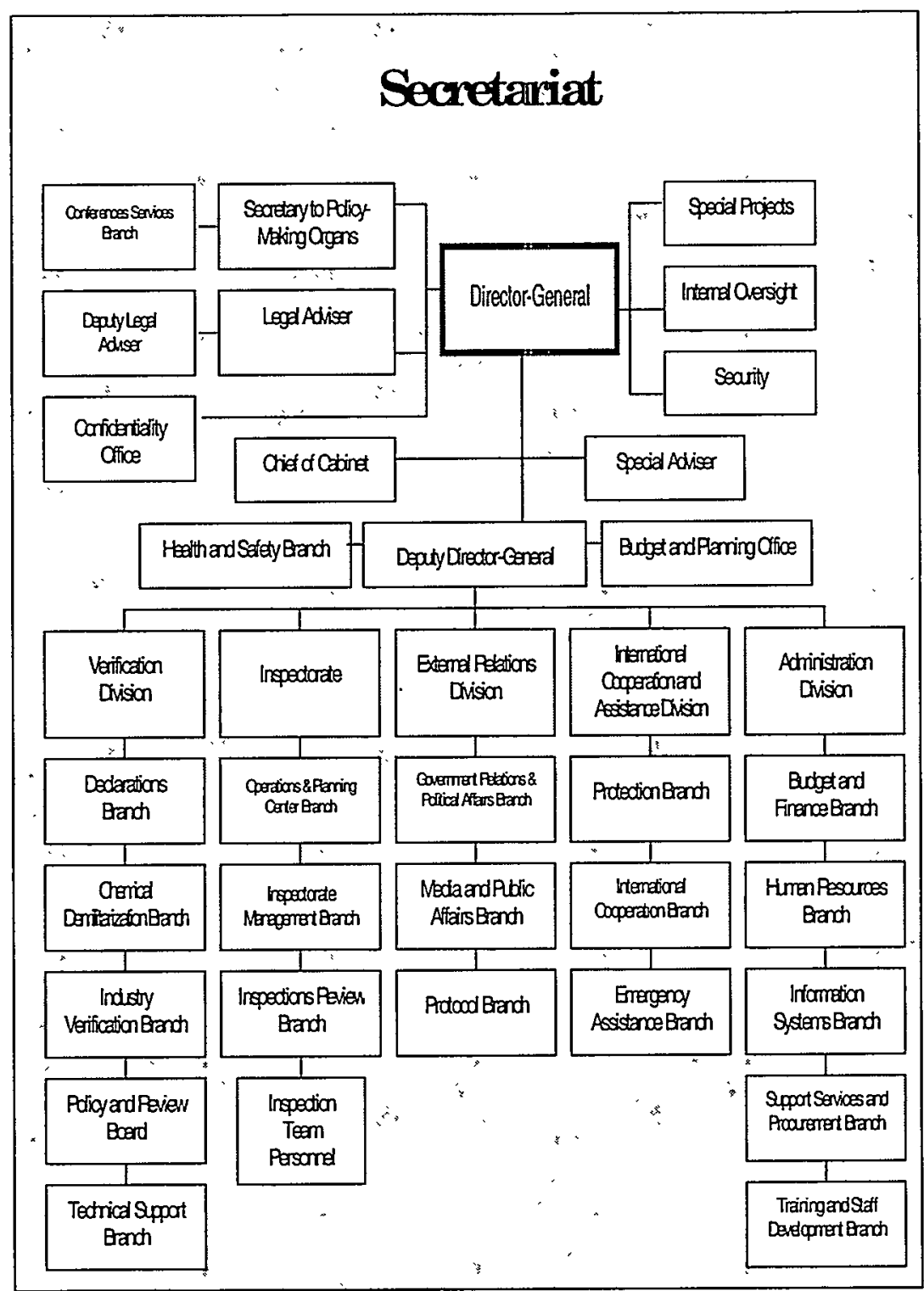




\section{Chemical weapons: verification and destruction}

As of 1 March 1999, the Secretariat of the OPCW had conducted 413 inspections at both chemical weapons and industry facilities and at sites in 29 States Parties, including 43 inspections of Schedule 1 facilities, and 96 Schedule 2 and Schedule 3 industrial plant sites. These inspections have been undertaken with a total of only 11 substantive officers. These officers are responsible for inspection planning. The inspectorate corps had a total of 208 inspectors by the beginning of 1999 .

The destruction of chemical weapons and verification will be the most important activities of the Organization over the next decade. States Parties to the Convention must declare, if they possess chemical weapons, within 30 days after the Convention enters into force. They must further declare the quantities and types of chemical weapons that exist on their territory and those chemicals that they are responsible for outside of their territory. States Parties also agree to place all storage sites that contain chemical weapons, the facilities which produced them, and the facilities that are used to destroy them under an international verification regime.

The CWC defines a chemical weapon in the following manner:

- Toxic chemicals and their precursors, except where intended for purposes not prohibited under this Convention, 
as long as the types and quantities are consistent with such purposes;

- Munitions and devices, specifically designed to cause death or other harm through the toxic properties of those toxic chemicals specified in subparagraph (a), which would be released as a result of the employment of such munitions and devices; and,

- Any equipment specifically designed for use directly in connection with the employment of munitions and devices specified in subparagraph (b).” [Article II, paragraph 1]

In terms of the Convention, the definition of a chemical weapon is not limited to a toxic chemical filled munition, but also includes toxic chemicals (except where they can be shown to have a legitimate use), the munition components and any equipment specifically designed for use with the chemical weapons.

The Convention also makes a distinction between various classes of chemical weapons. They are:

- $\quad$ old chemical weapons produced before 1925;

- $\quad$ old chemical weapons produced between 1925 and 1946 and determined to be unusable;

- chemical weapons produced after 1946, irrespective of their condition;

- $\quad$ chemical weapons buried before 1 January 1977 (and which remain buried); 
- $\quad$ chemical weapons dumped at sea before 1 January 1985; and,

- $\quad$ abandoned chemical weapons.

All chemical weapons storage facilities and chemical weapons destruction facilities are subject to systematic verification through on-site inspection and continuous monitoring with on-site instruments. Once a declaration has been made according to fixed time lines, a State Party is not permitted to remove these chemical weapons, except for their transfer and destruction. The declared facilities must all receive a prompt initial inspection after they have been declared. The purpose of these inspections is to verify information provided and to obtain any additional information needed for planning future verification activities at the facility and to initiate work on the facility agreement.

The purpose of the CWC regarding the verification of $\mathrm{CW}$ destruction is twofold. First, to confirm the identity and quantity of chemical weapons stocks to be destroyed; and second, to confirm that these stocks have, in fact, been destroyed. For the purpose of their destruction, chemical weapons that were produced between 1925-1946 and determined to still be usable, and those produced after 1946 are further divided into three categories:

- Category 1 chemical weapons employing chemicals which appear on Schedule 1 of the list of chemicals annexed to the 
Convention, as well as their parts and components must be destroyed within 10 years;

- Category 2 chemical weapons produced on the basis of all other chemicals and their parts and components; and,

- $\quad$ Category 3 unfilled munitions and devices, and equipment specifically designed for use directly in connection with employment of chemical weapons must be destroyed with five years of the Treaty coming into place.

An extension of up to two years for the destruction of Category 1 weapons may be granted by the Conference of the States Parties upon the recommendation of the Executive Council.

\{Figure 3:

Order of Destruction of Category 1 Chemical Weapons

Following Page\} 
Figure 3

Order of Destruction of Category 1 Chemical Weapons

REQUIRED DESTRUCTION RATE UNDER CWC

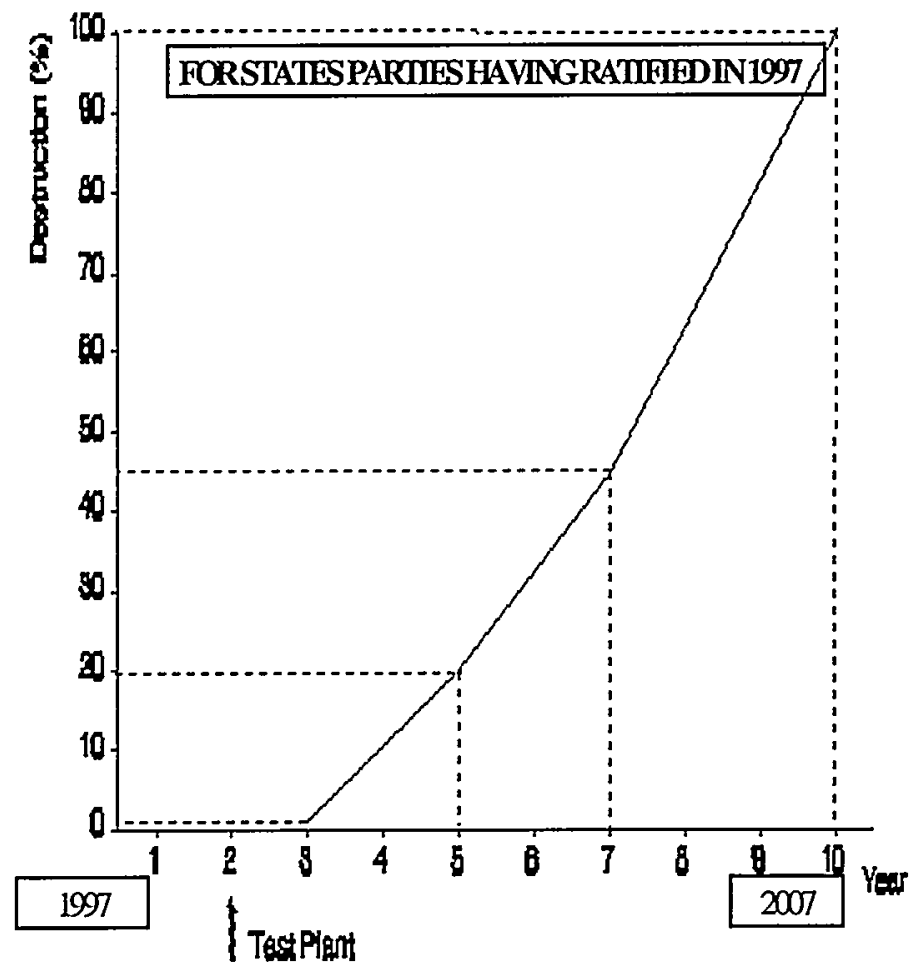

A distinct category in the CWC deals with old and abandoned chemical weapons. These chemical weapons, which were produced either before 1925 or chemical weapons which were produced between 1925 and 1946 and which are determined to be unusable, are both classified as old chemical weapons. Furthermore, weapons produced before 1925 must be declared, and after their status has been verified by the Secretariat, destroyed as 
toxic waste. Old chemical weapons that were produced between 1925 and 1946 must also be declared, and their status verified at which time they must be destroyed in accordance with Article IV and Part IV (A) of the Verification Annex. The practical problem that has been facing the Secretariat since the CWC's entry into force is the absence of any agreed guidelines for determining the usability of chemical weapons. This requires the Secretariat to treat the cases of declared old chemical weapons as chemical weapons, and to assess the risks posed by such cases.

Abandoned and old chemical weapons are defined by the Convention as all chemical weapons that were abandoned by a State after l January 1925 on the territory of another State without the latter's consent. The abandoning State Party is required to provide all necessary technical and financial assistance to the State on whose territory the chemical weapons were abandoned.

The Convention states that it is up to the State Party possessing the chemical weapons to decide how it will destroy them. Destruction must be undertaken at specially designated and appropriately designed and equipped facilities and in a safe manner. Dumping these chemical weapons in a body of water, land burial, or open pit burning is specifically forbidden under the terms of the CWC. These are specific rules that stipulate in the Convention the past disposal of chemical weapons by either burial or sea dumping.

Furthermore, the CWC requires that verification take place through continuous monitoring with on-site instruments and 
physical presence of inspectors of the destruction of chemical weapons stocks. The inspectors are responsible for maintaining an inventory of chemical weapons received and destroyed, and to witness their destruction.

The Convention further requires that a State Party constructs and operates its destruction facilities in a manner, which will readily permit verification of the destruction of chemical weapons in accordance with the provisions of the Treaty. This requirement is not only important from the viewpoint of allowing the Secretariat to do its job in a most efficient manner, but also is directly relevant for the inspected State Party's cost in the destruction operations.

By far the largest share of the Secretariat's verification efforts and consequently the costs of verifications are supported by the States Parties who possess chemical weapons. Therefore, it is essential that verification requirements must be considered fully during the design and construction of any chemical weapons destruction facility. This will help minimize the costs of verification and allow the Secretariat's resources to be used in a cost-effective manner.

Furthermore, when designing a destruction facility maximum consideration should be given to the installation of remote instrumentation and monitoring equipment such as video cameras. This in turn will help minimize the inspecting workload, and correspondingly, the number of inspectors that need to be present on-site. 
Four States Parties to the CWC, including the Russian Federation and the United States, made declarations of their current holdings of chemical weapons stored at 33 chemical weapons storage facilities, and four have submitted their general destruction plans. Although only the United States has started a full-scale operation destroying its chemical weapons stockpile, significant results have been achieved in the destruction phase from the Convention's entry into force.

For example, during the period from 1 August 1997 until 1 February 1999, when monitoring operations began at destruction sites in the United States, inspection teams witnessed the destruction of a total of approximately 2,052 metric tons (MTs) of nerve agent (GB), blister agent ( $\mathrm{HD}$ ), and 159,813 unitary munitions. Furthermore, 293 MTs of binary components, and 11,814 items were destroyed that fall under Category 3 chemical weapons. During the same period the Secretariat also conducted 67 rotations of chemical weapons storage facilities inspection teams. One other State Party began the destruction of a limited amount of Category 3 chemical munitions in late 1998, while the remaining CW possessors are expected to begin destruction operations during the years 1999-2000.

There were nine States Parties that submitted declarations of old chemical weapons or abandoned chemical weapons on their territory upon the CWC's entry into force. As of 1 March 1999, a total of 29 initial inspections had been conducted at declared sites. 
One of the key goals of the CWC is the elimination of the production base for chemical weapons. A total of 69 current States Parties have declared such sites. According to the CWC, all production facilities must be destroyed within 10 years of its entry into force or must be converted to non-prohibited purposes. At the time of this writing, 11 production facilities in five States Parties were certified by the Organization as destroyed.

If a State Party desires, it may convert a chemical weapons production facility into a destruction facility. However, at the end of the destruction process, the converted facility must be destroyed. Thus far, only one chemical weapons production facility has been put under the temporary conversion procedure for $\mathrm{CW}$ destruction purposes.

Additionally, a State Party may also request, in exceptional cases, permission to use a chemical weapons production facility for purposes not prohibited by the Convention. The CWC stipulates that the conversion must be done in a manner that will make the facility less capable of being reconverted into a chemical weapons production facility than any other facility used for industrial, agricultural, research, medical, pharmaceutical, or for other peaceful purposes not involving chemicals listed in Schedule 1 of the Convention. It should be noted that the approval of a conversion request is the prerogative of the Executive Council that makes an appropriate recommendation to the Conference of the States Parties. Thus far, only two conversion requests involving 
facilities in the United States and the United Kingdom have been approved by the Conference. A conversion request for a facility in the Russian Federation has passed the scrutiny of the Executive Council and is to be presented to Conference shortly.

\section{Chemical industry: CW nonproliferation}

The declaration and verification requirements for the chemical industry under Article VI of the Convention are very extensive.

It requests that all Schedule 1 chemical production facilities with the exception of certain medical, pharmaceutical, or research facilities with the production of under 100 grams per year, must be declared. Also all transfers of Schedule 1 chemicals between States Parties must be declared. Furthermore, all declared Schedule 1 facilities are subject to on-site inspections. For example, facilities producing over 100 grams per year of nitrogen mustard for pharmaceutical purposes must be declared and be ready to receive systematic inspections.

For Schedule 2 sites, declarations must be made of the production, processing, consumption, import, and export of Schedule 2 chemicals when the operations of these plants exceed certain thresholds, ranging from $10 \mathrm{~kg}$ in the case of the substance $\mathrm{BZ}$ used in analgesic production, to one ton in the case of chemicals like DMMP that are used for flame retardant plastics. Initial and routine inspections will be necessary when verification 
thresholds are exceeded, which are approximately 10 times the declaration thresholds.

In the case of Schedule 3 plants, declarations are necessary for the 17 high volume, toxic, and precursor chemicals listed when production exceeds 30 tons per year. Routine inspections can be expected when production exceeds 200 tons per year. Thus, plant sites producing chemicals like phosgene, used in the production of polyurethane chemicals, and sulphur dichloride used in the vulcanization of rubber products, must be declared when production exceeds 30 tons per year.

The verification regime of the CWC also covers plant sites involved in the production by synthesis of Discrete Organic Chemicals when the plant exceeds 200 tons per year. For sites where the production of specific chemicals containing phosphorus, sulfur, or fluorine takes place the threshold for these plant sites to be inspected is set at 30 tons per year. These are plants that produce organic chemicals containing carbon, hydrogen, and at least one other element, such as ethylene oxide used to produce ethylene glycol, and polyethylene glycols used in producing speciality resins, glues, plastics, and additives.

There are 24 Schedule 1 facilities currently declared by 19 of the States Parties. All these facilities are subject to inspection. In fact, 43 inspections have been completed during the period between the inspection of the CWC and 1 March 1999, and additional 17 facilities will be inspected, some of which will be 
initial inspections of newly declared facilities and re-inspection of facilities known to the Secretariat.

As of 31 December 1998, 24 States Parties have declared 297 Schedule 2 plant sites whose activities include producing and processing activities above the declaration thresholds. Of these 119 plant sites were determined to be inspectable under the requirements of the Convention.

It appears that Schedule 2 declarations reflect an imbalance in the world distribution of the chemical industry that is covered by the CWC. The locations of the declared Schedule 2 plant sites are primarily in the Asian, Western European, and other geographical regions. Eight States Parties had declared a combined total of 246 or $83 \%$ of these Schedule 2 plant sites. It should be noted that the number of declared Schedule 2 plant sites remains significantly below the 400 that expected to be declared by the Conference of the States Parties. The Secretariat believes that the difference between anticipated and declared sites is in part due to the non-submission or under-submission of initial industry declarations by some of the States Parties.

As of 1 March 1999, 83 initial inspections of Schedule 2 plant sites have been conducted. As of the end of 1998, 28 States Parties declared under Schedule 3, 395 plant sites producing above their declared threshold. Of these, there were 329 Schedule 3 plant sites whose production above the verification threshold of 200 tons annually made them eligible for inspections. The geographic 
locations of the declared Schedule 3 plants, as is the case of the declared Schedule 2 sites, are mainly located in the regions of Asia, Western European, and others states (over $90 \%$ ).

The inspections of Schedule 3 facilities were launched in 1998 in an effort to redress the geographic balance of the chemical industry inspections. As of 1 March 1999, 14 inspections of Schedule 3 plant sites were carried out by the Secretariat. The selections of such sites were made on a random basis using a specially designed computer software program featuring two weighing factors: equitable geographical distribution of inspections, and the availability of information on the declared plant sites. Because of the limited number of sites and their locations, a few States Parties resulted in inspections in countries that were scrutinized under Schedule 2.

A significantly larger network of chemical industry facilities is covered by the CWC's regime relating to plant sites producing discrete organic chemicals. Forty-three States Parties declared 3,507 such sites, of which 3390 were found to be inspectable under the Convention. The inspection of these facilities is not expected to begin until the fourth year after the entry into force of the CWC. This requirement was obviously included in the Treaty to allow for initial inspections of all declared Schedule 2 plant sites. As is the case of the chemical weapons related facilities, follow-up inspections of the chemical industry are expected to be conducted largely on the basis of individual facility 
agreements concluded between the Organization and the inspected State Party. Unlike in the chemical weapons area, the need for such agreements will reflect the perceived risk different industry facilities pose to the objectives of the CWC.

\section{Confidentiality and transparency: two sides of the same coin}

Adhering to the Convention imposes stringent obligations on its States Parties, but this stringency is tempered by the assurance that the States Parties' sensitive information, be it national security or confidential business information, will be treated in a highly confidential manner. In order to meet these concerns, all declaration and inspection information within a regime governing the handling of confidential information as embodied in the OPCW Policy on Confidentiality.

The protection of confidential information requires any organization, agency or company, and the persons employed by it to work in a secure environment. The OPCW building was specially designed and constructed to ensure high levels of physical and electronic security. Access to classified declarations, verification and facility agreements' information is strictly controlled. Authorization to see a classified document is reviewed on a case-by-case basis. For example, when an inspection team is selected for an inspection of a particular facility, they will be given access only to that specific facility information. Furthermore, each 
member of the team is on the access roster of the State Party in question and each inspector has a specific access authorization signed by the Director of the Inspectorate. There is no doubt that the OPCW's approach to accessing and safeguarding of confidential information in many instances goes beyond what States Parties do themselves. This rigorous approach is pursued with the purpose of providing governments and their industries confidence that their interests will be protected.

The process described above does not mean that the OPCW Secretariat is a "black hole" providing no feedback to the States Parties on the results of its verification activities. Quite to the contrary! The CWC, including its Confidentiality Annex, establishes very clear procedures for States Parties as to how to access the data obtained by the Secretariat that States Parties need to be assured of the continued compliance with the Convention by other OPCW members. This data is routinely provided to them, including initial and annual reports and declarations submitted by States Parties to the Secretariat, general reports on the results and effectiveness of verification-activities, as well as information supplied to all States Parties in accordance with specific provisions in the Convention.

Apart from the declaration data provided to any requesting State Party, the Secretariat also submits two basic reports to the States Parties. The first is the Status of Implementation Report prepared for each regular session of the Executive Council, which 
includes data on the status of declarations and other information required from States Parties, progress on the inspection activities and on technical cooperation and assistance issues. In addition to these two basic reports, the Secretariat provides additional information on various aspects of the CWC implementation, such as data on the status of chemical weapons and on chemical weapons destruction programs, when so requested by the Executive Council.

Over the past two years, States Parties have been engaged in discussions of how best to ensure a balance between the interests of confidentiality and transparency. Although no specific conclusions have been reached, the discussions seem to lead in the direction of the Secretariat circulating among the States Parties its reports on specific issues that contain sensitive information in a highly classified form. This will allow the necessary degree of transparency, and at the same time effectively retain such information "in house". To achieve the latter, all States Parties are required to institute internal procedures to protect the OPCW's confidential information that is made available to them.

\section{Issues and lessons learned}

Looking back these past two years, there is no doubt that the regime of the Chemical Weapons Convention has worked. This is due to the high degree of practical cooperation between the Member States and the OPCW Secretariat. However, one should 
not lose sight of a certain number of problems that were encountered such as incomplete or non-timely submission of declarations/notifications required under different elements of the Convention, restrictions on the use of approved inspection equipment, and over protection of confidential information. It would be useful here to discuss in some detail the problems related to natural declarations by States Parties.

Due to the nature and complexity of national declarations, the Secretariat provided assistance so that States could meet their declaration requirements. As of March 1999, only 91 of 121 States Parties had submitted their initial declarations, which are required within 30 days of the Convention's entry into force. A significant part of these declarations are inaccurate or incomplete. This, for example, has resulted in serious imbalances in the number of chemical industry sites declared to the Secretariat, particularly to Schedule 2 facilities.

Another area of concern is the lack of completeness and uniformity of the declarations provided most especially in the aggregate national data on transfers of Schedule 2 and 3 chemicals between States Parties. In some cases, the amounts of imported and exported or transferred chemicals between two States Parties differ by an order of one magnitude or more. Over 90 percent of declared transfers could not be reconciled on the basis of data provided to the Secretariat. 
Although a lot more effort is needed to increase the number of declarations and to improve their completeness and uniformity, the information declared to the Secretariat permits on-site inspections to proceed as required under CWC. Despite hectic administrative, technical, and logistical arrangements involved in launching or receiving an on-site inspection thus far, the OPCW has been successful without major incidents.

\section{Looking ahead}

Given the technical complexity and political sensitivity of the CWC regime, the political will of States Parties to implement it is essential. The smoothness with which the Convention's verification provisions have been applied suggests that there is no lack of willingness on the part of the States Parties for its implementation. When the Convention is universally implemented, and when existing chemical weapons have been or are in the process of being destroyed, and when the monitoring of industry is in place to ensure that prohibited chemical activity cannot occur, the world will have witnessed an unprecedented achievement: the elimination from this planet of an entire category of Weapons of Mass Destruction. 


\section{Part V}

Nonproliferation Review -2000 


\title{
Chapter 16
}

\section{Security Assurances and the NPT}

\author{
Michael O. Wheeler
}

Since the time of the Baruch Plan in 1946, a search for security assurances has been part of the arms control agenda. States that give up or promise not to acquire Weapons of Mass Destruction (WMD) seek safeguards against seriously compromising their security because of such actions. This theme always has been in the backdrop of arms control negotiations. When the Nuclear Nonproliferation Treaty (NPT) was negotiated in the 1960s, the specialized vocabulary of 'positive' and 'negative' security assurances emerged to help define the type of world envisioned by the NPT. It is a world in which for an undefined period, five states legally would have nuclear weapons while all other states (assuming eventual universality of the NPT regime) would not. Positive security assurances were guarantees extended to the Non-Nuclear Weapon States (NNWS) that they would receive assistance if they were threatened or attacked with nuclear weapons. Negative security assurances were promises sought from the Nuclear Weapon States (NWS) that they would not use or threaten to use nuclear weapons against Non-Nuclear Weapon States that had joined the NPT. 
This paper will briefly sketch the history of positive and negative security assurances; explain the current issues and circumstances surrounding the security assurance debate; explore why in the author's opinion there is little prospect at the NPT Review Conference in the year 2000 (hereafter referred to as NPT '00) for breaking existing stalemates; and recommend a new framework for future discussion which may provide a way around the current deadlocks.

\section{Positive security assurances and the NPT}

In October 1964, the People's Republic of China conducted its first nuclear test, joining the United States, the Soviet Union, Britain, and France as the fifth acknowledged Nuclear Weapon State in the world. President Johnson immediately issued a statement that "Nations that do not seek nuclear weapons can be sure that if they need our strong support against some threat of nuclear blackmail, they will have it." $\quad$ This statement had been worked out ahead of time in an interagency committee, which was conducting the quiet dialogue that had begun in the Kennedy Administration and was continued in the Johnson Administration of how to approach the problem of nuclear proliferation. ${ }^{2}$ That committee met again in November 1964, under the chairmanship of Secretary of State, Dean Rusk, who "asked the basic question [in light of the recent Chinese test] of whether the US should oppose other countries' obtaining nuclear weapons over the next 
ten years." Rusk raised the point that one "could conceive of situations where the Japanese or Indians might desirably have their own nuclear weapons [to defend against China]." Secretary of Defense, Robert McNamara, admitted that this question had not been examined thoroughly. Looking forward to the results of reviews then underway within the interagency and in the independently commissioned Gilpatric Committee, McNamara "raised the question of whether a nonproliferation policy automatically meant providing a nuclear guarantee to all countries." The meeting ended inconclusively, with the admonition to keep the discussion and the on-going review highly classified, so as not to prejudice the outcome of the policy review in this sensitive area. ${ }^{3}$

As we now know, President Johnson accepted the advice of his government advisers, the Gilpatric Committee, and powerful members of Congress to seek a treaty that would prohibit further proliferation of nuclear weapons. The Johnson Administration fully expected that to achieve the NPT, the Non-Nuclear Weapon States would demand that their security not be jeopardized as a result of their acceptance of a duty not to acquire nuclear weapons. Some of those states, namely those allied to nuclear powers, might be satisfied with guarantees extended them by terms of their alliances, although even that might prove inadequate to the task. For instance, when negotiations on the NPT began in 1965, two of America's North Atlantic Treaty Organization (NATO) allies, 
West Germany and Italy, expressed concern that the Article V guarantees in the North Atlantic Treaty might not last forever and they could someday lose the American nuclear umbrella. ${ }^{4}$ There also were rumblings in the US Congress about whether the United States was on the verge of extending a nuclear guarantee beyond its existing alliances - something that was especially sensitive given the fact that the United States then was fighting a war in Vietnam, which raised fundamental questions about America's future role in the world. ${ }^{5}$

In November 1966, the UN General Assembly (UNGA) formally requested the nuclear powers to provide security assurances to Non-Nuclear Weapon States willing to join the new nonproliferation regime. In August 1967, William Foster, the director of the Arms Control and Disarmament Agency (ACDA) and the chief US NPT negotiator, told the Eighteen Nation Disarmament Commission (ENDC), the venue for the NPT negotiations, that the security assurance problem was too complicated to be dealt with in the emerging treaty itself and that the US was prepared to seek a formula outside the NPT, but within the context of the United Nations, which would address the issue. By early 1968, American, Soviet, and British negotiators were discussing options in this regard, the outcome of which was UN Security Council (UNSC) Resolution 255, adopted on 19 June 1968, one week after the General Assembly resolved to open the NPT for signature. ${ }^{6}$ Resolution 255 provided that "Aggression 
with nuclear weapons or the threat of such aggression against a Non-Nuclear Weapon State would create a situation in which the Security Council and above all its Nuclear Weapon State permanent members would have to act immediately in accordance with their obligations under the United Nations Charter."7

Two months after the NPT was opened for signature, the UNGA convened a conference of Non-Nuclear Weapon States in Geneva. A total of 92 states attended, 81 of which had by that time signed the NPT. The attendees were uncomfortable with the UNSC veto-governed procedures as a basis for security guarantees, but could not come up with a better solution. A proposal for an international convention to provide more satisfactory measures failed by one vote to obtain the required two-thirds majority, because nobody had a specific proposal on how to make positive security assurances stronger or more binding. Subsequently, the issue has been readdressed annually in the Geneva-based Conference on Disarmament (CD), a successor once removed from the ENDC, and in the NPT review conferences in 1975, 1980, 1985, and 1990. At the 1990 review conference, Egypt urged revision and clarification of Resolution 255. Mexico and others repeated this proposal when the first preparatory conference for the 1995 NPT review and extension conference was held in New York in May 1993. At the 1995 review and extension conference, the outcome was a new Security Council Resolution (984), accompanied by unilateral statements from the five permanent 
members of the Security Council, which expanded upon, but arguably did little to decisively strengthen Resolution 255 . The eight sections of UNSC Resolution 984 are repeated below, specifying that the UNSC: ${ }^{8}$

- Takes note with appreciation of the statements made by each of the Nuclear Weapon States...in which they give security assurances against the use of nuclear weapons [negative security assurances, to be discussed in a moment] to Non-Nuclear Weapon States that are Parties to the Treaty on the Nonproliferation of Nuclear Weapons.

- Recognizes the legitimate interest on Non-Nuclear Weapon States' Parties to the Treaty on the Nonproliferation of Nuclear Weapons to receive assurances that the Security Council, and above all its Nuclear Weapon State permanent members, will act immediately in accordance with the relevant provisions of the Charter of the United Nations, in the event that such states are the victim of an act of, or object of a threat of, aggression in which nuclear weapons are used.

- Recognizes further that, in case of aggression with nuclear weapons or the threat of such aggression against a NonNuclear Weapon State Party to the Treaty on the Nonproliferation of Nuclear Weapons, any State may bring the matter immediately to the attention of the Security Council to enable the Council to take urgent action to 
provide assistance, in accordance with the Charter, to the State victim of an act of, or object of a threat of, such aggression. Also, recognize that the Nuclear Weapon State permanent members of the Security Council will bring the matter immediately to the attention of the Council and seek Council action to provide, in accordance with the Charter, the necessary assistance to the State victim.

- Notes the means available to, if for assisting such a NonNuclear Weapon State Party to the Treaty on the Nonproliferation of Nuclear Weapons, including an investigation into the situation and appropriate measures to settle the dispute and restore international peace and security.

- Invites member States, individually or collectively, if any Non-Nuclear Weapon State Party to the Treaty on the Nonproliferation of Nuclear Weapons is a victim of an act of aggression with nuclear weapons, to take appropriate measures in response to a request from the victim for technical, medical, scientific, or humanitarian assistance, and affirms its readiness to consider what measures are needed in this regard in the event of such an act of aggression.

- Expresses its intention to recommend appropriate procedures, in response to any request from a Non-Nuclear Weapon State Party to the Treaty on the Nonproliferation of 
Nuclear Weapons that is the victim of such an act of aggression, regarding compensation under international law from the aggressor for loss, damage, or injury sustained as a result of the aggression.

- Welcomes the intention expressed by certain States that they will provide or support immediate assistance, in accordance with the UN Charter, to any Non-Nuclear Weapon State Party to the Treaty on the Nonproliferation of Nuclear Weapons that is a victim of an act of, or an object of a threat of, aggression in which nuclear weapons are used.

- Urges all States, as provided for in Article VI of the Treaty on the Nonproliferation of Nuclear Weapons, to pursue negotiations in good faith on effective measures relating to nuclear disarmament, and on a treaty on general and complete disarmament under strict and effective international control which remains a universal goal.

- Reaffirms the inherent right, recognized under Article 51 of the Charter, of individual and collective self-defense if an armed attack occurs against a member of the United Nations, until the Security Council has taken measures necessary to maintain international peace and security.

- Underlines that the issues raised in this resolution remain of continuing concern to the Council. 
To summarize, the concept of positive security assurances related to the NPT has been examined many times from many different perspectives since the 1960s. I am aware of no proposal that advances the argument on how to create stronger positive security assurances related to the NPT, beyond those known in $1995 .^{9}$

\section{Negative security assurances and the NPT}

As early as 1964, Non-Nuclear Weapon States considering proposals for a nonproliferation treaty were asking whether the United States and other nuclear powers would promise not to use nuclear weapons against them. In his public response to the Chinese nuclear test in the fall of 1964, President Johnson did not address this question. On the same day as its test, the Chinese government announced "that China will never, at any time, under any circumstances, be the first to use nuclear weapons." 10 This led to calls for the other Nuclear Weapon States to issue similar negative security assurances.

Within the US interagency, agencies were divided on the wisdom of such assurances. As a result, the draft American treaty that was made public in Geneva in September 1965 contained no non-use provisions. Countries such as Nigeria and India who registered their displeasure duly noted this. In 1966, the Soviets proposed a treaty clause that would prohibit "the use of nuclear weapons against Non-Nuclear States Parties to the treaty, which 
have no nuclear weapons on their territory." ${ }^{11}$ This transparently was aimed at American NATO allies such as West Germany, Italy, and Turkey, and thus was opposed by the United States. Later in 1966, the eight non-aligned states that were members of the ENDC joined in a proposal to seek codified negative security assurances, and during the UNGA debates on disarmament that fall, 46 nonaligned countries introduced a similar draft resolution. Again, with divided opinions in the US interagency, the Johnson Administration debated how to respond. By the time an administration position was developed, the language of the draft UNGA resolution had dropped the negative security assurance proposal. Eventually the UNGA recommended for signature the NPT, notwithstanding the absence of a non-use commitment in the treaty or in a separate declaration or resolution.

Meanwhile, in the aftermath of the Cuban missile crisis, the presidents of Bolivia, Brazil, Chile, Ecuador, and Mexico called for an agreement to establish a Nuclear-Weapon-Free Zone in Latin America and the Caribbean. The result was the Treaty of Tlatelolco signed at Mexico City in February 1967. The United States did agree to a codified, legally binding non-use commitment with respect to this treaty, subject to the understanding that an armed attack by a contracting party in which it was assisted by a Nuclear Weapon State would be incompatible with the contracting party's obligations and would relieve the United States of its nonuse pledge. In explaining to the Senate Foreign Relations 
Committee why the US was willing to make this pledge for the Latin American Nuclear-Free Zone, but not for the NPT, officials stated:

\begin{abstract}
Assessment of the non-use undertaking at the time the Treaty [Protocol II of the Treaty of the Treaty of Tlatelolco] was signed by the United States resulted in agreement within the government that it was acceptable in this particular case in view of (a) the special historic relationship which the United States has maintained with hemispheric neighbors, and (b) the difficulty of conceiving of circumstances in which the United States would find it in its interest to use or threaten to use nuclear weapons against a Latin American party to the Treaty which was abiding by its obligations thereunder, as understood by the United States... . ${ }^{12}$
\end{abstract}

Thus by 1968 the situation was one where the United States had agreed to a non-use pledge for a regional treaty (Tlatelolco), but not for the global nonproliferation regime anchored by the NPT. This contributed to the establishment of an agenda item at the regular Geneva disarmament conference calling for a non-use treaty. At the special session on disarmament of the UNGA in 1978, each of the Nuclear Weapon States issued separate and different negative security assurances for the benefit of Non-Nuclear Weapon NPT Parties. The American declaration, made in the name of President Carter, stated:

The United States will not use nuclear weapons against any Non-Nuclear Weapons State Party to the 
NPT or any comparable internationally binding commitment not to acquire nuclear explosive devices, except in the case of an attack on the United States, its territories or armed forces, or its allies, by such state allied to a Nuclear Weapon State or associated with a Nuclear Weapon State in carrying out or sustaining the attack. ${ }^{13}$

Non-aligned countries continued to urge draft treaties, which would codify non-use without exception. The United States continued to oppose these initiatives. In 1994, to persuade Ukraine to relinquish the nuclear weapons on its territory, new negotiations took place between Russia, the US, and Ukraine, resulting in a second American non-use promise to a Non-Nuclear Weapon State. ${ }^{14}$ A year later during NPT '95, the five Nuclear Weapon States made separate non-use declarations. The declarations by the US, Russia, Britain, and France generally followed the Ukrainian formula. The Chinese declaration contained no exceptions and repeated the Chinese promise, dating to 1964 , not to be the first to use nuclear weapons under any conditions. $^{15}$ Notwithstanding the fact that these guarantees are recognized in Security Council Resolution 984, most legal experts agree that the negative security assurances remain politically, not legally, binding commitments undertaken by the Nuclear Weapon States. 


\section{The current stalemate on security assurances}

Unfortunately, as experience has proven, the promise of timely and decisive Security Council action to secure a state against aggression is problematic. Moreover, if the aggression is being accomplished by one of the permanent five members (who also are the declared nuclear weapons states), or by one of their associates, the power of the veto casts a shadow over all related Security Council activities. Notwithstanding these facts, there are no proposals for significantly strengthening the positive security assurances beyond what was recorded in Security Council Resolution 984. In this regard, generalized positive security assurances will be strengthened only when the international system is relatively peaceful and when the major powers are united in intent and purpose. Enforcement of international peace and security remains sporadic, highly dependent on circumstances and on the interests of the parties involved in any particular conflict.

It is in the area of negative security assurances that most room for change appears to reside. There have been two separate developments in that regard: a call to extend the numbers and areas of Nuclear-Weapon-Free Zones, and a call for codifying the negative security assurance in some sort of treaty. In both cases, the intent is to commit the Nuclear Weapon States to a legal obligation not to be the first to use nuclear weapons. 
With the exception of China, the Nuclear Weapon States continue to reject this agenda. If anything, Russia has become even more reliant on nuclear weapons than it was during the Cold War. ${ }^{16}$ Britain and France remain opposed to calls for codifying no-first-use. ${ }^{17}$ Notwithstanding activism by Canada and Germany in favor of change, NATO's Washington Summit ended in April 1999 with endorsement of a new strategic concept that retains the option of first use. ${ }^{18}$

The United States is reluctant to get ahead of its NATO allies in this regard and is further disposed given the nature of the new threat environment to retain ambiguity of possible nuclear use to deal with proliferation of WMD. Over the past several years, US officials have discussed this issue obliquely, but in recent testimony to the Senate Armed Services Subcommittee on Strategic Forces, Assistant Secretary of Defense for Strategy and Threat Reduction, Edward L. (Ted) Warner III, made the case bluntly that "for the foreseeable future, the United States will retain sufficient strategic and theater nuclear forces to ... help deter an adversary's use of chemical or biological weapons [as

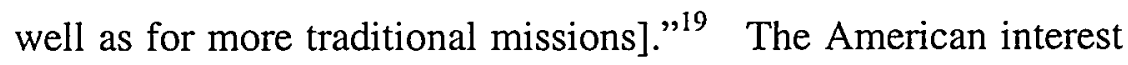
in preserving nuclear ambiguity in the face of WMD proliferation is further buttressed by the fact that the US sees over 50 states (one out of every four in the international community) as being of proliferation concern as a supplier, conduit, or potential proliferator of WMD. ${ }^{20}$ There is little prospect that the Clinton 
Administration will change this position prior to NPT '00, especially since the call for codifying negative security assurances is seen as partly motivated by the desire of some to further erode the legitimacy of nuclear weapons; and, hence, to weaken whatever efficacy remains for their deterrent role in the post-Cold War world.

\section{The logic of security assurances: a reappraisal}

It is of course possible that NPT ' 00 will muddle through with the current impasse on security assurances - a visibly weak political commitment for positive assurances, a standoff on any stronger negative assurances - merely carried over to the year 2001 and beyond. That is the most likely outcome. However, in the remaining pages of this paper, I wish to explore another option, reflecting the fact that there are three converging streams of issues which intersect the security assurances debate and which suggest that the time is right for a fresh approach. Those issue areas are the rules of international law concerning the use of force, the rules of international law concerning the use of nuclear weapons, and Article VI of the NPT, and the entire issue of next steps toward nuclear disarmament. 


\subsection{International law and the use of force}

Since 1945 the international system has been constructed around the UN Charter which, inter alia, redefined the international rules regulating state behavior with respect to use of armed force. $^{21}$ The Charter registered a general prohibition against the threat or use of force in international relations except for individual or collective self-defense or for enforcement actions authorized by the Security Council. The triggering event in both instances traditionally has been seen as cross-border aggression by one state against another. For the past several years, however, a debate has been unfolding whether armed intervention for reasons other than resisting aggression might be consistent with international law. ${ }^{22}$ Current NATO action concerning Kosovo has intensified, and the debates on this crises are far from over.

Clearly, the question of the nature of the international rules governing the use of armed force cuts across the arms control and security assurance agendas. As the CD ended the first part of its 1999 session, NATO air strikes on Kosovo and Yugoslavia were just commencing. At the CD, Mexico's Under Secretary of State for Foreign Affairs suggested some of the more extensive debate to come in saying that "we can only hope to make progress in the disarmament field if States in their reciprocal relations renounce the threat or use of force, except in the cases set forth in the United Nations Charter, to conduct themselves in accordance with generally accepted principles and rules of international law and 
strengthen the institutions that the international community has set up to maintain peace and international security." ${ }^{23}$ This debate is far from over.

\subsection{International law and the use of nuclear weapon}

In July 1996 the International Court of Justice (ICJ), commonly known as the World Court, delivered advisory rulings on the use of nuclear weapons. The World Court said inter alia that:

- There are no specific rules of international law regulating the use of nuclear weapons per se;

- Non-use of nuclear weapons has not created a customary prohibition against their use because the international community is profoundly divided on this question; and,

- The fundamental rules of humanitarian law in time of war - the protection of civilian populations and the prohibition against causing unnecessary suffering to combatants - apply to the threat or use of nuclear weapons.

With respect to this last point, the World Court concluded that while the destructive nature of nuclear weapons "in fact seems scarcely reconcilable" with the strict requirements dictated by humanitarian law, there does not today exist a sufficient basis for definitive conclusions as to whether the use of nuclear 
weapons would or would not be at variance with the principles and rules of law applicable in armed conflict, in extreme circumstances of self-defense in which a State's survival is at stake. $^{24}$

Advisory opinions of the World Court are non-binding but generally are recognized as being of considerable importance to the further development of international law. One can anticipate further moves to narrowly define the conditions under which nuclear use may be deemed legal. The most clear-cut case of legitimacy upon which there is little disagreement is that nuclear use is justified in retaliation for prior nuclear aggression. Beyond that, one engages in much the same debate that animates the dialogue on negative security assurances.

\subsection{Nuclear disarmament}

Article VI of the NPT calls for "negotiations in good faith on effective measures relating to cessation of the nuclear arms race at an early date and to nuclear disarmament, and on a treaty on general and complete disarmament under strict and effective international control." The World Court in its advisory opinion in 1996 reaffirmed the importance of this commitment, and the United States government repeatedly has asserted that it is fully committed to this article. The issue raised by Article VI is when nuclear disarmament eventually will take place, on what timetable, and under what conditions. 
This has become a major issue at the $\mathrm{CD}$ and will certainly be raised at NPT '00. At the first session of the CD in 1999, five proposals were tabled for addressing nuclear disarmament.

Numerous commission and study group reports during the past several years have begun to engage this issue. The United States with support from all the Nuclear Weapon States except China has argued that it is premature to begin this type of discussion and that a more realistic approach is to continue the step-by-step process toward nuclear arms control that is carried over from the Cold War.

The CD closed the first part of its 1999 session without having started negotiating a ban on the production of fissile materials for nuclear weapons, and without taking any other important decisions on its program of work. The failure to agree on a mechanism for engaging in a discussion of nuclear disarmament is widely seen as contributing to this failure. How long that state of affairs will persist is uncertain.

\section{Comprehensive security assurances}

The year 2000 is an appropriate point to reorient the security assurances debate and NPT ' 00 offers a useful forum. My proposal is to move beyond discussion of negative and positive security assurances toward "comprehensive" security assurances, which address the security concerns of both Nuclear 
and Non-Nuclear Weapon States Party to the NPT. The comprehensive security assurances would be the following:

- States, where they have undertaken international obligations not to acquire WMD, will not have their security fundamentally compromised as a result of their faithful compliance with their commitment;

- States which have agreed not to acquire WMD will not violate, and should be effectively monitored to insure they are not violating, their pledges;

- All states have a commitment to help identify and achieve conditions where nuclear weapons are not needed to maintain international peace and security or to remove threats to peace; and,

- If WMD are threatened or used for aggressive purposes, the international community, an obligation not only for Nuclear Weapon States, but also for all states, will effectively and quickly counter this in the international system.

These comprehensive assurances recognize the fact that achieving a reasonable security formula is an inherently political activity, and that sound international politics - especially for representative democracies - should have demonstrable links to international law. There is no quick or easy solution to the dilemmas posed by nuclear weapons. In the final analysis, 
resolving those dilemmas is - as was recognized many years ago in the original American disarmament proposal - a matter of dealing with the problem of war itself.

\section{Notes}

1. Quoted in Glenn T. Seaborg with Benjamin S. Loeb, Stemming the Tide: Arms Control in the Johnson Years (Lexington, Massachusetts: Lexington Books, 1971), pp. 115-116.

2. See George Bunn, "Security Assurances Against Nuclear Attack: The Legal Framework for the NPT Extension Conference and Beyond," in Virginia I. Foran, (ed.), Security Assurances: Implications for the NPT and Beyond (Washington DC: Carnegie Endowment, 1995), p. 11.

3. "Memorandum of Conversation, Committee of Principals, 23 November 1964." secret, declassified 1993. Lyndon Baines Johnson Library, National Security File, Box 12, folder-Committee of Principals, Vol. I [1 of 3]."

4. See Michael O. Wheeler, Positive and Negative Security Assurances, Paper No. 9 (College Park, Maryland: University of Maryland, Center for International and Security Studies at Maryland, Project on Rethinking Arms Control, February 1994), p. 10. 
5. When Robert McNamara was questioned on this during congressional testimony in early 1966, he replied that although the United States was considering some form of security guarantee for states outside of its formal alliance structure, "the administration [in pursuing nonproliferation] had no intention of making the United States a policeman of the world." Wheeler, Positive and Negative Security Assurances, p. 10.

6. Wheeler, Positive and Negative Security Assurances, op. cit., pp. 10-11.

7. Security Council Resolution 255 was adopted on 19 June 1968 at the 143 rd meeting of the UNSC by 10 votes with five abstentions (Algeria, Brazil, France, India, and Pakistan).

8. Foran, Security Assurances, op. cit., pp. 65-67.

9. For the status of the debate as of 1995, see Harald Müller, "Between Security Council Inaction and Self-Helplessness: The Case for a Positive Security Assurances Alliance," Foran, Security Assurances, pp. 25-38, and Michael O. Wheeler, "Security Assurances: Towards Actions, Not Simply Words," Foran, Security Assurances, op. cit., pp. 49-64.

10. For a discussion of the development of the American position on negative security assurances, see George Bunn, "The Legal Status of U.S. Negative Security Assurances to 
Non-Nuclear Weapon States," The Nonproliferation Review (Spring-Summer 1997), pp. 1-17.

11. Ibid., p. 3.

12. Ibid., p. 5 .

13. United States Arms Control and Disarmament Agency, Arms Control and Disarmament Agreements (Washington, DC: ACDA, 1990), p. 94.

14. See Bunn, "The Legal Status of U.S. Negative Security Assurances to Non-Nuclear Weapon States," p. 7.

15. Foran, Security Assurances, op. cit., pp. 69-76.

16. International Institute for Strategic Studies, "Nuclear Weapons First in Russia's Defense Policy," Strategic Comments, 4 (January 1998), pp. 1-2.

17. See Bruno Tertrais, Nuclear Policies in Europe, Adelphi Paper 327 (London: International Institute for Strategic Studies, 1999), p. 43.

18. NATO's Strategic Concept, 1999, Paragraph 62, www.usia.gov.

19. Prepared Statement of Edward L. Warner, III, Assistant Secretary of Defense for Strategy and Threat Reduction, to the Senate Armed Services Subcommittee on Strategic Forces, Hearing on Nuclear Deterrence, 14 April 1999.

20. Prepared Statement of John Lauder, Special Assistant to the Director of the Central Intelligence Agency, to the Commission to Assess the Organization of the Federal 
Government to Combat the Proliferation of Weapons of Mass Destruction, 29 April 1999.

21. See Anthony Clark Arend and Robert J. Beck, International Law and the Use of Force (London: Routledge, 1993); and John F. Murphy, "Force and Arms," Chapter Four in Christopher C. Joyner, (ed.), The United Nations and International Law (New York: Cambridge University Press, 1997).

22. See Lori Fisler Amrosch and David J. Scheffer, Law and Force in the New International Order (Boulder, Colorado: Westview Press, 1991); and Michael J. Glennon, "The New Interventionism," Foreign Affairs, 78 (May/June 1999), pp. 2-7.

23. Quoted in Rebecca Johnson, "CD Fiddles While Kosovo Burns?" Disarmament Diplomacy, 35 (March 1999), p. 1, www.gn.apc.org/acronym/dd35.htm.

24. See Peter H. F. Bekker, "Advisory Opinions of the World Court on the Legality of Nuclear Weapons," ASIL Insight, 14 (Washington DC: The American Society of International Law, 1996). 


\section{Preparing for the 2000 Review Conference of the Parties to the Treaty on the Nonproliferation of Nuclear Weapons}

\section{Hannelore Hoppe ${ }^{1}$}

It has been four years since the States Parties to the Treaty on the Nonproliferation of Nuclear Weapons (NPT) decided at their 1995 Review and Extension Conference to adopt a package of decisions by which the Treaty was extended indefinitely. These initiatives included a new strengthened review process of the implementation of the Treaty's provisions, which was to begin in 1997, and benchmarks established to measure the performance of all treaty parties, (Nuclear Weapons States and Non-Nuclear Weapons States). The three decisions and the resolution on the Middle East had an impact beyond the indefinite extension of the Treaty. The States Parties ensured that the Treaty was not only maintained as the core of the global nuclear nonproliferation regime, but its indefinite extension both reinforced and rendered permanent the international legal norm against the proliferation of nuclear weapons.

Today, membership of the Treaty has grown to 187 countries. Since the 1995 Conference, nine additional States - Andorra, Angola, Chile, Comoros, Djibouti, Oman, United Arab Emirates, Vanuatu and last September Brazil — acceded to the Treaty. The fact that more countries have ratified the NPT than any other arms 
limitation and disarmament agreement attests to the Treaty's significance.

\section{The 1995 Review and Extension Conference}

The Treaty, in particular Article VIII.3, provides for the holding at five-year interval conferences to review the Treaty's operation and to implement its provisions. Four such conferences have been held prior to the Review and Extension Conference in 1995. Each conference attempted to find agreement on a final declaration, which would assess the status of implementation of the Treaty's provisions and make recommendations on measures for further action. Consensus on a final declaration was reached only at two of these conferences, namely in 1975 and in 1985, but could not be obtained in 1980 and 1990. The divergence of views on the implementation of the provisions of Article VI, in particular, and on such issues as continued nuclear testing, qualitative nuclear weapons development, and security assurances to Non-Nuclear Weapons States, made it impossible for the States Parties to reach agreement on a final declaration.

The 1995 Conference combined both the provisions of Article VIII.3 of the Treaty as well as of Article X.2. Article X.2 stipulates that after 25 years of entry into force, a conference was to be convened to decide whether to give permanence to the Treaty or to seek some alternative arrangements.

On 11 May 1995, a majority existed among the Treaty's parties to extend the Treaty indefinitely; a package of decisions was 
adopted without a vote that gave the Treaty enduring legal status. Together with the decision to extend the Treaty indefinitely, ${ }^{2}$ the Conference also decided to "Strengthen the Review Process for the Treaty," (Annex I of this paper), and adopted "Principles and Objectives for Nuclear Nonproliferation and Disarmament," (Annex II of this paper). The Conference also adopted a "Resolution on the Middle East," (Annex II of this paper). Because emphasis was placed on reaching a decision on the future of the Treaty, and the short time available to overcome the divergent views, especially on the implementation of Article VI of the Treaty, it became impossible for the Conference to agree on a final declaration.

\section{Decision on strengthening the review process for the NPT}

The decision on "Strengthening the Review Process for the Treaty" reflected the willingness of the States Parties to be held accountable for their actions and to ensure that the undertakings in the Treaty and in the decisions adopted in 1995 would have greater prospects of being achieved. With the new review process, the States Parties created a mechanism that allows them to look forward, as well as backward, and to focus on specific issues and to identify areas for further progress. To make the Treaty work in practice was the challenge that lay ahead for the States Parties when the preparatory process for the 2000 NPT Review Conference began in April 1997. 
Article VIII.3 of the NPT, stipulates that conferences should be held to review the operation of this Treaty with a view to assuring that the purposes of the Preamble and the provisions of the Treaty are being realized. This remains the legal foundation on which to base the review process. However, the decision on strengthening the review process for the Treaty has given it a new meaning.

Paragraph 1 of this decision to strengthen the review process determines the objective of the process, i.e. it ensures that the purposes of the Preamble and the provisions of the Treaty are being realized, thus giving full effect to Article VIII.3 of the Treaty.

Through the provision in paragraph 2 , the convening of Review Conferences in five-year intervals has been regularized. In the past, a decision to hold a review conference was made by the States Parties at the end of a review conference and reaffirmed by a resolution of the General Assembly following consultations among States Parties.

Additionally, Paragraph 3 stipulates that, beginning in 1997 , a meeting of the Preparatory Committee will be held in each of the three years prior to the Review Conference. If necessary, there could also be a fourth session just preceding the Conference. The Committee's mandate is spelled out in paragraph 4. Accordingly, the Committee would consider principles, objectives, and ways to promote the full implementation of the Treaty, as well as its universality, and to make recommendations thereon to the Review Conference. At the same time, the Preparatory Committee should 
also make the procedural preparations for the Review Conference.

Paragraphs 5, 6, and 7 refer to the work of the Review Conference. The Preparatory Committee has been given greater responsibility in making recommendations with regard to the allocation of items to be discussed in the Main Committees established by the Conference, so as to avoid overlapping of issues. In addition, the Preparatory Committee could also recommend to the Conference the establishment of subsidiary bodies within the respective Main Committees for the study of specific issues relevant to the Treaty. In doing so, the specific objectives of the Review Conference would have to be considered. Paragraph 7 determines that the Review Conferences should look forward as well as backward. This applies to the Preparatory Committee as well, given the requirement in paragraph 4 , i.e. to make substantive recommendations on how to promote the full implementation of the Treaty.

\section{Preparatory process for the 2000 NPT Review Conference}

In December 1996 the General Assembly, by its Resolution 51/45 A, established the Preparatory Committee for the 2000 NPT Review Conference and decided to convene the Committee's first session for the period 7 to 18 April 1997 in New York.

The first session of the Preparatory Committee was expected 
to set the stage for the implementation of the decision on strengthening the review process for the Treaty. What was foremost in the minds of those involved was to see how the commitment to embark upon a new and strengthened review process of the Treaty would be fulfilled. The questions that arose most frequently in discussions prior to the deliberations were: What the strengthened review process should aim to achieve and how it could be achieved? How would the Committee deal with procedural and substantive issues and how much time would it devote to them? What would be the form in which the outcome of the work of the Committee would be reflected, i.e. what kind of document should the Committee forward to the Conference?

Furthermore, the role, which the Preparatory Committee was to assume, differed significantly from that of the preparatory processes of past review conferences. In accordance with paragraph 4 of the decision, the Committee was expected to focus primarily on the consideration of principles, objectives, and ways to promote the full implementation of the Treaty, as well as, the Treaty's universality, while at the same time making procedural arrangements related to its own work and that of the 2000 Review Conference.

The preparatory process for the 2000 NPT Review Conference commenced under the chairmanship of Pasi Patokallio of Finland. Patokallio's election to the post of chairman of the first session was part of an understanding reached among delegations at the outset. According to that understanding, a representative of the 
Western Group would chair the First Session. A representative of the Group of Eastern European States would chair the Second Session. A representative of the Group of Non-aligned and other States Parties would chair the Third Session. Furthermore, a representative of the Group of Non-aligned and other States Parties would also be proposed for the presidency of the 2000 Review Conference.

The Committee's tasks were twofold as laid out in paragraph 4 of the decision on strengthening the review process. It was to engage in a substantive debate on the issues while at the same time making procedural arrangements related to the Committee's own work and that of the 2000 Review Conference. The agenda adopted by the Committee fully reflected this approach, and guided the work of the Committee throughout its sessions.

\section{Work of the Preparatory Committee on substantive issues}

At its first session, the Preparatory Committee agreed to devote most of its deliberations to a substantive structured discussion on the review of the operation of the Treaty, taking into account the decisions and resolution adopted at the 1995 NPT Review and Extension Conference. The following issues were considered: universality of the Treaty; nonproliferation and nuclear disarmament; security assurances to Non-Nuclear Weapons States; establishment of Nuclear-Weapon-Free Zones; IAEA safeguards; and, peaceful uses 
of nuclear energy. Numerous proposals were put forward by States Parties in which developments since the 1995 Conference were reviewed and concrete measures for further action were outlined.

The form in which the outcome of the Committee's substantive discussion would be reported and carried forward to the next session was also discussed at length. Many delegations favored a detailed working document, either as a Chairman's paper or a "rolling text," which would contain recommendations for the next session and draft recommendations for the 2000 Review Conference. As a result of consultations, the Chairman presented a paper that was intended to serve as the basis for further work on draft recommendations to the Review Conference. The paper consisted of two parts: identifying points of general agreement on draft recommendations for the 2000 Review Conference, (subject to review and updating at subsequent sessions and pending agreement on all draft recommendations at the last session); and listing the specific proposals put forward by delegations on the understanding that they did not commit the Preparatory Committee and these proposals were without prejudice to the position of any delegation. Since concern was voiced regarding the status of the Chairman's paper and the individual proposals by delegations, the Committee finally agreed that the Chairman's working paper and the documents and proposals put forward by delegations would be taken into account during further work of the Preparatory Committee. ${ }^{3}$

During consultative meetings, proposals were also put 
forward to allocate additional time at the second session to consider proposals on the following subject areas:

- $\quad$ Security assurances for parties to the NPT;

- The resolution on the Middle East adopted at the 1995 Review and Extension Conference; and,

- The provision in paragraph 4 (b) of the Decision on "Principles and Objectives for Nuclear Nonproliferation and Disarmament" on a non-discriminatory and universally applicable convention banning the production of fissile material for nuclear weapons or other nuclear explosive devices.

However, one delegation viewed as the primary objective of the strengthened review process for the NPT, was to hasten toward nuclear disarmament and that this priority must be duly reflected in any consideration of a substantive nature. Therefore, nuclear disarmament should be the fourth issue, and to which additional time should be allocated. There was no consensus within the Committee on such a position. In the end, the Chairman read a statement which the Committee recommended that within the existing agenda and in accordance with the methods of work adopted at the first session, time should be allocated at the Committee's second session for discussion on, and the consideration of, the topics suggested by him without prejudice to the importance of other issues. 
At the second session, the Committee continued to devote a very substantial part of its meetings to the consideration of all aspects of the Treaty in a structured and balanced manner. The Committee also allocated additional time for the discussion on, and consideration of, the three subject areas identified in the statement read by the Chairman at the First Session (as noted above). Work on draft recommendations to the 2000 Review Conference and to the next session of the Preparatory Committee continued within the consultative framework held by the Chairman assisted by a small number of States. The Chairman's working paper of the First Session $^{4}$ and the numerous proposals made by the several delegations at both the First and Second Sessions formed the basis for this effort.

The main objective was to identify those areas and issues on which the Committee could reach a consensus, and to formulate concrete language for inclusion in the Chairman's paper and to streamline the various other proposals put forward by the several delegations. Although some new draft recommendations were added to the working paper, however, tangible results on the preparation of substantive recommendations to the 2000 Review Conference were lacking. The outcome of the Second Session clearly indicated that deep divisions existed, especially over the implementation of Article VI of the Treaty, on security assurances in legally binding form, and on the status of the resolution on the Middle East. The Chairman's working paper was subsequently issued as an official document of the session as were the various proposals put forth by the delegations. ${ }^{5}$ In 
addition, the session revealed the differing perspectives of States Parties on the nature of the strengthened review process, as well as different interpretations of the package of decisions that were adopted at the 1995 NPT Review and Extension Conference.

In the end, the Committee was unable to agree on the inclusion in its report of any of the extensive discussion that took place on all the substantive issues, including on the three issues to which additional time had been allocated. There was also no agreement on the status of the Chairman's working paper and on recommendations to the Review Conference. Consequently, the report merely describes the procedures of work of the Committee at the Second Session. ${ }^{6}$

5. Procedural issues related to the organization of work of the Preparatory Committee and the 2000 NPT Review Conference

On most of the issues regarding the organization of the Preparatory Committee's work, decisions were taken at the First Session. This left the Committee's further sessions to discuss and decide on the procedural and organizational arrangements for the 2000 Review Conference. 


\subsection{Officers of the Preparatory Committee}

In accordance with the understanding reached among the delegations at the outset of the First Session, ${ }^{7}$ Patokallio of Finland served as its Chairman. Eugeniusz Wyzner of Poland served as Chairman of the Second Session, and Camilo Reyes Rodríguez of Colombia served as Chairman of the Third Session. The Committee also agreed that the persons, when not serving as Chairmen, would serve as Vice-Chairmen of the Committee.

\subsection{Dates and venues for further sessions}

The Committee agreed that the Second Session would be held from 27 April to 8 May 1998 in Geneva, that the Third Session would take place from 12 to 23 April 1999 in New York. Following discussions among the NPT States Parties, it was decided to reschedule the Third Session from 10 to 21 May 1999 in New York.

\subsection{Methods of work}

\subsubsection{Decision-making}

The Preparatory Committee decided to make every effort to adopt all of its decisions by consensus. In the event that consensus could not be reached, the Committee would then take decisions in accordance with the rules of procedure of the 1995 NPT Review and Extension Conference, which would be applied mutatis mutandis. ${ }^{8}$ 


\subsubsection{Participation}

Of the 186 States Parties to the NPT, 146 attended the First Session; 97 States Parties attended the Second Session.

Furthermore, the Committee decided to permit specialized agencies, intergovernmental organizations and nongovernmental organizations to attend the open meetings of the Committee as observers. Accordingly, representatives of Brazil and Israel attended the First and Second Sessions. Representatives of Cuba and Pakistan attended the First Session. Furthermore, the Agency for the Prohibition of Nuclear Weapons in Latin America and the Caribbean (OPANAL), the South Pacific Forum, the League of Arab States, the Organization of the Islamic Conference and the Preparatory Commission for the Comprehensive Nuclear Test Ban Treaty Organization (CTBTO) attended the sessions as observers.

As compared to the preparatory process for the 1995 Review and Extension Conference, the modalities for attendance of representatives of nongovernmental organizations (NGO) were significantly different. The Committee decided to set aside time at each session for NGOs to make presentations to the several delegations. At the first session, the Committee heard nine such presentations, and representatives of 13 NGOs addressed the Committee at its Second Session. 


\section{Organization of the $\mathbf{2 0 0 0}$ Review Conference}

The Committee's decision taken at the Second Session, the 2000 Review Conference of the Parties to the NPT convened from 24 April to 19 May 2000 in New York.

Regarding the procedural issues relating to the Conference, decisions have already been taken on the appointment of the Secretary General of the Conference and of the financing of the Conference, including its Preparatory Committee. The nomination of an official to assume the function of provisional Secretary General will be made by the United Nations Secretary General in consultation with the States Parties. In addition, a document providing detailed information on the estimated costs of the Conference, including its Preparatory Committee, was circulated to all States Parties at the Second Session by the Secretariat.

Work of the Committee has proceeded and includes: the draft rules of procedure; the election of the President and the other office bearers; the provisional agenda; the background documentation; and, final document(s).

\subsection{Draft rules of procedure}

The draft rules of procedure were considered at the Second Session. However, the Committee deferred a decision on them until the Third Session. Differences of view persisted among delegations on a proposal by the Group of Non-Aligned States to include a 
provision in the draft rules of procedure that would allow for the establishment of subsidiary bodies within the Main Committee to provide for focused considerations of specific issues relevant to the Treaty.

\subsection{Election of the President and other officers}

The Committee's decision taken at the First Session proposed that a representative of the Group of Non-Aligned and other States Parties to the NPT should be proposed for the presidency of the 2000 Review Conference. Jacob S. Selebi of South Africa has been nominated for that post. The Committee is expected to endorse the candidacy of Selebi at its Third Session.

The Committee must agree on the chairmanships of the three Committees. The Chairman of the Drafting Committee and the Chairman of the Credentials Committee and traditionally the chairmen of the sessions of the Preparatory Committee serve as chairmen of the Main Committees.

\subsection{Provisional agenda}

The Committee needs to discuss and agree upon the provisional agenda for the 2000 Review Conference. Closely linked with the provisional agenda is the question of the allocation of issues to the three Main Committees. A recommendation by the Committee will have to be included in the Committee's final report to the Review 
Conference. In this connection, it is important to recall the provisions contained in paragraphs 5 and 6 of Decision 1, which, inter alia, address the structure of the Main Committees and their working groups, including the establishment of subsidiary bodies within the Main Committees. Regarding the latter, a number of recommendations have already been put forward by delegations at the Second Session. However, the Committee was unable to take a decision on these proposals and referred them to the Committee's Third Session for further consideration.

\subsection{Background documentation}

In the past, the UN Secretariat and the IAEA had prepared background documentation on various provisions of the Treaty. Treaty organizations, such as OPANAL and the South Pacific Forum were also requested to submit memoranda on their activities relevant to the NPT. The Prohibition of Nuclear Weapons in Latin America and the Caribbean (Treaty of Tlatelolco) and the South Pacific Nuclear-Weapon-Free Zone Treaty (Treaty of Rarotonga), respectively, were of interest. These presentations dealt with the overall implementation of the several provisions of the Treaty and described relevant developments that occurred since the last review conference.

A similar approach was proposed by the Chairman of the Second Session, taking into account the results of the 1995 Conference and developments that have taken place since. This 
includes comments from such organizations as the Organization of African Unity regarding the African Nuclear-Weapon-Free Zone Treaty (Pelindaba Treaty) and the Government of Thailand in its capacity as depositary of the Treaty on the Southeast Asia NuclearWeapon-Free Zone (Bangkok Treaty). However, controversy over the resolution on the Middle East, which was adopted at the 1995 Conference, prevented the Committee from making a decision.

\section{Third session of the Preparatory Committee}

The third session of the Preparatory Committee was held from 10 to 21 May 1999 in New York. The States Parties faced many challenges in light of developments that occurred since the Committee's Second Session in May 1998. The States Parties had to address these developments. This session was the final session of the Preparatory Committee; therefore, agreement had reached closure on all outstanding procedural issues relating to the organization of work of the 2000 Review Conference. The States Parties are expected to also continue to work on draft recommendations on substantive issues to the Review Conference.

The results of the preparatory process provides an indication as to whether the NPT will emerge from the 2000 Review Conference in stronger or weaker form. In this context, I would like to quote the Under Secretary General for Disarmament Affairs, Jayantha Dhanapala, who in his address at the Seventh Carnegie International Nonproliferation Conference in January 1999 stated, "The success of 
the 2000 Conference will ultimately depend on the evolution of fresh consensual approaches transcending political divisions and abandonment of rigid postures or complacent attitudes over the 'done deal' of the Treaty's indefinite extension."

\section{Final note}

Since the presentation of this paper in April 1999, the Preparatory Committee concluded its preparations for the 2000 Review Conference and adopted its final report to the Conference. States Parties were able to reach agreement on all outstanding procedural issues, including on the draft rules of procedure, the provisional agenda of the Conference, and on background documentation. The candidacy of Jacob S. Selebi of South Africa for the presidency of the Conference was unanimously endorsed. Agreement was also reached on the chairmanship of the three Main Committees. Accordingly, a representative of the Group of Nonaligned and other States Parties to the NPT (Colombia) will chair Main Committee I. This Committee will review the implementation of the provisions of the Treaty relating to nonproliferation of nuclear weapons, disarmament and international security, and the issue dealing with security assurances. Main Committee $\Pi$, is to be chaired by a representative of the Group of Eastern European States (Poland), and will address the implementation of the provisions of the Treaty relating to nonproliferation, safeguards, and Nuclear-Weapon-Free Zones. 
Finally, Main Committee III, to be chaired by a representative of the Western Group (Finland) will review the implementation of the provisions relating to the inalienable right of all parties to the Treaty to conduct research, to produce and use nuclear energy for peaceful purposes, without discrimination, and to conform to Articles I and II on the nonproliferation of nuclear weapons.

During its general exchange of views, the Committee also considered proposals concerning the expected outcome of the 2000 Review Conference. It recalled for the Conference to evaluate the results of the period under review, including the implementation of undertakings of the States Parties under the Treaty; identifying the areas in which, and the means through which, further progress should be sought in the future; and addressing specifically what might be done to strengthen the implementation of the Treaty and to achieve its universality.

The Committee also continued its work on draft recommendations to the Review Conference. The Chairman tabled a working paper containing elements of draft recommendations. Following consultations on this paper and the submission of written proposals by delegations, the Chairman submitted a revised version of his working paper. The Committee was unable, however, to reach agreement on any substantive recommendations to the Review Conference. The Chairman's working papers as well as the written proposals by the delegations are annexed to the report of the Preparatory Committee to the Review Conference. ${ }^{9}$ 


\section{Notes}

1. The views expressed in this paper are those of the author and do not necessarily reflect the view or position of the United Nations Secretariat.

2. NPT/CONF.1995/32, Part I, Decision 3.

3. NPT/CONF.2000/PC.I/32 and Corr.1, annex II and appendix.

4. NPT/CONF.2000/PC.I/32, annex.

5. NPT/CONF.2000/PC.II/35.

6. NPT/CONF.2000/PC.II/36.

7. NPT/CONF.2000/PC.I/32, pp. 6 and 7.

8. NPT/CONF.1995/28.

9. NPT/CONF.2000/1. 


\section{Addenda}

\section{Annex 1}

"Strengthening The Review Process For The Treaty"

1. The Conference of the Parties to the Treaty on the Nonproliferation of Nuclear Weapons examined the implementation of Article VII, paragraph 3, of the Treaty and agreed to strengthen the review process for the operation of the Treaty with a view to assuring that the purposes of the Preamble and the provisions of the Treaty are being realized.

2. The States Party to the Treaty participating in the Conference decided, in accordance with Article VIII, paragraph 3, that Review Conferences should continue to be held every five years and that, accordingly, the next Review Conference should be held in the year 2000 .

3. The Conference decided that, beginning in 1997 , the Preparatory Committee should hold, normally for a duration of 10 working days, a meeting in each of the three years prior to the Review Conference. If necessary, a fourth preparatory meeting may be held in the year of the Conference.

4. The purpose of the Preparatory Committee meetings would be to consider principles, objectives and ways in order to promote the full implementation of the Treaty, as well as its 
universality, and to make recommendations thereon to the Review Conference. These include those identified in the decision on principles and objectives for nuclear nonproliferation and disarmament, adopted on 11 May 1995. These meetings should also make the procedural preparations for the next Review Conference.

5. The Conference also concluded that the present structure of three Main Committees should continue and the question of an overlap of issues being discussed in more than one Committee should be resolved in the General Committee, which would coordinate the work of the Committees so that the substantive responsibility for the preparation of the report with respect to each specific issue is undertaken in only one Committee.

6. It was also agreed that subsidiary bodies could be established within the respective Main Committees for specific issues relevant to the Treaty, so as to provide for a focused consideration of such issues. The establishment of such subsidiary bodies would be recommended by the Preparatory Committee for each Review Conference in relation to the specific objectives of the Review Conference.

7. The Conference further agreed that Review Conferences should look forward as well as back. They should evaluate the 
results of the period they are reviewing, including the implementation of undertakings of the States Parties under the Treaty, and identify the areas in which, and the means through which, further progress should be sought in the future. Review Conferences should also address specifically what might be done to strengthen the implementation of the Treaty and to achieve its universality. 


\section{Annex II \\ "Principles and Objectives for Nuclear Nonproliferation and Disarmament"}

The Conference of the Parties to the Treaty on the Nonproliferation of Nuclear Weapons,

Reaffirming the preamble and Articles of the Treaty on the Nonproliferation of Nuclear Weapons,

Welcoming the end of the cold war, the ensuing easing of international tension and the strengthening of trust between States,

Desiring a set of principles and objectives in accordance with which nuclear nonproliferation, nuclear disarmament, and international cooperation in the peaceful uses of nuclear energy should be vigorously pursued and progress, achievements and shortcomings evaluated periodically within the review process provided for in Article VIII, paragraph 3, of the Treaty, the enhancement and strengthening of which is welcomed,

Reiterating the ultimate goals of the complete elimination of nuclear weapons and a treaty on general and complete disarmament under strict and effective international control,

The Conference affirms the need to continue to move with determination towards the full realization and effective 
implementation of the provisions of the Treaty, and accordingly adopts the following principles and objectives:

\section{$\underline{\text { Universality }}$}

1. Universal adherence to the Treaty on the Nonproliferation of Nuclear Weapons is an urgent priority. All States not yet party to the Treaty are called upon to accede to the Treaty at the earliest date, particularly those States that operate unsafeguarded nuclear facilities. Every effort should be made by all States Parties to achieve this objective.

\section{Non-proliferation}

2. The proliferation of nuclear weapons would seriously increase the danger of nuclear war. The Treaty on the Nonproliferation of Nuclear Weapons has a vital role to play in preventing the proliferation of nuclear weapons. Every effort should be made to implement the Treaty in all its aspects to prevent the proliferation of nuclear weapons and other nuclear explosive devices, without hampering the peaceful uses of nuclear energy by States Parties to the Treaty.

\section{Nuclear disarmament}

3. Nuclear disarmament is substantially facilitated by the easing of international tension and the strengthening of trust between States which have prevailed following the end of the cold 
war. The undertakings, with regard to nuclear disarmament as set out in the Treaty on the Nonproliferation of Nuclear Weapons, should thus be fulfilled with determination. In this regard, the Nuclear Weapon States reaffirm their commitment, as stated in Article VI, to pursue in good faith negotiations on effective measures relating to nuclear disarmament.

4. The achievement of the following measures is important in the full realization and effective implementation of Article VI, including the program of action as reflected below:

(a) The completion by the Conference on Disarmament of the negotiations on a universal and internationally and effectively verifiable Comprehensive Nuclear Test Ban Treaty no later than 1996. Pending the entry into force of a Comprehensive Test Ban Treaty, the Nuclear Weapon States should exercise utmost restraint;

(b) The immediate commencement and early conclusion of negotiations on a non-discriminatory and universally applicable convention banning the production of fissile material for nuclear weapons or other nuclear explosive devices, in accordance with the statement of the Special Coordinator of the Conference on Disarmament and the mandate contained therein; 
(c) The determined pursuit by the Nuclear Weapon States of systematic and progressive efforts to reduce nuclear weapons globally, with the ultimate goal of eliminating those weapons, and by all States of general and complete disarmament under strict and effective international control.

\section{Nuclear-Weapon-Free Zones}

5. The conviction that the establishment of internationally recognized Nuclear-Weapon-Free Zones, on the basis of arrangements freely arrived at among the States of the region concerned enhances global and regional peace and security is reaffirmed.

6. The development of Nuclear-Weapon-Free Zones, especially in regions of tension, such as in the Middle East, as well as the establishment of zones free of all weapons of mass destruction, should be encouraged as a matter of priority, taking into account the specific characteristics of each region. The establishment of additional Nuclear-Weapon-Free Zones by the time of the Review Conference in the year 2000 would be welcome.

7. The cooperation of all the Nuclear Weapon States and their respect and support for the relevant protocols is necessary for the maximum effectiveness of such Nuclear-Weapon-Free 
Zones and the relevant protocols.

\section{$\underline{\text { Security assurances }}$}

8. Noting United Nations Security Council Resolution 984 (1995), which was adopted unanimously on 11 April 1995, as well as the declarations of the Nuclear Weapon States concerning both negative and positive security assurances, further steps should be considered to assure Non-Nuclear Weapon States Party to the Treaty against the use or threat of use of nuclear weapons. These steps could take the form of an internationally legally binding instrument.

\section{$\underline{\text { Safeguards }}$}

9. The International Atomic Energy Agency is the competent authority responsible to verify and assure, in accordance with the statute of the Agency and the Agency's safeguards system, compliance with its safeguards agreements with States Parties undertaken in fulfillment of their obligations under Article III, paragraph 1, of the Treaty, with a view to preventing diversion of nuclear energy from peaceful uses to nuclear weapons or other nuclear explosive devices. Nothing should be done to undermine the authority of the International Atomic Energy Agency in this regard. States Parties that have concerns regarding noncompliance with the safeguards agreements of the Treaty by the States Parties should direct 
such concerns, along with supporting evidence and information, to the Agency to consider, investigate, draw conclusions and decide on necessary actions in accordance with its mandate.

10. All States Parties required by Article III of the Treaty to sign and bring into force comprehensive safeguards agreements and which have not yet done so should do so without delay.

11. International Atomic Energy Agency safeguards should be regularly assessed and evaluated. Decisions adopted by its Board of Governors aimed at further strengthening the effectiveness of Agency safeguards should be supported and implemented and the Agency's capability to detect undeclared nuclear activities should be increased. Also, States not party to the Treaty on the Nonproliferation of Nuclear Weapons should be urged to enter into comprehensive safeguards agreements with the Agency.

12. New supply arrangements for the transfer of source or special fissionable material or equipment or material especially designed or prepared for the processing, use or production of special fissionable material to Non-Nuclear Weapon States should require, as a necessary precondition, acceptance of the Agency's full-scope safeguards and internationally legally binding commitments not to acquire nuclear weapons or other 
nuclear explosive devices.

13. Nuclear fissile material transferred from military use to peaceful nuclear activities should, as soon as practicable, be placed under Agency safeguards in the framework of the voluntary safeguards agreements in place with the Nuclear Weapon States. Safeguards should be universally applied once the complete elimination of nuclear weapons has been achieved.

\section{Peaceful uses of nuclear energy}

14. Particular importance should be attached to ensuring the exercise of the inalienable right of all the parties to the Treaty to develop research, production and use of nuclear energy for peaceful purposes without discrimination and in conformity with Articles I, II as well as III of the Treaty.

15. Undertakings to facilitate participation in the fullest possible exchange of equipment, materials and scientific and technological information for the peaceful uses of nuclear energy should be fully implemented.

16. In all activities designed to promote the peaceful uses of nuclear energy, preferential treatment should be given to the Non-Nuclear Weapon States Party to the Treaty, taking the needs of developing countries particularly into account. 
17. Transparency in nuclear-related export controls should be promoted within the framework of dialogue and cooperation among all interested States Party to the Treaty.

18. All States should, through rigorous national measures and international cooperation, maintain the highest practicable levels of nuclear safety, including in waste management, and observe standards and guidelines in nuclear materials accounting, physical protection and transport of nuclear materials.

19. Every effort should be made to ensure that the International Atomic Energy Agency has the financial and human resources necessary to meet effectively its responsibilities in the areas of technical cooperation, safeguards and nuclear safety. The Agency should also be encouraged to intensify its efforts aimed at finding ways and means for funding technical assistance through predictable and assured resources.

20. Attacks or threats of attack on nuclear facilities devoted to peaceful purposes jeopardize nuclear safety and raise serious concerns regarding the application of international law on the use of force in such cases, which could warrant appropriate action in accordance with the provisions of the Charter of the United Nations. 
The Conference requests that the President of the Conference bring the present decision, the decision on strengthening the review process for the Treaty and the decision on the extension of the Treaty on the Nonproliferation of Nuclear Weapons, to the attention of the heads of State or Government of all States and seek their full cooperation on these documents and in the furtherance of the goals of the Treaty. 


\section{Annex III}

"Resolution on the Middle East"

The Conference of the Parties to the Treaty on the Nonproliferation of Nuclear Weapons,

Reaffirming the purpose and provisions of the Treaty on the Nonproliferation of Nuclear Weapons,

Recognizing that, pursuant to Article VII of the Treaty, the establishment of Nuclear-Weapon-Free Zones contributes to strengthening the international nonproliferation regime,

Recalling that the Security Council, in its statement of 31 January $1992 \underline{a}$ /, affirmed that the proliferation of nuclear and all other weapons of mass destruction constituted a threat to international peace and security,

Recalling also General Assembly resolutions adopted by consensus supporting the establishment of a Nuclear-Weapon-Free Zone in the Middle East, the latest of which is Resolution $49 / 71$ of 15 December 1994 ,

Recalling further the relevant resolutions adopted by the General Conference of the International Atomic Energy Agency concerning the application of Agency safeguards in the Middle East, the latest of which is GC(XXXVIII)/RES/21 of 23 September 1994, and noting 
the danger of nuclear proliferation, especially in areas of tension,

Bearing in mind Security Council resolution 687 (1991) and in particular paragraph 14 thereof,

Noting Security Council Resolution 984 (1995) and paragraph 8 of the decision on principles and objectives for nuclear nonproliferation and disarmament adopted by the Conference on 11 May 1995,

Bearing in mind the other decisions adopted by the Conference on 11 May 1995,

1. Endorses the aims and objectives of the Middle East peace process and recognizes that efforts in this regard, as well as other efforts, contribute to, inter alia, a Middle East zone free of nuclear weapons as well as other Weapons of Mass Destruction; a/S/23500.

2. Notes with satisfaction that, in its report (NPT/CONF.1995/MC.III/), Main Committee III of the Conference recommended that the Conference "call on those remaining States not parties to the Treaty to accede to it, thereby accepting an international legally binding commitment not to acquire nuclear weapons or nuclear explosive devices and to accept International Atomic Energy Agency safeguards on all their nuclear activities;" 
3. Notes with concern the continued existence in the Middle East of unsafeguarded nuclear facilities, and reaffirms in this connection the recommendation contained in Section VI, paragraph 3, of the report of Main Committee III urging those non-parties to the Treaty on the Nonproliferation of Nuclear Weapons that operate unsafeguarded nuclear facilities to accept full-scope International Atomic Energy Agency safeguards;

4. Reaffirms the importance of the early realization of universal adherence to the Treaty, and calls upon all States of the Middle East that have not yet done so, without exception, to accede to the Treaty as soon as possible and to place their nuclear facilities under full-scope International Atomic Energy Agency safeguards;

5. Calls upon all States in the Middle East to take practical steps in appropriate forums aimed at making progress towards, inter alia, the establishment of an effectively verifiable Middle East zone free of Weapons of Mass Destruction, nuclear, chemical and biological, and their delivery systems, and to refrain from taking any measures that preclude the achievement of this objective; and,

6. Calls upon all States party to the Treaty on the Nonproliferation of Nuclear Weapons, and in particular the 
Nuclear Weapon States, to extend their cooperation and to exert their utmost efforts with a view to ensuring the early establishment by regional parties of a Middle East zone free of nuclear and all other Weapons of Mass Destruction and their delivery systems. 
Chapter 18

The Nuclear Nonproliferation Treaty Review - 2000

Tariq Rauf

Barring any last minute schedule changes, the Sixth Review Conference of the Parties to the Treaty on the Nonproliferation of Nuclear Weapons (NPT) will take place at United Nations headquarters from 24 April to 19 May 2000. It goes without saying that expectations will be high regarding the review of the operation and implementation of the Treaty during the five years since the historic 1995 NPT Review and Extension Conference (NPTREC), which on 11 May 1995, agreed without a vote to a package of decisions and resolution that extended the Treaty indefinitely.

The conduct of the 2000 Review Conference will be viewed, in large part, through the lens of the 1995 package of extension decisions and resolution. Decision 1 on "Strengthening the Review Process for the Treaty"2 elaborated a framework for an enhanced and more substantive Treaty review process to facilitate a full and balanced review of the implementation of the NPT and to forward recommendations on future steps to the quinquennial NPT Review Conferences. Decision 2 on "Principles and Objectives for Nuclear Nonproliferation and Disarmament,"3 established substantive guidelines and indicated targets designed to promote greater accountability regarding the full implementation of the Treaty. 
Decision 3 on "Extension of the Treaty on the Nonproliferation of Nuclear Weapons, ${ }^{, 4}$ emphasized the two preceding decisions adopted by the NPTREC and reaffirmed the NPT's Article VIII.3; and was taken in accordance with Article X.2 that provided for the indefinite continuation in force of the Treaty and, hence, it was legally binding. The importance of the two decisions on principles and objectives and a strengthened treaty review process reflects that they have been referred to, respectively as "the hammer and the anvil of the postNPT extension epoch." ${ }^{5}$ In addition, a resolution on the Middle East ${ }^{6}$ co-sponsored by the depositary States was also adopted, which inter alia endorsed the on-going peace process, stressed the importance of the treaty's universality in the region, and called for the establishment in the region of an effectively verifiable zone free of Weapons of Mass Destruction (WMD) and their delivery systems.

The euphoria following the indefinite extension of the NPT quickly evaporated as bickering broke out at the NPTREC between some members of the Group of Non-Aligned States (NAM) and certain members of the Western and Others Group (WEOG) including the three Western Nuclear Weapon States (NWS), over the heavy pressure applied by the NWS to secure indefinite extension and over the lack of binding agreement on a framework for nuclear disarmament. ${ }^{7}$ This resulted in the failure of the 1995 Conference to cap its historic success with a Final Declaration.

In the four years that have elapsed since the indefinite extension, and as States finalize preparations for the next NPT review 
conference in 2000 , differences are already rife over the meaning and interpretation of the NPTREC decisions and on their implementation that possibly threaten to cast a cloud over the new Treaty review process, even before it gets underway.

The aim of this paper is to contribute some thinking on how best to approach the conduct of the next, the sixth, Review Conference of the Parties to the NPT, and the first under the "strengthened review process" scheduled for the year 2000. It will be crucial to ensure a full and balanced review of compliance with all of the provisions of the Treaty, as well as the implementation of the decisions of the 1995 NPTREC. This paper begins with an analysis Decisions 1 and 2 of the NPTREC, comments on the enhanced review process for the Treaty in light of these decisions, and offers perspectives on how to approach the work of the Review Conference.

\section{Decision 1: Strengthening the review process for the Treaty}

The original concept of a "strengthened review process" in the context of the extension decision was first elaborated in a Canadian "non-paper" in early 1995 . $^{8}$ The Canadian concept paper outlined the characteristics of an "enhanced review process" as comprising, inter alia:

- $\quad$ Retention of the current structure of review conferences;

- Investing the preparatory process with a substantive character 
(i.e. discussion of both procedural and substantive issues);

- Elaborating, at Review Conferences, indicative targets for compliance with given articles of the Treaty; and,

- Establishing a framework for ways of strengthening the Treaty and its implementation.

These ideas found their way into the South African draft on the enhanced review mechanism, and through the process of the President's Consultations at the NPTREC were eventually elaborated in the decisions on the extension package. The term "strengthened review process," in Decision 1, was crafted by Ambassador Adolfo Taylhardat (Venezuela), who prevailed in arguing that "enhancing implied only 'cosmetic' changes and that what was required was a process that should lead to a full implementation of the NPT, having in mind, specifically, Article VI." During the President's Consultations, the drafters struck a political compromise between those who feared that in indefinitely extending the NPT, the NonNuclear Weapon States (NNWS) would lose their leverage as regards the NWS' nuclear disarmament obligations and those who preferred a simple extension of the Treaty without any collateral measures to complement the future implementation of the NPT. In other words, the compromise provided not only to make all States Parties accountable for full compliance with the provisions of the Treaty, but more specifically to hold the NWS to fulfilling their Article VI commitments. To quote Ambassador Christopher Westdal (then Canadian Ambassador for Disarmament and the head of Canada's 
delegation to the NPTREC):

The Nuclear Weapon States need to understand that the Non-Nuclear Weapon States accepted indefinite extension because they want the Nuclear Weapon States to be permanently held accountable to Article VI on disarmament. ${ }^{10}$

Ambassador Dhanapala in his closing statement to the NPTREC also emphasized the concept of permanence with accountability, originally coined by Canada:

The 'strengthened review process' that we have established will now ensure a sharper focus on review conferences of the future and their preparatory committees. These forums of rigorous accountability will play a more crucial role in the operation of the treaty than ever before. As States Parties to the Treaty, we have to ensure that we make maximum use of this mechanism of accountability in the fulfillment of the undertakings of the Treaty. ${ }^{11}$

Laurence Scheinman (former Assistant Director of the US Arms Control and Disarmament Agency), speaking on the same issue but in a slightly different vein, summed it up as:

Interest in 'strengthening' or 'enhancing' the traditional treaty review process grew out of a concern shared by many Non-Nuclear Weapon States that the Nuclear Weapon States would lose any incentive to make progress toward nuclear disarmament as called for by Article VI of the NPT once they had secured indefinite extension. A way to deal with this desire for greater Nuclear Weapon State accountability was 
to endow the NPT review conferences and the associated preparatory meetings with a more substantive character, thus 'strengthening' the process. This struck a chord with the NPT NonNuclear Weapon State members who saw this as an opportunity to promote the goal of full implementation of the Treaty by all its parties including the Nuclear Weapon States. ${ }^{12}$

Decision 1 consisted of seven operative paragraphs, of which five dealt with the review conferences $(1,2,5,6$, and 7$)$, while two others ( 3 and 4 ) with the Preparatory Committee, though some of the paragraphs are better understood if read in conjunction with others.

The NPT created the precedent, for multilateral arms control agreements, of periodic reviews to assess the implementation of the Treaty after its entry into force. ${ }^{13}$ Article VIII.3 specifically provided for the first review conference to be held in Geneva in 1975, five years after the Treaty's entry into force in 1970, and left open the option for subsequent quinquennial reviews, thereafter, if requested by a majority of States Parties. In practice, however, NPT review conferences have been held every five years since 1975. The traditional procedure had been for a majority of parties to request the three depositaries (the United States, United Kingdom, and the then USSR now Russian Federation) to initiate proceedings to hold a review conference. This wish was manifested through a draft resolution crafted in the United Nations' General Assembly (UNGA) First Committee (disarmament and international security), and subsequently adopted by the General Assembly two years prior to the 
next Conference. The Final Declaration of the 1985 review conference, however, noted in its review of Article VIII that the "States Party to the Treaty participating in this Conference propose to the Depositary Governments that a fourth Conference to review the operation of the Treaty be convened in $1990 .^{14}$

Decision 1 institutionalized the past practice of five-yearly reviews, thus in effect it could be said to indirectly clarify the meaning of Article VII.3 in regularizing quinquennial reviews, as a way of strengthening the review process for the Treaty and to provide greater accountability. Henceforth, there will be a near-continuous review process that no longer requires the formality of a majority of States Parties requesting the depositaries to arrange a review conference. Furthermore, the Preparatory Committee (PrepCom) will now meet for a duration of ten working days, instead of the previous five. Also, the Committee will meet in each of the three years prior to the next review conference, and if necessary, a fourth session may be held in the year of the conference. This doubling of the working days of the PrepCom was designed to facilitate a full and frank substantive exchange of views on the operation and implementation of the Treaty, with the decisions of the NPTREC providing the guidance.

For the most part, the Preparatory Committee for previous review conferences traditionally focused primarily on procedural, logistical, and legal matters. The third and fourth sessions of the PrepCom for the 1995 NPTREC had also engaged in discussion on 
substantive matters, though this was more the exception than the rule. Decision 1 thus served to formalize the inclusion of substantive matters, along with procedural issues, in the work of the Preparatory Committee and clearly specified that:

The purpose of the Preparatory Committee meetings would be to consider principles, objectives and ways in order to promote the full implementation of the Treaty, as well as its universality, and to make recommendations thereon to the Review Conference. These include those identified in the Decision on Principles and Objectives for Nuclear Nonproliferation and Disarmament adopted on 11 May 1995. These meetings should also make the procedural preparations for the next Review Conference. $^{15}$

In many ways this is the crux of the "strengthened review process," in that the Preparatory Committee, which is now specifically mandated to consider 1) principles; 2) objectives; and, 3) ways, in order to promote the full implementation of the Treaty, as well as its universality. In both 1997 and 1998 sessions of the Preparatory Committee, these issues became a source of controversy and conflict as competing interpretations of Decision 1 emerged. The "intent" of the drafters was to transform the review into a more credible and meaningful process of accountability for the Treaty's implementation by all States Parties, and for future reviews to encompass the full scope of the nuclear disarmament and nuclear nonproliferation agenda. The reference to the terms "principles" and "objectives" in this context included those captured in the framework 
of Decision 2 on "Principles and Objectives for Nuclear Nonproliferation and Disarmament."16 Furthermore, the term "ways," added in one of the penultimate revisions of the draft decision, was taken to mean defining ways or setting indicative targets to promote the full implementation of the Treaty. In practice, however, with the passage of time memories have faded, officials have been reassigned, differing interpretations have emerged, as have some efforts to challenge the negotiating history or the "intent" of the drafters that might result in dampening down the scope of Decision 1.

While endorsing the current structure of the three Main Committees (MC), at review conferences, Decision 1 (paragraph 5) also empowered the General Committee to resolve the question of overlap in the work of the MCs in a manner as to delegate responsibility for review and subsequent reporting on each specific issue to only one of the relevant Main Committees. The record of the previous five NPT review conferences suggests that the Main Committees' program of work has been organized in an inefficient, somewhat redundant, and inordinately complex manner. It is worth recalling that the 1975 and 1980 Review Conferences each operated with only two Main Committees. Main Committee I (MC I) dealt with political and disarmament matters, while Main Committee II (MC I) dealt with safeguards/export controls and peaceful uses. The near-failure of the 1975 Review Conference (RevConf), and the complete failure of the 1980 RevConf, to agree on a Final Declaration, together with the political requirement to give the 
Eastern Group the chairmanship of a main committee, led the United States at the third Review Conference in 1985 to propose three Main Committees. This established the precedent for the current MC structure and their allocation of work.

The issue of setting up subsidiary bodies (paragraph 5), within the respective Main Committees, was not entirely new as at previous review conferences. Informal working groups had been created to resolve certain clusters of issues and to draft language for the MC's report on the review of the Treaty. In 1995, for example, MC I established an open-ended working group on security assurances, while MC II established two working groups, one to consider Nuclear-Weapon-Free Zones and the other export controls. After 1995, the task of recommending the establishment of subsidiary bodies was assigned to the Preparatory Committee. Even this was not entirely a new practice as the PrepCom for the 1995 NPTREC had created a working group to consider and report on its Rules of Procedure. This group continued its work through the first few days of the NPTREC to try to finalize Rule 28.3 on the extension decision. Decision 1 in building upon informal past practice formalized the role of subsidiary bodies in providing for a focused consideration of such issues. The "strengthened review process" did not in any way limit the duration of such subsidiary bodies. There can be no reason why specific subsidiary bodies should not be mandated to work intersessionally or even on an on-going basis. An improvement in the quality of debate and better chances for the success of more complex 
initiatives, including those regarding institutional objectives, might thereby be expected.

The final paragraph of Decision 1 enjoined States Parties that the focus of Review Conferences on the implementation of the Treaty could look back at the period under review, as well as make recommendations on the areas where further progress was required, and to identify the necessary means for its achievement. Future Review Conferences were charged with specifically addressing ways to strengthen the implementation of the Treaty and its universality. This suggested that at least two products were expected from future review conferences: an assessment of the operation of the Treaty in the five-year period under review (i.e. 1995-2000); and a set of goals to promote the implementation of the Treaty in the next five-year period (i.e. from 2000 through 2005).

One of the most important aspects of the "Decisions on Strengthened Reviews and of Principles and Objectives" was that of the evolving nature of the contents of both documents. That the process of reviewing the operation of the treaty was augmented at the NPTREC in 1995 implied that this could - and should - be repeated in the future. The same holds true of the "Principles and Objectives." It would be wise to regard both documents as rolling texts to be reviewed and appropriately augmented quinquennially. 


\section{Decision 2: Principles and Objectives for Nuclear} Nonproliferation and Disarmament

In many respects, interpreting and implementing Decision 2 will be more challenging than Decision 1 . The drafters of this decision, while negotiating in the President's Consultations at the NPTREC, apparently intended to establish what has been variously referred to subsequently as a "yardstick" or a "template" against which to measure future implementation of the Treaty. ${ }^{17}$ Further, this decision has been characterized as comprising a "rolling text" that was designed to be dynamic and responsive to changing international conditions. John Holum, Senior Advisor, Department of State, described Decision 2 as "a rolling report card on the world's efforts to live up to the bargains struck in the NPT and since affirmed."18 In Laurence Scheinman's view, "The decision on 'Principles and Objectives' outlined an 'agenda' of issues that the parties identified as important to future efforts to implement and sustain the NPT. It encompassed the elements generally regarded as critical to the longterm success of the Treaty and of the nonproliferation regime that it supports." ${ }^{19}$ He noted further that:

Some NPT countries refer to the 'Principles and Objectives' decision as the 'yardstick' against which future progress will be measured... . For the United States, the 'Principles and Objectives' decision represents the important collective political interest and commitment of NPT parties to see further progress made toward assuring the full 
implementation of the NPT and a useful reference point for our continued efforts toward that end. The recommendations outlined in the decision are ones we and others should strive to meet. However, it is the Treaty itself that is the source of our obligations and a full and balanced review of the Treaty is the objective of NPT review conferences. ${ }^{20}$

Peter Goosen (South Africa's delegate at the NPTREC) suggested that in formulating the principles agreed in Decision 2 "it was important to stretch the parameters of the debate but yet not to break the envelope of what was possible."21 Ambassador Christopher Westdal (Canada) captured this theme succinctly:

Non-Nuclear Weapon States see indefinite extension as a permanent commitment by the Nuclear Weapon States to pursue disarmament. Thus, the Non-Nuclear Weapon States will now, in effect, call on the Nuclear Weapon States to fulfill their commitments under Article VI: to lower the numbers of such weapons, and to get rid of them. That is the message to Nuclear Weapon States, a message some of them might not welcome. The world has, in effect, proclaimed permanent values and what must be done now is to get on with the hard work of fulfilling them. ${ }^{22}$

Decisions 1 and 2 established new parameters of discourse on nonproliferation and nuclear disarmament. However, the nature and context of this debate will need to be worked out during the deliberations of the 2000 Review Conference. The challenge will remain of finding credible ways for a balanced review of the Treaty. However, this balance inevitably will need to favor a greater focus on 
the nuclear disarmament provisions of the NPT, as it was never the intent either of the drafters of the Treaty, or of the extension package, or of the States Parties at the NPTREC to perpetuate the status of the Nuclear Weapon States.

Decision 2 set out, under seven headings comprising 20 operative paragraphs, a set of indicative targets for the full implementation of the Treaty. These indicative targets relate both to Treaty compliance issues as well as to other related nuclear nonproliferation and disarmament priorities that emanate from the NPT. Falling into the former category are nonproliferation (Articles I and II), nuclear disarmament (Article VI), Nuclear-Weapon-Free Zones (Article VII), safeguards (Article III), and peaceful uses of nuclear energy (Article IV). In the latter category belong universality and security assurances. In practice, both sets of issues have been routinely discussed at previous review conferences. At the 1995 NPTREC, Main Committee I discussed security assurances, while both Main Committees II and III discussed universality ("measures aimed at promoting the wider acceptance of the Treaty").

One of the key issues to be resolved was whether the "Principles and Objectives" outlined in Decision 2 represented fixed targets or indicative targets that could be updated periodically, and as certain objectives were achieved (e.g., a comprehensive test ban treaty) other objectives take their place (e.g., multilateral nuclear arms reductions or general and complete disarmament)? The intent of the drafters was to regard Decision 2 as a "living document" that could 
be added to or subtracted from as merited by progress in nuclear nonproliferation and disarmament and other related developments.

\section{Substantive Issues at the $\mathbf{2 0 0 0}$ Review Conference}

Previous review conferences have traditionally addressed substantive matters in terms of the three general objectives of the NPT: nuclear nonproliferation, nuclear disarmament, and safeguarded cooperation in the peaceful uses of atomic energy under a three Main Committee structure. It is likely that format for a structured and balanced review will continue. However, the merits of an article-byarticle review might be examined in search for a more harmonious and productive review. In practice, however, the next review conference will have to deal with substantive issues of two types: issues emanating directly from the NPT itself; and issues that bear on NPT matters, but which do not stem directly from the Treaty. In general, political and security issues of the day have tended to play an important role at review conferences, since such conferences are intensely political. External events threatening to cast their shadow over the 2000 review conference might include, among others: the longer-term implications of Russian reactions to NATO expansion and the alliance's out-of-area use of force; the fate of the AntiBallistic Missile Treaty, and US plans for theater and national missile defense systems; status of START II before the Duma; the tenor of US-China relations; developments in the Middle East, Korean 
Peninsula, and South Asia; progress, or lack thereof, at the Conference on Disarmament; and, CTBT ratification and entry-intoforce developments.

The 1995 Decision 2 on "Principles and Objectives" set out seven key items and established a set of parameters to evaluate the implementation and operation of the Treaty that included: universality, security assurances, nonproliferation, nuclear disarmament, safeguards, peaceful uses of atomic energy ,and Nuclear-Weapon-Free Zones (The order is changed to reflect the order of the articles of the NPT.)

\subsection{Universality}

At the time of the NPTREC in 1995 the NPT had attracted 178 adherents. The number of States Parties now stands at 187 (not including Taiwan and Yugoslavia), which means that 9 additional states have joined the Treaty. With the near-universal adherence to the Treaty, only Cuba, India, Israel, and Pakistan remain outside the Treaty. Last May's (1998) nuclear tests by India and Pakistan, and both countries' overt declarations claiming NWS status, posed a grievous challenge to the integrity of the Treaty and its associated regime. While UN Security Council Resolution 1172 of last June rejected recognition of any new NWS and established certain nonproliferation benchmarks for South Asia, there is growing ease about the nature and thrust of US engagement policy with India and Pakistan. 
Since 1995, the Middle East, especially the question of Israeli accession to the NPT as a NNWS has emerged as an issue squarely pitting the US and its allies against the Arab states, as well as the nonaligned countries (NAM). There are clear signs that the US would like to undermine the 1995 NPTREC Middle East Resolution and is opposed to utilizing the NPT review forum as a way of highlighting Israel's unsafeguarded nuclear weapon activities, or to bring pressure upon Israel. Indeed, the US disagreement to accept any compromise language on the Middle East was the catalyst that led to the collapse of the 1998 NPT PrepCom. Lost in the shuffle is the crucial fact that the Middle East Resolution, every word of which was cleared by the US with Israel before the document was adopted by the NPTREC, served as the mechanism that made it possible for the Arab states not to stand in the way of the Treaty's indefinite extension. As noted earlier in this paper, the 1995 package of decisions and resolution reflects an historic compromise reached at the NPTREC that enabled agreement on indefinite extension without a vote. Having said that, more thought needs to be devoted to what actions might be required regarding this resolution at the 2000 Review Conference, where it is virtually certain that the Arab states, led by Egypt, will again stress the importance of universal application of the Treaty within their region. How will the Treaty membership react to, or deal with, any notice by some or all of the Arab states to either suspend their acceptance of the Treaty or to withdraw from it, if Israel does not renounce its nuclear weapon capability and join the NPT as a Non- 
Nuclear Weapon States (NNWS) within some specified time frame?

At the 2000 Review Conference, political pressure is bound to increase on the three perennial holdouts - India, Israel, and Pakistan. In practice, however, bringing these three undeclared Nuclear Weapon States into the Treaty poses not only major political, but also technical challenges. In all three instances, NPT membership will have to be preceded by a process of nuclear rollback and the precedent established by South Africa would be useful in this regard. By way of background, the biggest challenge was not that of dismantling South Africa's weapons capability, but that of the IAEA subsequently verifying the completeness of Pretoria's declaration of inventory of nuclear material and facilities. ${ }^{23}$ This was the first time that the IAEA had "looked back" at a state's nuclear activities and had to verify operating records, declared outputs, completeness of dismantling and destruction, and the reassignment of dual-use equipment to peaceful or non-military work. ${ }^{24}$ In this task, the IAEA's tasks were facilitated by full and extensive disclosures by South Africa and cooperative verification. This experience gained by the IAEA will be useful in verifying post facto other similar renunciations of weapons capabilities - were they to take place in the threshold states or eventually in the NWS.

Operative paragraph 1 of Decision 2 calls upon all States Parties to promote universal adherence to the NPT. However, proponents of NPT universality need to exercise great care that in the interest of promoting universal adherence, the Treaty itself is not 
damaged or weakened. Better to have three pariahs who are denied nuclear assistance and remain the focus of political and economic pressure than to damage the credibility of the Treaty by admitting these states without first clearly establishing the total destruction of all nuclear weapons and the conversion of weapon-related facilities and fissile materials, as well as a comprehensive accounting of all previously unsafeguarded nuclear materials. Finally, pending the capture of the three holdouts by the Treaty, it might be useful for NPT parties to consider, in the context of the deliberations of the Preparatory Committee, a harmonized approach for devising ways to encourage the adherence of all states still remaining outside the Treaty in conjunction with the application of full-scope safeguards on all (not just new) supply arrangements. Further, the traditional approach of selective pressure and differentiated policies toward the three-holdout states might well be re-examined with a view to developing a common nonproliferation strategy. I would strongly recommend that the Review Conference explicitly name the countries remaining outside the NPT and examine a variety of diplomatic and economic instruments to pressure the holdouts to join the global nuclear nonproliferation norm.

\subsection{Security Assurances}

Since the initial attempts to conclude the NPT, security assurances to Non-Nuclear Weapon States have been considered an important component of a credible global nonproliferation regime. 
UN Security Council Resolution 255 (1968) provided positive assurances, i.e., a pledge to come to the assistance of Non-Nuclear Weapon States threatened with nuclear attack. The NNWS have also sought negative assurances as defined as a pledge by the nuclear powers not to use or threaten to use nuclear weapons against NPT Non-Nuclear Weapon States. At the First Special Session of the UN on Disarmament in 1978 , the five nuclear powers gave separate negative security assurances. Only China's assurance was comprehensive and unconditional. Since that time, Egypt and Nigeria have worked on various drafts of negative security assurances.

Over time all five declared nuclear powers have made unilateral and conditional statements on negative assurances, but the NNWS wanted to harmonize these negative assurances into a legally binding document. On the eve of the 1995 NPT Conference, the Nuclear Weapon States (NWS) agreed to Security Council Resolution 984 updating the earlier resolution, and four of the five Nuclear Weapon States harmonized their unilateral declarations. China did not join because its commitments are more far-reaching. One continuing problem is that except for China, none of four other nuclear powers have unconditionally renounced the first-use of nuclear weapons. In the context of the 1995 NPT Conference, many developing states voiced the requirement for legally binding security assurances from the five Nuclear Weapon States - in the form of a multilateral, binding, Security Council resolution. In practice, however, the NWS issued a statement in Geneva in March 1995 on 
negative security assurances to NPT states and agreed to Resolution 984 (April 11, 1995) on positive assurances to NPT member states. ${ }^{25}$ These, however, still fall short of legally binding assurances.

The controversial Presidential Decision Directive 60 (PDD) of the US, referred to above, whereby the role of US nuclear weapons, includes deterrence of Chemical and Biological Weapons (CBW) attacks raises questions about the efficacy of Washington's national security agencies. Some prominent US-based international lawyers are of the view that perhaps the International Court of Justice (ICJ) could be asked to render an opinion to clarify this matter.

At the 1997 PrepCom, South Africa proposed special time for discussion of security assurances at the 1998 session. At the 1998 PrepCom, South Africa outlined some ideas about a legally binding instrument on security assurances to be negotiated at the 2000 Review Conference. This caused some controversy and certain states argued that such a course would undermine the $C D$, where this issue is also considered. Nonetheless, South Africa seems determined to raise this matter at the 2000 Review Conference. The Conference, however, could usefully consider a process to encourage the NWS to agree on enhanced, uniform and multilateral security assurances to NPT parties. Since declaring itself to be an NWS, in fall 1998, India offered security assurances to member states of NWFZs, however, this offer was not considered to be serious or to have any legal standing. 


\subsection{Nonproliferation (Articles I/II)}

The global nonproliferation norm was further strengthened with the indefinite extension of the NPT. In this context, the review process of the Treaty provides States Parties with the opportunity to exercise vigilance regarding full compliance with the Treaty in all its aspects as agreed in paragraph 2 . In this context, it would be useful to recall the statement released on January 31,1992 , by the Security Council on the maintenance of international peace and security in a post-Cold War world. ${ }^{26}$ The real importance of this Council statement lies in its recognition that the primary threat to international security now emanates from the spread of nuclear weapons to countries in conflict prone regions, and that proliferation of all Weapons of Mass Destruction must be prevented. In a sense, this statement also reflects the divergence in views on nuclear arms issues between the countries of the North and the South. For the North, now that the Cold War is over and a number of arms reduction and confidence-building agreements are in the process of being implemented, the threat to security emanates not from the former East bloc, but from the countries of the South that are believed to possess capabilities for nuclear and other Weapons of Mass Destruction. For the South, the principal interest is in seeing not just the US and Russia, but also Britain, China, and France reduce their nuclear arms in the first instance, with total elimination to follow, as well as a permanent end to unsafeguarded production of weapon-usable fissile material. Other important issues concern NATO nuclear sharing 
arrangements and stationed nuclear forces, whether an international nonproliferation norm has been created by the NPT regime, and if so, how will challenges to it be dealt with?

\subsection{Nuclear Disarmament (Article VI)}

Paragraphs 3-4 related to nuclear disarmament, and reaffirmed the commitments under Article VI of the NPT. Paragraph 4 outlined a program of action in regard to the full realization and effective implementation of Article VI, that included: a) a Comprehensive Test Ban Treaty (CTBT) to be concluded no later than 1996; b) the immediate commencement and early conclusion of negotiations on a multilateral convention banning the production of fissile material for nuclear explosives; and c) global nuclear weapon reductions with the goals of eventual elimination of nuclear weapons, and general and complete disarmament. In practice, however, in addition to the two specific measures noted above, additional nuclear disarmament measures will need to be considered, such as, for example: limitations on non-strategic nuclear weapons; verified destruction of warheads; and the disposition of excess weapons fissile materials.

\subsection{Comprehensive Test Ban Treaty}

After nearly fifty years of debate and years of complex negotiations, a Comprehensive Test Ban Treaty (CTBT) was signed 
at the United Nations in New York on September 24, 1996. Currently 152 states have signed the Treaty including the five Nuclear Weapon States, and some 33 states have ratified this document. Of the 44 states whose ratification is necessary for entry into force, 41 have signed (excluding DPRK, India, and Pakistan) ${ }^{27}$ and 17 have thus far ratified (including France and the United Kingdom). The compromise entry into force (EIF) formula depends upon treaty ratification by 44 states of the $\mathrm{CD}$, listed by name, that operate research or power reactors. India rejected this compromise, denied consensus at the $\mathrm{CD}$ on the adoption of the draft CTBT, and refused to sign the Treaty. Pakistan, too, linked its signature to that of India, and the DPRK has not yet signed. As already noted, both India and Pakistan carried out nuclear tests last May. In September 1998 at the UNGA, India committed "not to stand in the way of the CTBT," which was widely interpreted as meaning that India would join the treaty. However, this statement has never been clarified or interpreted by New Delhi. Pakistan, too, at UNGA committed to join the CTBT, but continued to link its signature to that of India.

The earliest that the CTBT could have entered into force was September 24,1998 , but without the ratification by all 44 designated states the CTBT cannot enter into force at all. However, under CTBT Article XIV (2), which was added at Canada's insistence, the signatories to the Treaty are scheduled to hold a political conference in 1999 to discuss the implementation of the CTBT.

Given the current pace of ratifications, it is highly unlikely 
that the CTBT's EIF conditions will be met by April 2000. Thus, the Review Conference could report that one of the items in the program of action had been achieved and that barring any surprises, nuclear weapon testing by the original five proliferators halted, even though the CTBT had not yet entered into force. On the other hand, it is also likely that there will be intense debate on issues such as: the science based stockpile stewardship (SBSS) program in the US (and similar programs in China, France, and Russia); the efficacy of the prototype International Monitoring System (IMS); and, the status of national test sites.

\subsection{Fissile Material Treaty}

The program of action outlined in paragraph 4(b) of Decision 2 called for the "immediate commencement and early conclusion of negotiations on a non-discriminatory and universally applicable convention banning the production of fissile material for nuclear weapons or other nuclear explosive devices." Such a multilateral treaty purportedly would further strengthen the legitimacy of the nonproliferation regime, and would add to the pressure on the holdout states to place all of their nuclear facilities under IAEA safeguards. As well, it is claimed that it would complement strategic arms reduction treaties by facilitating verifiable stockpile reductions and prevent the manufacture or stockpiling of new weapon-grade fissile material.

As long ago as 1946, under the Baruch Plan tabled at the 
United Nations, the US proposed placing under international control all dangerous aspects of the nuclear fuel cycle, including uranium enrichment and fuel reprocessing. President Eisenhower made other proposals to this effect in 1956, in 1964 by President Johnson, in 1969 by President Nixon, and in 1993 by President Clinton. The Soviet Union in 1982, for the first time proposed a cut-off, as a first step toward a freeze on nuclear weapons, at the UN Second Special Session on Disarmament. In 1988, US plutonium production was stopped due to safety reasons and a lack of demand. In 1989, President Gorbachev stated that the USSR would halt the production of highly enriched uranium (HEU), and closed two plutonium producing reactors, with the remaining two to be closed by the year 2000. President Clinton in his UN speeches in 1994, 1995, and 1996 reiterated the call for such a ban on the production of weapon-grade material, and Russian President Yeltsin is also in favor. Clinton in his speech noted that the US, Russia, France, and the United Kingdom had already halted production of fissile material for weapons. ${ }^{28}$

In November 1993, UN General Assembly Resolution No. 48/27, on the "Prohibition of the Production of Fissionable Material for Weapon Purposes" was adopted by consensus. During 1994-1995, discussions took place at the Conference on Disarmament (CD) in Geneva to define a mandate to commence negotiations. On March 25, 1995, the Special Coordinator recommended a negotiating mandate based on the UNGA resolution of 1993 , which was then 
adopted by the $C D$.

However, due to disagreements between the NWS and the threshold states, as well as others, no agreement had been possible in the $\mathrm{CD}$ even to agree on the negotiating format, i.e. to establish an $A d$ Hoc Committee. In the aftermath of the CTBT fiasco at the CD in August, India linked the establishment of an $A d$ Hoc Committee on a cut-off to that on nuclear disarmament - a move strongly opposed by the three Western NWS - thus continuing the stalemate at the CD into its 1997 and 1998 sessions. Furthermore, the General Assembly also had been unable in its 1994-1997 sessions to agree on a resolution on a fissile material production ban. Decision 2 specifically called for the immediate commencement and early conclusion of negotiations on a fissile material cut-off treaty.

At the 1997 PrepCom, it was agreed (as a result of Canadian and German joint proposals) to set aside time for consideration of a Fissile Material Cut-off Treaty (FMCT) at the 1998 PrepCom. Such a discussion did take place at the 1998 PrepCom, but it only served to air well known positions from all sides. The United States rejected acceptance of a compromise statement calling for the start of negotiations at the $\mathrm{CD}$ on the grounds that the PrepCom was not empowered to make statements on substantive matters.

Feeling the political heat after their nuclear detonations, both India and Pakistan modified their positions and the $C D$ reached agreement on a decision and a presidential statement on 11 August 1998 , “...to establish under item 1 of its agenda entitled 'Cessation of 
the nuclear arms race and nuclear disarmament' an Ad Hoc Committee which shall negotiate, on the basis of the report of the Special Coordinator (CD/1299) and the mandate contained therein, a non-discriminatory, multilateral and internationally and effectively verifiable treaty... ."29 Consequently, Ambassador Mark Moher (Canada) was appointed chair of the ad hoc committee, but no progress was registered on any of the key issues (such as scope, verification, stocks, etc.) in the remaining weeks of the 1998 session of the CD. Thus far at its 1999 session, the $\mathrm{CD}$ has failed to reestablish the ad hoc committee.

Given current developments, and barring some miracle, it is unlikely that serious negotiation will commence on a fissile material treaty by the opening of the 2000 NPT conference, thus representing failure on the second item in the 1995 program of action. Perhaps, it might be best if at the Review Conference the issue of a multilateral Fissile Material Cut-off Treaty (FMCT) were abandoned in lieu of an agreement among the five NWS to codify their moratoria on new production and to include transparency and safeguards measures. An FMCT is a relic of the Cold War arms control agenda and it will not succeed in achieving through the backdoor what the NPT has not achieved - capture of the three undeclared NWS.

\section{Nuclear Disarmament}

The third item in the program of action referred to nuclear disarmament. With the end of the Cold War, "classical" nuclear arms 
control has moved away from its emphasis on confrontational and technological approaches to focusing on cooperative and essentially political approaches to avoiding nuclear war and furthering nuclear disarmament. The Nuclear Weapon States have not put forward any agenda for the phasing out of nuclear arms. Despite declaratory statements favoring an eventual phasing out of nuclear weapons, both the US and Russia have only concurred to "study" the prospects of further reductions. At the March 21-22, 1997, Helsinki Summit, between Presidents Clinton and Yeltsin, the US proposed a START III framework of ceilings of 2,000-2,500 deployed strategic warheads on either side, as a way of facilitating ratification of START II by Russia. $^{30}$ Of the three lesser Nuclear Weapon States, both France and the United Kingdom have unilaterally removed obsolete, nonstrategic nuclear weapons; cancelled or slowed down certain strategic modernization programs; and in some cases reduced the op tempo of their alert nuclear forces, but neither was prepared to renounce reliance on nuclear arms. ${ }^{31}$ China continues to modernize its strategic nuclear forces, citing the threat from the US and reportedly will continue with modernization as long as large nuclear arsenals continue to exist.

Even after the Cold War, nuclear weapons remain the principal danger to global security. The United States and Russia plan to reduce their strategic arsenals by about 80 percent by the year 2007 and to cut back their nonstrategic nuclear weapons by about a third to a half (under the framework of the 1991 unilateral 
reductions). Even so, by the turn of the century the five nuclear powers will still retain a greater number of strategic nuclear warheads than they had collectively in 1970 when the NPT entered into force. The 1994 US Nuclear Posture Review endorsed a nuclear force structure that will remain at START II level, with an additional 2,500 intact but non-deployed warheads as a "strategic hedge." Furthermore, in fall 1996, President Clinton approved a new Presidential Decision Directive authorizing the use of nuclear weapons to deter chemical and biological weapon threats. Russia's new nuclear doctrine has reintroduced the concept of a nuclear first strike. It is building and deploying new mobile ground-launched strategic missiles albeit fewer than it previously planned in order to meet START II levels, and has threatened to deploy new nonstrategic nuclear weapons as a response to NATO enlargement. China's nuclear modernization continues, while the United Kingdom and France have cancelled or cut back certain strategic and nonstrategic programs, but persist with strategic modernization in general. Nuclear weapon programs in India, Israel, and Pakistan are also continuing. In sum, rather than diminishing in importance, nuclear weapons probably will continue to have a major effect on international security. Increasingly arms control experts are making the case for moving to minimal nuclear forces and the elimination of all nuclear arms, while others have noted that the United States and Russia will be hard put even to dismantle the number of warheads required under START I/II/III, given their limited warhead 
dismantling and fissile material storage capabilities.

Many Non-Nuclear Weapon States took the opportunity of the 1995 NPT Review and Extension Conference to press the case for nuclear elimination as called for under Article VI, and the decision on "principles and objectives" contained in the compromise language on this issue. As noted above, the NPTREC was unable to agree on a Final Declaration because of irreconcilable differences between the NAM and the Western nuclear powers over the report of Main Committee I. These unresolvable differences were essentially over nuclear disarmament - the NWS did not offer any new proposals, nor were they willing to countenance any kind of a timetable for nuclear weapon reductions or elimination. ${ }^{32}$

The frustration of the NNWS continued throughout the 1997 and 1998 sessions of the NPT PrepCom, and the NWS have nothing useful or new to report at the 1999 PrepCom. The NWS have taken to issuing joint statements extolling their virtues and listing the great progress achieved in nuclear disarmament. While indeed nuclear disarmament has and is continuing to take place, there have been no new strategic arms reduction agreements since 1993 and the existing ones might be in jeopardy. Furthermore, expansive new justifications for retaining nuclear weapons and broadening the conditions of their use, i.e. deterring biological and chemical attacks, as well as "rogue" states, have been espoused.

Three developments are likely to shape much of the consideration of Article VI issues at the 2000 Review Conference: a) 
the advisory opinion of the International Court of Justice; b) the continuing stalemate at the $\mathrm{CD}$; and, c) the "New Agenda" for nuclear disarmament (furthering the process initiated by the 1996 Canberra Commission Report).

On 8 July 1996, the International Court of Justice ruled on an advisory opinion requested the UN General Assembly (Resolution $49 / 75 \mathrm{~K}$ of 15 December 1994) on the use of nuclear weapons in armed conflict. ${ }^{33}$ While the ICJ opinion was inconclusive in general, the Court effectively concluded that the threat or use of nuclear weapons could be legally defensible only in extremis where national survival was at stake. The Court, however, unanimously ruled that:

There exists an obligation to pursue in good faith and bring to a conclusion negotiations leading to nuclear disarmament in all its aspects under strict and effective international control. ${ }^{34}$

More specifically, the ruling added:

[T]he legal import of that obligation goes beyond that of a mere obligation of conduct; the obligation involved here is an obligation to achieve a precise result - nuclear disarmament in all its aspects by adopting a particular course of conduct, namely the pursuit of negotiations on the matter in good faith. ${ }^{35}$

Attempts by a number of states to establish an ad hoc committee at the $C D$ to discuss nuclear disarmament have been consistently opposed particularly by the US and Russia, with the support of the lesser NWS. For example, a US view held that: 
Supporters of nuclear disarmament thus must take care what they ask for. To demand complete elimination of nuclear arms according to a fixed calendar is to throw sand into the gears of disarmament. It is a formula not for pressing ahead, but for standing still and resuming a sterile argument that leads nowhere. For it challenges not only existing weapons, but an unshakeable premise of defense planning.

As a staunch friend of the $C D$, let me say that nuclear disarmament there would be an inappropriate forum taking up an unamenable subject. It is no act of friendship to elevate expectations for a forum far beyond its capacities. Climbing down from Cold War peaks of nuclear weapons has been an intricate process, involving careful bilateral trade-offs, specialized verification, and a constant and shifting menu of sensitive national security calculations. There is no realistic prospect that the CD could manage such an effort. And given the CD's recent history, I must ask as well, do we really want to make all further nuclear disarmament progress subject to the CD's rule of consensus?

But, we're told, the $C D$ would not negotiate the treaties, but merely ventilate the issues - and tell the Nuclear Weapon States how to proceed. Well, the $\mathrm{CD}$ is a negotiating body. As to further NWS nuclear disarmament, if it is a negotiation, the $\mathrm{CD}$ is ill suited to do it; on the other hand, if it's not a negotiation, we should not water down the CD mission.

Last year's NPT conference itself recognized the practical realities. The program of action declares that the test ban and the fissile cut-off should be completed by the Conference on Disarmament. But 
it says efforts to reduce nuclear weapons should be pursued 'by the Nuclear Weapon States'. Those are the right assignments. ${ }^{36}$

It is evident that positions on the future of nuclear disarmament, and the proper venue and format for negotiations, remain polarized with no compromise in sight. As expected, at the opening of the 1997 through 1999 sessions of the $C D$, discord has reigned over the "Agenda" of the CD, with the NAM pressing for the establishment of an $A d H o c$ Committee on nuclear disarmament and the three Western NWS plus Russia opposing any such initiative. What is needed is flexibility in the NWS' position allowing for discussion and consideration of nuclear disarmament at the $C D$ with the actual negotiation left to the parties concerned.

Frustrated by the lack of progress on nuclear disarmament, on 9 June 1998, eight states issued a Joint Declaration on "A NuclearWeapons-Free World: The Need for a New Agenda." The foreign ministers of Brazil, Egypt, Ireland, Mexico, New Zealand, Slovenia, South Africa and Sweden joined together in reiterating the call for the total elimination of nuclear weapons. This New Agenda Coalition then went on at the 1998 UNGA with 30 cosponsors to introduce Resolution 53/77Y "Towards a Nuclear-Weapons-Free World: The Need for a New Agenda," that was adopted by a vote of 114:18:38 on 4 December. What was significant was the pressure from the US on its NATO allies to join it in opposing this resolution. Countries such as Canada, which have been pushing for discussion on nuclear disarmament at the $\mathrm{CD}$, were inclined to support the resolution; but 
in the end, under US pressure, 12 NATO countries decided to abstain rather than to oppose the new agenda resolution.

Furthermore, on 2 February 1999, Belgium on behalf of five NATO members - Belgium, Germany, Italy, Netherlands and Norway - proposed an ad hoc working group to study ways and means of establishing an exchange of information and views within the $\mathrm{CD}$ on endeavors toward nuclear disarmament. ${ }^{37}$

Thus, the stage is being set for yet again a fractious debate on nuclear disarmament in the context of an NPT review conference. The United States has already warned "efforts to treat the NPT process as a single-minded referendum on the Nuclear Weapon States' progress in nuclear disarmament are not well conceived.",38 What might be useful during the Review Conference would be a consideration of different views on Article VI, with the aim of promoting a realistic and balanced consideration of the complex and highly political issues involved in the context of NPT obligations. While actual negotiations on nuclear weapon reductions properly belong within the purview of the NWS, the NPT review process could usefully serve to provide an opportunity for a discussion on the guiding principles for future measures such as:

- $\quad$ enhanced transparency in the reduction process, i.e., reports provided by the NWS on the actual numbers of warheads currently deployed, in active and inactive status, and dismantled; 
- greater openness on nuclear doctrine, i.e., current status of alert forces and targeting practices; and,

- $\quad$ steps already taken and contemplated for further nuclear arms reductions leading to the eventual elimination of all nuclear weapons.

\subsection{Strengthened IAEA Safeguards (NPT Article III) and Export Controls}

Decision 2 devoted five paragraphs to safeguards, the most on any one issue, thus highlighting the importance that States Parties placed on compliance. Effective international safeguards, under NPT Article $\mathrm{II}$ and the related INFCIRC/153 type agreements with the IAEA, are an essential element of the nuclear nonproliferation regime. Export controls have also become an indispensable part of that regime, and derive from Article III.2. Safeguards are a technical means to the political goal of verifying that NPT Non-Nuclear Weapon States (NNWS) are in compliance with their obligations under the Treaty. Following the discovery of Iraq's clandestine nuclear weapons program, and questions about North Korea's nuclear activities, safeguards have been strengthened through a greatly enhanced flow of information. The reaffirmation of the Agency's right to conduct "any time, any place" special inspections, together with new verification techniques (such as environmental monitoring and use of intelligence data). The IAEA now has in place an enhanced safeguards regime under its Additional Protocol 
(INFCIRC/540) - 40 states have concluded the Additional Protocol and it is now in force in five states. However, 38 NPT states still have to conclude NPT safeguards agreements (INFCIRC/153).

The safeguards program is under threat from two quarters. First, a zero-growth in the IAEA budget for the last decade at a time of rapid expansion of safeguards to cover the entire scope of nuclear activities in South Africa, Argentina, Brazil, and NIS states. Second, resistance from some developing countries that perceive safeguards as an invasion of national sovereignty, as well as from certain traditionally secretive European Union countries reluctant to permit greater inspection access to their nuclear industries.

The Review Conference could endorse a call for an increase in the IAEA's budget, as well as reinforcing the Agency's primary role in the verification of NNWS compliance with the NPT, and to the extent possible, support an enhanced role for the IAEA in verifying nuclear disarmament by the NWS - but the additional costs of safeguards activities in the NWS must be borne by these five states.

\subsection{Cooperation in Peaceful Uses of Atomic Energy}

The principal suppliers of nuclear materials and technology (except for China) have also agreed in the Nuclear Suppliers Group (NSG) upon new guidelines governing such exports, including dualuse items. Further, the NSG has agreed that nuclear items not be supplied to a NNWS that has not accepted full-scope safeguards, 
i.e., has not accepted IAEA monitoring over its entire spectrum of nuclear activities. Many developing countries regard export controls as onerous and discriminatory. Supplier countries, on the other hand, consider export controls as supplementing safeguards and preventing nuclear proliferation. Some developing countries have raised this issue at both the 1995 NPT Review and Extension Conference and at previous review conferences, and it is probable that at future Review Conferences differences over export controls could well jeopardize the enhanced NPT review process.

The Review Conference could profitably discuss ways of promoting the early implementation of "strengthened safeguards" and of creating increased transparency in export controls, with a view to providing assessments on the political and technical feasibility on issues including, but not limited to: enhanced flow of information on national nuclear activities to the IAEA; new verification techniques (such as environmental monitoring and use of intelligence data); "any time, any where" inspections; and, enhanced transparency in export controls.

A controversial issue waiting in the wings is the question of the treatment that certain NPT parties found in breach of their safeguards agreements are receiving, as compared to some in good standing. This refers to the nearly $\$ 6$ billion package offered to DPRK, including the supply of light water reactors, in return for allowing IAEA inspection of its nuclear facilities while Iran, where IAEA safeguards are in normal application without problems, is 
facing a US-led blockade banning transfers of nuclear and dual-use items.

\subsection{Nuclear-Weapon-Free Zones (NPT Article VII)}

Article VI of the NPT both recognizes and encourages the establishment of Nuclear-Weapon-Free Zones (NWFZs) as a means of promoting nuclear nonproliferation through regional measures. The 1995 NPT Review and Extension Conference also endorsed the concept of NWFZs and recommended that countries in various regions consider the establishment of zones free of all Weapons of Mass Destruction, in particular the Middle East and Central Asia.

NWFZ agreements present additional effective options to complement global nonproliferation efforts and can serve to roll back proliferation where it has already taken place. Furthermore, NWFZs can create mutually binding obligations that can be more wideranging than those subsumed under the NPT. Although the concept of NWFZs actually predates the NPT, until 1990, no NWFZ, except the Antarctic Treaty, was fully operational. Recently, however, considerable progress has been made in expanding the territory covered by NWFZs, and there is now a good prospect that before long five regional treaties, covering over 100 countries and the entire southern hemisphere, will be in full force. Since the 1995 NPTREC, two additional NWFZ agreements have been signed that establish such zones in Southeast Asia and in Africa. In 1996, the US, the UK, and France, all signed the Protocols to the Treaty of Rarotonga. 
While attempts at UNGA, to set up a Southern Hemisphere NWFZ were unsuccessful, it was clear that there exists a broad measure of support for such a treaty. ${ }^{39}$ Further, informal discussions have taken place on setting up a NWFZ in Central Asia, and Belarus and Ukraine have joined Russia in calling for a NWFZ in Central/Eastern Europe as a counter to NATO expansion. On February 28, 1997, the five Central Asian heads of state signed the "Almaty Declaration", followed by the Tashkent Declaration by their foreign ministers on September 15, both of which called for the establishment of a NWFZ in their region. In addition, UNGA resolutions on a CANWFZ were adopted unanimously in 1997 and 1998.

The Review Conference could recommend modalities to assist countries and regions in assessing the viability of a NWFZ in their particular geographic environment, with a view to promoting a balanced and productive discussion on during the new review process of the NPT, establishing additional zones.

\section{Role of the Treaty and the NPTREC Decisions at the 2000 NPT Review Conference}

The traditional view of States regarding the scope of previous NPT Review Conferences was that it was the implementation of the Treaty that is being reviewed. The Treaty is the source of legally binding commitments on the part of signatory States. Therefore, it is 
the Treaty which lies at the heart of the review process-in terms of "assuring that the purposes of the Preamble and the provisions of the Treaty are being realized" - as noted in Article VIII.3. In September 1996, the United States made clear that it preferred "past practice...as a guide...in determining how to proceed" in the PrepCom process. ${ }^{40}$ And at the 1997 PrepCom, the US stressed that:

It was essential to bear in mind that the obligations of the States Parties stemmed from the Nonproliferation Treaty, which should, therefore, be considered the primary source of guidance. ${ }^{41}$

Another prevalent view was that the Treaty had been enhanced by the decisions of 1995 and future reviews must take into account not only the Treaty, but the decisions and resolution agreed at the 1995 NPTREC. For example, at the 1997 PrepCom, China stated that:

The 2000 Review Conference would be the first meeting since the indefinite extension of the Treaty. In addition to full consideration of the three decisions and one resolution adopted by the 1995 Conference, consideration should also be given to a number of relationships in order to enhance the review process and ensure the success of the 2000 Review Conference.... Secondly, the consideration of substantive issues at the Review Conference and in its Preparatory Committee should be based on the Treaty, and full use should be made of the 'Principles and Objectives'. The review process should focus on the implementation of the provisions and on the preamble of the Treaty and should take the relevant 'Principles 
and Objectives' fully into account. ${ }^{42}$

Canada emphasized that:

...while the review process should focus on the Treaty itself, work should be guided by the conclusions of the 1995 Conference of the Parties, specifically the recommendations contained in the principles and objectives and in the decision on strengthening the review process... . ${ }^{43}$

And New Zealand, for its part, noted that:

The indefinite extension decided in 1995 was an important statement of confidence in the Treaty and its role as a cornerstone of international cooperation in the field of security. The decisions adopted at the same time had placed the Treaty and its subsequent reviews within the framework of an enhanced multilateral nuclear nonproliferation and disarmament process. $^{44}$

The preceding statements reveal that States Parties still have not come to a common understanding on the scope of the "strengthened review process" and of the role of the Treaty and the NPTREC outcomes in that process. Jayantha Dhanapala recently cautioned that:

The success of the [2000 Review] Conference will ultimately depend on the evolution of fresh consensual approaches transcending political divisions and the abandonment of rigid postures or complacent attitudes over the 'done deal' of the Treaty's indefinite extension. ${ }^{45}$ 
Decision 1 of the 1995 NPTREC on "strengthening the review process for the Treaty," provided guidance on the structure of three Main Committees and on the possibility of establishing subsidiary bodies within each Main Committee, but it only provided limited clarity on the scope of future review conferences. It included the provision that:

The Conference agreed further that Review Conferences should look forward as well as back. They should evaluate the results of the period they are reviewing, including the implementation of undertakings of the States Parties under the Treaty, and identify the areas in which, and the means through which, further progress should be sought in the future. Review Conferences should also address specifically what might be done to strengthen the implementation of the Treaty and to achieve its universality. ${ }^{46}$

Given the context of the negotiation in 1995 on the decisions and resolution adopted by that Conference, it can be asserted that future reviews would need to focus not only on the implementation of the Treaty but also that of the NPTREC outcomes. As such, the 1995 "Principles and Objectives" serve to provide an important context and touchstone to assess the implementation of the Treaty in the period under review. The "Principles and Objectives" comprise a loose compilation of an expression of general principles as well as an expression of key goals to be achieved to further the full implementation of the Treaty and its universality.

The two sessions of the PrepCom to date have reinforced the 
concepts of "permanence with accountability" (outlined in 1995) and of a qualitatively different review process. In this context, it can be asserted that the 1995 decisions on "Principles and Objectives" and on a "Strengthened the Review Process" are politically binding, whereas the extension decision is legally binding. Under customary international law, politically binding decisions could become equally as binding as those taken under specific treaty law could. Failure to honor the 1995 NPTREC decisions could dissolve commitments to the Treaty's permanence. As such, it may be argued that the scope of future review conferences is: 1 ) to review the implementation of the Treaty per se as well as of the decisions and resolution adopted at the 1995 NPTREC; and, 2) to make specific recommendations on strengthening the implementation of the Treaty (including achieving its universality) through a new principles and objectives document.

The first task would involve a product, i.e. a final report, comprising an assessment of the implementation of the Treaty, plus the 1995 NPTREC decisions and resolution, from 1995 to 2000. In addition, the report would identify the areas in which progress should be sought in the full implementation of the Treaty over the next review period. For example:

- $\quad$ nuclear disarmament;

- $\quad$ strengthened safeguards;

- Nuclear-Weapon-Free Zones - and the means through which - e.g., ratification and implementation of START II;

- $\quad$ negotiation, ratification and implementation of START III \& 
IV involving the participation of all five NWS;

- negotiation, ratification and implementation of a fissile material treaty involving the five NWS, India, Israel and Pakistan; negotiation and implementation of INFCIRC/540 Additional Protocol by all NPT NNWS; negotiation of a NWFZ in Central Asia; and,

- $\quad$ entry into force of the CTBT, Bangkok and Pelindaba NWFZ treaties.

This document, the final report, of the 2000 Conference could be structured either along traditional lines, based on the reports of the three Main Committees, comprising both an evaluation of past implementation and recommendations for future progress; or could be based on an article-by-article review of the Treaty factoring in the 1995 NPTREC decisions and resolution.

The second task would involve the drafting and adoption of a Year 2000 "Principles and Objectives for Nuclear Nonproliferation and Disarmament" (Y2KP\&O), comprising specific recommendations and milestones directed at strengthening the full implementation of the Treaty and the 1995 NPTREC decisions and resolution. This Y2KP\&O could either emulate the structure of the $1995 \mathrm{P} \& O$, or alternatively it could reflect the articles and preambular paragraphs of the Treaty plus universality and security assurances. A Y2KP\&O should strive to better reflect the structure of the Treaty and in this context to lay out the preferred goals and strategies for the next five-year period. As such, the document, while being substantive, 
pragmatic, and results oriented, should also be concise and avoid unnecessary platitudes.

Adopting both products either by consensus or without a vote would be a worthy goal to strive for in 2000 . However, given the present penchant of the NWS to minimize the scope of the 1995 NPTREC decisions and resolutions and that of some members of the NAM to push grandiose disarmament schemes, it is unlikely that harmony will prevail at the 2000 Review Conference. In the event that neither consensus nor agreement without a vote is achievable, it might be worthwhile for the Chair in consultation with an extended bureau and the "Friends of the Chair" to find an appropriate mechanism for capturing the views of an overwhelming majority of States present, rather than risking yet another failed NPT meeting.

\section{Salvaging the NPT review process}

The failure of the 1998 session of the NPT PrepCom, due to the single-minded opposition of the NWS, in particular the United States, in rejecting moderately worded recommendations on nuclear disarmament and related nonproliferation priorities, has reduced the "strengthened review process" to a virtual dead letter. For the NWS, a strengthened review has come to mean only a discussion of substance and drafting of recommendations to the 2000 NPT Review Conference, without States Parties necessarily addressing issues of substance, or identifying agreed priorities for the implementation of the Treaty and the NPTREC decisions, or even expressing views on 
current matters of importance to the Treaty.

What might be done to complete the preparations for the 2000 Review Conference, with a view to salvaging some vestiges of a strengthened review? The only practical way forward seems to be that based on innovative, yet practical initiatives; i.e., devising qualitatively new modalities to promote the review and implementation of the Treaty, in accordance with the NPTREC decisions and resolution.

In 1995, a small number of states that were committed to the continuing viability of the NPT were successful in establishing unprecedented, new parameters that were captured in NPTREC Decisions 1 and 2. A similar effort is now required to ensure "permanence with accountability" of the NPT, an effort that once again explores unprecedented measures - and stretches the parameters of the debate. These might include, for example: redefining the consensus rule; revising the structure of the review process; refocusing the role of the depositaries; and augmenting the role of the chairs.

\subsection{Redefining the consensus rule}

According to the "Draft Rules of Procedure for the 2000 Review Conference, ${ }^{, 47}$ reflecting the traditional rules of procedure governing the conduct of NPT review conferences, Rule 28 deals with the "Adoption of Decisions." This particular Rule (28) states that: 
- The task of the Conference being to review, pursuant to paragraph 3 of article VIII of the Treaty, the operation of the Treaty with a view to ensuring that the purposes of the preamble and the provisions of the Treaty are being realized, and, thus, to strengthen its effectiveness, every effort should be made to reach agreement on substantive matters by means of consensus. There should be no voting on such matters until all efforts to achieve consensus have been exhausted.

- Decisions on matters of procedure and in elections shall be taken by a majority of representatives present and voting.

Given the failure of the 1998 PrepCom and the record of failures at previous review conferences to produce a consensus final report, perhaps it would be opportune to learn from past mistakes and to amend or adapt the rule for decision-making on substantive matters.

First, the rule needs to be updated from its present 1995 vintage. In making the Treaty of permanent duration in 1995, States Parties enriched the Treaty with the adoption without a vote of the decisions on a "Strengthened the Review Process" and on "Principles and Objectives," as well as the Middle East resolution. Hence, any and all future strengthened reviews must take into account not only the Treaty, but also the NPTREC outcomes. This leads us to the conclusion that the wording in Rule 28 needs to be updated to reflect the new reality. A preliminary draft of an updated Rule 28.1 might 
be as follows:

The task of the Conference being to review, pursuant to paragraph 3 of Article VIII of the Treaty and of paragraph 7 of NPTREC Decision 1, the implementation of undertakings of States Parties under the Treaty with a view to ensuring that the purposes of the preamble and the provisions of the Treaty [and the NPTREC decisions] are being realized, and thus, to strengthen its effectiveness, every effort should be made to reach agreement on substantive matters by means of consensus. There should be no voting on such matters until all efforts to achieve consensus have been exhausted.

Generally speaking, "consensus" is understood to mean the absence of any objection as expressed by a participating State to the taking of the decision in question. Consensus, as such, could be redefined as to mean consensus minus " $x$ "; i.e., with 187 States Parties consensus could be deemed to have been achieved if all States present and voting (at PrepCom sessions and at review conferences) agree to a common text except for a very small number (say between one to five, which desist from joining the rest). Such a modified definition of consensus is by no means unknown in other international security fora. For example, several OSCE mechanisms envisage the possibility of undertaking executive action without the requirement of a traditionally defined consensus ${ }^{48}$ - the Prague mechanism of 1992 and the Moscow mechanism are two such cases in point. Hence, a modified Rule 28.1 could provide for agreement on matters of substance, such as a "Principles and Objectives 2000," by means of a modified consensus definition. Such an approach, on 
substance, would be preferable to a resort to voting as provided for in Rule 28.1.

The disadvantages of this approach might be that the NWS and some of their allies could end up in this small group of five whose views might be over ridden in the interests of the overwhelming majority. However, the risk of being over ridden might well result in a more productive exchange of views between the NWS and the NNWS possibly resulting in compromise forward-looking text.

Already, in the context of the Preparatory Committee, some States Parties have voiced their opinion on the merits of moving away from a strict definition of consensus as it has traditionally been applied.

For example, it is interesting to recall that in its plenary statement at the second session of the PrepCom, New Zealand stated:

There may be many areas on which we can agree now: those can be folded into the consensus recommendations before us. But we do not think that we need to necessarily be bound by consensus at this time. Rather our inclination would be, in areas where this is not achievable, to capture initiatives and proposals on the basis of them enjoying broad support and agreement. Confining ourselves to a consensus product might risk a sterile and probably meager outcome. On many issues there is a strong coincidence in approach. But on others there are obvious differences. We should not be coy in recognizing them or in attempting to paper over them. ${ }^{49}$ 
And, at the 1997 PrepCom session, Japan went so far as to state that:

The Preparatory Committee should not prepare a consensus document at each one of its sessions, since doing so would be extremely difficult and much too time-consuming. Rather, the most appropriate and productive procedure would be for the Chairman of the Preparatory Committee for the session to issue his own summary report, with the relevant annexes. The report would be drafted under the Chairman's sole responsibility and would not be binding on any delegation. ${ }^{50}$

At the 2000 RevConf, procedural and factual reports could be issued under the authority of the "Chairman in consultation" with an expanded bureau and the "Friends of the Chair," even though Rule 28.2 provides for adoption of decisions on procedure by means of a majority of States present and voting. Thus, the final report of the 2000 RevConf is preferable to a final declaration dealing with the implementation of the Treaty from 1995 to 2000 , could be adopted either under the authority of the Chair (as described above) or through the mechanism of voting as stipulated under Rule 28.2-6. Again, in order to avoid the possibility of divisiveness resulting from voting, it would be preferable to rely upon the authority of the Chair (in consultation) to decide on matters of procedure. 


\subsection{Revising the structure of the Treaty review process}

Since 1985, NPT Review Conferences have structured the review of the Treaty into three main committees, broadly dealing respectively with nuclear nonproliferation and disarmament, safeguards and export controls, and cooperation in the peaceful uses of nuclear energy. This three main committee structure was devised by the US, for the 1985 Review Conference, in part to provide a committee for the Eastern group to chair. The division of work between the three main committees tends to overlap in places and has not proven especially efficient or conducive to generating agreed reports. Indeed three of the previous five NPT Review Conferences have failed to agree on final documents, while the 1985 conference only agreed on a report that reflected fundamental differences in views between States Parties.

NPTREC Decision 1, in its wisdom, retained the existing main committee structure but recommended discussion of the issue of overlap and also recommended the establishment within the main committees of "subsidiary bodies" or working groups to provide focused consideration of specific issues. Decision 1 empowered the PrepCom to recommend the creation of such subsidiary bodies for each review conference. This recommendation for subsidiary bodies merely regularized past practice at review conferences, where working groups or "Friends of the Chair" would break off from the main committees to resolve differences on specific items, such as rules of procedure, security assurances, and export controls at the 
1995 NPTREC. It was noteworthy that at the 1998 PrepCom, the NWS rejected attempts to draft recommendations on setting up such bodies at the 2000 Review Conference.

The 1997 PrepCom contributed to further complicating the structure of the review process by creating so-called "clusters" based on the allocation of work of the main committees and then subdivided the "clusters" according to the seven headings under the "Principles and Objectives." Instead of contributing to a "structured and balanced" review, this procedure introduced imbalances between the "clusters" even though each of the three "clusters" would be given equal time - leading inevitably to sterile, unproductive, debate.

A practical, common sense, approach to a revitalized review of the Treaty suggests an article-by-article approach, factoring in the relevant preambular paragraphs and NPTREC decisions, which would include items such as universality and security assurances, as well. In this context, it would be useful to modify the existing Main Committee structure and to reorganize the review process to deal sequentially with the articles and related preambular paragraphs of the Treaty, factoring in, as required, the seven principal themes from the 1995 "Principles and Objectives." Subsidiary bodies, or working groups, could be established for the purpose of deliberation and drafting assessments and recommendations for the final report on Treaty implementation. A preliminary breakdown of working groups could be as follows: A) nuclear nonproliferation - including universality, security assurances, Nuclear-Weapon-Free Zones, 
compliance; B) nuclear disarmament - including fissile material treaty, CTBT implementation, reduction and elimination of nuclear weapons, compliance; C) safeguards and export controls - including cooperation in peaceful uses of nuclear energy, compliance. Such an approach might facilitate a structured and balanced review of the Treaty and the NPTREC outcomes, in addition to providing greater focus on those elements of the Treaty requiring further effort for full implementation. The 1999 PrepCom could recommend a revised structure for review to the 2000 Conference, which forum would have the power to adopt a decision governing its methods of work

\subsection{Refocusing the role of the depositaries}

The NPT established the precedent for reviewing the operation of the Treaty. NPT Article VIII.3 provided authority for the first review conference to be held in Geneva five years after its entry into force. At intervals of five years thereafter, further review conferences could be convened at the request made to the depositaries by a majority of States Parties. Since 1975, NPT review conferences have been convened every five years. NPTREC Decision 1, however, reinterpreted Article VIII.3 to the effect that review conferences shall continue to be held every five years in perpetuity beginning with the 2000 conference.

Traditionally the depositaries, at the request of NPT parties, made the preliminary preparations for review conferences, and in doing so heavily influenced the structure of the reviews. As noted 
above, the three main committee structures were invented by one of the depositaries. Over the years, reportedly the depositaries have come to exercise a preponderant degree of influence over the chairs of the PrepCom sessions and of the main committees, as well as over the presidency of the review conferences and their bureau.

The Treaty does not invest the depositaries with any special privileges or responsibilities, save under Article Vul.3 on convening review conferences, and under Article IX.5 and 6, respectively, on recording and reporting accessions to the NPT and registering the Treaty pursuant to article 102 of the UN Charter. As such, the Treaty itself does not devolve any special or specific role or responsibility to the depositaries as regards the nature or the structure of the review process. However, traditionally the depositaries have exercised a lead role, and the NNWS by default have allowed the depositaries to bring what could be considered as an undue degree of influence on how Treaty reviews are structured

Under the authority of NPTREC Decision 1, review conferences have been institutionalized on a quinquennial basis and there is no longer a requirement for NPT states to request the depositaries to convene review conferences. This is now the responsibility of all NPT States Parties and can easily be expressed through appropriate resolutions drafted through the First Committee for adoption by the UN General Assembly. Thus, all States Parties would take on the responsibility of ensuring the continuation of the "strengthened review process." 
The review process of the Treaty could benefit from the input of interested States Parties, in addition to that provided by the depositaries. At the 1999 PrepCom, a recommendation could be made to enlarge the bureau beyond comprising the depositaries and the coordinators of the three political groups. The expanded bureau could include several States with a past record of bridge-building in contributing to the review process, and might include for example: Algeria, Argentina, Australia, Brazil, Canada, Chile, Egypt, Malaysia, Mexico, Morocco, Nigeria, Republic of Korea, Ukraine, and Zimbabwe. An expanded bureau could not only provide useful assistance to the chair but also reflect a broader constellation of views, which could serve to democratize the process and to potentially facilitate an improved and more productive consultative mechanism.

Jayantha Dhanapala, Under-Secretary General for Disarmament, has the formation of "a voluntary group of "bridgebuilders' drawn from all regional and political groups to establish links among the treaty parties and to act as a 'fire-brigade' to defuse controversies and seek negotiated solutions to problems as they arise." ${ }^{51}$ Such a group, called an "Executive Council," as suggested by Dhanapala or an expanded bureau, could be set up at the next review conference, and could serve to assist the president and vicepresidents. 


\subsection{Augmenting the role of the Chairs}

One unfortunate result of the dominant role of the depositaries is their seemingly excessive influence on the Chairs. In some cases, Chairs do not receive adequate support from their own national delegations. In other cases, due to political considerations, Chairs might be more receptive or susceptible to the views of the depositaries, and yet, in other cases (direct or indirect) pressure might be brought to bear. There are unconfirmed reports that in some cases Chairs engage in private consultation with the depositaries, singly or jointly, and their chairmanship, rulings and drafts then tend to be sympathetic to the views of the depositaries, to the detriment (in some cases) of the interests of the majority of States Parties and the review process itself.

It would be unrealistic, except in the most exceptional cases, to expect Chairs to resist the influence or pressure exercised by the depositaries. An innovative approach might be to establish a "troika plus" whereby the previous, current, and future Chairs, together with an expanded bureau, meet to deliberate on issues relating to the structure and procedure of the review process. Chairs could also rely informally upon the advice and expertise of qualified NGOs and academic experts, as well as NPT anciens. 


\section{Political Groupings}

Even though the Cold War has ended and the old ideological divisions have been transformed for the most part, on international security issues the traditional regional groupings persist, despite their not being reflective of the current status of the international community. It can be said that all three regional groupings are facing internal stresses and strains. The Western group no longer represents a homogenous viewpoint, and within it a subgroup - the European Union -is emerging as a force with its own interests. Some NonNuclear Weapon States within the Western group, contrary to the preferences of their Nuclear Weapon States allies and other friends, favor not only continuing, but also achieving greater progress in nuclear disarmament. The Eastern group rarely meets and it suffers from serious internal contradictions apparent to all. One specific contradiction is the continuing membership in this group of certain former Eastern bloc or former Warsaw Treaty Organization members, which are now members of an expanded NATO - the lynchpin of the Western group. In this regard, with Poland joining NATO and the Western Group at the 1999 PrepCom, a new country will need to be found to take over the chairmanship vacated by Poland.

The Non-Aligned Movement (NAM) continues in serious disarray to its own detriment, and apparently while the NAM has lost coherence, common interests might coalesce on general principles, though on balance NAM cohesion cannot be counted upon. Reportedly, some 80 percent of group members do not actively 
participate in NAM deliberations. Nonetheless, at the 1998 PrepCom, the NAM demonstrated new found solidarity and it would be interesting to see if this continues and grows under South African chairmanship.

Given the unnecessary tendencies toward rigidity and confrontation emanating from the obsolete Cold War driven group structure that still persists, interest-based coalitions could be formed on the basis of shared goals and involving the participation and involvement of the great majority of NPT states from across the traditional regional groupings to push for structural innovations as suggested above as a means of promoting substance and efficiency in the work of the Review Conference.

\section{Conclusions}

While NPTREC Decision 1 clearly established that the purpose of the Preparatory Committee meetings is to undertake both preparatory and substantive work for the review of the operation of the Treaty in keeping with Article VIII, paragraph 3, taking into account the decisions and the resolution adopted by the 1995 NPTREC, it became painfully evident in 1998 that the NWS have scant interest in or commitment to ensuring a qualitatively new "strengthened review process" that goes beyond tedious statements on matters of substance. They clearly opposed the preparatory committee becoming an on-going review mechanism for ensuring permanence with accountability. During the 1998 PrepCom, speaking 
to NGOs, Dhanapala cautioned that the "strengthened review process" must be more than a mere "talk shop." 52 Though the NWS have signed-off on devoting at least fifty percent of the PrepCom's working time to statements on substantive matters, by the same token they do not want the PrepCom to engage in any substantive work other than procedural preparations and drafting a list (whether agreed or not) of recommendations to the review conference. It would not be a surprise, if at the 2000 Conference, the NWS insisted on allocating time to go through the verbiage generated by the PrepCom and resisted or delayed the formulation of a new document on “principles and objectives". Again, as Dhanapala has noted:

The leverage that the NNWS may have lost by agreeing to an indefinite extension does not have to be regained through confrontation or the extreme step of exercising their rights under Article X.1.... Initiatives must also come from the NWS to stimulate the review process in the same way that the decision to negotiate a CTBT paved the way for the success of the 1995 NPTREC. The review process must be given a fair chance to prove itself and realize its potential. ${ }^{53}$

The package of interrelated extension decisions adopted at the 1995 NPTREC were the means by which NPT parties agreed without a vote to indefinitely extend the Treaty. The decisions were the product of both compromise and expectation. Compromise to make the NPT permanent as it enhanced the security of all states. Expectations that the decisions would help establish new parameters of discourse on nonproliferation and nuclear disarmament, beginning with the April 
1997 session of the Preparatory Committee. It is somewhat disturbing that the political milieu in which the 2000 Review Conference will convene does not look particularly hospitable to a harmonious and productive ushering in of the much vaunted "Strengthened the Review Process," as not unexpectedly the NWS are seemingly striving to deflect attention from the lack of substantive new progress on nuclear disarmament while the NNWS will attempt to "hold the feet of the weapon states to the fire."

As aptly noted by Ambassador Hasmy bin Agam of Malaysia: "A new phase of persuading and prodding Nuclear Weapon States to rethink their nuclear policy in the post-cold war era must begin." 54

The burden on the shoulders of Ambassador J. S. Selebi of South Africa, the President-designate of the 2000 Review Conference will be both heavy and shifting. Given South Africa's key role at the 1995 NPTREC, it would not be out of character for South Africa (assisted by other staunch proponents and defenders of a "strengthened review process") to ensure that the first review conference of the strengthened process establishes a positive and constructive precedent for future reviews of the Treaty. The main challenge likely will be that of the high expectations and ambitious agendas of many Non-Nuclear Weapon States led by South Africa, that will be pitted against the conservatism and obstructionism of most of the NWS, especially the US, which has already let it be known that it will be cautious regarding the creation of new precedents and will dampen down high expectations. 
In the end, politics will prevail as NPT reviews have always been intensely political and will remain such due to the very nature of the issues discussed, and at its heart, the NPT is a security bargain. It must not be forgotten, however, that unless States Parties are willing to demonstrate the same shared sense of purpose and compromise that delivered the indefinite extension of the NPT in 1995, they risk undermining the very Treaty that provides for their own and for global security. If the NPT is undermined, or if some or a group of states threaten to leave the Treaty citing their dissatisfaction with the way in which the package of extension decisions is being implemented, the results would be disastrous, not only would proliferation dangers increase, but the present climate for nuclear disarmament could be severely disrupted. It is up to all NPT parties to ensure that the indefinite extension of the Treaty and its effectiveness is buttressed by the full implementation of the NPT in the context of the decisions of the 1995 NPTREC, and that this is manifested through a successful 2000 Review Conference that reaches consensus agreement on both a new "Principles and Objectives," as well as a final declaration.

\section{Notes}

1. This paper draws heavily upon previous writings by the author on the subject of the NPT review, in particular: "The 1999 NPT PrepCom," by Tariq Rauf and John Simpson (The Nonproliferation Review/Winter 1999, pp. 118-133) on-line 
at: http://cns.miis.edu/pubs/npr/62toc.htm; “Decision-making, and the Role of the Treaty and of the 1995 NPTREC Decisions in structuring the discussions at, and the products of the 2000 NPT Review Conference," by Tariq Rauf; and "The 1998 PrepCom: Farewell to the NPT's 'strengthened review process'," by Tariq Rauf (Disarmament Diplomacy/May 1998), on-line at: http://www.gn.apc.org/acronym/26tariq.htm.

2. 1995 Review and Extension Conference of the Parties to the Treaty on the Nonproliferation of Nuclear Weapons, Final Document: Part I - Organization and work of the Conference, Decision 1 "Strengthening the Review Process for the Treaty," (New York: United Nations, 1995), Annex, p. 8.

3. 1995 Review and Extension Conference of the Parties to the Treaty on the Nonproliferation of Nuclear Weapons, Final Document: Part I - Organization and work of the Conference, Decision 2 "Principles and Objectives for Nuclear Nonproliferation and Disarmament," (New York: United Nations, 1995), Annex, pp. 9-12.

4. 1995 Review and Extension Conference of the Parties to the Treaty on the Nonproliferation of Nuclear Weapons, Final Document: Part I - Organization and work of the Conference, Decision 3 "Extension of the Treaty on the Nonproliferation of Nuclear Weapons," (New York: United Nations, 1995), Annex, p. 12-13. 
5. Laurence Scheinman, "Remarks to the 13th Annual Ottawa NACD Verification Symposium," Le Chateau Montebello, Ottawa, Canada, March 13, 1996.

6. 1995 Review and Extension Conference of the Parties to the Treaty on the Nonproliferation of Nuclear Weapons, Final Document: Part I - Organization and work of the Conference, "Resolution on the Middle East," (New York: United Nations, 1995), Annex, pp. 13-14.

7. For a description, see Tariq Rauf \& Rebecca Johnson, "After the NPT's Indefinite Extension: The Future of the Global Nonproliferation Regime," (hereafter "Rauf \& Johnson") The Nonproliferation Review 3 (Fall 1995), p. 30; and Susan Welsh, "Delegate Perspectives on the 1995 NPT Review and Extension Conference," (hereafter "Welsh"), The Nonproliferation Review 2 (Spring-Summer 1995), pp. 5-9.

8. Nonproliferation, Arms Control and Disarmament Division, Department of Foreign Affairs (Canada), A Non-Paper on Strengthening Review Conferences, (Ottawa: March 1995), unpublished.

9. Personal communication dated January 6, 1997. See also, Ambassador Taylhardat's comments in Welsh, p. 9.

10. As quoted in Welsh, p. 5.

11. "Statement by the President," Verbatim Record of the $19^{\text {th }}$ Meeting (12 May 1995), 1995 NPTREC Final Document, Part III, Summary and Verbatim Records, 
NPT/CONF.1995/32 (Part III), (New York: United Nations, 1996), p. 214.

12. Laurence Scheinman, "Remarks to the 13th Annual Ottawa NACD Verification Symposium," Le Chateau Montebello, Ottawa, Canada, March 13, 1996.

13. Ben Sanders is probably the first analyst to make this observation. See Ben Sanders, "NPT Review Conferences and the 1995 Extension Conference: Working Towards Consensus," in Tariq Rauf (ed.), Extending the NPT: Perpetuating the Global Norm Aurora Papers 27, (Canadian Centre for Global Security), pp. 43-44.

14. Rauf \& Johnson, note 32, pp. 40-41.

15. NPT/CONF.1995/32 (Part I), Decision 1, paragraph 4.

16. Laurence Scheinman goes even further than the language in Decision 1, in saying that the "Principles and Objectives" agreed to at the 1995 NPTREC "is one element that could be considered by NPT parties in determining 'ways and means' to ensure the full implementation of the Treaty during the 2000 NPT Review Conference" (emphasis added). See Scheinman, 13th Annual Ottawa NACD Verification Symposium," March 13, 1996.

17. Rauf \& Johnson, p. 34.

18. John D. Holum, "Remarks to the International Conference on Nuclear Nonproliferation, Sponsored by the Carnegie Endowment," Washington, D.C., February 12, 1996. 
19. Laurence Scheinman, "Remarks to the 13th Annual Ottawa NACD Verification Symposium," March 13, 1996.

20. Laurence Scheinman, "Preparing for the 1997 NPT PrepCom," Address to the Regional Seminar sponsored by The Monterey Institute of International Studies, Centre for Nonproliferation Studies, International Organizations in Nonproliferation Project; University of Southampton, Program for Promoting Nuclear Nonproliferation; and The National Institute for Strategic Studies (Ukraine)," (Kyiv: September 28, 1996).

21. Quoted in Welsh, p. 3.

22. Quoted in Welsh, p. 5.

23. Waldo Stumpf, "South Africa: Nuclear Technology and Nonproliferation," letter to the editor, Security Dialogue (December 1993), pp. 497-498. For an interesting account of South Africa's nuclear weapon program, see: Frank Pabian, "South Africa's Nuclear Weapon Program: Lessons for US Nonproliferation Policy," The Nonproliferation Review (Fall 1995, Vol. 3, No. 1), pp. 1-19.

24. Adolf von Baeckmann, Gary Dillon, and Demetrius Perricos, "Nuclear verification in South Africa," LAEA Bulletin Vol. 37 , No. 1), pp. 42-48.

25. Lewis A. Dunn, "High Noon for the NPT," Arms Control Today (July/August 1995), p. 7.

26. United Nations Security Council, S/23500, 31 January 1992, 
27. Report No. 92-04224F - (Statement at the 3046th meeting of the Security Council, held at the level of Heads of State and Government).

28. Program for Promoting Nuclear Nonproliferation, PPNN Newsbrief Number 36 (4th Quarter 1996), p. 5.

29. Remarks by the President in Address to the 51st General Assembly of the United Nations, p. 3.

30. $\mathrm{CD} / 1547,12$ August 1998 , adopted at the $802^{\text {nd }}$ Plenary on 11 August 1998.

31. Alison Mitchell, "Summit Talks End With Agreements, but Not for NATO," The New York Times, March 22, 1997, p. A6.

32. See, example, United Kingdom Strategic Defense Review, "Modern Forces for a Modern World," United Kingdom Ministry of Defense (8 July 1998).

33. Rauf \& Welsh, p. 29.

34. International Court of Justice, "Legality of the Threat or Use by a State of Nuclear Weapons in Armed Conflict (Request for Advisory Opinion by the General Assembly of the United Nations)," Communiqué No. 96/23 (8 July 1996).

35. Ibid., paragraph $\mathrm{F}$.

36. Ibid., Summary of the Advisory Opinion: "Obligation to negotiate nuclear disarmament," (paras. 98-103). I am indebted to Ambassador George Bunn (Former General Counsel, US Arms Control and Disarmament Agency, and a 
negotiator of the NPT) for highlighting the nuances and importance of the ICJ decision.

37. John D. Holum, "Remarks to An International Seminar on Nuclear Disarmament after the Indefinite Extension of the NPT," Kyoto, Japan (December 2, 1996).

38. CD/PV.812 of 2 February 1999, reported under "Geneva Update No. 43" by Rebecca Johnson, Disarmament Diplomacy (December 1998/January 1999), p. 21.

39. Holum (December 2, 1996), speaking in Kyoto.

40. The vote on UNGA resolution $(\mathrm{A} / 53 / 77 \mathrm{Q})$ on 4 December 1998 was 154:3:10; and on resolution (A51/56/Add.11), on 10 December 1996, was 129:3 against (France, United Kingdom, and United States): 38 abstentions.

41. Laurence Scheinman, "Preparing for the 1997 NPT PrepCom," Address to the Regional Seminar sponsored by the Monterey Institute of International Studies, Program for Promoting Nuclear Nonproliferation, and The National Institute for Strategic Studies (Ukraine), Kyiv, September 28, 1996.

42. Summary of Statement by Laurence Scheinman (United States), Preparatory Committee for the 2000 Review Conference of the Parties to the Treaty on the Nonproliferation of Nuclear Weapons, First Session, Summary Record of the $3^{\text {rd }}$ Meeting, New York, 8 April 1998, p. 9 (paragraph 41). 
43. Summary of Statement by Ambassador Sha Zukang (PRC), Preparatory Committee for the 2000 Review Conference of the Parties to the Treaty on the Nonproliferation of Nuclear Weapons, First Session, Summary Record of the $2^{\text {nd }}$ Meeting, 8 April 1998, NPT/CONF.2000/PC.I/SR.2, p. 8 (paragraphs 34-35).

44. Ibid., p. 10 (paragraph 44).

45. Ibid., p. 24 (paragraph 123).

46. See, Jayantha Dhanapala, "The NPT Regime: External and Internal Challenges," statement at The Seventh Carnegie International Nonproliferation Conference, Washington, D.C., January 11, 1999, on-line at: http://www.ceip.org/programs/npp/dhanapala.htm.

47. NPT/CONF.1995/32/DEC.1, paragraph 7, 11 May 1995.

48. NPT/CONF.2000/PC.II/CRP.1, 6 May 1998.

49. See "OSCE Decision-Making" at http://www.osceprag.cz/info/facts/decsmake.htm.

50. Statement by the New Zealand Head of Delegation, Clive Pearson, Ambassador for Disarmament, to the Second Session of the Preparatory Committee for the 2000 Review Conference of the Parties to the Treaty on the Nonproliferation of Nuclear Weapons, Geneva, 27 April 1998, pp. 3-4.

51. Summary of Statement by Japan, Preparatory Committee for the 2000 Review Conference of the Parties to the Treaty on 
52. the Nonproliferation of Nuclear Weapons, First Session, Summary Record of the $2^{\text {nd }}$ Meeting, New York, 8 April 1998 , p. 15 (paragraph 69).

53. Jayantha Dhanapala, "The NPT Review Process: Identifying New Ideas to Strengthen the Regime," The Enhanced Review Process: Towards 2000, UNIDIR Newsletter No. 37, p. 10.

54. Cited in Douglas Roche, "An Analysis of the Second Preparatory Committee Meeting for the 2000 Review of the NPT," Project Ploughshares at the University of Waterloo, p. 9, http://watserv1.uwaterloo.ca/ plough/98prepcom.html.

55. Dhanapala, op. cit., UNIDIR Newsletter No. 37, p. 14.

56. United Nations General Assembly, Press Release GA/DIS/3052 (October 14, 1996), p. 10. 


\section{Chapter 19}

\section{Using 1999 to Rescue the NPT Review Process}

\section{Rebecca Johnson}

At the Ninth Annual International Arms Control Conference in April 1999, I argued that the review process of the Treaty on the Nonproliferation of Nuclear Weapons (NPT) was in trouble after two preparatory committee meetings (PrepCom) in 1997 and 1998, which had been less than productive and successful. By the second PrepCom in 1998, which ended in deadlock and acrimony, it was clear that there were such wide divergences of opinion over the purpose, powers, and limits of the so-called "strengthened review process" agreed in 1995, that it was necessary for the 1999 PrepCom to come to grips with these questions. This paper, written within a few weeks after the third PrepCom, which was held in New York (May 10-21, 1999), will analyze the outcome of the meeting, and consider the prospects for the NPT Review Conference in 2000 , focusing particularly on the implications for arms control and disarmament.

The primary tasks of the 1999 PrepCom were:

- $\quad$ to decide on the procedures and organization of the 2000 Review Conference, including the President and chairs, agenda, rules of procedure, and background documentation; and, 
- in accordance with the 1995 decisions, to "consider principles, objectives, and ways in order to promote the full implementation of the Treaty, as well as its universality, and to make recommendations to the Review Conference."

This meant the PrepComs needed to take decisions that were essential to holding the 2000 Review Conference and it also had to address substantive issues, which in the minds of some States Parties meant deciding what to do with the paragraphs of negotiated, but not necessarily agreed text, of the Chair's working papers from 1997 and 1998.

Additionally, arising from proposals at the earlier PrepComs, I argued that it would be useful if the PrepCom could consider, and if possible, make recommendations on:

- what form of agreements or documents the Review Conference should aim to produce; and,

- the role of the PrepComs, particularly whether they could have a role and function independently of the five-yearly review conferences. For example, in making contemporaneous statements on relevant issues, such as nuclear testing or START.

\section{Organizing the 2000 conference}

Although there was some tough bargaining on some of the procedural issues, the Chair of the 1999 PrepCom, Ambassador 
Camilo Reyes of Colombia, managed to secure consensus for adopting a report with all the agreements necessary for convening and conducting the 2000 Review Conference, which will take place in New York from 24 April to 19 May. It will be presided over by Jacob J. Selebi, formerly South Africa's ambassador in Geneva, where he participated in the Conference on Disarmament. Selebi also chaired the Human Rights Commission in 1997 and the first PrepCom of the newly established Comprehensive Test Ban Treaty Organization (CTBTO) in 1996, as well as the Oslo meeting on landmines, which finalized the Ottawa Treaty.

Although some delegations challenged the division of issues among three main committees, which they contended was confusing and inefficient, the third PrepCom decided that the committees would be re-established in 2000 , pending a debate and any future decision on a more appropriate way of addressing the issues. The following chairs were designated:

- Main Committee I (MC) on nuclear disarmament Camilo Reyes of Colombia;

- $\quad$ MC II on safeguards and Nuclear-Weapons-Free Zones Eugeniusz Wyzner of Poland;

- $\quad$ MC III on nuclear energy - Markku Reimaa of Finland.

Canada and New Zealand argued that an article-by-article review would now be more efficient, but agreed that any alternative format would have to be decided at the review 
conference, where they will again present their arguments. There were challenges to the recommendations that the group of Eastern European states, which now comprises both NATO and former Warsaw Pact countries, should additionally chair the drafting committee, with the Movement of Non-Aligned States (NAM) taking-up the post of Chair of the Credentials Committee. These positions are important as, together with the depository states, Britain, Russia and the United States, they comprise the Bureau, which formally assists the President and acts as a conduit for planning and coordination of decision-making, especially on procedural issues.

The agenda and rules of procedure to govern the 2000 Conference were adopted after States Parties agreed to an amendment on subsidiary bodies. The issue preventing adoption of the rules in 1998 was a disagreement over whether Rule 34, which referred to the establishment of "working groups" should be amended to reflect the provision on subsidiary bodies in Paragraph 6 of Decision 1 (1995) on Strengthening the Review Process. In 1998, South Africa, backed by most of the NAM countries and others, had argued for subsidiary bodies to be specifically denoted in the rules; Russia, the United States, and others objected, mostly arguing that working groups were the same thing by a different name. In 1999, the amendment went through smoothly on the second day. Though some of the Nuclear Weapons States (NWS) reiterated that this was only a cosmetic change, other parties 
believed that the rule change paves the way for the establishment of subsidiary bodies in 2000. Egypt and South Africa also insisted on written acknowledgement that some States Parties had proposed subsidiary bodies on nuclear disarmament. The 1995 Resolution on the Middle East, left this issue to be decided by the 2000 Review Conference, in accordance with the 1995 decisions. An additional question from Austria over observer status for the CTBT Organization was resolved by agreeing to the CTBTO having the same observer status as the agencies for overseeing the various Nuclear-Weapon-Free Zones, but not the same status as the International Atomic Energy Agency (IAEA), which acts as the Treaty's verification agency through the safeguards agreements undertaken bilaterally between the IAEA and each States Party.

The question of which background documentation should be provided for the 2000 Conference was blocked in 1998 on Egypt's insistence on documentation relating to the 1995 Resolution on the Middle East, which the US refused. Late on the last day of the 1999 PrepCom, it was finally agreed upon that the UN Secretariat would be requested to prepare documents on the various treaty articles, as well as the CTBT and implementation of the 1995 resolution on the Middle East, "reflecting developments since 1995 with a view to realizing fully the objectives of the resolution." Documents were also requested from the IAEA and the various secretariats overseeing the NWFZ, the Treaties of Tlatelolco, Rarotonga, Pelindaba, and Bangkok. This means, 
Egypt reinforced the perception of the Resolution on the Middle East as an integral part of the package of decisions taken in 1995, while the United States was able to lead-off any special privileges for this Resolution, including avoiding any additional responsibilities being assigned to the depository states (Britain, Russia and the United States), who had sponsored the Resolution in 1995. Some expressed surprise that the United States had "given in" on this issue, but from the beginning of the PrepCom the US's more flexible approach lent hope that a compromise agreement would be possible.

\section{Recommendations on substance and implementation}

The second important task for the PrepComs was to make recommendations to the review conference on "principles, objectives, and ways" to promote full implementation of the Treaty. The first PrepCom had produced a Chair's paper containing some paragraphs that had been negotiated and agreed upon, and a section comprising various proposals from States Parties. The second PrepCom attempted to continue negotiations aimed at agreeing language for the Chair's paper, but was unable to secure a consensus beyond the lowest common denominator, and in the end failed to adopt the Chair's paper at all. By this time, the various paragraphs and proposals ran over 60 pages, with much repetition and redundancy. 
After the general debate, the first week of the 1999 PrepCom was devoted to close plenary sessions on the various clusters of issues grouped under the headings of nuclear disarmament, safeguards, and nuclear energy. Although no decision had been taken in 1998 to recommend special time for focusing on particular issues, most delegations welcomed Camilo Reyes' proposal to devote three sessions to practical nuclear disarmament issues, the fissile material ban, and the Middle East, respectively.

These debates largely consisted of statements of national positions or common positions from groups. As expected, there were statements from Indonesia on behalf of the NAM, which was accompanied by a working paper similar to last year's, from Germany on behalf of the European Union (EU) and associated states, and from Algeria on behalf of the League of Arab States. For the first time the New Agenda Coalition (NAC), formed by the foreign ministers of eight nations in June 1998, also made a presentation, which was co-sponsored by 32 States Parties. The NAC working paper issued a few days later drew 44 co-sponsors, including Switzerland, Indonesia, Chile, and Nigeria. During the general and specific discussions and airing of national statements, the issues of major concern and most frequently mentioned were the following (not in any order): 
- the importance of the NPT and nonproliferation regime and the risks of undermining it by failing to implement the strengthened review process constructively;

- concerns were voiced regarding the impasse in the START process, the necessity for more effective progress on nuclear disarmament, and suggestions for steps that could be undertaken with frequent and specific mention of the need to address, and preferably remove all tactical nuclear weapons, taking nuclear weapons off alert; calling for the conference on disarmament to address nuclear disarmament; negotiate a nuclear weapons convention; and calls for all five nuclear powers to engage in more practical negotiations;

- condemnation of the nuclear tests conducted by India and Pakistan in 1998;

- the importance of securing sufficient signatures and ratifications for the Comprehensive Test Ban Treaty (CTBT) to enter into force;

- the bombing by NATO of the Chinese Embassy in Yugoslavia and the effect of NATO's actions on future prospects for arms control;

- concerns regarding the destabilizing impact of US missile defense plans;

- the importance of undertaking negotiations on the fissile materials ban; 
- $\quad$ security assurances;

- universal and adherence to the NPT, especially the need to find ways to bring India, Pakistan, and Israel into the nonproliferation regime as Non-Nuclear Weapon States, as well as, concerns regarding Iraq and North Korea, and ways to prevent violations of the treaty;

- establishing Nuclear-Weapon-Free Zones (NWFZ), especially in relation to the Middle East and Central Asia;

- $\quad$ nuclear energy;

- $\quad$ safeguards;

- nuclear safety and physical security; and,

- $\quad$ export controls.

Eschewing the working papers from the two previous PrepComs, Reyes sought to reflect this discussion by means of a draft working paper from the Chair, in the hopes that this might form the basis for recommendation for the year 2000. Comprising of 31 paragraphs covering over eight themes (the seven in the 1999 Principles and Objectives plus the Middle East), his first draft, circulated on May $14^{\text {th }}$, covered universality, nonproliferation, nuclear disarmament, Nuclear-Weapon-Free Zones, security assurances, safeguards, the resolution on the Middle East and "peaceful uses" of nuclear energy. 


\section{The May $14^{\text {th }}$ draft Chair's working paper}

After reaffirming commitment to the Treaty, the Chair's working paper welcomed new accessions from nine countries since 1995 and urged states not yet party to the Treaty to accede. It contained paragraphs reaffirming the importance of full implementation of Article II and calling on NPT parties to refrain from nuclear sharing within military or security alliances. Concerns regarding NATO nuclear sharing had particularly been raised in the NAM working paper and by Egypt, South Africa, and China, but the argument that these security arrangements impinged on their NPT obligations was vigorously rejected by the NATO states. Addressing the nuclear test explosions in South Asia in 1998, three paragraphs affirmed earlier condemnations and called for full compliance with United Nations Security Council Resolution 1172 , pledging not to give recognition or status to any additional states possessing nuclear weapon's capabilities.

There were five paragraphs on nuclear disarmament, ranging from general declarations of "unequivocal commitment" to eliminating nuclear weapons to more specific calls, including for the ratification of the CTBT, so that it can enter into force without delay; for immediate negotiations on a fissile materials treaty at the Conference on Disarmament (CD); further progress in START, including increased transparency on the dismantlement of tactical nuclear weapons; and for the rest of the Nuclear Weapon States to join US-Russian efforts "at an appropriate stage." Two paragraphs 
endorsed existing Nuclear-Weapon-Free Zones (NWFZ), such as in Central Asia, and also expressed support for proposals for such zones in the Middle East and South Asia. One paragraph on security assurances urged re-establishment of a committee in the $\mathrm{CD}$, which angered South Africa and others who wanted security assurances addressed in the NPT context rather than in the CD. South Africa had submitted a working paper containing a draft protocol on security assurances, which it would like the 2000 Review Conference to consider attaching to the Treaty.

Six paragraphs supported the additional protocol to the IAEA safeguards agreement negotiated as part of the $93+2$ program, which urged states to ratify, and called upon on all states not party to the NPT to accept comprehensive IAEA safeguards. They also urged strengthening of the current regime on the physical protection of nuclear material. Two paragraphs urged full implementation of the Resolution on the Middle East. One stressed the "urgent need for Israel to accede to the Treaty without further delay." The second, to place its nuclear facilities under full scope IAEA safeguards so as ... "to avert the risk of nuclear proliferation in the Middle East." The final five paragraphs reaffirmed commitment to implementation of Article IV on nuclear energy and expressed support for initiatives on nuclear safety and security.

Although Ambassador Reyes had taken care to represent views with substantial support as a basis for seeking consensus, it 
was inevitable that some paragraphs pleased some delegations while infuriating others. Some delegations wished to start immediate negotiations, seeking to insert their proposals into the text or delete paragraphs they did not like, but Reyes opted for an open discussion on the paper. More than 30 delegations offered verbal and written proposals in any case. After enabling the States to discuss the paper and related ideas for a few days, Reyes brought out a revised draft on 20 May covering the same eight themes. The revised draft ran to 61 paragraphs. In a highly controversial strategy, Reyes then devoted a day to eliciting delegations' responses in order to gauge the strength of acceptance or opposition to each of the paragraphs.

\section{May 20 revised draft}

In the 20 May revision, there were eight reaffirmations of the principles and provisions of the Treaty and the 1995 decisions, which were largely accepted. Iran objected to one of the paragraphs on universality, which referred to the enhancement of regional security, particularly in areas of tension, such as the Middle East and South Asia. The United States did not object to the provisions of urging by name all states not party to the Treaty to accede as Non-Nuclear Weapon States, (i.e., Cuba, India, Israel, and Pakistan). The more direct reference to nuclear sharing was omitted from the eight-paragraph section on nonproliferation, which also contained less specific exhortations of not transferring 
devices or controls over devices, directly or indirectly. Iraq objected to a paragraph expressing concern of two cases of noncompliance by NPT-parties, though Iraq and North Korea were not mentioned by name. There were also objections to a paragraph that condemned the South Asian nuclear tests. Some nations considered this paragraph as being too strong, and others considered it to have been weakened too much. Gone was the explicit reference in the first draft to 9 UNSC 1172.

One or another of the Nuclear Weapon States objected to almost all the paragraphs on nuclear disarmament. They accepted one paragraph which recognized the progress undertaken by the NWS unilaterally and under the START process, and paragraphs urging entry into force of the CTBT and negotiations on a fissile materials production ban. France was unhappy regarding making an unequivocal commitment to the ultimate elimination of nuclear weapons. China did not like the call on all the NWS to "declare collectively a moratorium on the production of such material for such devices." The US and Russia objected to recommending a subsidiary body at the Review Conference and the provision of special time at subsequent PrepComs for "a structured opportunity to deliberate on the practical steps for systematic and progressive efforts to eliminate nuclear weapons" as had been proposed by South Africa, nor did they want to urge the $C D$ to establish a committee to address nuclear disarmament. 
The US and Russia further objected to a set of calls to reduce reliance on nuclear weapons based on the New Agenda consisting of Japanese and Canadian proposals, among others, of revitalizing the START process; a "seamless process" by which the other NWS would join the US and Russia in negotiations. These negotiations would address non-strategic (tactical) nuclear weapons, transparency steps to reduce nuclear dangers (de-alerting, de-activating and de-mating nuclear warheads), and to review strategic doctrine as urged in the New Agenda resolution to the UN General Assembly (53/77Y). By December 1998, this Resolution had gained 114 votes. Both Moscow and Washington also objected to a paragraph suggesting that a nuclear-weapon-free world would ultimately require the underpinnings of a multilaterally negotiated instrument or framework of mutually reinforcing, legally binding instruments. No one objected to a paragraph welcoming the significant contribution to Article VI of actions by Belarus, Kazakhstan, and Ukraine in withdrawing all their nuclear weapons from their territories.

The section on NWFZ fared rather well, although the United States registered its inevitable objection to a paragraph urging urgent steps be taken towards establishing a NWFZ in the Middle East as a first step towards a zone free of Weapons of Mass Destruction (WMD). Similarly, the US objected to almost the whole section on the 1995 Resolution on the Middle East. While some of the NWS were unhappy with some of the language on 
security assurances, South Africa, and others disliked the retained emphasis on addressing security assurances in the CD.

Unsurprisingly, the main points of the long sections on safeguards and nuclear energy, safety and security were almost all accepted. South Africa did not like approving the framework of voluntary safeguards that the NWS arrogate to themselves, and China reportedly disliked the wording on nuclear control regimes.

\section{Not recommendations but a resource for $\mathbf{2 0 0 0}$}

During the last two days of the PrepCom, a split emerged between those countries who wanted to differentiate between the paragraphs which had been formally objected to, and those which had not; and also those who argued that such a procedure would badly misrepresent the priorities and work of the PrepCom. Attempts were made to establish the "status" or "standing" of the working paper and the United Kingdom, Belgium, France and others offered different introductory paragraph(s) to place the paper in an acceptable context (the "chapeau").

France, Russia, and the United States were in favor of identifying and possibly attaching the "agreed" sections to the PrepCom Report, with the rest given secondary status or relegated to the mass of non-negotiated proposals from previous PrepComs. Such a maneuver would have delivered substantive recommendations on energy and safeguards, but only a few sparse, bland lowest-common-denominator references to progress on 
nuclear disarmament, testing, nonproliferation or the Middle East. Since the recommendations, which would have been omitted, were of greatest importance to a large and significant number of States Parties, Egypt, Mexico, Indonesia, South Africa, and others refused to consider this artificial separation.

Although time was running out, most would not permit inclusion of only the least controversial half of the Chair's paper. Few wanted another total deadlock. Indonesia warned that the nonaligned states would not accept a truncated procedural report, shorn of all reference to substance. In the end, Ireland and New Zealand brokered a solution acceptable to all. Paragraph 17 of the PrepCom report gave a brief account of the discussions on the Chair's papers and annexed both the May 14 and May 20 papers, together with the various written proposals. This compromise was hailed as a victory by those who wanted the text to be forwarded to the 2000 Review Conference as representative of the priority issues the PrepCom had discussed and proposed, while those that wished to, (Russia, France, and the United States), could claim victory in preventing the paper from having special authority or status.

\section{Aims and objectives for 2000}

Responding to the desire by a large number of States Parties for a discussion of the aims of the review process and desired outcome of the 2000 Conference, Ambassador Reyes opened the PrepCom with a general debate, requesting delegations 
to give their views on aims, outcomes, and products. While several statements failed to mention these questions, the majority attempted to fulfill his request. Four distinct options emerged:

- two documents, one forward-looking beyond the year 2000, along the lines of the 1995 Principles and Objectives $(\mathrm{P} \& O)$, in effect, a year $2000 \mathrm{P} \& \mathrm{O}$, and a second to encompass the review of the Treaty's implementation from 1995 to 2000. The two-document option was a clear front runner, advocated by South Africa, the United States, Australia, Switzerland, most of the European Union (EU) countries, and various others nations;

- one document combined both forward and backwardlooking elements, preferred by Iran and France, but with significant differences and reasons. Iran suggested that the final declaration should be in two sections, one reviewing the Treaty's implementation, article-by-article, while the second would update the Principles and Objectives. As the week progressed, more non-aligned delegations, notably Mexico and Egypt, became interested in having one document. Because it would provide better leverage on the Nuclear Weapon States as a "stand or fall" single document, and thereby deny them the option of claiming partial success if they agreed on only part of the review or program for implementation; 
- three documents, a 2000 Principles and Objectives, a review summary, and (if deemed necessary) a document clarifying the purpose, powers, and limits of the strengthened review process. Because the review process had revealed the need to revisit and at least clarify some of the 1995 provisions, Canada, and Japan advocated this approach. South Africa, New Zealand, and as the PrepCom progressed, a number of other states acknowledged that some additional work in this area was necessary without necessarily requiring a third document in the review process. Some, however, were concerned that "reopening" the 1995 consensus could be dangerous; and,

- a set of decisions and/or resolutions mirroring the 1995 package. A decision on further strengthening the review process; decisions on Principles and Objectives; a program of action on nonproliferation and disarmament; and a resolution on the Middle East or possibly other issues, as deemed relevant. This position was proposed by the delegation of Burma.

Some delegations, including the United States and France, emphasized the need for full consensus on all documents. Others, including Canada, Japan, New Zealand, and South Africa, considered that the review document would not necessarily have to have all its elements agreed upon by consensus, as that approach tended to result either in failure or in anodyne expressions pitched 
at the lowest common denominator of agreement. Instead, the aim would be to adopt by consensus a review document that reflected agreement where possible, with a factual summary or reflection of differing views where necessary. There was, however, general agreement that any forward-looking program, such as the Principles and Objectives, should be agreed upon by consensus.

By taking a position strongly opposed to the majority of the EU states, who favored separate documents, including a negotiated Principles and Objectives for year 2000, France prevented a common EU position from being put forward, to the annoyance of Germany. France argued for a return to the pattern followed since 1985, with three reports generated by the Main Committees (nuclear disarmament, safeguards, and nuclear energy), each looking both forward and backwards. France also suggested that there could be a common "chapeau" or synthesizing document or introduction prepared by the Conference Chair, which might incorporate recommendations of some kind. France clearly did not want a further set of Principles and Objectives to be brought forward.

There was some speculation that France saw reverting to one document in the year 2000 as a way to return to pre-1995 patterns and expectations. France certainly wants to ensure that the progress made since 1995 is properly recorded and appreciated. Like the United States in 1997, 1998, and again in 1999, and France, Britain, and Russia this year presented the PrepCom with 
factsheets or brochures setting out their achievements in nuclear reductions and disarmament. France, for example, proudly presented its cessation of nuclear testing and the halting of its production of fissile materials for weapons, and noted that it was now the first nuclear power to close and dismantle its test sites in the Pacific and the facilities at Marcoule and Pierrelatte for producing military plutonium and highly enriched uranium. During the 1990s France withdrew all but two of its nuclear weapon systems, scaling down to four submarines (Triomphant SSBNs) and Super Étendard and, like the other nuclear states, detargeted its weapons (although they can be retargeted in minutes).

In undertaking these steps, however, Paris may have gone as far as it is prepared to go. A new set of Principles and Objectives, with a program of action as a yardstick for measuring progress after 2000, may, therefore, be the last thing France deserves. It may be the last thing any of the nuclear powers want, but the others may feel less vulnerable having nothing more to put on the table. The United States and Russia are still committed to further reductions, if they can overcome the obstacles to the START process, and Britain is more positive than France regarding further opportunities for transparency and confidence-building among the nuclear powers. China is habitually silent on such questions. 
In addition to believing that a single set of inseparable decisions would act as more effective leverage, Iran also seemed to want to avoid having dual track negotiations, as had occurred in 1995. During the 1995 Review and Extension Conference, the decisions on strengthening the review process were negotiated among 25 approximate key delegations under the auspices of the Chair, Ambassador Jayantha Dhanapala of Sri Lanka, while the rest pursued the process with varying degrees of success in the main committees. At that time most considered the Chair consultations to be the major game, relegating the committee work to a secondary status.

On that occasion, Main Committee $I$ on nuclear disarmáment became hopelessly deadlocked, while Main Committees $\mathrm{II}$ and III were able to negotiate consensus text. Because of the disagreements over nuclear disarmament, however, the 1995 Conference was unable to secure a consensus on the final review document, despite having the previous day agreed on extending the Treaty indefinitely and strengthening its review process, as well as bringing forth the resolution on the Middle East. Some advocates of one document wanted to avoid institutionalizing a process of conducting the principal negotiations among a select group of states, and fear that this would happen if parallel negotiating tracks were established. Mexico also argued that any objectives or forward-looking measures should arise from 
a thorough review and analysis of the Treaty's implementation to date, and, therefore, could not be separated.

Agreement on recommendations on the products or outcome of the 2000 Review Conference slipped further away as the PrepCom progressed, so that in the end, Reyes settled for consensus on a document that hedged the options and merely reinforced the 1995 decisions in all their ambiguity. Again, Egypt was able to include the 1995 resolution on the Middle East, together with the decisions on Principles and Objectives, and strengthening the review process, and thereby reinforcing their validity as a package. South Africa, which will chair the 2000 Conference, was disappointed that a more specific recommendation for two primary documents had not been achieved, as its delegation believed such a decision would have assisted in its planning and structuring for the Year 2000 meeting.

In view of the strong opposition to having two documents from France and the growing number of non-aligned states latching onto Iran's position, the best that the third PrepCom could achieve was to air the options and arguments. By holding consultations over the next year, South Africa may be able to secure an agreement before the 2000 Conference. If not, it will have to begin with a flexible approach and steer the Conference into making the required decisions, and deciding as the review progresses whether to aim for one, two, or more documents. 


\section{The role of the PrepComs}

Following the South Asian nuclear tests, Canada was joined by a number of other States Parties in believing that the preparatory committee meetings should be able to have an independent role in commenting on relevant and contemporaneous issues. In view of the difficult tasks facing the third PrepCom, however, Canada only reiterated its proposal but did not press the 1999 meeting to conduct negotiations on such a statement. Instead, Canada served notice that it would seek a debate and decision from the 2000 Review Conference on the role of PrepComs.

\section{The political context}

The third PrepCom, which took place in 1999, was a tense period in international relations, amidst deteriorating relations among some of the key governments, notably China and the United States, following the inadvertent bombing of the Chinese Embassy in Belgrade by NATO warplanes and a "spy scandal" over the alleged theft of nuclear weapon designs by a Chinese-American scientist based at Los Alamos National Laboratory. NATO's recent expansion of membership and missions, highlighted by its air war on Yugoslavia, also caused greater tension with Russia and further, and possibly fatal, delays over START II ratification process in the Duma. President Clinton's decision to proceed in January for research and development funding for missile defense 
programs caused increased concern internationally, but especially in Russia and China, who fear a diminution of the credibility of their own nuclear arms and thus view missile defense as destabilizing strategic security. Other issues that directly or indirectly affected the political environment surrounding the third PrepCom included:

- NATO's Summit and its reaffirmation of a strategic concept embedding nuclear deterrence;

- the nuclear tests by India and Pakistan, their bids (spearheaded by India) to become accepted as additional Nuclear Weapon States and rising tension over Kashmir; and,

- a seeming collapse in commitment to arms control, exemplified by the political games in the Russian Duma and the US Congress over START, the ABM Treaty and the ratification of the CTBT.

Several of China's interventions at the PrepCom castigated "US-led NATO's... gunboat policies" and attempt to gain international hegemony. China considered that the use of force in international relations and recent events, such as the bombing of Yugoslavia, were not conducive to international security and stability, and further jeopardized efforts to prevent the proliferation of Weapons of Mass Destruction. Though the Chinese were the only ones publicly to wonder if NATO would have bombed 
Belgrade if Yugoslavia had also been nuclear armed, there were many in the corridors of the United Nations who made the obvious connection. This was underlined by recent debates in Belarus and Ukraine in which their decisions to give up nuclear weapons, taken as the Cold War ended, were criticized by parliamentarians as hasty with the inference that had they known then what they know now, they would not have surrendered their nuclear weapon "status" so quickly. Though few inferred that Belarus or Ukraine intended to renege on their post-1991 obligations, including as non-nuclear weapon NPT parties, the debates flashed warning signals that over the past year nuclear weapons seem to have been reinforced as a currency of power, influence, and by reference to a demonstrated vulnerability in their absence of security.

\section{The Nuclear Weapon States}

The third PrepCom in 1999 has revealed fundamental schisms in how the nuclear powers and a growing group of nonnuclear weapon countries want nuclear disarmament to be addressed in the context of the NPT.

The United States led the way in 1998 in providing more detailed information on what it was undertaking to control, reduce, and dismantle nuclear weapons and how it was handling the weapons materials such as plutonium and highly enriched uranium. The US delegation provided a further factsheet to the third PrepCom, entitled "The US Commitment to the Treaty on the 
Nonproliferation of Nuclear Weapons." Quoting statements by Clinton, regarding the goal of nuclear disarmament, the factsheet outlined US efforts in reducing strategic and tactical nuclear weapons and reducing the roles and risks associated with nuclear weapons. Furthermore, the factsheet presented its case on the CTBT, cessation of plutonium production and the disposition of fissile materials. Information was included on other initiatives, including US efforts on the physical protection of nuclear material and its support for strengthened IAEA safeguards.

A group of US-based nongovernmental organizations (NGOs) challenged the factsheet's claims. They, in turn, provided information on nuclear weapon modernization programs and juxtaposed the statements of presidential commitment to "the ultimate goal" of nuclear disarmament with Presidential Decision Directive 60 and other recent documents from the Joint Chiefs of Staff. These documents affirm that the United States continues to rely on nuclear arms as a cornerstone of its national security for the indefinite future, with provision for the use of nuclear weapons against chemical and biological threats. Among other refutations of the official factsheet, the NGOs also noted that the CTBT has yet to be ratified by the United States. Furthermore, that the stockpile stewardship program was intended to compensate by providing design capabilities greater than those available during the Cold War, thereby circumventing a primary objective of the nuclear test ban. 
Under pressure from the United States, Russia also provided more detail on its efforts to implement the Treaty. Although, noting that the government's attempts to persuade the Duma to ratify START II had been severely hampered by the actions of NATO and the United States, including NATO expansion, the continued siting of US nuclear weapons in Europe under NATO nuclear sharing arrangements and the Alliance's actions in bombing Yugoslavia were also hampering the ratification process. Russia also criticized the US's determination to push ahead with missile defense programs and Washington's cavalier attitude towards the $\mathrm{ABM}$ Treaty and other bilateral agreements and understanding.

Britain, having concluded its strategic defense review shortly after the second PrepCom in 1998 was also keen to publicize the actions it has taken since 1995. The UK delegation offered an information package describing the decisions and policy underpinnings of the strategic defense review and recent policy statements from the Secretary of State for Defense, George Robertson. France also provided information, charts and figures on the reductions in its arsenals and production capabilities and other measures to support the NPT. Only China did not heed US exhortations for the Nuclear Weapon States to pay more attention to public relations and to the necessity of presenting their actions and successes more effectively. 
Following the bombing of the Chinese Embassy in Yugoslavia, China's delegation refused to participate in meetings with the other nuclear powers aimed at negotiating a collective statement that was to be made to the PrepCom, as had been done in 1997 and 1998. Though these statements went barely further than rhetoric, they were regarded by countries as symbolically important. In particular, Britain had hoped to persuade the other nuclear powers to pledge further efforts in transparency, something which China is particularly reluctant to offer, claiming that the small size of its nuclear arsenal would make transparency too risky, increasing its vulnerability vis-à-vis the other nuclear powers or potential aggressors.

China's main approach was to argue that its doctrine of no-first-use, rejection of deterrence concepts, and restraint in the build-up of its arsenal over the years was proof of its commitment to the Treaty. Other than that, China provided no information on its nuclear forces or any measures it had undertaken since 1995. President Jiang Zemin to the Conference on Disarmament detailed much of Beijing's policy approach before the PrepCom in the speech in March 1995. Though his statement covered the range of disarmament-related topics, it particularly raised concerns regarding programs for anti-missile systems and the weaponization of space, condemning the "research, development, deployment, and proliferation of sophisticated anti-missile system[s]" and of any attempts to revise or withdraw from the Anti-Ballistic Missile 
(ABM) Treaty "on which global strategic equilibrium hinges." China is known to be concerned not only about US plans, but also about the likelihood of Japan and possibly Taiwan being assisted by the US to develop national missile defense programs. Raising fears of "a new round of arms race in new areas," Jiang argued that the international community "should pay close attention to this and adopt the necessary measures to pre-empt such dangerous developments." Jiang also emphasized that the indefinite extension of the NPT "has by no means given Nuclear Weapon States the prerogative to permanently retain their nuclear weapons." He reiterated China's long-held position on security assurances and no-first-use, and advocated negotiations on a "convention on the comprehensive ban of nuclear weapons." These positions were all re-emphasized by China during the PrepCom.

Apart from their stated commitments to the CTBT, which China, Russia, and the United States have yet to ratify, and to negotiating a ban on fissile material production (fissban) in the Conference on Disarmament, the weapons States said little about further concrete steps they would be prepared to take or regarding how to move beyond the impasse that exists in the START process. Almost echoing China's points regarding conditions not being "conducive" to good progress, the United States commented that "external realities" such as "domestic and international policy 
factors, the global security environment, and... financial resources," were related to the process of arms control and disarmament.

\section{Nuclear disarmament: the Non-Nuclear Weapon States}

The Non-Nuclear Weapon States annunciated their positions in national and collective statements. It was particularly noticeable that many of the ideas contained in the working paper from the New Agenda Coalition (NAC) were reproduced in the revised version of the Chair's working paper. Originally formed in June 1998 by the foreign ministers of Brazil, Egypt, Ireland, Mexico, New Zealand, Slovenia, South Africa, and Sweden, the NAC first presented a joint statement by 32 delegations and then obtained 44 co-sponsors for its working paper, both of which echoed the ideas from its Resolution (53/77Y) to the UN General Assembly, which had garnered 114 votes in December 1998. In an attempt to deflate the New Agenda ideas, Norman A. WuIf, head of the US delegation dismissed those "trying to identify a new agenda" for disarmament and said that "we have an existing agenda that remains to be completed." While many agreed that much more work needed to be done to fulfill the START process, and the commitments to negotiate a ban on the production of weapons plutonium and highly enriched uranium, calls for further measures came from many countries. While the weapon states may have found it easy to dismiss the familiar NAM proposals at the 
Conference on Disarmament to negotiate a timetable for nuclear disarmament, on the other hand, they found the more pragmatic arguments more challenging.

After reviewing the situation, including the START process, CTBT, nuclear testing in South Asia, failure to make progress on negotiating a fissile materials ban and security assurances, the New Agenda statement concluded that "the pace of efforts to implement all the obligations of the NPT is faltering." Concerned that the weapon states were reaffirming their nuclear doctrines and re-rationalizing the continued possession of nuclear weapons, the Coalition accused them of not fulfilling their obligations with sufficient vigor and emphasized that "we must not enter the next millennium with the prospect that the retention of these weapons will be considered legitimate for the indefinite future." The New Agenda Coalition called for mutually reinforcing bilateral, plurilateral (among the five declared Nuclear Weapon States), and multilateral efforts to be pursued in concert. This also includes greater progress on deeper cuts and steps to be taken to de-emphasize the role of nuclear weapons in security strategies, including de-alerting and de-mating warheads from delivery vehicles, and reducing reliance on non-strategic nuclear weapons, as well as transparency and Confidence-Building Measures (CBM). Critical of NATO's recent affirmation of the central role played by nuclear weapons in its alliance doctrine, 
NAC also called for "the early examination of measures to enhance strategic stability and to review strategic doctrines."

While not joining the New Agenda Coalition, Japan and Canada also proposed more, far-reaching programs to accelerate progress on nuclear disarmament. Japan warned that unless the tasks of nuclear disarmament were "thoroughly addressed, the NPT could lose its credibility," with grave consequences. After emphasizing the importance of the START process, CTBT and fissban, Japan and Canada both called for direct engagement in disarmament talks by all five NWS "in the near future." Like many, Japan and Canada also underscored the importance of taking such practical measures as de-alerting and de-targeting, as well as assistance in dismantling nuclear weapons, and managing and disposing of the resultant fissile materials.

Canada was also among a diverse group, including the New Agenda Coalition, Finland, Switzerland, Nigeria, and the Kyrgyz Republic to raise the problems associated with tactical nuclear weapons. Concerned that the role of non-strategic nuclear weapons could increase in importance again, these delegations advocated measures ranging from greater transparency and confidence-building to reductions and even elimination, preferably with verification regimes. Russia, which has in recent months, indicated a growing reliance on tactical nuclear weapons, hinted at the possibility of redeploying some weapon systems in Belarus with the consent of the Belarus government, and further noted that 
it supported the implementation of "declared unilateral initiatives" on tactical nuclear weapons. China and Russia both supported calls for the US tactical nuclear weapons currently stationed in seven NATO countries be withdrawn to United States' territory.

\section{Assessment}

The third PrepCom was a limited success in that it finalized the primary arrangements for the year 2000 Review Conference without necessitating a further meeting, as was threatened at one stage in the deliberations. But together with the previous PrepComs, it has clearly failed to address substantive issues in the meaningful ways intended by the majority of those who crafted and agreed upon the decisions on strengthening the review process. Although many delegations expressed disappointment at the meeting's failure to send recommendations on substance to the Review Conference, there was also present an undercurrent of relief at having averted another public debacle, and a feeling that Ambassador Reyes probably achieved the best result possible under the circumstances. If that is the case, then the problems are systemic rather than specific. In the interests of a meaningful contribution to strengthening the nonproliferation regime, it is not helpful to paper-over all the political cracks for the sake of securing an agreement. Similarly, a crisis of deadlocks and failures year after year will weaken the credibility of the Treaty and its collective norms against proliferation and nuclear weapons. If 
these are the two systemic alternatives, the circumstances need to be examined and perhaps changed.

External political realities in the 1999 meeting were bad, but in many ways they intruded less than what might have been expected. At times, the meeting appeared surrealistically cocooned in its own space, earnestly debating subsidiary bodies and ignoring the political realities outside the UN's building. While it is important to note that the meetings are not abused or held hostage for short-term political agendas, it is equally important for the States Parties to take into account the political environment, particularly when developments impinge on arms control and nonproliferation prospects as directly as some of the events of 1998-99.

The health of the nonproliferation regime and the prevailing security environment are inextricably linked, both depending on and creating the conditions for each other. In this regard, the 1999 PrepCom clearly signaled NPT parties' concerns regarding the destabilizing or counterproductive effects of the US plans on missile defense, NATO's strategic concept, lack of CTBT ratification, the US "protection" of Israel's nuclear capabilities, the nuclear ambitions exhibited by India and Pakistan, the unresolved violations by Iraq and North Korea, and the continued concern regarding their clandestine nuclear programs. Some of these problems could be directly mitigated by more constructive actions by some of the nuclear weapon State Parties to the Treaty; other 
problems have deep and complex roots and need multi-pronged regional and international strategies going much wider than the NPT regime and its obligations. Without denying the connections, realistic distinctions have to be made on what can be addressed in the context of the NPT regime and what has to be addressed by other means.

In relation to the Treaty and especially the 1995 decisions on extension and review of the NPT, there are problems that can and should be analyzed. Looking back at all three PrepComs, it is clear that the 2000 Review Conference consider some important questions and clarify the powers, limits, and tasks of what are called PrepComs, and ask itself what is wrong with how the formal papers from 1995 have been interpreted. What needs to be changed? Does it make sense to use a series of three annual meetings to churn out a generally platitudinous rolling text of recommendations for the next review conference?

The three or four meetings scheduled between two review conferences were regarded as "implementing" rather than "preparatory" committees. Could these conferences be better employed focusing their debates more systematically on facilitating implementation of the Principles and Objectives agreed upon by the State Parties at the previous Review Conference? If that is the case, would it be more relevant for the parties to attempt to negotiate agreement on how well the Principles and Objectives are being implemented in that particular year so as to provide a kind of 
snapshot, against which the next year's progress can be compared? Rather than being delivered as a rolling text of recommendations, the Review Conference could receive and take into account the three "snapshot" reports, comparing and contrasting progress over the five-year period. Such an interpretation would place the forward-looking responsibility almost entirely on the five yearly review conferences. The misnamed "PrepComs" would have the main function of measuring implementation of the Treaty, and Principles and Objectives, and ensuring year-by-year accountability through their "annual reports" or snapshots, which would also take into account the international and political environment. The previous year's PrepCom could be assigned the additional tasks of procedural preparations for the next Review Conference.

The major hurdles for the 1999 PrepCom were in connection with the Middle East and nuclear disarmament, as had been widely predicted. Blamed for much of 1998's stalemate and through bilateral meetings with Egypt over the past year, the United States came prepared to compromise on some issues. For example, the United States agreed to name Israel together with India, Pakistan, and Cuba, in calls for universality, but would not name Israel on its own in relation to the Middle East. Intensive US-Egyptian negotiating sessions, and regular and close consultations among the Arab states, sometimes involving the Chair, enabled the final compromises to be made. In the end the Middle East resolution was linked several times with the decisions 
taken in 1995. It was agreed upon to request the UN Secretariat to prepare a document on this issue, which (like the rest) was to "give balanced, objective, and factual descriptions of the relevant developments, be as short as possible and be easily readable."

The way for agreement on subsidiary bodies in 2000 was paved by acceptance of the change to the rules of procedure, which went through smoothly at the beginning of the PrepCom. Canada, which re-iterated its proposal for PrepComs to have an independent role in commenting on contemporaneous events, did not insist on a recommendation on this issue from the PrepCom. As a whole, South Africa set down markers regarding security assurances and its 1998 proposal for a subsidiary body to consider practical proposals on nuclear disarmament, but did not insist on recommendations from 2000. Egypt, however, insisted that "nothing was agreed upon until everything was agreed" and tried to push for a recommendation on establishing a subsidiary body based on the 1995 Resolution on the Middle East, before finally agreeing to the Year 2000 Conference would consider this proposal.

The United States came across as more engaged and flexible this year. The Egyptian delegation, by contrast, appeared divided among itself, and that some of its tactics raised concerns, even among NAM colleagues, that risked becoming counterproductively divisive. Following the US precedent that was set in 1998, four out of the five NWS (Britain, France, Russia and the United States) presented some form of factsheet summarizing 
their actions, especially on Article VI, but they were not at all disposed to discuss present difficulties or future actions. Russia engaged more, but clearly wanted to limit progress or implementation under the review process, warning that overly high expectations or unacceptable demands could undermine the sense of collective ownership of the Treaty. Able to announce the decisions of the 1998 UK strategic defense review, Britain appeared more comfortable and was most prepared to demonstrate flexibility on a number of issues, actively seeking solutions.

The bombing of the Chinese Embassy in Belgrade just days before the PrepCom started ensured that the Chinese would raise security questions about the use of force and sovereignty. Despite its refusal to work within the P-5 context, China participated fully in the PrepCom. Among the familiar Chinese positions on no-firstuse etc., there were clear signals that any discussion of steps towards quantitative or qualitative nuclear disarmament would be met by linked concerns regarding missile defense, which should be expected to play a larger role in the coming year and through 2000 .

\section{Implications for $\mathbf{2 0 0 0}$}

The implications for arms control and nonproliferation of the Indian and Pakistani proliferation, and NATO's war on Yugoslavia, are still not clear. Some NPT parties, including Japan, South Africa, Egypt, and the Middle East states have indicated in no uncertain terms that any recognition, conferring of status or 
exchange of technology assistance that accepts that India and Pakistan have crossed from ambiguous to de facto Nuclear Weapon States would be an anathema, and could change the basis of their terms for acceding to the nonproliferation regime as non-nuclear weapon parties, thereby initiating the collapse of the nonproliferation norm. These and other States have also emphasized the need to make even greater progress towards nuclear disarmament and to increase the international pressure on Israel, as well as India and Pakistan, to accede to the Treaty. At the same time, there is a serious and worrying deterioration of relations between the United States and Russia and China, due to NATO's actions and US plans for developing missile defense programs. This could enhance closer relationships between Russia and China as exemplified by the joint Russian-Chinese communiqué on issues related to the ABM Treaty, issued April 14, 1999. It is too early to judge whether the changing alliances are a short term response to political conditions in 1999 or a symptom of a deeper transformation in international relations, making nonproliferation and arms control progress more difficult in the future.

Below are some preliminary thoughts on the implications of the politics, conflicts, and conduct of the 1999 PrepCom for the 2000 Review Conference:

- Nuclear Disarmament is an inextricable component of nonproliferation. Until Article VI goals are substantially achieved in the way that most parties consider the other 
articles, nuclear disarmament will continue to be the major subject of debate and disagreement, a reality that the NWS must acknowledge and address more constructively;

- There will need to be intersessional bilateral meetings between Egypt and the United States to attempt to establish ground rules for how to address the possession of nuclear weapons by one Middle East state without overloading the treaty review process with the related regional and security demands;

- Nuclear testing and the self-declared nuclear "status" by the two South Asian non-NPT members will need careful handling if the basis of the nonproliferation norm is to remain intact and credible;

- Preparation and advance consultations by the President/Chair are vitally important in soliciting ideas, trouble-shooting likely problems, and building a sense of collective ownership and responsibility for the outcome in this meeting;

- The present outmoded group system is increasingly irrelevant and could be quite counterproductive in terms of managing the conduct, information flow, and decisionmaking of the Review Conference and future PrepComs. Issue based coalitions, such as the New Agenda Coalition are likely to play a greater role, but may not be the most effective conduits for facilitating the exchange of 
information and collective decisions with the Chair and Bureau;

- Voting, though provided for in the Treaty, should not be regarded as an easy option to bypass consensus. The forcing of a vote may have unintended political consequences and may become very messy and complicated; and,

- $\quad$ Some thoughts must be directed to interpreting the 1995 decisions so that the review process can be more effective. The role of the PrepComs, the meaning and status of any "recommendations" and other issues needs to be debated and perhaps refined. 
Chapter 20

\title{
Safeguards into the Next Millennium
}

\author{
Kaluba Chitumbo \\ And \\ Malcolm Nicholas
}

With the indefinite extension of the Nuclear Nonproliferation Treaty (NPT) in 1995, the international community reaffirmed that nuclear nonproliferation and nuclear disarmament enhanced global security. Crucial to the NPT is the capability to verify compliance. At the heart of NPT, verification is the safeguards system of the International Atomic Energy Agency (IAEA).

Yet securing the NPT's permanence does not quarantine safeguards from the forces of change. One vital task in the crafting of enduring safeguards is to ensure they resonate with global developments. This is especially pertinent in a world where uncertainties of a political and security nature abound. Equally, while it is instructive to learn from lessons of the past, it is also important to anticipate future safeguards issues. Hence, foresight and flexibility are increasingly essential to the operation of a robust safeguard regime - one geared for the nonproliferation and disarmament challenges of the new millennium. 


\section{The evolution of strengthened safeguards}

\subsection{Political and technical factors}

The safeguards system has continuously evolved since the creation of the IAEA in 1957. Unsurprisingly, a mix of political and technical developments has catalyzed this evolutionary process. Many international and regional strategic rivalries, which once forged powerful military competitions, have either abated or been resolved. Prime examples are the Cold War struggles between the Western powers and the former Soviet Bloc, rivalries among South American states, and the tensions in southern Africa. Important initiatives in the spheres of nonproliferation, arms control, and disarmament have arisen in the wake of these geostrategic contests. These initiatives coalesced widespread support for enhancing Confidence-Building Measures in verification processes.

The progress in nuclear and verification technologies has also left its hallmark on safeguards. Across the fuel cycle, invention and innovation is frequent. Moreover, nuclear technologies have generally become more affordable through global economic growth. These factors ensure that nuclear capabilities will improve and spread. Indeed, many developing countries are now capable of absorbing nuclear technologies, which were once the exclusive domain of those with advanced industries. The architects of safeguards have kept pace with the 
dynamism of technological change by introducing new concepts and new procedures complemented by new technologies.

\subsection{The limitation of early safeguards measures}

The influence of political and technical factors on the evolution of safeguards has been evident even since the negotiations for the first system in the late 1950s. At that time, the United States' policy for preventing nuclear proliferation by severely restricting international access to nuclear technologies and materials had been abandoned. This amounted to recognition that numerous other States would eventually develop independent nuclear industries. As an alternative, spreading nuclear technology under strict international controls - the "Atoms for Peace" program - had become the pivot for US nonproliferation efforts. Safeguards provided the foundation for this approach.

While the IAEA was seen as an indispensable organ for verifying the peaceful use of nuclear technologies and materials, some States wanted to limit the intrusiveness of safeguards. Their main arguments were premised on avoiding excessive financial costs and protecting commercial information. Consequently, the first safeguards system, prescribed by INFCIRC/26, only covered reactors with a power rating up to 100 megawatts in total power output. Even this category was incomplete; any reactors that were not furnished by the IAEA could be exempted. 
Clearly, this system of safeguards needed improvement because of the trend towards the export of larger power reactors. Yet, it was the indirect consequence of a grave security dilemma - the Cuban missile crisis - that triggered the next fundamental phase in the evolution of safeguards. The aftermath of that crisis saw the emergence of closer political cooperation between the United States and the Soviet Union. Important nonproliferation and disarmament initiatives arose from these improved bilateral relations. In addition, the appropriate conditions emerged for the creation of INFCIRC/66/Rev.2 that allowed the application of safeguards to reactors of any power rating, as well as reprocessing plants and fuel fabrication plants.

\subsection{Comprehensive safeguards}

The early system of safeguards was implemented at the discretion of States, chiefly as a condition for nuclear export. However, an increasing diffusion of nuclear technologies during that period meant many countries were acquiring the independent capability to build and export nuclear facilities. That meant a growing number of countries were capable of building nuclear facilities free from safeguards. Hence, over time this safeguards system would have had a diminishing impact on nonproliferation efforts. The solution to this problem had to be found through national commitments to nuclear nonproliferation backed by comprehensive verification means. This requirement culminated 
in the Nuclear Nonproliferation Treaty (NPT) which entered into force in 1970.

Under the NPT, the scope of safeguards was expanded across the nuclear fuel cycle. However, some industrialized States were worried that comprehensive safeguards could compromise commercial and proprietary information. Accordingly, the system that was eventually agreed upon was built on the principle of nuclear materials accountancy. Access to facilities, however, was essentially restricted to pre-agreed positions where nuclear materials could be measured. The designers of comprehensive safeguards also recognized the possibility of cheating on the NPT through the construction of undeclared facilities, but it was tacitly assumed that such facilities would be detected by means other than IAEA safeguards. Besides, few countries wished to allow IAEA inspectors unrestricted access within their territories.

\subsection{Strengthened safeguards - the protocol}

Nuclear material accountancy remains indispensable for the timely detection of the diversion of significant quantities of nuclear material from declared nuclear activities. Yet, the unraveling of Iraq's clandestine nuclear weapons program in 1991 clearly indicated that supplementary measures were needed for an effective safeguards system.

For almost a decade, Iraq had built a large undeclared nuclear infrastructure. That feat was accomplished through 
combined indigenous production and imports of nuclear technology and materials. Furthermore, Iraq exploited the limited scope of inspections. With inspections generally restricted to establish points where nuclear materials could be measured, inspectors could not access most parts of safeguarded facilities. Similarly, the scope of safeguards did not extend to facilities used for nuclear-fuel-cycle related research, but which did not utilize nuclear material. Such facilities could allow considerable progress in a clandestine nuclear program. Therefore, accounting solely for declared nuclear material provided limited verification.

The safeguards system needed to be strengthened by enhancing transparency in nuclear related activities and by broadening inspection rights. Preliminary measures were introduced without the need to change the IAEA mandate. States were required to provide information concerning planned or shut down of nuclear facilities at an earlier stage. This was intended to reduce the risk of illicit use. To further improve the prospect of detecting undeclared facilities and locations, the IAEA Board of Governors reaffirmed the IAEA's right to conduct special inspections. Environmental sampling measures were also introduced as a consistency check for declared nuclear related activities.

While these preliminary measures were identified as a means for strengthening safeguards, other verification methods were still needed to enhance transparency. This prompted the 
development of the Additional Protocol to Safeguards Agreements, which was approved by the Board of Governors in 1997. To enhance transparency, the Protocol requires States to provide more information on their nuclear programs. This includes information on nuclear research, nuclear materials at the pre-safeguards stage, nuclear materials in waste, and specified imports and exports. Such information establishes a comprehensive baseline for consistency checks, thus making it more difficult to conduct significant clandestine activities. Furthermore, broader inspection rights that encompass all buildings on a nuclear site complement the provision of more information and those involved in nuclear fuel cycle research, even if nuclear material is not involved.

However, implementing the Additional Protocol is a gradual process because many issues need careful consideration during the formal national processes for accepting the agreement. The IAEA will also require time to familiarize itself with the nature of information to be reported. Unlike the precise nature of nuclear material accountancy data, much information that will be provided through the Additional Protocol will be descriptive. The IAEA will need to gain experience in processing and evaluating this new information and State-reporting procedures will need to be refined.

A priority will be to integrate the measures of the Protocol with the measures of traditional safeguards. Both types of measures are needed to verify that declared nuclear material is not 
diverted and that no undeclared nuclear facilities or activities exist. Fusing all of these safeguard measures into a seamless mechanism will substantially enhance the effectiveness and efficiency of safeguards. Such integration will improve the transparency and verification of nuclear activities and consequently build confidence among States that have put their faith in the NPT.

\section{The flexibility of safeguards}

\subsection{Reversing proliferation}

The events that have most influenced the IAEA's activities since the NPT's creation have occurred within a relatively short span of time. Until the revelations of Iraq's nuclear program, the IAEA's role was essentially confined to nonproliferation. Because of the extent of its illicit nuclear program, dealing with Iraq meant a twist to the IAEA's work, reversing proliferation. For example, verifying the true extent of Iraq's nuclear program, required the addressing of weaponization issues. This was difficult to tackle because the IAEA had no safeguards function that required knowledge in that area. Moreover, such sensitive information had to be handled without compromising the IAEA's nonproliferation responsibilities.

Furthermore, the IAEA had to widen its analytical horizons. The connectivity between ballistic missile programs and the nuclear weapons work had to be investigated. The organizational 
infrastructure for the nuclear weapons effort had to be clarified. Procurement networks had to be identified. Individuals had to be questioned. All of these tasks required knowledge and skills that were completely different from nuclear materials accountancy.

The prospect of other States following Iraq's illicit path cannot be ignored. The calculus governing any decision to conduct activities that are incompatible with NPT obligations inevitably includes the probability of being caught. However, a cast-iron guarantee of detection is impossible - verification can always be improved but it can never provide absolute assurance. Thus, the IAEA must preserve fields of knowledge and expertise that are exceptional rather than routine to its work.

\subsection{Disarmament}

Following South Africa's decision to join the NPT in 1991, the IAEA was able to draw on its knowledge on reversing proliferation to disarmament. In 1993, South Africa disclosed that it had possessed and subsequently dismantled six nuclear weapons before acceding to the NPT. Thus, in addition to verifying South Africa's initial declaration of nuclear material, the IAEA verified that its nuclear weapons program had been terminated. All the key elements of South Africa's nuclear weapons cycle could be identified, and, hence, thoroughly investigated with authority and credibility. As part of this process, the IAEA also witnessed the 
destruction of important weapons components. This work again underlines the need for preserving knowledge and skills which are non-routine within the IAEA. For no matter how unlikely it may seem, other States that legitimately have nuclear weapons may disarm at some stage.

\subsection{Dealing with ambiguity}

The flexibility of the IAEA's mandate has also been tested in the case of the Democratic Peoples' Republic of Korea (DPRK) where restrictions on safeguards activities have created major problems for verifying its compliance with the NPT. A specific complication is whether the necessary technical evidence can be preserved with the passage of time to enable the IAEA to verify the DPRK's inventory of plutonium. Furthermore, the DPRK's refusal to grant the IAEA's request to conduct special inspections of two undeclared facilities is a serious concern. Thus, major challenges lie ahead if and when the DPRK complies with its NPT obligations.

Addressing the DPRK nuclear issue has also provided another confidence-building role for the IAEA. Under the Agreed Framework with the United States, the DPRK has "frozen" its indigenous nuclear reactor program in exchange for imported light water reactor technology. Through the benefit of on-site inspections, the IAEA has been able to verify the cessation of this element of the DPRK's nuclear activities. This verification role is 
important as the Agreed Framework ultimately provides a route intended to bring the DPRK into compliance with the NPT.

\subsection{Safeguards and verification in Nuclear Weapon States}

Safeguards are applied under Voluntary Offer Agreements in all the Nuclear Weapon States, but only to designated facilities. Why are safeguards applied in States that are legally entitled to have nuclear weapons? The reasons are varied. They include providing support for disarmament, inspecting nuclear material belonging to Non-Nuclear Weapon States, improving the IAEA's ability to safeguard sensitive facilities, and demonstrating that the effort of implementing safeguards is not solely restricted to NonNuclear Weapon States.

Considerable inspection effort is being given to support arms reduction as part of the disarmament process. Since the end of the Cold War, the global stockpile of nuclear weapons has been shrinking. As a consequence, the military infrastructure supporting nuclear arms is being pared. Production facilities are closing and much fissile material is no longer required for military purposes. However, disarmament is likely to remain a slow, long-term process. The level of success will in part depend on ensuring confidence in the verification of former military fissile material. Thus, the implementation of IAEA verification measures is important to disarmament. 
Some former military material belonging to the United States is subject to safeguards under a Voluntary Offer Agreement. The United States intention is to place more of such material under safeguards. Furthermore, under an initiative between the United States, Russia and the IAEA, verification measures will be applied to large quantities of plutonium from dismantled nuclear weapons. This challenge is unique as measures are being considered to protect sensitive information, especially data that might reveal nuclear weapon design secrets.

The additional work for the IAEA from this first phase of nuclear disarmament is substantial. How large the burden eventually becomes will depend on the prognosis for further arms reductions. More progress would probably lead to additional US and Russian military nuclear material requiring verification measures. It is also possible that other Nuclear Weapon States will seek IAEA verification of any former military nuclear material. Without question, the disarmament process is also hostage to many political uncertainties. Thus, planning for verification in support of disarmament is difficult beyond the near term.

Designated nuclear facilities in Nuclear Weapon States may also be subject to safeguards because they are used to process and store nuclear material belonging to Non-Nuclear Weapon States, particularly in Japan. Furthermore, Non-Nuclear Weapon States wish to see greater universality in safeguards. They would prefer the Nuclear Weapon States to experience the "burden" of having 
facilities safeguarded. The "hexapartite" agreement is an example. It obliges the UK and US, Netherlands, Germany, Japan, and Australia to accept safeguards on civil centrifuge uranium enrichment facilities. In practice, for the two Nuclear Weapon States, only the British Capenhurst centrifuge facility is currently operational and thus subject to safeguards. A more recent development is the application of safeguards to China's centrifuge plants supplied by Russia. These safeguards are not for the purpose of universality as both are Nuclear Weapon States. Instead, IAEA inspections are to ensure that these facilities are used for peaceful purposes. The inspection effort required at these British and Chinese centrifuge facilities is substantial.

\subsection{Safeguards and regional treaties}

Verification and confidence building are characteristically distinct, yet inextricably linked. Improving one benefits the other. However, confidence building in the sphere of nonproliferation extends beyond the NPT. Other mechanisms exist which are aimed at preventing the spread of nuclear weapons and ultimately eliminating them. Although not created by grand design, these mechanisms provide an architecture capable of addressing many complicated global nonproliferation issues. The IAEA plays a central role.

Nuclear-Weapon-Free Zones (NWFZ) are proving useful in complementing global nonproliferation efforts by enhancing 
confidence at the regional level. Each has distinct features that reflect regional characteristics. While all of the Southern Hemisphere falls within a NWFZ of one sort or another, most of the Northern Hemisphere is not, including regions where nuclear proliferation has been a particular concern. Nevertheless, NWFZs have been proposed for Central Asia, South Asia, Central and Eastern Europe, and the Middle East. Should the correct conditions emerge for the creation of a NWFZ in the Middle East or South Asia, the requisite safeguard regime may have to go beyond even the IAEA's strengthened safeguards system.

The IAEA has been asked to play a broad role in verifying NWFZs. This includes an increasing number of requests to verify compliance with the provisions of the African, South East Asian, and South Pacific NWFZs which ban the dumping of radioactive materials. It also includes providing assurances that former nuclear weapons manufacturing facilities subject to the African NWFZ have been dismantled, destroyed, or converted for other purposes.

Regional relationships with the IAEA also include multinational organizations with safeguard responsibilities. These are EURATOM which is the regional system for accounting and control of nuclear materials in States belonging to the European Union, and $\mathrm{ABACC}$ which is responsible for the implementation of bilateral safeguards for Argentina and Brazil. In the future, it is possible that the relationship between regional and IAEA 
inspection regimes could be expanded into other places like Asia where nuclear power capacity is growing.

\subsection{Illicit trafficking of nuclear materials}

Since the end of the Cold War, international concerns regarding the illicit trafficking of nuclear materials have intensified. The IAEA has a direct interest in this issue as the loss or seizure of nuclear material affect the inventories of safeguardable material in the States concerned. Furthermore, the IAEA has been mandated to help its member States reduce the threat of such trafficking because of the nuclear proliferation and safety aspects.

Reducing the risks associated with illicit trafficking depends on the implementation of many measures. Principally, this starts with the adoption by States of robust physical protection procedures for nuclear material. Essentially, this means the proper accounting of nuclear material and stringent physical security during its use, storage and transport. As prevention cannot be perfect, trafficking countermeasures must include the ability to detect the illicit acquisition of nuclear material.

States have ultimate responsibility for dealing with trafficking incidents. However, the IAEA has provided extensive support in defining physical protection standards and advising on their implementation. Support has also been given to States on establishing appropriate national legal infrastructure. Furthermore, 
the IAEA has assisted in coordinating programs for States to help each other in aspects of physical protection and detection.

Developing effective countermeasures is one objective, but they can only work where they are adopted. While much attention on such countermeasures has been devoted to the former Soviet Union, it has to be remembered that nuclear technology is spreading and consolidating in other global regions. As this process continues, so too will be the holdings of nuclear material in these regions, some of which are prone to political tensions. Countermeasures must also be of an acceptable standard. The IAEA is working for broader global acceptance of physical protection measures and their harmonization among States.

Furthermore, the IAEA helps to cement a collective international approach to illicit nuclear trafficking by sustaining authoritative information. Since 1995, the IAEA has maintained a database containing official data submitted by a number of Member States on trafficking incidents. This database is recognized as a particularly unique source of useful information which can help States concerned with trafficking activities.

The IAEA is also acting as a catalyst in bringing together other international organizations with roles in combating trafficking so that coordination and information sharing processes can be enhanced. These organizations encompass functions such as customs, communications, transport and policing. A truly international response to trafficking must include close cooperation 
between such organizations as well as national governments. An IAEA objective is to deepen the level of interaction between these organizations to improve the international effort in combating trafficking.

\section{Being prepared for a "Cut-off" Treaty}

The international community's resolve to prevent nuclear proliferation requires a robust system of treaties designed to tackle the numerous dimensions of the problem. The anchor treaty is the NPT, complemented by Nuclear-Weapon-Free Zone Agreements. Although the Comprehensive Test Ban Treaty (CTBT) is yet to enter into force, it acts as a moral restraint against proliferation. It also pressures those States with nuclear weapons to refrain from nuclear tests, thus removing an incentive for other States to reciprocate. Yet, the production of nuclear weapons is subject to the availability of suitable fissile material. Thus, a truly comprehensive nuclear nonproliferation regime would include global restraint in the production of weapons-grade fissile material, in other words, a Fissile Material Cut-off Treaty (FMCT).

However, many contentious issues need to be resolved. Should old stocks be included? Should all civil reactors be included? How will unsafeguarded facilities be dealt with? How much funding would States provide for such activities? It is unclear as to what might be the final form of a FMCT. What is clear is that, if requested, the IAEA could play a fundamental role 
in verifying a FMCT regardless of its final form. For example, it could verify the closure of relevant nuclear facilities and the nonproduction of agreed fissile materials. Further investigations and studies are warranted for additional verification measures to be put in place.

\section{Information management and analysis}

\subsection{The deepening sea of information}

Information is the lifeblood of the strengthened safeguards system. The collation of information from State declarations through safeguards agreements, the Protocol, inspections, open sources, and in-house data is intended to provide the transparency necessary for verifying compliance. Information, however, must be converted to knowledge for it to be useful. That knowledge must be panoramic, encompassing nuclear facilities, nuclearrelated facilities, potential nuclear-related facilities, and closeddown nuclear facilities. The depth of knowledge must include production capacities, actual production, technical processes, nuclear material accountancy, nuclear-related imports and exports. Moreover, the breadth of knowledge must cover politics, economics, security, other weapons of mass destruction, and advanced delivery systems.

Information-related skills required within the IAEA are experiencing considerable changes. Before Iraq's noncompliance 
with the NPT was discovered, the information processing skills required within the Agency could be precisely defined. At that time, virtually all information for verifying compliance was derived from physical measurements of nuclear materials and corresponding State declared inventories. Such information is primarily numeric, directly measurable, precise, and can be statistically measured. The processing and analysis of this type of information is very much a science.

\subsection{New analytical challenges}

However, gaining a broader knowledge of nuclear activities within Member States now requires many different kinds of additional information and completely different collection procedures in addition to existing ones. Information declared under the Protocol is inherently more descriptive compared with that needed for nuclear materials accountancy. Other information, especially from open-sources, varies enormously in quality. This makes the process of evaluation complex because the information can range from political statements, through to the activities of individuals, as well as media rumors regarding developments in nuclear programs. It also includes the exploitation of commercial satellite pictures. Moreover, verification of information can only be conducted on an ad hoc basis, and without the benefit of sharply defined procedures like those that typify safeguards inspections of nuclear material. 
A major challenge for analysts is to be able to splice together these fundamentally different types of information from inspections and other sources so they form a comprehensive picture of States' nuclear activities. Furthermore, it is important that the IAEA has a variety of analysts. Inspectors are experienced in technical measurements and possess firsthand knowledge of inspected facilities. Yet, because other types of information are usually much broader and more descriptive than nuclear material accountancy data, it is also important to recruit staff with analytical backgrounds in these other areas.

\subsection{Software tools}

Analysts also need technological support because the volumes of information are too large for manual processing. Special software tools are being used within the IAEA to filter out low-grade information so the analyst has a more manageable task. Analysis can also be augmented with software tools capable of pattern-recognition. Indeed the IAEA has already begun to utilize an advanced tool that has shown some early promising results. Still, the pace of technological development in information processing tools is rapid. It is imperative that the IAEA remains at the fore in the use of such software tools so that the ever-growing volumes of information can be exploited. Therefore, the IAEA must ensure that it remains able to absorb these technologies. 


\section{Final thoughts}

Clearly, the scope and complexity of IAEA safeguards have evolved rapidly in this decade. While the discovery of Iraq's clandestine nuclear program spurred this evolution, other events have injected momentum in to the process. US and Russian disarmament initiatives, born from the embers of the Cold War, have created fresh challenges for safeguards. Verifying the DPRK's nuclear "freeze" has expanded the activities of the IAEA, as has the assistance being given to States in combating nuclear trafficking.

Understandably, the culture of the IAEA is changing to meet the challenges of strengthened safeguards and additional activities. New disciplines are being introduced; new safeguards activities are being performed; and, new expertise is being recruited. Information analysis is being broadened and deepened.

\subsection{Financial constraints}

Sweeping changes that reach to the very roots of any organization cannot be introduced cost-free. Yet since 1992, the IAEA has been subject to a zero, real growth budget. Finding the resources to perform the new responsibilities and support activities is arguably the most daunting challenge in the future for the IAEA. Efficiency measures are being implemented so that resources can be reallocated. There are concerns, however, as to how far that 
process can go, bearing in mind that the workload in these areas is also growing.

Indeed, between 1992 and 1998 the number of nuclear facilities under safeguards has increased by $17 \%$. Another important measure of the safeguards workload is the amount of nuclear material under safeguards. In terms of "significant quantities" (a nuclear accountancy unit used to simplify the accounting process for the many different types and forms of nuclear material) the amount increased by $58 \%$ between 1992 and 1998. Most of these additional significant quantities comprise plutonium. Although highly enriched uranium included a much smaller portion of the additional significant quantities, there was, nevertheless, a $95 \%$ increase during the same period in the amount being safeguarded.

\subsection{New technologies}

One way to help square the circle on resources is through the implementation of new technologies. Throughout its history, the IAEA has relied heavily on utilizing cutting-edge technologies. With a greater emphasis on processing open source information, the revolution in information technology is expanding analytical capabilities - efficiency in analysis saves time and reduces overall costs. New technologies are also having a direct impact on inspections. Miniaturization of diagnostic equipment has meant a considerable reduction in the volume of diagnostics to be 
transported. Nowadays, instruments that use to be transported in something the size of a suitcase can fit comfortably in the hand. Such equipment is quicker to set-up and faster to use, again saving time and money.

New technologies are being tested to reduce the frequency of inspections. Remote monitoring - the use of video cameras installed at nuclear facilities - is showing considerable promise. These systems rely on the installation of video cameras to monitor nuclear facilities across the globe and transmit real time images to the IAEA. This approach will reduce the time needed for inspectors to go in to the field to replace films used in current optical surveillance systems. Real-time video surveillance also helps to build confidence because of the continuous coverage of nuclear facilities.

\subsection{Essential requirements}

New technologies, though essential, have limits in terms of savings. Inspectors are not indispensable. Nor are proliferation analysts. Indeed, both of these groups need considerable support within the IAEA. For the IAEA to execute its statutory duties in an evolving safeguard environment, it is an absolute requirement to retain and recruit high caliber staff, maintain high morale, replenish equipment, and implement the optimum organizational structure. 
Therefore, as the IAEA heads into the next millennium, the reconciliation of available resources with priorities will warrant scrutinous attention. More than ever, competing priorities will need to be carefully evaluated to ensure scarce resources are used with maximum impact. With these points uppermost in its approach, the IAEA will ensure it provides the best capability for verifying the peaceful use of nuclear materials. 
Chapter 21

\section{Comprehensive Nuclear Test Ban Treaty Towards a Safer and More Secure World}

\section{Masabumi Sato}

In 1963, the parties to the Treaty Banning Nuclear Weapon Tests in the Atmosphere, in Outer Space and Under Water, (PTBT) proclaimed their determination "to achieve the discontinuance of all test explosions of nuclear weapons for all time" and to continue negotiations to this end. That determination was recalled in the preamble to the 1968 Treaty on the Nonproliferation of Nuclear Weapons (NPT). However, given the prevailing international situation, the lack of trust in the capabilities to monitor and adequately verify a nuclear test ban was a major obstacle to an agreement. Ultimately, it was the work of the Ad Hoc Group of Scientific Experts - established in 1976 by the Conference of the Committee on Disarmament to consider international cooperative measures to detect and identify seismic events using a global network of seismic monitoring stations - that showed it was possible to verify a ban on nuclear weapon test explosions.

Negotiations got under way in January 1994, after the Conference on Disarmament was able to give its Ad Hoc Committee on a Nuclear Test Ban the mandate to negotiate a Comprehensive Nuclear Test Ban Treaty (CTBT). These 
negotiations were given a boost in 1995 when the NPT Review and Extension Conference adopted the Principles and Objectives for Nuclear Nonproliferation and Disarmament, which recognized that "the completion by the Conference on Disarmament of the negotiations on a universal, internationally, and effectively verifiable Comprehensive Nuclear Test Ban Treaty no later than 1996 is important in the full realization and effective implementation of Article VI" of the NPT. The scope of the CTBT was also defined in 1996 when the United States committed itself to adopting a true zero-yield CTBT, an absolute ban on explosive tests. Despite agreement on most outstanding issues in 1996, the Conference on Disarmament was unable to reach consensus on a final text. As a result, 127 States then sponsored a resolution endorsing the draft Treaty, which was overwhelmingly adopted by the UN General Assembly on 10 September 1996 with 158 votes in favor, three against (Bhutan, India, and Libyan Arab Jamahiriya), and with five abstentions (Cuba, Lebanon, Mauritius, Syrian Arab Republic, and United Republic of Tanzania).

\section{Significance of CTBT}

The CTBT decrees a comprehensive ban on any nuclear explosion in any environment and for whatever purpose. Under Article I (basic obligations):

- $\quad$ "Each State Party undertakes not to carry out any nuclear weapon test explosion or any other nuclear explosion, and 
to prohibit and prevent any such nuclear explosion at any place under its jurisdiction or control;" and,

- $\quad$ "Each State Party undertakes, furthermore, to refrain from causing, encouraging, or in any way participating in the carrying out of any nuclear weapon test explosion or any other nuclear explosion."

The CTBT reinforces the nonproliferation regime established under the NPT; whereas the NPT and its verification regime address the issue of the proliferation of fissile material. It is the CTBT and its global verification regime, which set out a framework for the prevention of explosive testing of nuclear devices. The CTBT thus closes the door on the development of sophisticated and qualitatively newer nuclear weapons. The CTBT also inhibits nuclear proliferation. In addition, the CTBT provides a strong impetus to further implement the above-mentioned "Principles and Objectives for Nuclear Nonproliferation and Disarmament" of the NPT.

Furthermore, the Comprehensive Test Ban Treaty will enter into force when it has been ratified by the 44 States that participated in the 1996 session of the Conference on Disarmament and that are listed by the International Atomic Energy Agency as maintaining nuclear facilities, as set out in Annex 2 to the Treaty. If the Treaty has not entered into force "three years after the date of the anniversary of its opening for signature," a conference of those States that have ratified it may be held to decide what 
measures may be taken to accelerate the ratification process in order to facilitate early entry into force (Article XIV, "Entry into Force"). Discussions are continuing to hold such a conference in the last months of 1999.

As of May 1999, 18 of the 44 nuclear-capable States listed in the Treaty, including France and the United Kingdom, have deposited their instruments of ratification with the Treaty Depositary, the UN Secretary General. An additional 18 have also ratified the Treaty, thus making a total of 36 ratifications. Three of the 44 nuclear capable States have yet to sign the Treaty: the Democratic People's Republic of Korea, India, and Pakistan. On the other hand, several non-signatory States, including Pakistan, participated in the Treaty's implementation.

\section{Global verification regime}

The key to the viability of the CTBT is its verification regime. In order to monitor and verify compliance with the Treaty, Article IV ("Verification") and the Protocol to the Treaty provide for a global verification regime to be established so as to be operational at the time the Treaty's entry into force. This regime is to consist of an International Monitoring System (IMS), consultation, and clarification, On-Site Inspections (OSI), and Confidence-Building Measures (CBM). The IMS is to be supported by the International Data Center (IDC). 
Additionally, the Treaty provides for the establishment of the Comprehensive Test Ban Treaty Organization (CTBTO), the Conference of the States Parties, which consists of all States Parties to the CTBT, the Executive Council (51 States elected by geographical region), and the Technical Secretariat.

\section{Establishment of the Preparatory Commission}

Paralleling the last six months of negotiations, the text on the Establishment of a Preparatory Commission for the Comprehensive Test Ban Treaty Organization was developed in open-ended negotiations at the Conference on Disarmament. The Secretary General of the UN, as CTBT Depositary, convened a meeting of CTBT States Signatories in New York on 19 November 1996. The participating States adopted Resolution CTBT/MSS/RES/1 establishing the Preparatory Commission for the CTBTO, as well as a provisional Technical Secretariat "to assist it in its activity, and to exercise such functions as the Commission may determine."

The CTBTO PrepCom is required to carry out the necessary preparations for the effective implementation of the CTBT, and for preparing the first session of the Conference of States Parties to the Treaty.

The Provisional Technical Secretariat began to work at its offices in the Vienna International Center on 17 March 1997 with a 
staff of nine individuals from six countries. By May 1999, the number of staff had grown to 192 from 61 countries.

Thus far, the Preparatory Commission has held eight sessions. During these sessions it has considered, inter alia, the program of work, the budget, financial and staff regulations and rules, and set milestones for the establishment of the verification regime. In between sessions, two working groups and an advisory group have been meeting: Working Group A and the Advisory Group to review financial, budgetary, and administrative issues; and Working Group B to consider verification issues.

The Preparatory Commission's budget for 1997 was $\$ 27.7$ million, for 1998 it was $\$ 58.4$ million, and for 1999 it is set at $\$ 74.7$ million. To date, 90.08 percent of the assessed contributions for 1998 , and 66.25 percent of those for 1999 had been paid by the States Parties. This is a clear reflection of the strong support given by the States Signatories for the work of the Preparatory Commission.

\section{Global verification system}

The International Monitoring System (IMS) consists of a global network of 170 seismic, 60 infrasound, 11 hydroacoustic, and 80 radionuclide stations; the latter supported by 16 laboratories. These 321 stations, to be established or upgraded in some 90 countries around the world, will be capable of registering vibrations in the underground, in the seas and in the air, as well as 
detecting radioactive particles released into the atmosphere that may emanate from a nuclear explosion. The stations will transmit data, via satellite, from the four technologies to the International Data Center (IDC) at Vienna, in near real time where they will be processed and analyzed, and used to detect, locate, and characterize events. Based on this data, the $\mathrm{IDC}$ will issue bulletins of events having taken place within hours and provide them to member States for their review and consideration. Ambiguous events may be subject to consultation and clarification. As a final verification measure, on-site inspection is foreseen as a tool in the Treaty.

\section{International Monitoring System}

The IMS network is being built according to a schedule determined by the Preparatory Commission. As of $1999, \$ 57.5$ million in capital investment has been budgeted for this network, representing about forty percent of the total capital investment required to complete the IMS network.

The CTBTO PrepCom has expeditiously moved to implement its work. Information was collected on the extent of existing facilities by questionnaires and site surveys. The coordinates and identification codes of the monitoring stations that were listed in the Treaty were checked for accuracy. At the same time, a legal framework for establishing or upgrading facilities on the territory of States hosting these facilities was developed. This 
served as a basis for negotiation between the States concerned and the Provisional Technical Secretariat (PTS). Further, in order to expedite the work on these facilities while formal agreements are negotiated - a process requiring decisions to be taken at the national level - a provisional framework for IMS work to begin has been instituted, which is based on exchanges of letters between the Secretariat and the State Party involved.

By May 1999, letters had been exchanged with thirty-seven States to cover the work that was scheduled up through the end of 1999 at some 157 stations. The Secretariat is, however, moving to finalize facility agreements, since they provide a full legal framework, which covers all aspects of the work to be done. By May 1999, three such bilateral agreements have been concluded (Canada, New Zealand, and South Africa).

The IMS will be under the authority of the Technical Secretariat. Its facilities will be owned and operated by the States hosting or taking responsibility for them. If a State meets the costs of establishing new monitoring facilities or upgrading existing facilities, it is entitled to compensation "by an appropriate reduction in its assessed financial contribution to the Organization. Such a reduction shall not exceed 50 percent of the annual assessed contribution ... but may be spread over successive years," (Article IV, paragraph 22). In 1999, claims for reduced assessment were received from eleven States for work scheduled at 48 stations.

Seismology is the most mature of the four CTBT verification technologies. This is because there are many existing 
stations that had been established for earthquake monitoring purposes, some of which also serve as research facilities for seismic verification. The seismological network will receive the largest investment over the next several years. Site surveys to determine the suitability of a station, as well as the technical specifications for its construction and for the purchase of equipment needed, have been completed or are under way for many sites. By the end of 1999 , approximately 75 percent of the primary and 50 percent of the auxiliary seismic network will be operational.

Additionally, the three hydroacoustic stations are on line to IDC although they will need to be upgraded to meet IMS specifications. Site surveys have been completed or are under way for four hydroacoustic stations. It is anticipated that by the end of 1999 , approximately 50 percent of the hydroacoustic networks will be operational.

Only one infrasound station existed previously, at a location specified in the Treaty. Site surveys are presently under way or have been completed to expand this verification technology to 14 infrasound stations. Approximately 25 percent of the infrasound network may be operational by the end of 1999 .

Radionuclide stations monitoring atmospheric radioactivity are plentiful, but few meet IMS specifications. As of May 1999, site surveys have been completed or are under way for 27 radionuclide stations. An experiment on four noble gas detection systems will be held in Germany beginning in October 1999. By 
the end of 1999, approximately 20 percent of the radionuclide network might be operational.

From the outset, the Provisional Technical Secretariat realized that the establishment of 321 monitoring stations around the globe would be a technical and logistical challenge. They have now begun to encounter some of the realities of these challenges, and many other challenges are expected in the implementation of this global task. Some examples of these challenges include:

- the installation of a seismic station halted for five months by the onset of the rainy season;

- $\quad$ site surveys conducted under Arctic weather conditions in extreme cold and wind;

- a hydroacoustic site survey pounded by twenty-meter waves in the southern Indian Ocean, where installation work can only be done during the Austral summer; and,

- a land-link from an underwater hydrophone station possibly coming ashore via a penguin community, causing environmental concerns.

Training programs have been instituted and have been held in five geographical regions, hosted by Argentina, Japan, Kazakhstan, the Russian Federation, and South Africa. These programs aim to provide an overview of the Treaty, its verification technologies, and to facilitate contacts with States hosting monitoring facilities and related national institutions. The participants are normally technical and scientific personnel 
representing the institutions responsible for CTBT verification, as well as military and diplomatic personnel. Manuals, describing the four verification technologies and their use in discriminating between natural phenomena and possible nuclear explosions, are complemented by lectures of scientific experts and the Secretariat Staff.

In addition, a technical training program (TTP) was convened for monitoring station operators in Vienna in October 1998, followed by practical, in-depth training at facilities in Argentina, Germany, Norway, and the United States. The purpose of this program is to familiarize technical and scientific personnel, who will operate and maintain monitoring facilities, with in-depth knowledge of the specific verification technology and data communications methodology within the IMS/DC systems.

\section{International Data Center}

The International Data Center (IDC) is, according to the CTBT, the focal point within the Technical Secretariat for data storage and processing. The technology is drawn from the efforts to develop and test a prototype international data center that a Group of Scientific Experts established in the early 1980s in Arlington, Virginia. The $\mathrm{DC}$ in Vienna will function around-the-clock with robust and reliable computer and communications operations. 
In the initial stage, $\mathrm{IDC}$ activities were directed in ensuring that it was fully prepared for the delivery, installation, and testing of the first of four releases of application software from the Arlington, Virginia Center. The first release was delivered and tested successfully in April 1998. By May 1998, real-time data from about 60 stations - that voluntarily transmit data from the four verification technologies - were being received at the Center via a high-speed communications link with the Center in Arlington. The first test products have been computed. These include seismic, hydroacoustic and infrasound events, and atmospheric radionuclide measurement reports. The second software release was delivered in May 1999 and will, after the completion of testing, provide IDC products and services to States Signatories, for the first time, beginning near the end of 1999.

Unfortunately, the first release of software had not yet been installed by the time of the nuclear tests that were announced by India in early May 1998. However, IDC was able to detect and locate seismic events associated with the 28 and 30 May nuclear tests announced by Pakistan, using data from some 30 stations from various regions of the world. The data and products were quickly reported to the Preparatory Commission.

Furthermore, the IDC also participated in, and was able to detect and locate a chemical calibration explosion of 100-tons yield at a former Soviet Union test site in Kazakhstan. Despite the incomplete state of the seismological network, and the very small yield, the automatic IDC processing system was able to detect and 
locate the event within two hours of its occurrence, and it was reported to the Preparatory Commission.

Given the very limited state of deployment of the current network, the detection and analysis of these events were quite impressive. They point to the ability of the evolving global verification regime to detect possible nuclear explosions in all environments, worldwide, and to monitor adherence to the CTBT. Nevertheless, much work still remains to be done to ensure the reliable detection, location, and identification of such events, and to provide a firm deterrent to clandestine nuclear testing.

\section{Global communications}

In 1998 a contract was signed with an international firm to establish the global communications infrastructure (GCI) for the CTBT verification regime. The basic GCI topology will route the data generated by the four technologies directly by satellite from the monitoring stations to the $\mathrm{DC}$, and then in customized packages of data and products from the IDC back to the States Signatories. A State may request that the data be routed through communications nodes or through a national data center provided that the extra costs are borne by the recipient.

The GCI network will be deployed so as to provide for swift and secure transmission of data between the 321 monitoring stations, 16 radionuclide laboratories, the $\mathrm{IDC}$, and the States Signatories. It will need to be operational for 99.5 percent of the 
time, and function in extreme weather and temperature conditions. The core of the GCI infrastructure is now in place. Because of the need to connect locations as far apart as Antarctica and Greenland, and as remote as, for instance, Tristan da Cunha and the Galapagos Islands, the establishment of the GCI presents a major but very unique challenge for data transmission.

\section{On-Site Inspection}

Work has now started to lay the foundations for on-site inspection procedures, provided for in the Treaty after its entry into force. International experts are assisting in drawing-up an operational manual, a concept of OSI operations, an information data bank, and equipment storage and maintenance facility, as well as a list of basic equipment for use in the field. The prototype Operations Support Center is to be integrated with the IDC Operations Center in order to reduce costs.

Low, as well as high frequency, aftershocks are important aids in localizing an inspection area and in determining the nature of a particular seismic event. States Signatories have been asked to nominate institutions able to loan or lease passive seismographic aftershock monitoring equipment and to assist the CTBTO PrepCom in testing and evaluating equipment related to aftershock monitoring. Also, four experts' workshops have thus far been held, along with two introductory training courses, which included simulation of the on-site inspection process. 


\section{International cooperation}

The Treaty stipulates that "cooperation ... to facilitate and participate in ... exchange relating to technologies used in the verification of this Treaty" should "enable ... States Parties to strengthen ... national implementation of verification measures and benefit from the application of such technologies," (Article IV, paragraph 12). To enhance this cooperative effort, two workshops have been held; in Vienna in 1998 and in Cairo in June 1999.

The Vienna workshop suggested, and the Cairo workshop developed, a number of elements, such as:

- $\quad$ the CTBT enhances peace and security, both international and regional;

- States should support the Treaty by moving through signature to ratification, thus promoting entry into force;

- training opportunities advance the transfer of knowledge and foster fuller participation in verification efforts;

- $\quad$ open access to IMS data and IDC products is a prerequisite for their utilization;

- national data centers are an important component of the Treaty regime;

- regional data centers promote cooperation in CTBT verification-related technologies;

- "centers of excellence" be a visible means for regional cooperation; and, 
- the CTBTO PrepCom act as an information clearing house/catalyst for bilateral/multilateral cooperation.

No doubt the CTBT, first and foremost, advances the cause of international security by its comprehensive ban on explosive nuclear testing. However, the potential spin-off benefits arising from the CTBT verification technologies may be no less significant. The knowledge of the earth and the atmosphere that is gained through IMS data, processed through the IDC, enables States Signatories to better plan major infrastructure projects; more efficiently exploit their natural resources; and foresee the movements of weather fronts and volcanic eruptions, which could be vital for the early warning of populations and civil aviation. The possibilities are, as yet, unfathomable.

\section{Synergies}

"As an independent body," and in accordance with the Treaty, the Provisional Technical Secretariat aims are "to utilize existing expertise and facilities, as appropriate, and to maximize cost efficiencies, through cooperative arrangements with other international organizations such as the International Atomic Energy Agency," (Article II, The Organization).

As a result, in 1997, IAEA provided financiál services until CTBTO PrepCom was able to undertake its function. The Preparatory Commission has also taken on the structure of the IAEA budget and modeled its financial rules on those of the Organization 
for the Prohibition of Chemical Weapons, which in turn closely followed those of the IAEA. The United Nations Industrial Development Organization, too, assisted with procurement until CTBTO PrepCom was able to undertake this function, once it had become clear that outsourcing was not necessarily most costeffective.

As each stage in the operationalization of the verification regime is attained, and more instruments of ratification are deposited, the CTBT increases its profile as a universal and effective instrument of arms control. All efforts to provide a credible deterrent to nuclear testing and to promote restraint on the part of those who have not yet signed the Treaty are worthwhile, as they contribute to making the world more secure as it prepares to enter the 21st Century.

\section{The way ahead}

These successes are reflective in the number of Treaty signatures (152) and ratifications (36) since the Treaty was appended for signatures in September 1996, and in the high rate of collecting the assessed contributions. Primarily, the budget is focused on the verification process $(83 \%)$ while administrative costs are about $17 \%$. Overall it is the goal of the CTBTO PrepCom to move ahead and secure an early entry into force of the Comprehensive Test Ban Treaty. 
$\because \quad \quad \therefore$

:

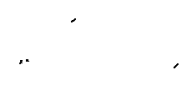

